B I BLIOTE C A INSTITUTO DE QUIMICA

Universidade de São Paulo 20650

Universidade de São Paulo

Instituto de Química

\title{
FRAGMENTOS DE TROPOMIOSINA - ESTUDOS DA ESTABILIDADE CONFORMACIONAL E DA INTERAÇÃO CABEÇA-CAUDA
}

\author{
ADRIANA APARECIDA PAULUCCI
}

Tese de doutorado submetida ao Departamento de Bioquímica do Instituto de Química da Universidade de São Paulo

Orientador: Dr. Shaker Chuck Farah

São Paulo, 31 de julho de 2003 


\section{B I BLIOTECA

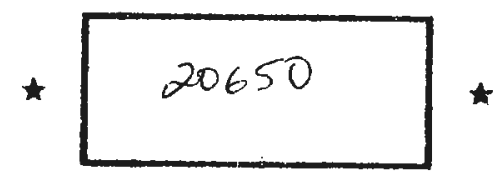 \\ INSTITUTO DE QUIMICA UNIVERSIDADE DE SAO PAULO}

\section{Ficha Catalográfica}

Elaborada pela Divisão de Biblioteca e

Documentação do Conjunto das Químicas da USP.

\footnotetext{
Paulucci, Adriana Aparecida

P333f Fragmentos de tropomiosina - estudos da estabilidade conformacional e da interação cabeça-cauda / Adriana Aparecida Paulucci. -- São Paulo, 2003.

1v. (paginação irregular)

Tese (doutorado) - Instituto de Química da Universidade de São Paulo. Departamento de Bioquímica.

Orientador : Farah, Shaker Chuck

1. Biofísica 2. Proteína : Estabilidade conformacional : Bioquímica 3. Interação proteína-proteína : Bioquímica I. T. II. Farah, Shaker Chuck, orientador.
} 


\section{"Fragmentos de tropomiosina - estudos da estabilidade conformacional e da interação cabeça-cauda"}

\section{ADRIANA APARECIDA PAULUCCI}

Tese de Doutorado submetida ao Instituto de Química da Universidade de São Paulo como parte dos requisitos necessários à obtenção do grau de Doutor em Ciências - Área: Bioquímica.

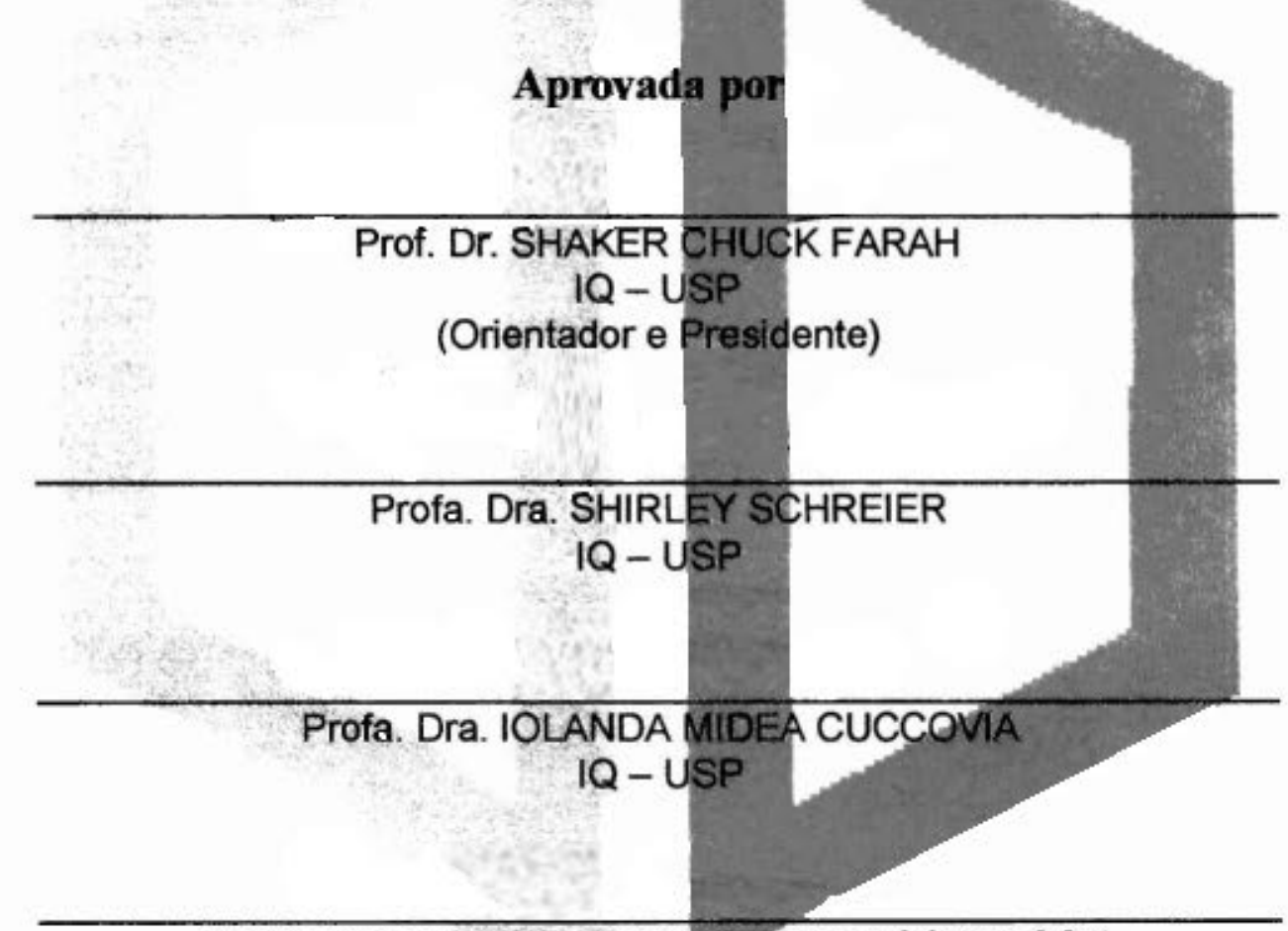

Profa. Dra. MARTHA MERIWERTHER SORENSON

UFRJ

Profa. Dra. THELMA DE AGUIAR PERTINHEZ

LNLS

SÃo PAULO

03 DE OUTUBRO 2003. 
"Se você vestir um chapéu maior do que a sua cabeça, ele irá cobrir os seus olhos."

Marcelo Gleiser (citando o seu avô) 
$\mathrm{Tu}$, que me defendeste desde o primeiro instante.

defendeste-me das agressões do meio,

quando em teu útero eu estava.

Defendeste-me da sociedade,

quando na inocência eu vivia.

Defendeste-me da tristeza,

quando a vida eu já conhecia.

Tu, minha mãe, com teu amor,

foi dentre as defensoras, para mim, a melhor.

Pois, então, é a ti que cabe o título

desta defesa.

À minha querida mamãe

Cleide Sagioro Paulucci.

em memória 
Agradeço pelo apoio e interesse constantes de meu pai João Alberto Paulucci e pelo carinho e amizade de minha irmã Elaine Cristina Paulucci. 
Quanto a você, Luís, não é preciso nem dizer. Seus atos se refletem no amor, admiração e companheirismo que sinto por você. 


\title{
Agradecimentos
}

Àqueles que, mesmo não entendendo o meu trabalho, me cobriram com todo o seu apoio e amor...

Meus sogros, Elza Fernandes Holthauzen e Ricardo Luiz Holthauzen.

\author{
Vovó Maria Fernandes \\ Vovô Manoel Fernandes \\ Tia Eliza
}

Luís Maurício F. Holthauzen

Aos meus primos e amigos Flávia Sagioro Amati e Eduardo Sagioro Amati

A todos meus entes queridos, minha madrinha Maria José, minhas tias e tios.

\section{Àqueles que contribuiram profissionalmente e que tornaram os meus dias de trabalho mais alegres e produtivos...}

\author{
Eric Kors Vidsiunas \\ Sandro Fernandes Ataíde \\ Dr. Fernando Fortes de Valencia \\ Marcos C. Alegria \\ Dr. Deodoro de Oliveira \\ Dra. Daniela Mara de Oliveira \\ Dr. Ronaldo Bento Quaggio \& Cia. \\ Dra. Thelma Pertinhez \& Cia. \\ Dr. Cláudio Saburo Shida \\ Fábio Casallanovo \\ Dra. Maria Teresa M. de Miranda \\ Dra. Alessandra Machado \\ Dr. Cyril M. Kay \\ Les Hicks \\ Dr. Carlos Ramos \\ Dra. Izaura Nobuko Toma \\ Cássia Docena \\ Elaine Favaro \\ Ilda de Souza Costa \\ Daniela da Silva Costa \\ D. Cleusa Gabriel da Costa \\ Alessandra Vanessa de Paiva \\ Leonor M.P. Galvão de Botton \\ Cristiane R. Guzzo \\ Fernando Correa \\ Robson Francisco de Souza
}

Em especial a

Dr. Shaker Chuck Farah, pela sua orientação e amizade.

Ângela M. Katsuyama, pela dedicação, amor pela ciência e amizade.

Dra. Áurea D. de Sousa, pelo companheirismo e amizade.

Eduardo Dutra Pastor, pelo interesse e dedicação.

Luis Marcelo Fernandes Holthauzen, pelas maravilhosas discussões científicas.

Este trabalho só foi realizado graças ao suporte científico da FAPESP. 


\section{Resumo}

A Tropomiosina ( $\mathrm{Tm}$ ) está diretamente envolvida no processo de regulação da contração muscular, que é controlado por um mecanismo alostérico que envolve $\mathrm{Ca}^{2+}$, troponina $(\mathrm{Tn})$, actina $(\mathrm{Ac})$ e miosina. $\mathrm{A} T \mathrm{Tm}$ é uma proteína flexível, de estrutura "coiled-coil", constituída de duas $\alpha$-hélices com 284 aminoácidos cada uma. A molécula de Tm faz interações do tipo "cabeça-cauda" com outra molécula de Tm através da sobreposição de aproximadamente 8 a 15 resíduos da extremidade $\mathrm{N}$ - terminal de uma molécula com 8 a 15 resíduos da extremidade $\mathrm{C}$-terminal da outra molécula de Tm. Desta maneira, em baixas forças iônicas, formam-se filamentos lineares através de um processo de polimerização.

A estabilidade de regiões específicas da Tm pode ser importante para a sua função no controle da regulação da contração muscular. Além disso, a Tm pode ser usada como um modelo relativamente simples e de ocorrência natural para entendermos as interações intra- $e$ intermoleculares que governam a estabilidade das "coiled-coils". Assim sendo, nós produzimos oito

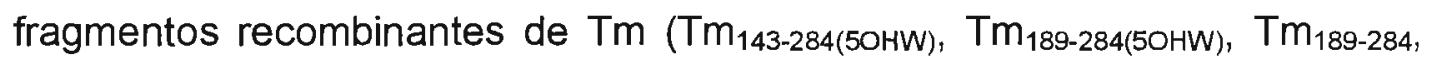
$\mathrm{Tm}_{220-284(50 H W)} \mathrm{Tm}_{220-284}, \mathrm{Tm}_{143-235}, \mathrm{Tm}_{167-260}$ e $T m_{143-260}$ ) e um peptídeo sintético $\left(\mathrm{Ac}-\mathrm{Tm}_{215-235}\right) \mathrm{com}$ a finalidade de investigar as estabilidades conformacionais relativas das diferentes regiões derivadas da metade Cterminal da proteína, a qual é conhecida por sua interação com o complexo troponina. Experimentos de ultracentrifugação analítica mostram que os fragmentos que incluem os últimos 24 resíduos da molécula ( $\mathrm{Tm}_{143-284(5 \mathrm{OHW}) \text {, }}$ $\mathrm{Tm}_{\text {189-284(5OHW), }} \mathrm{Tm}_{220-284(5 \mathrm{OHW})}, \mathrm{Tm}_{220-284}$ ) estão completamente dimerizados a $10 \mu \mathrm{M}$ (concentração do dímero em $50 \mathrm{mM}$ de tampão fosfato, $\mathrm{pH} 7,0 ; 100$ $\mathrm{mM}$ de $\mathrm{NaCl} ; 0,5 \mathrm{mM}$ de DTT e 0,5 mM de EDTA, $10^{\circ} \mathrm{C}$ ), enquanto que fragmentos que não possuem o C-terminal nativo $\left(\mathrm{Tm}_{143-235}, \mathrm{Tm}_{167-260} \mathrm{e}\right.$ $\mathrm{Tm}_{143-260}$ ) se encontram em equilíbrio monômero-dimero nestas condições. A presença de trifluoroetanol promove uma diminuição na razão $[\theta]_{222} /[\theta]_{208}$, observada por dicroísmo circular, em todos os fragmentos e induz a formação de trímeros estáveis apenas para aqueles contendo os resíduos 
261-284. Estudos de desnaturação por uréia, acompanhados por dicroísmo circular e fluorescência, mostram que os resíduos 261-284 da tropomiosina são muito importantes para estabilidade da metade C-terminal da molécula. Além do mais, a ausência desta região promove um aumento na cooperatividade do desenovelamento induzido por uréia. Os experimentos de desnaturação por temperatura e por uréia mostram que o fragmento $\operatorname{Tm}_{143-235}$ é relativamente instável quando comparado com outros fragmentos de mesmo tamanho. Nós identificamos alguns fatores que podem estar contribuindo para a particular instabilidade desta região, incluindo repulsões inter-hélices entre resíduos em posições $\mathbf{g}$ e e' da repetição heptapeptídica, um resíduo carregado na interface hidrofóbica da "coiled-coil" e por fim, uma grande fração de resíduos $\beta$-ramificados localizados em posições $\mathbf{d}$.

Sabe-se que a não acetilação do $\mathrm{N}$-terminal da molécula de $\mathrm{Tm}$, bem como a ausência de alguns resíduos na sua extremidade $\mathrm{C}$-terminal, fazem com que a Tm deixe de sofrer polimerização. Entretanto, trabalhos anteriores realizados em nosso laboratório haviam mostrado que um fragmento de Tm recombinante (ASTm1-260), contendo a fusão dipeptídica Ala-Ser (que é conhecida por restaurar a capacidade de polimerização de Tm não acetiladas no N-terminal), polimerizava-se mais do que a proteína recombinante de tamanho integral (ASTm), apesar da deleção dos últimos 24 aminoácidos Cterminais. Para investigar com mais detalhes a natureza da interação cabeça-cauda, nós construímos dois fragmentos que compreendem a metade $\mathrm{N}$-terminal da molécula de $\mathrm{Tm}, \mathrm{ASTm}_{1-142}$ e $\mathrm{nfTm}_{1-142}$, o primeiro deles contendo uma fusão dipeptídica AS no $\mathrm{N}$-terminal e o segundo com o $\mathrm{N}$-terminal não acetilado, sem a fusão dipeptídica. Estes dois fragmentos foram empregados em ensaios de interação cabeça-cauda, realizados através de ensaios de desnaturação térmica acompanhados por dicroísmo circular, juntamente com três fragmentos da região C-terminal da $\mathrm{Tm}$. Dois dos fragmentos C-terminais acabam na posição $260\left(\mathrm{Tm}_{167-260}\right.$ e $\left.T \mathrm{~m}_{143-260}\right) \mathrm{e}$ um deles termina na posição 284 ( $\left.\mathrm{Tm}_{220-284}\right)$, que corresponde ao C-terminal nativo da proteína. Os resultados mostram que ocorre uma interação cabeça- 
cauda entre o fragmento N-terminal ASTm $_{1-142}$ e todos os fragmentos Cterminais utilizados neste estudo. As moléculas recombinantes de Tm que terminam na posição 260 são, de fato, capazes de fazer interações cabeçacauda independentemente do fato de elas se apresentarem instáveis nas condições estudadas. Inclusive, após a interação, ocorre um aumento considerável na estrutura $a$-hélice, o que se dá preferencialmente nos fragmentos C-terminais. 


\section{Abstract}

Tropomyosin $(\mathrm{Tm})$ participates in the process of muscle contraction, which is controlled by an allosteric mechanism involving $\mathrm{Ca}^{2+}$, troponin $(\mathrm{Tn})$, actin (Ac) and myosin. Tm is a coiled-coil flexible molecule composed by two a-helices with 284 amino acids each. Tm molecule performs head-to-tail interactions with another Tm molecule through the overlap of approximately 8 to $15 \mathrm{~N}$-terminal residues of one molecule with 8 to $15 \mathrm{C}$-terminal residues of the other molecule. Thus Tm forms linear filaments in low ionic strengths, which is characteristic for a polymerization process.

The stability of specific regions of Tm may be important to its function in controlling the regulation of muscle contraction. Besides, Tm can be used as a relatively simple model and of natural occurrence to understand the intra- and intermolecular interactions that govern the stability of "coiled-coils".

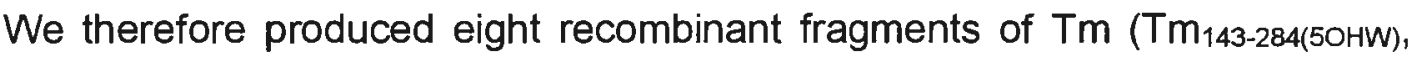

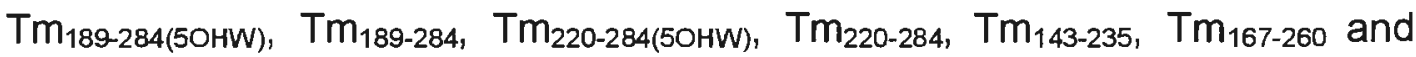
$\mathrm{Tm}_{143-260}$ ) and one synthetic peptide (Ac- $\left.\mathrm{Tm}_{215-235}\right)$ to investigate the relative conformational stabilities of different regions derived from the C-terminal end of the molecule, which is known to interact with the troponin complex. Analytical ultracentrifugation experiments show that fragments comprising the

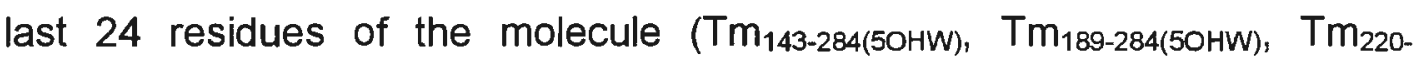
284(50HW), $\mathrm{Tm}_{220-284}$ ) are completely dimerized at $10 \mu \mathrm{M}$ (dimer concentration in buffer containing $50 \mathrm{mM}$ phosphate, $\mathrm{pH} 7.0,100 \mathrm{mM} \mathrm{NaCl}, 0.5 \mathrm{mM}$ DTT and $0.5 \mathrm{mM}$ EDTA, $10^{\circ} \mathrm{C}$ ), whereas the fragments that do not posses the native C-terminal portion ( $\mathrm{Tm}_{143-235}, \mathrm{Tm}_{167-260}$ and $\left.\mathrm{Tm}_{143-260}\right)$ present a monomer-dimer equilibrium at the same conditions. Trifluoroethanol promoted a decrease in the ratio $[\theta]_{222} /[\theta]_{208}$ for all fragments (observed by circular dichroism), and induced the formation of stable trimers for the fragments comprising the residues 261-284. Urea denaturation studies, followed by circular dichroism and fluorescence, show that residues 261-284 of Tm are very important for the stability of the C-terminal half of the molecule. Still, the absence of this region promotes an increase in the cooperativity of unfolding 
induced by urea. Urea and temperature denaturation experiments showed that the fragment $\operatorname{Tm}_{143-235}$ is relatively unstable when compared to other fragments of the same size. We identified some factors that may be contributing to the particular instability of this region, including interhelix repulsions between residues in positions $\mathbf{g}$ and $\mathbf{e}^{\prime}$ of the heptad repeat, a charged residue in the hydrophobic interface of the coiled-coil and a great fraction of $\beta$-branched residues located at $\mathbf{d}$ positions.

It is known that the non-acetylation of the N-terminus of the Tm molecule, as well as, the absence of some residues in the C-terminus of the molecule cause $\mathrm{Tm}$ to loose its ability to undergo polymerization. Former works performed in our laboratory showed that a fragment of recombinant Tm (ASTm1-260) with the dipeptide fusion Ala-Ser (which is known by its ability in restores the polymerization of non-acetylated Tms), despite the absence of the C-terminal 24 amino acids, polymerizes to a much greater extent than the corresponding full length recombinant protein. To better investigate the nature of the head-to-tail interaction we constructed two fragments that comprise the N-terminal half of the Tm: ASTm ${ }_{1-142}$ and nfTm $_{1-142,}$ the former containing the dipeptide AS (Ala-Ser) fusion to its N-terminus, and the latter presenting a bare non-acetylated $\mathrm{N}$-terminus without the dipeptide fusion. These two fragments were employed in thermal denaturation assays followed by circular dichroism to test their head-to-tail interaction along with three fragments comprising Tm's C-terminal region. Two of the C-terminal fragments ends at position 260 ( $\left(\mathrm{Tm}_{167-260}\right.$ and $\mathrm{Tm}_{143-260}$ ), whereas one ends at position 284 $\left(\mathrm{Tm}_{220-284}\right)$. Results show that there is a head-to-tail interaction between the $\mathrm{N}$-terminal fragment $\mathrm{ASTm}_{1-142}$ and all other C-terminal fragments employed in this study. Recombinant Tm molecules ending at position 260, are capable of performing head-to-tail interactions, regardless of their stability under the studied condition. Upon interaction, an increase in the $\alpha$-helix content occurs preferentially in the C-terminal fragments. 


\section{1- Introdução}

\section{1- A molécula de Tropomiosina.}

As tropomiosinas (Tms) constituem uma família de proteínas com estrutura em a-hélice que dimerizam para formar uma estrutura "coiled-coil" e que ligam no filamento de actina. Em vertebrados, as Tms são codificadas por 4 genes (gene $\alpha$ de contração rápida, gene $\beta$, gene $\alpha$ de contração lenta e gene TM-4) que dão origem a pelo menos 17 isoformas distintas através da combinação de promotores alternativos e "splicing" alternativo do RNA (veja Figura 1). (Lees-Miller e Helfman, 1991; Araya et al., 2002). As maiores diferenças entre as isoformas estão, em geral, localizadas no amino-terminal (codificado pelos exons alternativos $1 a, 1 b, 2 a$ e $2 b$ ), numa região interna (codificada pelos exons 6a e 6b) e no carboxi-terminal (codificado pelos exons 9a, 9b, 9c e 9d). (Araya et al., 2002; Lees-Miller e Helfman, 1991).

A Tm de músculo esquelético é composta por homo-dímeros de Tms codificadas pelo gene a ( $\alpha \alpha-T m$ ), ou por hetero-dímeros de Tms codificadas pelos genes $\alpha$ e $\beta$ ( $\alpha \beta-T m$ ). Em ambos os genes, a isoforma 9a codifica os resíduos de aminoácidos que vão de 258 a 284 (últimos 27 resíduos da molécula). Este exon é específico para as Tms de músculo estriado (LeesMiller e Helfman, 1991).

A função da Tms é mais bem entendida em células musculares cardíacas e esqueléticas, onde a Tm associa-se com o complexo troponina (Tn) para regular a interação com actina e miosina de maneira $\mathrm{Ca}^{2+}$ dependente (Smillie, 1979). As funções biológicas das Tms não musculares e de músculo liso ainda não são bem compreendidas. Como só as Tms esqueléticas e cardíacas têm o seu C-terminal codificado pelo exon 9a, suspeita-se que esta região da molécula esteja envolvida com a sua função regulatória, já que as Tms esqueléticas associam-se ao complexo Tn nesta região como será mostrado abaixo (White et al., 1987). 


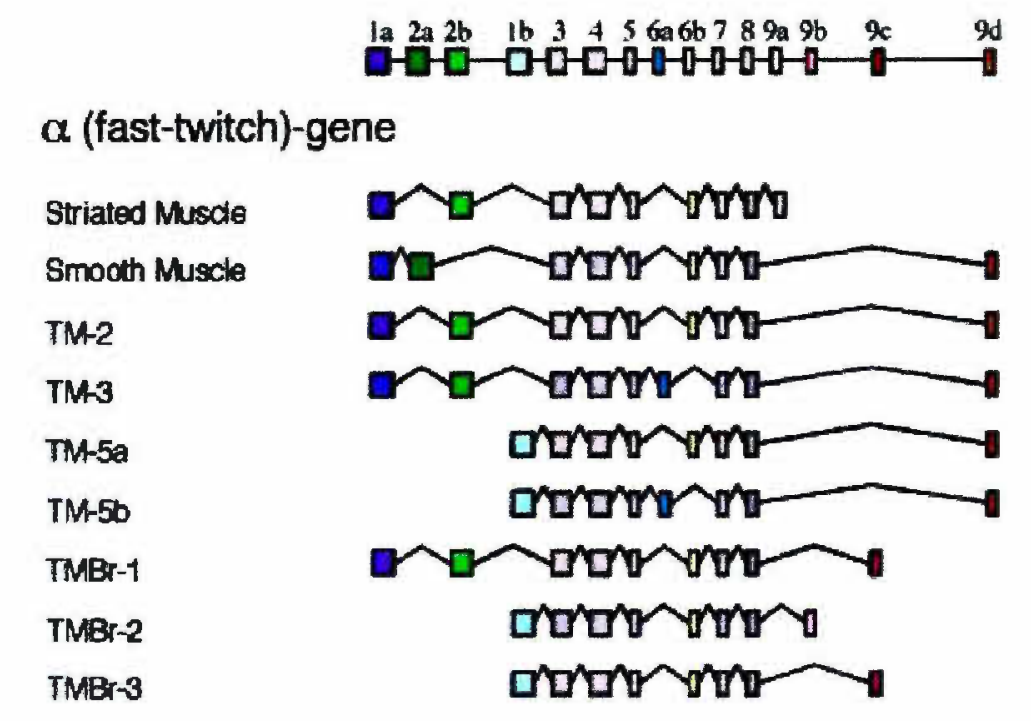

$\beta$-gene

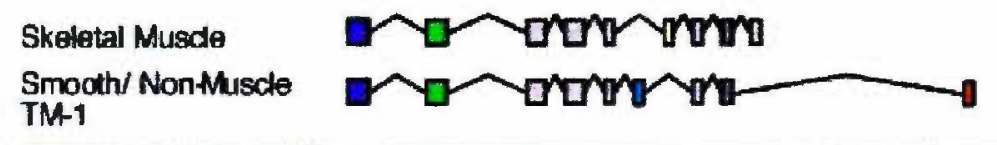

TM-4 gene

TM-4

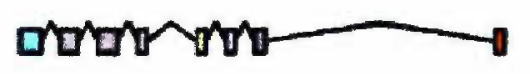

$\alpha$ (slow-twitch)-gene

Skeletal Musde
TM-5 NM-1
TM-5 NM-2
TM-5 NM-3
TM-5 NM-4

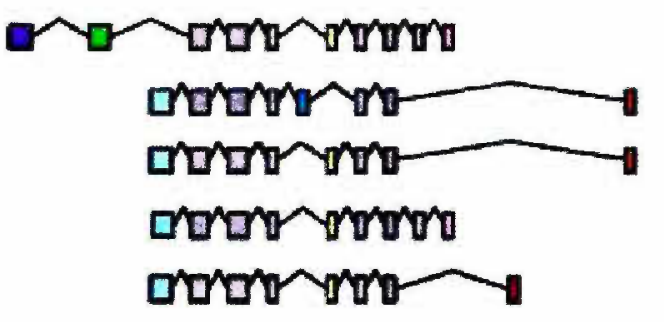

Figura 1 - Representaçâo das várias isoformas de $\mathrm{Tm}$ de rato expressa a partir de quatro diferentes genes (Figura retirada de Araya et al., 2002). No topo da Figura é mostrada a organização geral dos íntrons e exons do gene de Tm. Diferentes isoformas de Tm expressas a partir de cada gene através do uso do "splicing" alternativo de RNA e promotores alternativos são mostradas abaixo de cada gene. 


\section{2 - Papel Biológico da Tm}

A Tm está intimamente envolvida no processo de regulação da contração muscular, o qual é controlado por um mecanismo alostérico envolvendo: $\mathrm{Ca}^{2+}$, tropomiosina, troponina ( $\left.\mathrm{Tn}\right)$, actina ( $\mathrm{Ac}$ ) e miosina (Ebashi, 1976; Tobacman, 1996; Gordon et al., 2000). O processo da contração muscular é desencadeado pelo aumento da concentração de íons $\mathrm{Ca}^{2+}$ no interior do sarcômero (unidade básica da miofibrila). Ocorre um deslizamento entre os filamentos grossos (constituídos de miosina) e os filamentos finos (constituídos de tropomiosina, actina e troponina) através do impulso gerado pelos domínios motores (cabeças de miosina, S1) sobre a actina, às custas da hidrólise de ATP (Huxley, 1965; Huxley, 1969; Lymn e Taylor, 1971) (ver Figura 2).

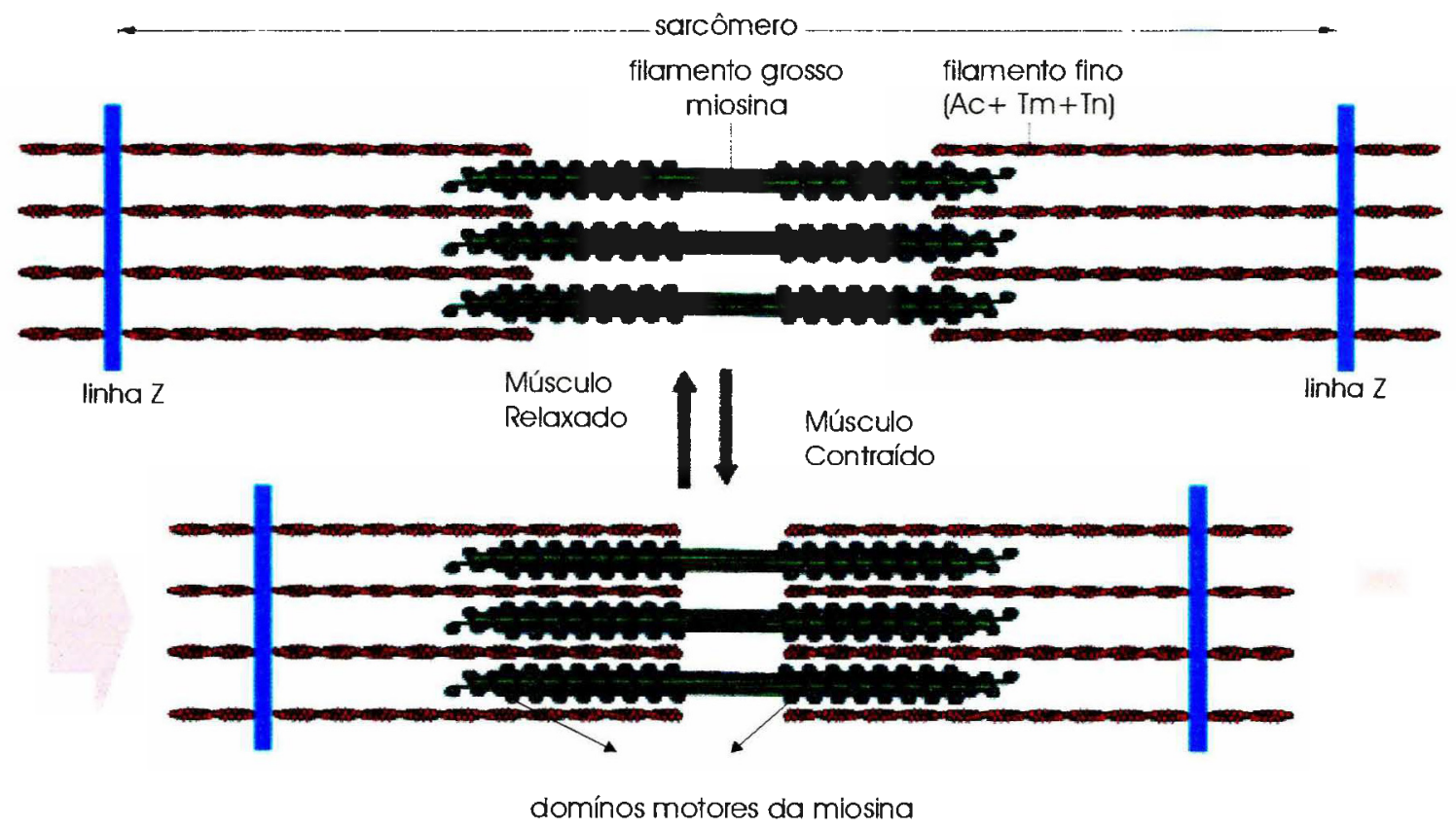

Figura 2- Representação esquemática da estrutura do sarcômero - unidade básica da miofibrila compreendida entre as duas linhas Z. Durante o processo da contração muscular ocorre uma maior sobreposição entre o filamento grosso (constituído de miosina) e o filamento fino (constituído de actina, tropomiosina e troponina) (Cohen, 1975). 
A miosina é uma proteína de $520 \mathrm{kDa}$ composta por seis polipeptídeos (Figura 3): duas cadeias pesadas (220 kDa cada), mostradas em verde e em laranja na Figura 3 e dois pares de cadeias leves ( $20 \mathrm{kDa}$ cada), mostrados em rosa e azul na Figura 3. A molécula divide-se em uma região globular (metade $\mathrm{N}$-terminal de uma cadeia pesada mais as duas cadeias leves) e uma região fibrosa (metade $\mathrm{C}$-terminal de cadeia pesada, a qual forma uma longa cauda em $\alpha$-hélice). A cauda da molécula é responsável pela formação de filamentos em meios com força iônica fisiológica (ver Figura 2, filamento grosso da miosina), enquanto que a região globular hidrolisa ATP e, através da sua interação com a actina, gera força (Adelstein e Eisenberg, 1980; Rayment et al.,1993b).

A miosina possui duas regiões que são particularmente lábeis ao ataque enzimático. A tripsina hidrolisa a miosina em dois tipos de fragmentos, chamados de meromiosina leve (LMM) e meromiosina pesada (HMM), sendo que esta última ainda pode ser dividida por digestão com papaína em outros dois fragmentos comumente chamados de S1 e S2 (Lowey et al.,1969) (Figura 3).

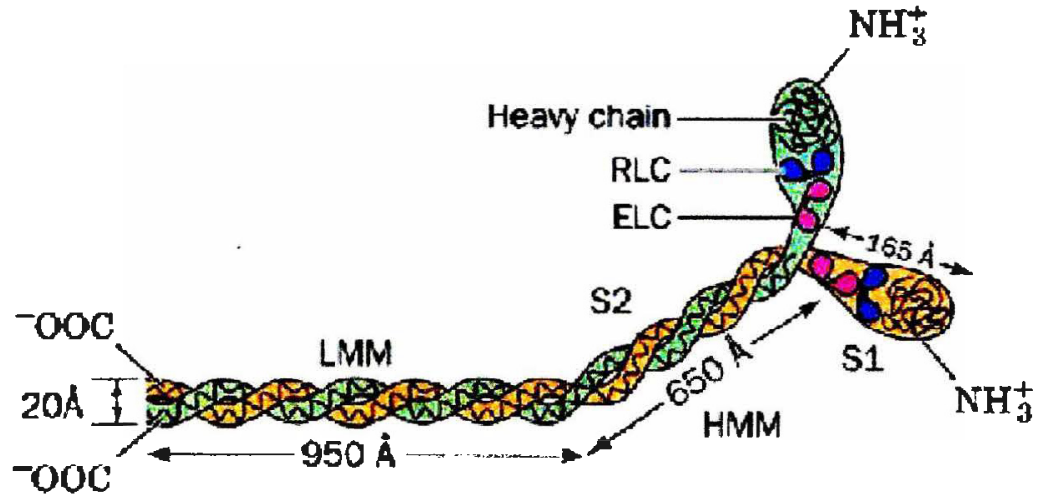

Figura 3. A molécula de miosina é composta de duas regiões que podem ser clivadas por tripsina: uma longa região "coiled-coil" (LMM - light meromyosin) e uma região que pode ser subseqüentemente clivada por quimotripsina em dois subfragmentos globulares (S1) com atividade ATPásica e um subfragmento filamentar (S2). RLC - regulatory light chain; ELC essential light chain; HMM - heavy meromyosin [Voet e Voet, 1995 cortesia de Henry Slayter, Harverd Medical School]. 
A actina é a proteína estrutural do filamento fino que está diretamente envolvida com a produção de força contrátil através da sua interação com miosina (Adelstein e Eisenberg, 1980). Ela pode existir na forma globular (Gactina) e fibrosa (F-actina). A G-actina é constituída de dois domínios, entre os quais se forma um sulco onde se liga um nucleotídeo (ATP ou ADP) e um ín $\mathrm{Ca}^{2+}$ ou $\mathrm{Mg}^{2+}$, garantindo desta forma a união dos dominios e a estabilidade da molécula (Kabsch et al.,1990). Estes monômeros se polimerizam em concentrações fisiológicas de sal para dar origem ao filamento de F-actina, o qual é composto de duas fitas enroladas helicoidalmente uma ao redor da outra (ver Figura 4; Hanson e Lowey,1963; Milligan et al.,1990). O filamento possui diâmetro total de $80 \AA$, e o ponto onde as hélices se cruzam estão espaçados em intervalos de $349 \AA$ ao longo do filamento, sendo que o número de subunidades globulares monoméricas por turno de hélice é aproximadamente igual a 13 (Hanson e Lowey, 1963). Cada molécula de Tm interage com sete monômeros de actina no filamento fino, como está esquematizado na Figura 4 e na Figura 6 . Note, na Figura 4, que sete monômeros de actina representam uma meia volta de hélice no filamento.

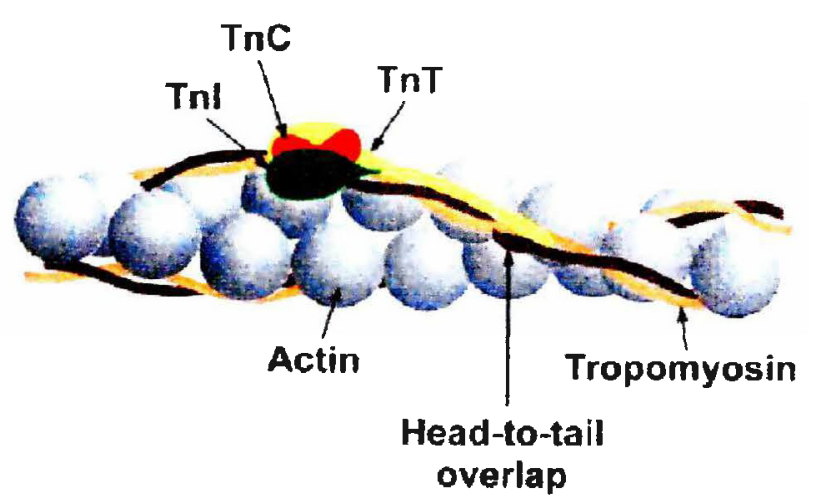

Figura 4- Modelo do arranjo molecular da Tm, Troponina (divida em três subunidades, $T n C, T n I$ e $T n T)$ e actina. Cada molécula de Tm recobre 7 monómeros de actina e se liga a uma única molécula de troponina. (Gordon et al., 2000, modificado de Heeley et al., 1987)

As interações que ocorrem entre Tm e o complexo Tn são de enorme importância para o processo da contração muscular. A troponina é o sítio primário do controle da contração muscular (para revisão ver Tobacman,1996; Farah e Reinach,1995 e Ohtsuki et al.,1986) e é constituída de três subunidades: troponina $C(T n C)$, troponina I (Tnl) e troponina $T(T n T)$ (Greaser 
e Gergely, 1971 e 1973). A troponina C é o componente ligante de $\mathrm{Ca}^{2+} \mathrm{e}$ possui dois domínios globulares, sendo que cada domínio possui dois sítios para $\mathrm{Ca}^{2+}$ (Herzberg e James,1985). A troponina l é um componente inibitório da interação contrátil, pois inibe a atividade $\mathrm{Mg}^{2+}$-ATPásica da actomiosina (Greaser e Gergely, 1973). A região N-terminal desta subunidade é responsável pela sua reunião ao complexo, enquanto a região C-terminal está envolvida com as funções regulatórias da molécula (Farah e Reinach, 1995). A troponina $\mathrm{T}$ é importante para a ligação do complexo com a tropomiosina, sendo que interage com a porção C-terminal da tropomiosina independentemente dos niveis de $\mathrm{Ca}^{2+}$ (Zot e Potter,1987) (ver subunidades da Tn na Figura 4).

Em soluções de baixa força iônica as moléculas de Tm se agregam através da sobreposição de aproximadamente 8 a 15 resíduos entre a região $\mathrm{NH}_{2}$-terminal de uma, e a região $\mathrm{COOH}$-terminal de outra molécula para formar um longo filamento (Phillips et al.,1986; McLachlan e Stewart,1975). Esta interação cabeça-cauda é altamente sensível à força iônica. A ligação da TnT ao filamento de a-tropomiosina aumenta a agregação cabeça-cauda das moléculas de tropomiosina. Supostamente, a TnT causa mudanças conformacionais na região C-terminal da Tm permitindo assim um aumento de afinidade na região de sobreposição cabeça-cauda (Pato et al., 1981a) (ver esquema da interação cabeça cauda na Figura 5).

Estudos de cristalografia de baixa resolução indicam que a região da tropomiosina que se liga a troponina está localizada entre os resíduos 150 e 284 , sendo que a junção cabeça-cauda é recoberta pelos resíduos N-terminais (1-70) da TnT e a região globular desta última (resíduos 157-263) encontra-se próxima aos resíduos 150-180 da molécula de tropomiosina (White et al., 1987). As interações entre TnT e Tm estão esquematizadas na Figura 5.

A Tm desempenha um papel importante no processo da regulação da contração muscular através do bloqueio de sítios de ligação da miosina na superfície da actina, segundo o chamado modelo de bloqueio estérico da contração muscular (Huxley, 1972; Haselgrove, 1972; Parry e Squire, 1973). 
Este modelo sugere que o sinal da ligação de $\mathrm{Ca}^{2+}$ à troponina está sendo transmitido para o sistema actina-miosina através da Tm (Hitchcock et al., 1973). A Tm atua como um mediador de informação enviada pela troponina, controlando a interação das moléculas de miosina com sete actinas ao longo do filamento fino (McLachlan e Stewart, 1975). Cada unidade regulatória de sete actinas é ligada à próxima unidade (da mesma fita) por uma sobreposição de tropomiosinas, produzindo um grande grau de cooperatividade ao longo do filamento, ou seja, a ligação de uma molécula de Tm aumenta a afinidade de ligação da próxima molécula (observado em isotermas de ligação de $\mathrm{Ca}^{2+} \mathrm{e}$ miosina) (Hill et al., 1980).

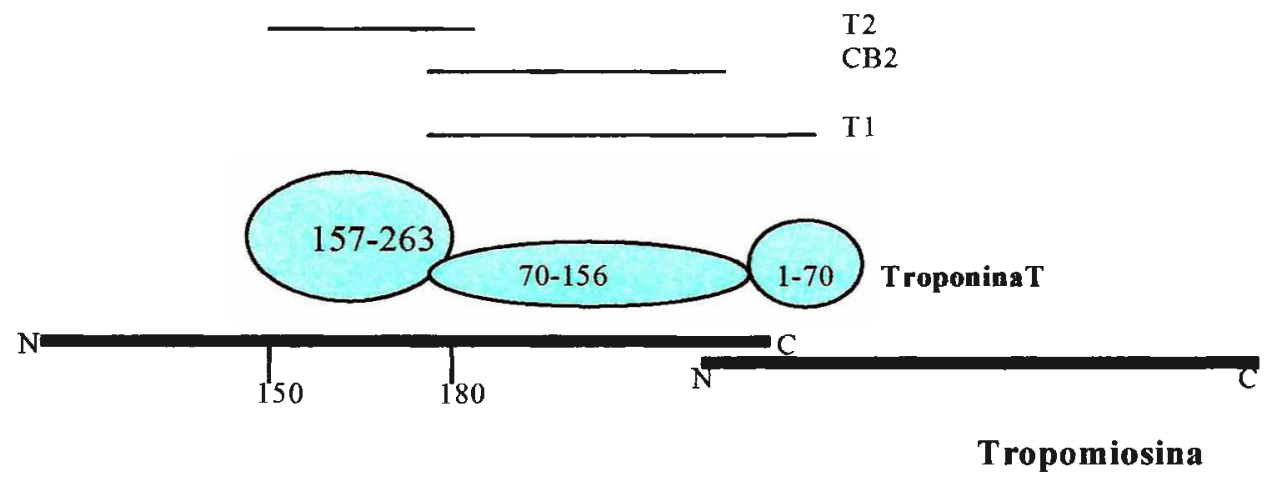

Figura 5 - Representa a ligação da TnT à Tm. A TnT liga-se ao longo da molécula de tropomiosina(Tm) de forma antiparalela, onde a região $N$-terminal da $T n T$ recobre a região $C$ terminal da Tm e uma pequena porção N-terminal da molécula adjacente (região de interação cabeça-cauda): T1- compreende os resíduos 1 a 156 da $\mathrm{TnT}$, que interagem com um comprimento considerável da região C-terminal da $T m$ e prolonga além da junção cabeçacauda da mesma, recobrindo um pequeno segmento ( $\cong 8$ a 15 aminoácidos) da molécula de Tm adjacente (White et al.,1987). CB2- compreende a região entre os resíduos 70 e 156 (região com grande quantidade de $\alpha$-hélice que prolonga-se para o centro da molécula de $\mathrm{Tm}$ (Pearlstone e Smillie,1978). T2- resíduos 157 a 263, fazem parte do domínio globular do complexo troponina e parecem estar associados com aos resíduos 150 a $180 \mathrm{da}$ Tm (White et al., 1987). 
Na Figura 6 podemos observar um esquema simplificado de como ocorre a regulação da contração muscular segundo o modelo do bloqueio estérico. A figura esquematiza uma unidade regulatória, onde sete monômeros de actina estão ligados a uma molécula de Tm e a uma molécula de Tn. Para uma simplificação representamos aqui só o domínio motor, a cabeça $\mathrm{S} 1$ de uma única molécula de miosina. Quando o músculo encontra-se no seu estado relaxado, ou seja, na ausência de $\mathrm{Ca}^{2+}$ a molécula de $\mathrm{Tm}$ assume uma posição que impede estericamente a ligação da cabeça $\mathrm{S} 1$ da miosina à $\mathrm{Ac}$. Nesta situação o complexo Tn está mantendo a Tm nesta posição através dos contatos das regiões inibitórias e C-terminal da subunidade $\mathrm{Tnl}$ com a Ac e com a Tm. A presença de $\mathrm{Ca}^{2+}$ promove mudanças conformacionais na $\mathrm{TnC}$ que são transmitidas para as regiões inibitórias e C-terminal da Tnl, resultando assim a sua liberação da $\mathrm{Ac}$ e da $\mathrm{Tm}$. Nesta situação, a Tm adota uma nova posição sobre o filamento de Ac, permitindo assim que os sítios de interação da miosina com a Ac sejam liberados. Em resumo, no modelo do bloqueio estérico o filamento fino pode existir em duas conformações, que podem ser distinguidas pelo posicionamento da Tm na superfície da F-actina (Figura 6).

Em 1993, McKillop e Geeves propuseram um modelo de três estados para o filamento fino. Estes três estados são chamados de "blocked" (bloqueado), "closed" (fechado) e "open" (aberto). No estado "blocked" a cabeça de S1 da miosina não pode se ligar especificamente à Ac. No estado "closed" a cabeça de S1 liga-se fracamente à Ac e no estado "open" a S1 ligase fortemente à molécula de Ac, gerando força e uma alta atividade ATPásica. A Figura 7 mostra o posicionamento da Tm sobre a molécula de Ac nos três estados descritos. 
A

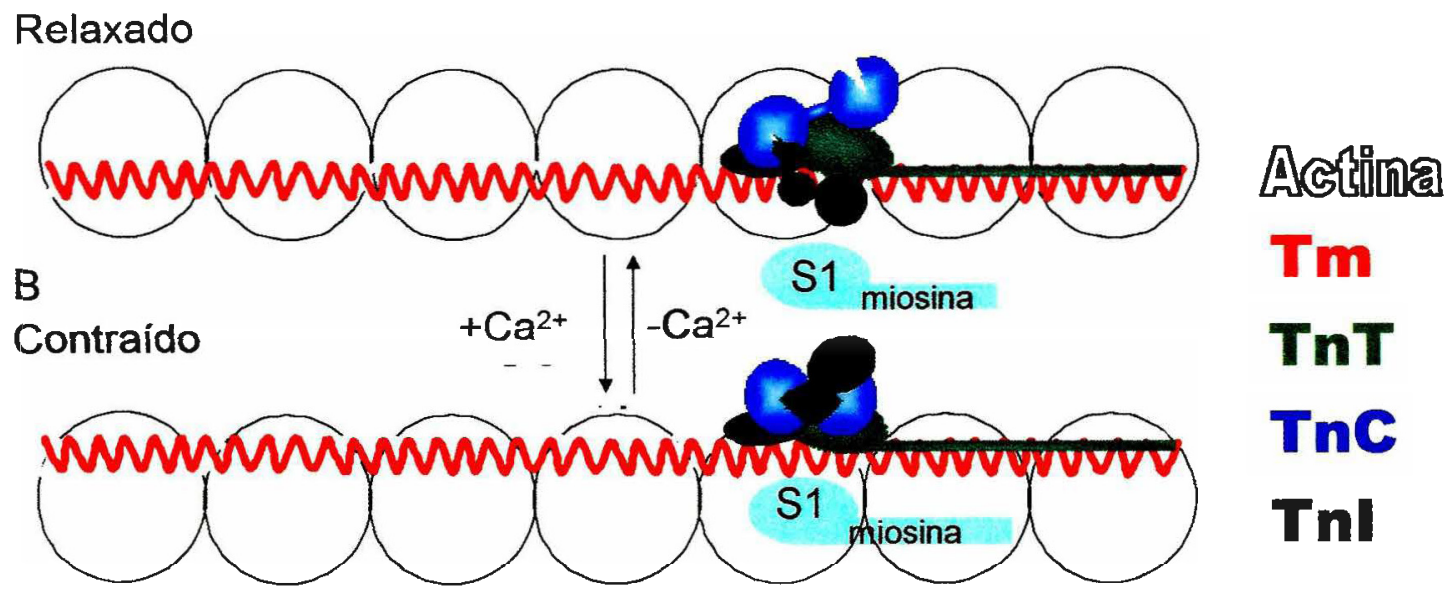

Figura 6- Modelo da regulação da contração muscular.

A) Modelo da interação Tn-Tropomiosina-Actina na ausência de $\mathrm{Ca}^{2+}$ onde os sítios $\mathrm{Ca}^{2+} \mathrm{Mg}^{2+}$ no domínio C-terminal da $\mathrm{TnC}$ estão ocupados com $\mathrm{Mg}^{2+}$, enquanto que os sítios $\mathrm{Ca}^{2+}$ específicos no domínio $\mathrm{N}$-terminal estão vazios. Neste caso, a região $\mathrm{N}$-terminal da $\mathrm{Tnl}$ está ligada ao domínio C-terminal da $\mathrm{TnC}$ bem como a região C-terminal globular da $\mathrm{TnT}$, enquanto que as regiőes inibitónas e C-terminal da Tnl fazem contato com actina e tropomiosina, mantendo o filamento fino numa conformação que inibe a interação da actomiosina. B) $A$ ligação de $\mathrm{Ca}^{2+}$ aos sitios $\mathrm{N}$-terminais $\mathrm{Ca}^{2+}$-especificos da troponina $\mathrm{C}$ aumenta a afinidade deste domínio pelas regiões inibitória e C-terminal de $\mathrm{Tnl}$, resultando na liberação desta última da actina e tropomiosina. Isto pode permitir à tropomiosina adotar uma posição nova no filamento de actina liberando assim a interação da actomiosina e levando à contração. (Farah e Reinach, 1995).

Sob o ataque enzimático da tripsina, a cabeça S1 da miosina é dividida em três fragmentos, nomeados de $25 \mathrm{~K}, 50 \mathrm{~K}$ e $20 \mathrm{~K}$ de acordo com as suas massas moleculares (Mornet et al., 1979). Rayment et al. (1993a) mostraram que o fragmento de $50 \mathrm{~K}$ é dividido em dois domínios (chamados de $50 \mathrm{~K}$ "upper domain" e 50K "lower domain") separados por uma longa fenda que vai desde o sítio de ligação ao ATP até o sítio de ligação à actina (ver figura 8). Em 1995, Holmes propôs um modelo mais completo englobando os modelos moleculares das interaçōes entre actina e miosina (com base nas estruturas das proteínas independentes) publicadas por Rayment et al. (1993a) e no modelo de McKillop e Geeves (1993), conforme pode ser visualizado na Figura 
7. Rayment et al. (1993a) sugerem que existem três tipos de interações entre a cabeça S1 da miosina e a Ac. Primeiramente, existe uma interação iônica em que os "loops" de $20 \mathrm{~K}$ e $50 \mathrm{~K}$, que fazem parte da cabeça S1 da miosina, encontram-se desordenados. Neste estado, a Tm promove um impedimento estérico entre uma das partes do fragmento de 50K ("lower domain") e a Ac (Figura 8a). No segundo tipo de interação, ocorre uma interação estéreoespecífica entre os resíduos hidrofóbicos da junção dos domínios de $50 \mathrm{~K}$ e $20 \mathrm{~K}$ com a Ac, permitindo uma ligação fraca entre S1 e Ac (Figura 8b). Neste estado a Tm promove um impedimento estérico entre Ac e a outra parte do fragmento de 50K ("upper domain"). No terceiro tipo de interação, ocorre um fortalecimento destas interações hidrofóbicas, trazendo todos os domínios (de $50 \mathrm{~K}$ e 20K) juntos e permitindo uma interação mais forte da S1 com a Ac, sem que haja um impedimento estérico por parte da Tm (Figura $8 \mathrm{c}$ ).

Como pode ser visto acima, a mobilidade da molécula de Tm sobre o filamento de Ac é de grande importância para o processo de regulação. Estudos de microscopia eletrônica e reconstrução de imagens tridimensionais realizados por Vibert et al. (1997) mostraram que a ligação de $\mathrm{Ca}^{2+}$ fazia com que a Tm realizasse um movimento azimutal de $25^{\circ}$ da posição em que ela se encontrava na ausência de $\mathrm{Ca}^{2+}$, em relação ao eixo da F-actina. A saturação do filamento com cabeças de miosina produzia um deslocamento azimutal adicional de $10^{\circ}$ na posição da Tm, expondo desta forma o sítio inteiro de ligação da Ac à miosina. Estes resultados sugerem que a mudança completa da Tm para o estado aberto ("open") requer a ligação seqüencial de $\mathrm{Ca}^{2+} \mathrm{e}$ cabeças de miosina, e complementam o modelo proposto por Holmes (1995). Desde que estas mudanças no posicionamento da $\alpha-T m$ podem estar acopladas a mudanças conformacionais na estrutura da Tm, a estabilidade conformacional desta molécula é de grande interesse. Como neste estudo nós iremos nos focalizar na metade C-terminal da Tm, principalmente no que diz respeito à estabilidade conformacional da molécula e as interações cabeçacauda, nós discutiremos a seguir sobre estrutura "coiled-coil" em geral e sobre a estrutura da Tm em particular. 


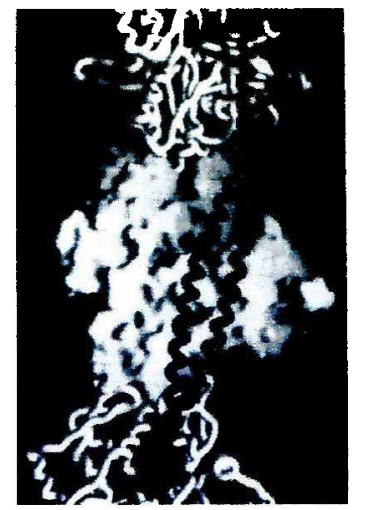

A

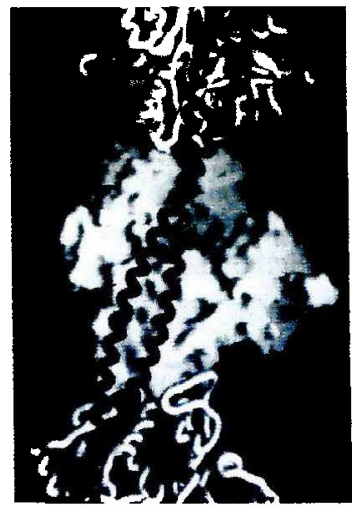

B

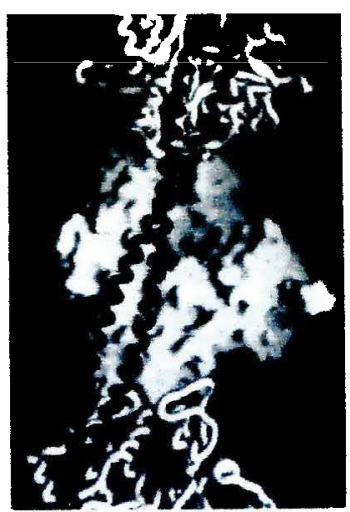

C

sem $\mathrm{Ca}^{2+} \quad$ com $\mathrm{Ca}^{2+} /$ sem ligação da S1 com $\mathrm{Ca}^{2+} /+\mathrm{S} 1$

Figura 7- Posicionamento da Tm (molécula helicoidal em cor mais escura) sobre a Ac (molécula globular representada por uma cor mais clara) em cada um dos estados propostos por McKillop e Geeves (1993): A) estado "blocked" na ausência de $\mathrm{Ca}^{2+}$, B) estado "closed" na presença de $\mathrm{Ca}^{2+}$ e C) estado "open" com $\mathrm{Ca}^{2+}$ e a ligação efetiva de S1. Figura retirada de Holmes (1995).

a

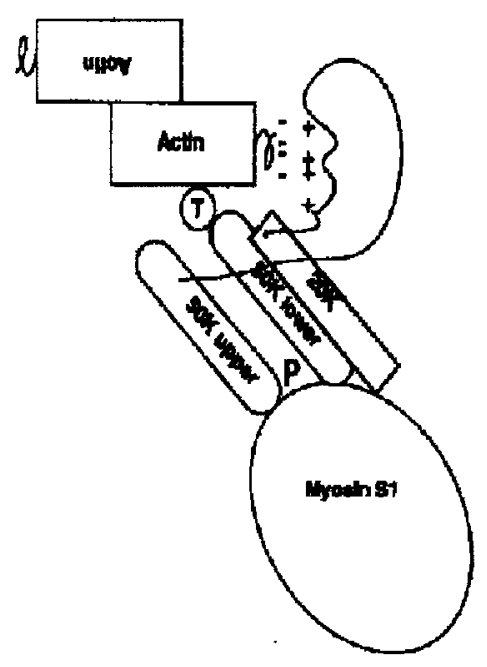

b

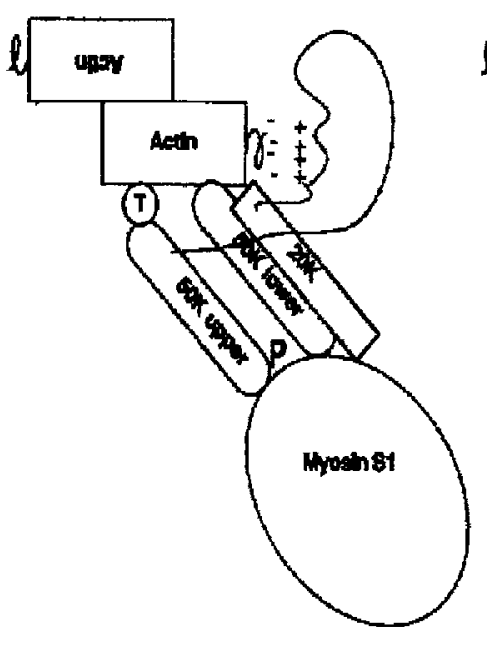

c

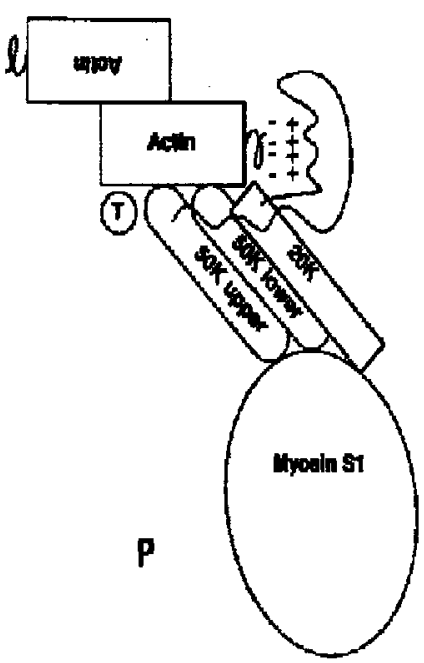

Figura 8 - Modelo proposto por Holmes (1995). a) a Tm inibe a ligação fraca estéreoespecífica da S1. O fragmento de 50K está dividido em duas partes por uma fenda onde se liga o ATP. b) Ocorre uma interação hidrofóbica entre $S 1$ e actina, porém com um pequeno impedimento estérico por parte da Tm. c) Ocorre uma aproximação dos "loops". A Tm não está mais impedindo o sítio de ligação da S1 e ocorre uma interação forte desta última com a Ac. A Tm está representada pela letra $\boldsymbol{T}$ e o fosfato inorgânico está representado pela letra $\boldsymbol{P}$. 


\section{3 - Estrutura "Coiled-coil"}

A estrutura "coiled-coil" foi primeiramente descrita em 1953 por Crick como principal elemento estrutural de uma grande classe de proteinas fibrosas, tais como miosina, queratina, tropomiosina e muitas outras (Lupas, 1996; Cohen e Parry,1990). A estrutura "coiled-coil" pode ser composta por dimeros, trímeros e até mesmo tetrâmeros de a-hélices. A "coiled-coil" formada por duas $\alpha$-hélices é caracterizada pela repetição heptapeptídica $(a, b, c, d, e, f, g)$ onde as posições a e d são normalmente ocupadas por resíduos hidrofóbicos (Hodges et al.,1972; Cohen e Parry, 1990), e as posiçōes e e $\mathbf{g}$ são freqüentemente ocupadas por resíduos carregados com cargas opostas como mostrado na Figura 9 (MacLachlan e Stewart, 1975). Os resíduos hidrofóbicos a e d estão voltados para o mesmo lado da hélice, resultando em uma interface hidrofóbica entre as duas hélices da "coiled-coil".
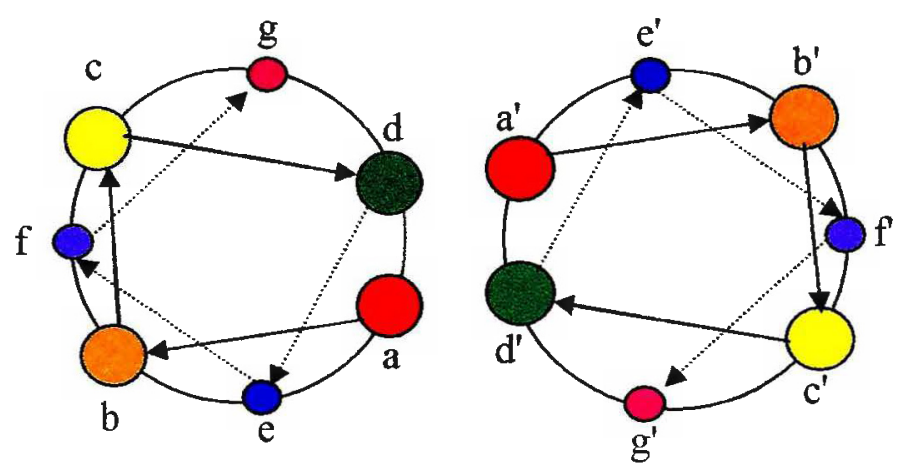

Figura 9 - Arranjo heptapeptídico- Visão transversal do N-terminal para o C-terminal das duas a-hélices que compõem a estrutura "coiled-coil" de duas fitas, mostrando as interações entre os resíduos hidrofobicos ad' e a'd, e as interaçőes iônicas entre os resíduos e g' e e'g (MacLachlan e Stewart, 1975).

Existem três propriedades que distinguem as hélices de "coiled-coils" das outras hélices anfipáticas: 1) a periodicidade dos resíduos hidrofóbicos (3,5 aminoácidos por volta versus 3,65 aminoácidos por volta). Isto ocorre por causa da geometria da estrutura "coiled-coil", na qual as cadeias laterais dos resíduos do centro hidrofóbico necessitam ocupar posições equivalentes a 
cada 2 voltas de 7 aminoácidos, para desta forma, permitir a intercalação entre os resíduos que ocupam estas posições (posições a e d). Isso não seria possível nas hélices que contêm 3,6 resíduos por turno, já que desta maneira a posição das cadeias laterais na sua superfície mudaria continuamente; 2) o comprimento (longo versus curto); 3) e as interações de empacotamento ("knobs-into-holes" versus "ridges into grooves"). No empacotamento chamado "knobs-into-holes" um resíduo de uma das hélices (knob) está encaixado em um espaço rodeado por quatro cadeias laterais na hélice vizinha (hole), diretamente do lado do resíduo equivalente na hélice vizinha (Veja Figura 10). Brown et al. (2001) mostram, através da estrutura cristalina do N-terminal da Tm com 2 Å de resolução, que o empacotamento "knob-into-holes" ocorre de forma que a cadeia lateral do resíduo i (knob) de uma das cadeias polipeptídicas está interagindo com as cadeias laterais dos resíduos i'-3, i', i'+1 e i'+4 (hole) da outra cadeia polipeptídica. No empacotamento "ridges into grooves", que ocorre em proteínas globulares contendo motivos helicoidais, o resíduo de uma das hélices encaixa-se acima ou abaixo do resíduo equivalente na hélice vizinha (Lupas, 1996).

A orientação das hélices numa "coiled coil" pode ser paralela ou antiparalela bem como hetero ou homo-oligoméricas. Ambos os padrões são determinados pelas interações entre os grupos polares e iônicos que flanqueiam o "core" hidrofóbico. Oakley e Kim (1998) mostraram que uma interação polar simples escondida na interface entre duas hélices é suficiente para determinar a orientação relativa das duas hélices constituintes. Alaninas localizadas dentro do "core" hidrofóbico também podem estabelecer uma orientação de acordo com o seu posicionamento (Monera et al., 1996). Estudos realizados com peptídeos sintéticos mostraram que, embora as atrações iônicas intercadeias não sejam essenciais para a formação de uma "coiled-coil", um grande número destas interações fracas pode ter um importante papel na união e alinhamento correto das hélices, além de contribuir significativamente para a estabilidade da proteina (Zhou et al., 1994 $a, b)$. 
Em tropomiosinas, os resíduos com cargas opostas, encontrados nas posições e e g, favorecem a formação de pares iônicos inter-hélices, os quais estabilizam o arranjo paralelo e "in register" (alinhado) das hélices da estrutura "coiled coil". Em 1975 McLachlan e Stewart, apenas através da análise da seqüência da $\mathrm{Tm}$, mostraram que as cadeias laterais dos resíduos em posições e tendem a ser ácidas em sua maioria e que as cadeias laterais dos resíduos em posições $\mathbf{g}$ tendem a ser básicas. Como estas posições estão face a face dentro da estrutura "coiled-coil", se as hélices estivessem antiparalelas haveria interações repulsivas entre as posições e-e' e g-g'. No entanto, em um arranjo paralelo, as atrações e-g são atrativas promovendo pontes salinas entre as cargas opostas e, portanto, estabilizando a estrutura. Neste mesmo trabalho, os autores mostram que os grupos hidrofóbicos, no centro da estrutura, apresentam um melhor empacotamento quando as duas hélices encontram-se alinhadas ("in register"), formando um "core" bem empacotado, sem buracos na sua superfície. Quando as hélices da Tm foram analisadas fora de alinhamento, ou seja, com um deslocamento de um, dois ou três aminoácidos de uma em relação à outra, os ajustes eram insatisfatórios, levando a um empacotamento pobre da região entre as hélices.

Vários fatores podem determinar o número de hélices de uma "coiledcoil": 1- O empacotamento dos resíduos que estão na interface entre as hélices; 2- A geometria das cadeias laterais dos resíduos em posições a e d com relação à cadeia principal das hélices; 3- A quantidade de resíduos hidrofóbicos existentes no "core"; 4- A natureza dos resíduos situados nas posições e e g.

Os resíduos nas posições a e $\mathbf{d}$ adotam diferentes geometrias com relação à cadeia principal da hélice vizinha nas "coiled-coils" de duas, três e quatro hélices, e portanto, têm diferentes preferências de posicionamento para a cadeia lateral. $\mathrm{Na}$ "coiled-coil" de duas fitas a ligação $\mathrm{C} \alpha-\mathrm{C} \beta$ do resíduo que está no centro hidrofóbico é paralela ao vetor $\mathrm{Ca}-\mathrm{C} \alpha$ na base da cavidade oposta quando em posição a e perpendicular quando em posição d (Figura 10). Nas "coiled-coils" constituídas de três hélices, ambas as posições a e d 
tem a sua ligação $\mathrm{C} \alpha-\mathrm{C} \beta$ formando um ângulo agudo com o vetor $\mathrm{C} \alpha-\mathrm{C} \alpha$ na base da cavidade oposta, ao passo que nas "coiled-coils" de quatro fitas a posição d encontra-se em geometria paralela e a posição a encontra-se em geometria perpendicular (Harbury et al.,1994; Lovejoy et al.,1993; Harbury et al.,1993; Lupas, 1996).

A

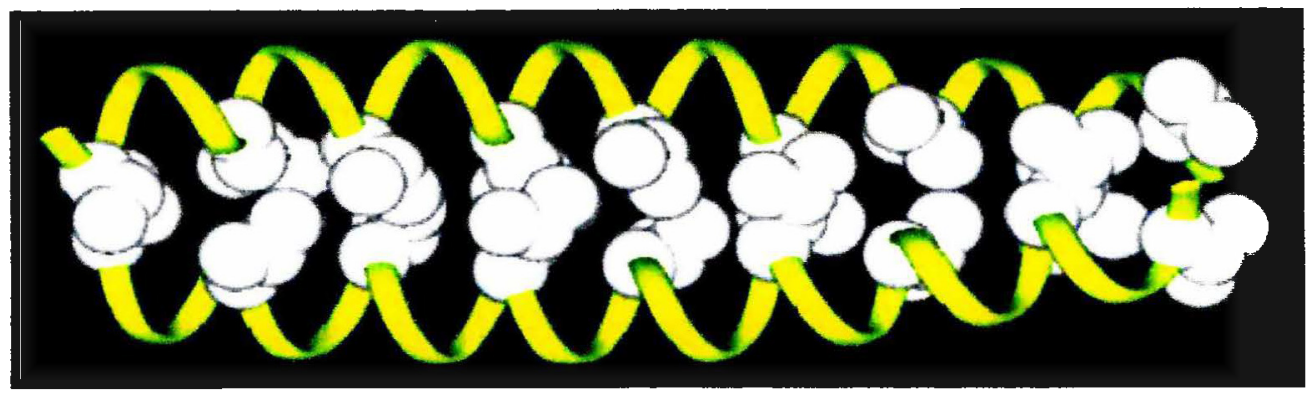

B

Posição a

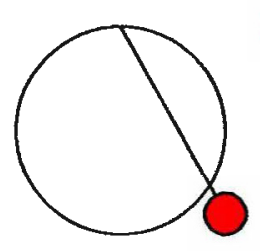

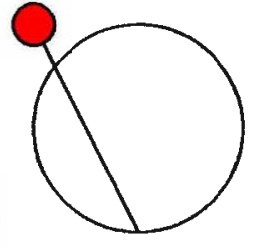

Figura 10 - A) Mostra o empacotamento "knobes-into-holes" dos residuos hidrofóbicos encontrados nas posições heptapeptídicas a $e$ d das estrutura "coiled-coil" composta de duas a-hélices (Yu, 2002). B) Mostra a geometria das cadeias laterais dos resíduos encontrados nas posiçóes a e d com relação à cadeia principal da a-hélice. Os vetores $C \alpha-C \beta$ das cadeias laterais dos aminoácidos na posição a estão apontando para fora e são paralelos ao vetor $C \alpha-C \alpha$ na base da cavidade oposta. Na posição d os vetores $C \alpha-C \beta$ estão apontando para dentro do centro hidrofóbico, sendo perpendiculares ao vetor $\mathrm{Ca}-\mathrm{Ca}$ na base da cavidade oposta (Lupas 1996).

As conseqüências destas diferenças estéricas são que: 1- a geometria paralela é favorecida por resíduos $\beta$-ramificados como isoleucina, valina e treonina e 2- a geometrias aguda e perpendicular são favorecidas por resíduos de leucina (Harbury et al.,1993). Isto promove diferenças na freqüência de ocorrência destes resíduos de acordo com o tipo de "coiled-coil". Portanto, em dímeros de "coiled-coil" observa-se uma grande quantidade de isoleucinas em 
posições a e leucinas em posições d. Além disso a presença de resíduos polares no "core" hidrofóbico favorece a formação de dímeros, pois nesta situação eles podem estar parcialmente solvatados, ao invés de trímeros e tetrâmeros onde o "core" fica mais escondido do solvente (Lupas et al.,1996).

Estudos com fragmentos sintéticos (com seqüências não derivadas da tropomiosina) contendo 35 aminoácidos mostraram que são necessários pelo menos oito resíduos hidrofóbicos (como Leu) nas posições a e d para que haja a formação de uma estrutura "coiled-coil", considerando este sistema modelo. Além do mais a substituição de leucina por alanina em algumas posições mostrou que nestes fragmentos sintéticos a queda na estabilidade do fragmento está diretamente relacionada com o grau de hidrofobicidade dos resíduos envolvidos (Zhou et al.,1992a, b e c; Tripet et al., 2000).

O motivo "coiled-coil" está presente em muitas estruturas protéicas e tem sido muito utilizado como modelo para o estudo do enovelamento de proteínas. Neste sentido, muitos estudos têm sido realizados com peptídeos sintéticos que adquirem estrutura "coiled-coil" paralela e antiparalela (Oakley e Kim,1998; Yu et al.,1996; Wagschal et al., 1999; Lau et al.,1984).

Um modelo desenhado e sintetizado por Hodges et al. (1981) para estudar a estrutura "coiled-coil" sugeriu que o tamanho mínimo requerido para a formação e estabilização de uma estrutura "coiled-coil" é de 28 resíduos. Trabalhos subseqüentes realizados pelo mesmo grupo mostram que a estabilidade da "coiled-coil" está diretamente relacionada com o tamanho da cadeia (Lau et al., 1984). Devemos ressaltar, entretanto, o fato de que tais estudos foram feitos com peptídeos sintéticos de baixa complexidade estrutural, onde obviamente são diminuídas as possibilidades de outros tipos de interações, tais como interações intra-hélices entre cadeias laterais (i, i+3 e i+4), com a finalidade de se evitar complicações na interpretação dos resultados. Desta forma, sabemos que a união de vários fatores combinados pode afetar a estabilidade de "coiled-coils" naturais.

Portanto, torna-se necessário estudar modelos de ocorrência natural que possam explicar melhor o mecanismo de enovelamento de proteínas 
"coiled-coils" e quais seriam as interações realmente importantes para a manutenção desta estrutura.

\section{4 - Considerações estruturais sobre a molécula de Tm.}

A $\alpha \alpha-T m$ muscular esquelética é uma molécula simétrica de duas $\propto-$ hélices paralelas que formam uma estrutura "coiled-coil" de aproximadamente 420 Å de comprimento (ver Figura 11) (Whitby,2000).

Figura 11- Modelo da estrutura da Tm com base nos dados de cristalografia de raios $X$ com resolução de $7 \AA$ (Whitby et al., 2000). As cadeias laterais são mostradas na conformação toda trans, mas não foram resolvidas na estrutura cristalina.

Além da repetição heptapeptídica, encontra-se uma outra pseudorepetição na seqüência da proteína que envolve a natureza química dos aminoácidos nas posições externas da "coiled-coil" (posições b,c,e,f,g). Cada monômero de Tm é constituído de um arranjo de grupos ácidos e não polares, repetidos quatorze vezes ao longo da cadeia polipeptídica. Estes quatorze períodos podem ser divididos em grupos de dois, chamados de zona a e zona $\beta$, que alternam através da seqüência. Cada zona (com $\cong 19,7$ resíduos) é dividida em uma parte amino-terminal básica/hidrofóbica ( 8 resíduos) e uma parte carboxi-terminal acídica (12 resíduos). Acredita-se que cada par alfa/beta interage com um monômero de Ac no filamento fino (McLachlan e Stewart, 1976) (ver Figura 12). A Tm se acomoda em duas fendas existentes no filamento de $A c$, interagindo com sete monômeros de actina e com um complexo de Tn. Em termos da estrutura do "coiled-coil", um par alfa-beta de 
aproximadamente 39 resíduos corresponde a uma meia volta da super-hélice do "coiled-coil" da Tm e ao comprimento de um monômero de Ac. Análises feitas através de deleções internas têm mostrado que alguns dos quatorze sítios periódicos contribuem mais do que outros para a ligação à Ac (Hitchcock-Degregori et al., 1996).

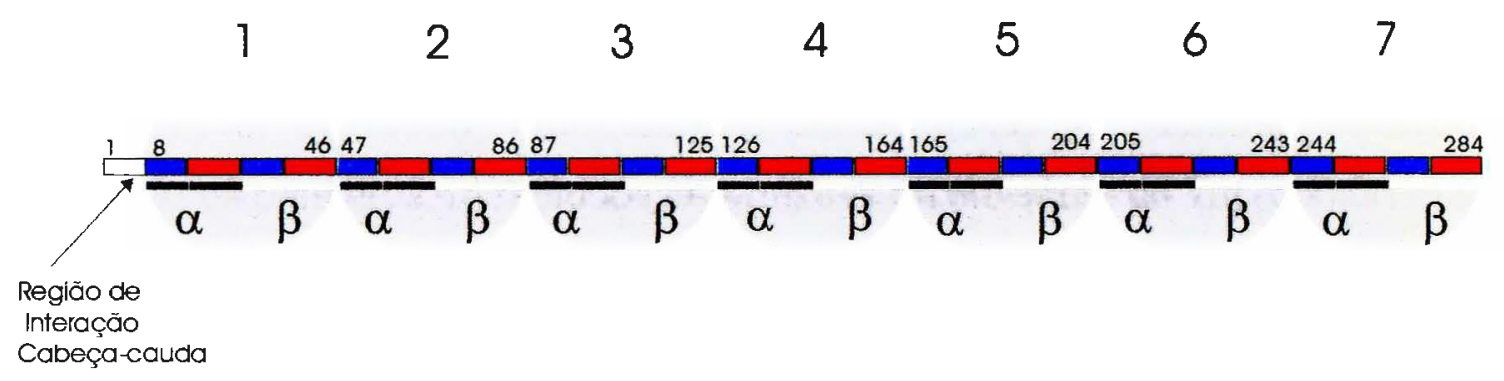

Figura 12 - Representação das zonas a e B propostas por McLachlan e Stewart (1976). As esferas cinzas representam os 7 monômeros de moléculas de actina que interagem com uma molécula de $\mathrm{Tm}$. Os retângulos rosas representam os 8 resíduos amino-terminais básicos e os retângulos azuis representam os 12 residuos carboxi-terminais ácidos nas zonas $\alpha \beta$ da molécula de Tm. Estes dois padrões de repetição somados (rosa+ azul) dão origem a uma repetição a (sublinhado em preto) ou $\beta$ (sublinhado em branco), totalizando 7 pseudorepetições $\alpha \beta$ ao longo da molécula de $\mathrm{Tm}$. Os números dentro das esferas indicam onde começa e onde termina cada repetição $\alpha \beta$.

Estruturas obtidas por difração de raios $X$ a partir de cristais de $\mathrm{Tm}$ mostraram que a molécula de Tm é muito flexível. Isto implica que mudanças locais na estrutura podem ser importantes para a regulação da contração muscular e para a ligação cooperativa entre a molécula de miosina e a Ac (Phillips et al.,1986).

Em estudos de cristalografia de raios $X$ recentes ( $7 \AA$ de resolução) (Whitby et al., 2000) detalhes atômicos da molécula de Tm não podem ser vistos, nesta faixa de resolução, principalmente na região de polimerização cabeça-cauda. Entretanto foi possivel demonstrar que existem variações no "pitch" (passo) da estrutura "coiled-coil" que se devem provavelmente a variações locais da seqüência. Tais resultados sugerem que a Tm não é uma 
molécula de estrutura altamente regular como se esperava, mas que existem graus de irregularidade dentro dela. Estes estudos também demonstraram que a "coiled-coil" da Tm tem uma curvatura natural que mimetiza o seu caminho helicoidal na superfície da actina. Esta curvatura pode ser bem visualizada na Figura 11 (Whitby et al., 2000).

Trabalhos publicados recentemente (Brown et al., 2001; Greenfield et al.,1998 e 2003; Li et al., 2002) revelam as estruturas com alta resolução de fragmentos localizados nas regiões $\mathrm{N}$ - e $\mathrm{C}$-terminais da molécula de $\mathrm{Tm}$. Greenfield et al. (1998) publicaram a estrutura de um peptídeo sintético contendo os primeiros 14 resíduos $\mathrm{N}$-terminais da molécula de $\mathrm{Tm}$ (contendo a acetilação $\mathrm{N}$-terminal) de músculo estriado de coelho, ligados aos últimos 18 resíduos C-terminais do fator de transcrição de levedura GCN4, o qual também possui uma estrutura "coiled-coil". Os resultados de ressonância magnética nuclear mostraram que o domínio "coiled-coil" se estende até a região $\mathrm{N}$-terminal como mostrado na Figura 13A.

A estrutura cristalina a $2 \AA$ de resolução de um fragmento $\mathrm{N}$-terminal de $\alpha-T m$ de músculo estriado contendo 81 resíduos de aminoácidos, porém com - N-terminal não acetilado, revela que nestas condições os resíduos 1 e 2 encontram-se em conformação estendida e não helicoidal, como esquematizado na Figura 13B. Além disso, a estrutura cristalina mostra as duas a-hélices paralelas onde um alto conteúdo de alaninas localizadas em posições a e $\mathbf{d}$ e em regiões específicas ao longo da seqüência produz quebras na simetria entre as duas $\alpha$-hélices. A união dessas regiões com seqüências vizinhas, onde as hélices estão em alinhamento axial, dá origem a dobras ("kinks") específicas no eixo molecular. Estas dobras promovem uma curvatura natural ao longo da molécula de Tm (Figura 11). Uma análise da seqüência de $\alpha$-Tm muscular mostra que estas regiões com alta densidade de alanina são um conjunto de 7 e estão bem distribuídas ao longo de toda a molécula (Brown et al., 2001). 
A)

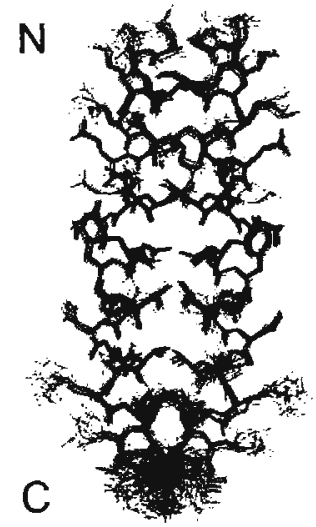

B)
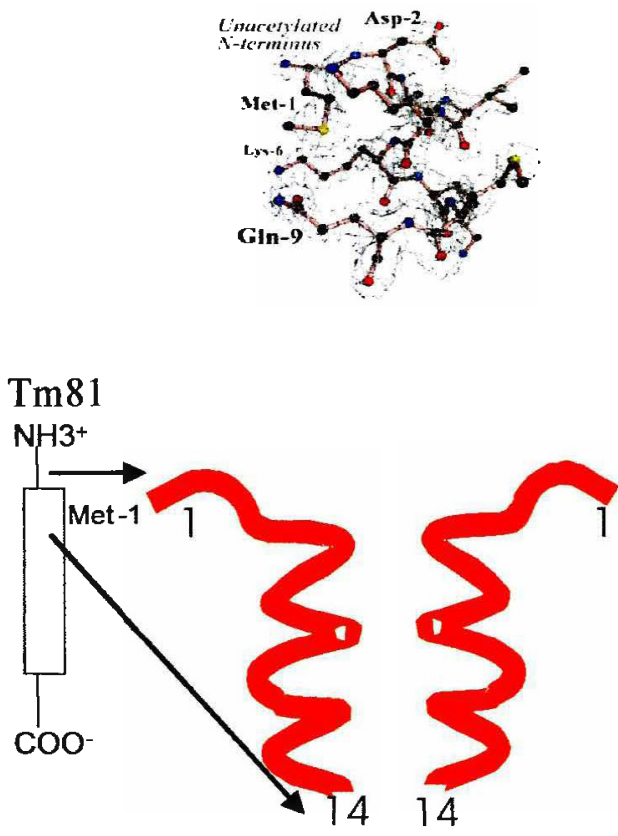

Figura 13 - Estruturas da Tm acetilada (A) e não acetilada (B) do $\mathbf{N}$-terminal. A) 0 esquema em verde mostra que na forma acetilada, o domínio "coiled-coil" se estende até o primeiro aminoácido. O esquema foi construído com base na estrutura determinada por RMN dos 14 primeiros aminoácidos $N$-terminais de $\alpha$-Tm de músculo estriado de coelho + os 18 últimos aminoácidos de GCN4, esquematizada do lado direito da parte $A$ da figura ( $A$ estrutura publicada por Greenfield et al., 1998 está mostrada do lado esquerdo da parte A da figura). B) O esquema em vermelho mostra que quando o primeiro aminoácido não está acetilado os resíduos 1 e 2 encontram-se em conformação estendida e não helicoidal. 0 esquema foi feito com base na estrutura cristalina, a $2 A$ de resolução, dos 81 primeiros resíduos $N$-terminais da $\alpha$-Tm de músculo estriado de galinha, esquematizado no lado esquerdo da parte $B$ da figura. (Parte da estrutura (resíduos 1 a 9) determinada por Brown et al.(2001) está mostrada acima do esquema em vermelho na parte $B$ da figura).

Recentemente Li et al. (2002) obtiveram uma estrutura cristalina, a 2,7 Å de resolução, da região C-terminal da Tm (residuos 254 a 284) fundida com a região 7 a 30 do zíper de leucina da GCN4. Este trabalho mostrou que este peptídeo de fusão forma uma interação do tipo "cauda-cauda" entre duas 
moléculas idênticas na célula unitária, onde os resíduos 263-284 da Tm não estão formando uma "coiled-coil" dupla como o resto da molécula (Figura 14B). Embora esta interação tetramérica "cauda-cauda" observada neste trabalho não possua nenhuma correlação com a estrutura fisiológica cabeçacauda entre as moléculas de Tm, ela sugere que a região C-terminal da Tm pode existir em múltiplas conformações, todas, possivelmente, com alto conteúdo de $\alpha$-hélice. Estas conformações podem ser relevantes para as interações feitas pela molécula de Tm. Recentemente, Greenfield et al.(2003) publicaram a estrutura, determinada por RMN, de um fragmento de Tm contendo os resíduos 251-284 da molécula de Tm, porém com algumas modificações que permitissem uma maior estabilidade deste fragmento. 0 fragmento designado Tm9a $a_{251-284}$ contém uma fusão tripeptídica (GCG) no Nterminal para permitir a formação de pontes dissulfeto e uma mutação pontual na posição 279 (N279K), que é responsável por um aumento na estabilidade do fragmento. Os estudos de RMN mostraram que o fragmento encontra-se estruturado da seguinte forma (Figura 14A): Os residuos 253-269 formam uma estrutura "coiled-coil", ao passo que os residuos 270-279, apresentam-se em estrutura $\alpha$-hélice, sendo que nesta região os dímeros estão arranjados de uma maneira paralela ao longo da molécula de Tm em vez de formar uma estrutura "coiled-coil". Além do mais, os resíduos 280-284 se encontram em estrutura não helicoidal. 
A
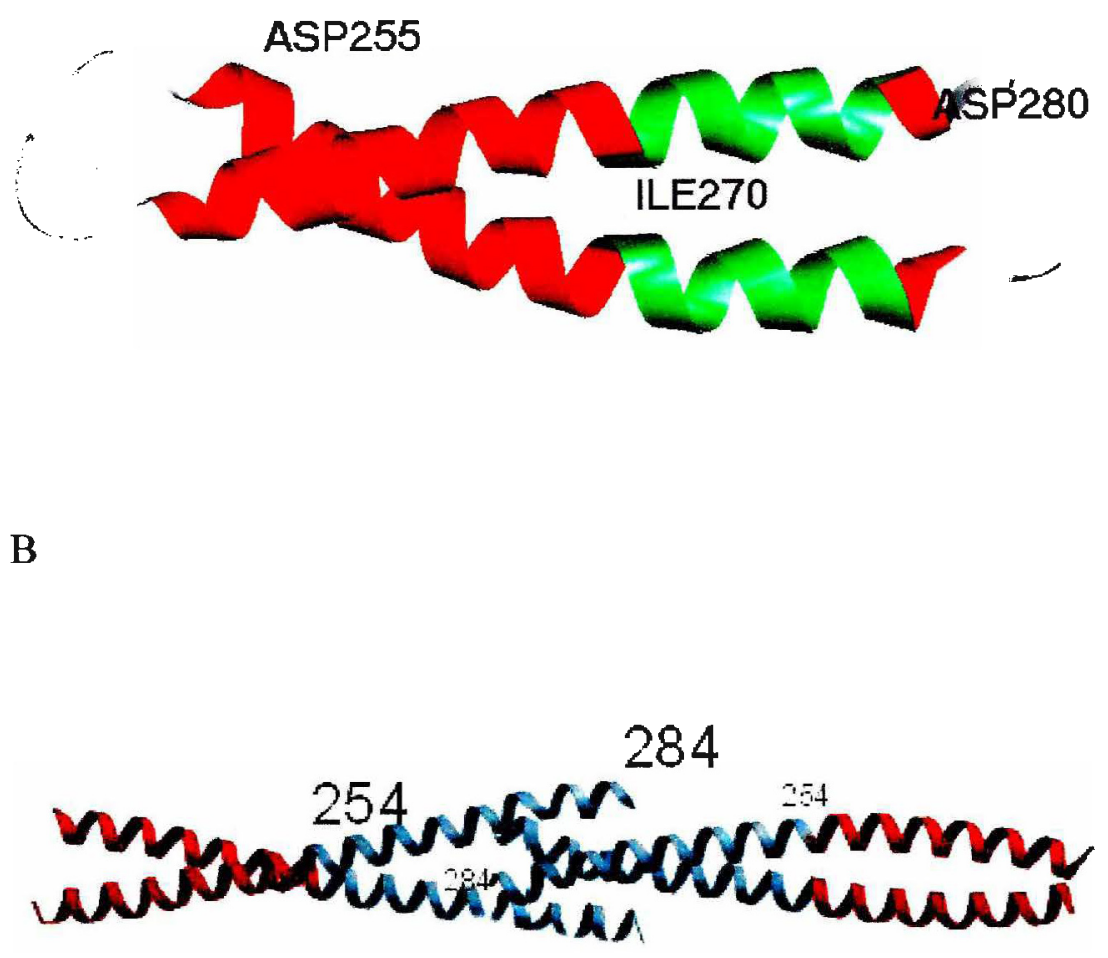

Figura 14 - A) Estrutura por RMN dos últimos 34 resíduos da $T m$. O peptídeo foi construído com uma mutação que aumenta a estabilidade do peptídeo (N279K) e uma seqüência tripeptídica GCG no N-terminal para permitir a dimerização via pontes dissulfeto (Greenfield et al.,2003). Os resíduos 270-279 (em verde), em ambas as cadeias polipeptídicas, formam hélices que se alinham paralelamente uma à outra. B) Estrutura cristalográfica a 2,7A de resolução dos últimos 31 aminoácidos da $\alpha-T m$ de músculo esquelético de rato, precedido por um fragmento de GCN4 (Li et al., 2002). A molécula, chamada de cGCN4-CTm, cristaliza na forma de um tetrâmero de $\alpha$-hélices, onde os dois Cterminais estão interagindo de forma "cauda-cauda". A seqüência de cada cadeia consiste de uma metiona N-terminal seguida pelos resíduos 7-30 do zíper de leucina GCN4 (vermelho) e os resíduos 254-284 da Tm (cinza). 


\section{5 - A Tm polimeriza através de interações cabeça-cauda}

Sabe-se que a Tm de músculo esquelético é acetilada no resíduo $\mathrm{N}$ terminal e que a não acetilação deste resíduo faz com que a tropomiosina perca a sua habilidade de se polimerizar (Cho et al., 1990; Heald e HitchcockDeGregori, 1988; Monteiro et al., 1994). A Tm não acetilada tem uma afinidade muito reduzida pelo filamento de Ac, deixando, desta forma, de inibir a atividade actomiosina - ATPase na ausência de Tn (Hitchcock e Heald, 1987). A observação de que a Tm não acetilada liga fracamente à actina indica que o efeito da carga no amino-terminal é crítico para a função da Tm (Hitchcock e Heald, 1987). A metionina inicial ocupa uma posição a (interna) na repetição heptapeptídica e a sua acetilação permite que não haja cargas no centro hidrofóbico da "coiled-coil, as quais, poderiam reduzir a estabilidade nesta região devido a repulsão eletrostática (ver Figura 13; Monteiro et al., 1994, Brown et al., 2001).

Outros estudos evidenciam que resíduos específicos no $\mathrm{N}$ e C-terminal são muito importantes para o processo de polimerização. Tms recombinantes com a deleção de poucos resíduos na região C-terminal também não são polimerizáveis (Ueno et al., 1976; Mak et al., 1981 e Cho et al., 1990). Tms tratadas com carboxipeptidases não polimerizam, ainda que na presença de Tn e também tem a sua afinidade por actina reduzida (Johnson e Smillie, 1977; Hitchcock e Heald, 1987). A polimerização da Tm não é afetada pela remoção dos três últimos resíduos terminais 282,283 e 284, entretanto quando o resíduo 281 é removido a polimerização é abolida (Johnson e Smillie, 1977).

Modificações dentro da molécula de Tm também podem abolir ou diminuir a intensidade da interação cabeça-cauda, como por exemplo, a acetilação do grupo amino $\varepsilon-\mathrm{NH}_{2}$ da lisina 7 (Johnson e Smillie, 1977) ou a introdução de um pireno na cisteína 190 (Graceffa e Lehrer, 1980). Variações na seqüência interna da Tm também podem afetar o grau de polimerização. Sano e colaboradores (2000b) mostraram que duas isoformas de Tm que diferem apenas em 15 resíduos dentro da região compreendida pelos resíduos 
39 a 80 possuem viscosidades completamente diferentes em baixas forças iônicas.

A polimerização da Tm de músculo esquelético recombinante não acetilada (expressa em bactéria) pode ser restaurada através da fusão de dois (AS) ou três (AAS) aminoácidos (Monteiro et al., 1994). O processo de polimerização é diminuído conforme se aumenta a força iônica (Kay e Bailey 1960; Ooi et al., 1962; Sousa e Farah, 2002) o que sugere que a interação cabeça-cauda tem um componente significativo de interações iônicas.

Como já foi mencionado anteriormente, a estrutura cristalina do complexo entre o C- e o N-terminal da Tm (complexo cabeça-cauda) não é conhecida, já que cristais da molécula de Tm inteira difratam com baixa resolução (7 Å) (Phillips et al., 1986; Whitby et al., 2000). Recentemente, Palm e colaboradores (2001) mostraram que um peptídeo C-terminal da molécula de Tm, Tm9a36ox (que consiste de 35 aminoácidos de a-Tm de músculo esquelético de rato codificada pelo exon 9 a e com uma ponte de cistina no $\mathrm{N}$ terminal), foi capaz de se ligar ao peptídeo N-terminal AcTm1azip (Greenfield et al., 1998). A mistura dos dois peptídeos mostrou um aumento na estabilidade térmica $\left(+5,4^{\circ} \mathrm{C}\right)$, quando comparada com a soma de componentes individuais, indicando desta maneira a formação do complexo, ou seja, de um dímero entre AcTm1azip e Tm9a36ox (Paim et al., 2001).

\section{6 - Estudos envolvendo a estabilidade da Tm}

Estudos envolvendo a estabilidade conformacional da Tm vêm sendo realizados nestas últimas décadas (Suarez et al., 2001; Lehrer e Yuan, 1998; Mo et al., 1990; Holtzer et al., 1995; Potekhin e Privalov, 1982; Willians et al., 1981; Bodwell et al., 1965) como uma tentativa de elucidar os mecanismos envolvidos no enovelamento de "coiled-coils" em geral.

Vários modelos sintéticos que assumem estrutura "coiled-coil" têm sido estudados (Wagschal et al., 1999; Oakley e Kim, 1998; Yu et al., 1996; Lau et al., 1984). Entretanto, estudos realizados com modelos de ocorrência natural, como a Tm, revelam que nem sempre os resultados obtidos através da 
utilização de modelos sintéticos são representativos quando comparados a estudos realizados com a Tm (Zhou et al., 1992a, 1994a; Holtzer e Holtzer,1990; Holtzer et al., 2001). Estes peptídeos modelo normalmente possuem uma baixa complexidade estrutural, em que as interações intrahélice $i, i+3$ e i+4 aparecem com menor freqüência.

Devido à sua relativa simplicidade estrutural, a Tm torna-se um modelo natural para o estudo de associação de cadeias que promovem a dimerização, bem como para o estudo das interações importantes para a manutenção da estrutura "coiled-coil" e para a estabilização das $\alpha$-hélices. Estudos realizados por Pato e Smillie (1978) e Holtzer e Holtzer (1990), utilizando fragmentos de Tm, mostram que a metade $\mathrm{C}$-terminal da molécula de Tm possui uma menor estabilidade térmica do que a região $\mathrm{N}$-terminal. Os experimentos realizados com os fragmentos $\left(11-127,142-281,1-189\right.$ e 190-284) mostraram que a $3^{\circ} \mathrm{C}$ todos têm um conteúdo de $90 \%$ de a-hélice ou mais, sendo que todas as curvas de desnaturação térmica dependem da concentração (indicando formação de dímero) e são completamente reversiveis em concentrações comparáveis. As soluções mostram valores de $T_{1 / 2}$ (temperatura na qual a conteúdo de hélice é de $50 \%$ em relação ao valor inicial) na seguinte ordem (Holtzer e Holtzer, 1990): 11-127 1-189 > 142-281 > 190-284. Além disso, trabalhos publicados por Holtzer e Holtzer (1991), Holtzer et al. (1995) e Pato et al. (1981b) sugeriam que fragmentos de Tm menores que 94 aminoácidos eram incapazes de assumir estrutura secundária. A Tabela 1 mostra todos os fragmentos de $\mathrm{Tm}$ cujas estabilidades conformacionais foram relatadas até 0 presente manuscrito. Recentemente, Holtzer et al. (2001) mostraram que um fragmento contendo resíduos 190-254 (65aa) era capaz de assumir estrutura em a-hélice apenas quando a $10^{\circ} \mathrm{C}$ e em alta concentração de proteína (115 $\mu \mathrm{M})$. Entretanto este fragmento encontrava-se quase completamente desenovelado a $25^{\circ} \mathrm{C}$. 
Tabela 1- Comparação da estabilidade conformacional (fração de estrutura $\alpha$-helicoidal nas temperaturas indicadas entre parênteses) de vários fragmentos de Tm encontrados na literatura até o presente momento. 1-Fragmentos estudados na literatura; 2Porcentagem de estrutura $\alpha$-hélice estimada pelos autores. Entre parênteses está indicada a temperatura em que foi feito o experimento; 3- Publicação de onde foram retirados os dados; 4- Condições do tampão e, entre parênteses, a concentração dos fragmentos considerando-os como dímeros (duas cadeias polipeptídicas) ou como monômeros (uma cadeia polipeptídica).

\begin{tabular}{|c|c|c|c|}
\hline $\begin{array}{l}\text { Fragmento } \\
\text { (1) }\end{array}$ & $\begin{array}{l}\text { Porcentagem de } \\
\alpha \text {-hélice /temp. } \\
\text { (2) }\end{array}$ & $\begin{array}{l}\text { Publicação } \\
\text { (3) }\end{array}$ & $\begin{array}{l}\text { Condições } \\
\text { (4) }\end{array}$ \\
\hline $1-284$ & $92\left(10^{\circ} \mathrm{C}\right)$ & $\begin{array}{l}\text { Pato e Smillie (1978) } \\
\text { Pato ef al. (1981a) }\end{array}$ & $\begin{array}{l}100 \mathrm{mM} \mathrm{KCl}, 1 \mathrm{mM} \text { DTT, } 50 \mathrm{mM} \text { fosfato de sódio, } \\
\mathrm{pH} 7,0 \text { (16 } \mu \mathrm{M} \text { do dímero) }\end{array}$ \\
\hline $1-133$ & $89\left(10^{\circ} \mathrm{C}\right)$ & $\begin{array}{l}\text { Pato e Smillie (1978) } \\
\text { Pato et al. (1981a) }\end{array}$ & $\begin{array}{l}100 \mathrm{mM} \mathrm{KCl}, 1 \mathrm{mM} \text { DTT, } 50 \mathrm{~m} \mathrm{M} \text { fosfato de sódio, } \\
\text { pH } 7,0(34 \mu \mathrm{M} \text { do dímero })\end{array}$ \\
\hline $13-125$ & $89\left(10^{\circ} \mathrm{C}\right)$ & $\begin{array}{l}\text { Pato e Smillie (1978) } \\
\text { Pato et al. (1981a) }\end{array}$ & $\begin{array}{l}100 \mathrm{mM} \mathrm{KCl}, 1 \mathrm{mM} \text { DTT, } 50 \mathrm{mM} \text { fosfato de sódio, } \\
\mathrm{pH} 7,0(40 \mu \mathrm{M} \text { do dímero })\end{array}$ \\
\hline \multirow[t]{2}{*}{$11-127$} & $81\left(10^{\circ}\right)$ & $\begin{array}{l}\text { Pato e Smillie (1978) } \\
\text { Pato et al. (1981a) }\end{array}$ & $\begin{array}{l}100 \mathrm{mM} \mathrm{KCl}, 1 \mathrm{mM} \text { DTT, } 50 \mathrm{mM} \text { fosfato de sódio, } \\
\mathrm{pH} 7,0 \text { (38 } \mu \mathrm{M} \text { do dímero) }\end{array}$ \\
\hline & $>90\left(3^{\circ} \mathrm{C}\right)$ & Holtzer e Holtzer (1990) & $\begin{array}{l}500 \mathrm{mM} \mathrm{NaCl}, 50 \mathrm{mM} \text { fosfato de sódio, } \mathrm{pH} 7,4 \text { e } 5 \\
\text { mM DTT (aproximadamente } 38,4 \mu \mathrm{M} \text { do dimero) }\end{array}$ \\
\hline \multirow[t]{2}{*}{$1-189$} & $63\left(10^{\circ} \mathrm{C}\right)$ & $\begin{array}{l}\text { Pato e Smillie (1978) } \\
\text { Pato et al. (1981a) }\end{array}$ & $\begin{array}{l}100 \mathrm{mM} \mathrm{KCl}, 1 \mathrm{mM} \text { DTT, } 50 \mathrm{mM} \text { fosfato de sódio, } \\
\mathrm{pH} 7,0(24 \mu \mathrm{M} \text { do dimero })\end{array}$ \\
\hline & $>90\left(3^{\circ} \mathrm{C}\right)$ & Holtzer e Holtzer (1990) & $\begin{array}{l}500 \mathrm{mM} \text { NaCl, } 50 \mathrm{mM} \text { fosfato de sódio, } \mathrm{pH} 7,4 \text { e } 5 \\
\text { mM DTT, (25 } \mu \mathrm{M} \text { do dímero) }\end{array}$ \\
\hline $1-169$ & $71\left(10^{\circ} \mathrm{C}\right)$ & Pato et al. (1981a) & $\begin{array}{l}100 \mathrm{mM} \mathrm{KCl}, 1 \mathrm{mMDTT}, 50 \mathrm{mM} \text { fosfato de sódio, } \mathrm{pH} \\
7,0(27 \mu \mathrm{M} \text { do dímero })\end{array}$ \\
\hline $16-46$ & $55\left(5^{\circ} \mathrm{C}\right)$ & Holtzer et al. (1995) & $\begin{array}{l}500 \mathrm{mM} \mathrm{NaCl}, 50 \mathrm{mM} \text { fosfato de sódio, } \mathrm{pH} 7,4 \text { e } 5 \\
\text { mM DTT (2 a } 2000 \mu \mathrm{M} \text { de cadeias polipetídicas) }\end{array}$ \\
\hline $26-46$ & $30\left(0^{\circ} \mathrm{C}\right)$ & Holtzer et al.(1995) & $\begin{array}{l}500 \mathrm{mM} \mathrm{NaCl}, 50 \mathrm{mM} \text { fosfato de sódio, } \mathrm{pH} 7,4 \text { e } 5 \\
\text { mM DTT ( } 80 \text { a } 795 \mu \mathrm{M} \text { de cadeias polipetídicas) }\end{array}$ \\
\hline $134-284$ & $81\left(10^{\circ} \mathrm{C}\right)$ & $\begin{array}{l}\text { Pato e Smillie (1978) } \\
\text { Pato et al. (1981a) }\end{array}$ & $\begin{array}{l}100 \mathrm{mM} \mathrm{KCl}, 1 \mathrm{~m} \text { MDTT, } 50 \mathrm{mM} \text { fosfato de sódio, } \\
\mathrm{pH} 7,0(30 \mu \mathrm{M} \text { do dímero }\end{array}$ \\
\hline $183-284$ & $64\left(10^{\circ} \mathrm{C}\right)$ & $\begin{array}{l}\text { Pato e Smillie (1978) } \\
\text { Pato et al. (1981a) }\end{array}$ & $\begin{array}{l}\text { 100mM KCl, 1mMDTT, 50mM fosfato de sódio, } \\
\mathrm{pH} 7.0 \text { (45 } \mu \mathrm{M} \text { do dimero) }\end{array}$ \\
\hline $183-244$ & $17\left(10^{\circ} \mathrm{C}\right)$ & $\begin{array}{l}\text { Pato e Smillie (1978) } \\
\text { Pato et al. (1981a) }\end{array}$ & $\begin{array}{l}100 \mathrm{mM} \mathrm{KCl}, 1 \mathrm{mM} \text { DTT, } 50 \mathrm{mM} \text { fosfato de sódio, } \\
\text { pH } 7,0(74,5 \mu \mathrm{M} \text { do dímero })\end{array}$ \\
\hline \multirow[t]{2}{*}{$142-281$} & $72\left(10^{\circ} \mathrm{C}\right)$ & $\begin{array}{l}\text { Pato e Smillie (1978) } \\
\text { Pato et al. (1981a) }\end{array}$ & $\begin{array}{l}100 \mathrm{mM} \text { KCl, } 1 \mathrm{mM} \text { DTT, } 50 \mathrm{mM} \text { fosfato de sódio, } \\
\mathrm{pH} 7,0(32,7 \mu \mathrm{M} \text { do dimero) }\end{array}$ \\
\hline & $>90\left(3^{\circ} \mathrm{C}\right)$ & $\begin{array}{l}\text { Holtzer e Holtzer (1990) } \\
\text { Pato et al. }(1981 \mathrm{a})\end{array}$ & $\begin{array}{l}500 \mathrm{mM} \mathrm{NaCl}, 50 \mathrm{mM} \text { fosfato de sódio, pH 7,4 e } 5 \\
\text { mM DTT, (33 } \mu \mathrm{M} \text { do dímero) }\end{array}$ \\
\hline $142-189$ & $12\left(0^{\circ} \mathrm{C}\right)$ & Holtzer et al. (1995) & $\begin{array}{l}500 \mathrm{mM} \mathrm{NaCl}, 50 \mathrm{mM} \text { fosfato de sódio, } \mathrm{pH} \text { 7,4 e } 5 \\
\text { mM DTT (110 } \mu \mathrm{M} \text { e } 440 \mu \mathrm{M} \text { de cadeias } \\
\text { polipetidicas) }\end{array}$ \\
\hline $170-284$ & $74\left(10^{\circ} \mathrm{C}\right)$ & Pato et al. (1981a) & $\begin{array}{l}100 \mathrm{mM} \mathrm{KCl}, 1 \mathrm{mM} \text { DTT, } 50 \mathrm{mM} \text { fosfato de sódio, } \\
\mathrm{pH} 7,0(39,8 \mu \mathrm{M} \text { do dímero })\end{array}$ \\
\hline \multirow[t]{2}{*}{$190-284$} & $62\left(10^{\circ} \mathrm{C}\right)$ & $\begin{array}{l}\text { Pato e Smillie (1978) } \\
\text { Pato et al. (1981a) } \\
\end{array}$ & $\begin{array}{l}100 \mathrm{mM} \mathrm{KCl}, 1 \mathrm{mM} \text { DTT, } 50 \mathrm{mM} \text { fosfato de sódio, } \\
\mathrm{pH} 7,0(48,3 \mu \mathrm{M} \text { do dimero })\end{array}$ \\
\hline & $>90\left(3^{\circ} \mathrm{C}\right)$ & \begin{tabular}{|l|l} 
Holtzer e Holtzer (1990) \\
\end{tabular} & 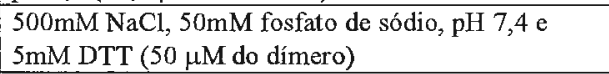 \\
\hline $253-280$ & $30 \%\left(0^{\circ} \mathrm{C}\right)$ & Holtzer et al. (1995) & $\begin{array}{l}500 \mathrm{mM} \mathrm{NaCl}, 50 \mathrm{mM} \text { fosfato de sódio, } \mathrm{pH} 7,4 \text { e } 5 \\
\text { mM DTT (1100 } \mu \mathrm{M} \text { de cadeias polipetídicas) }\end{array}$ \\
\hline \multirow[t]{2}{*}{$190-254$} & $43 \%\left(10^{\circ} \mathrm{C}\right)$ & Holtzer et al. (2001) & $\begin{array}{l}100 \mathrm{mM} \mathrm{NaCl}, 50 \mathrm{mM} \text { fosfato de sódio, } \mathrm{pH} 7,4 \text { e } 10 \\
\text { mM DTT (115 } \mu \text { M do dímero) }\end{array}$ \\
\hline & $\begin{array}{l}\text { Desenovelada } \\
\left(25^{\circ} \mathrm{C}\right)\end{array}$ & Holtzer et al. (2001) & $\begin{array}{l}100 \mathrm{mM} \mathrm{NaCl}, 50 \mathrm{mM} \text { fosfato de sódio, } \mathrm{pH} 7,4 \text { e } 10 \\
\text { mM DTT (115 } \mu \mathrm{M} \text { do dímero) }\end{array}$ \\
\hline
\end{tabular}


Sabe-se que a tropomiosina é estável em uma grande faixa de $\mathrm{pH}$ (2 a 9), sendo excepcionalmente estável em pHs baixos (Bodwell et al.,1965; Lowey, 1965). Resultados similares foram observados em experimentos realizados com "coiled-coils" sintéticas (Lau et al.,1984), que se mostraram mais estáveis numa faixa de $\mathrm{pH}$ entre 2,5 e 7,0 . À medida que se diminui o $\mathrm{pH}$, diminui também a repulsão intercadeias, uma vez que grupos ácidos adjacentes de mesma carga vão sendo protonados. É importante notar também a influência da força iônica quando se interpretam resultados de efeitos do pH para a estabilidade da molécula. Para um peptídeo sintético modelo de 36 resíduos com estrutura "coiled-coil", Yu et al. (1996) demonstraram que, em forças iônicas baixas (10 mM), as "coiled-coils" parecem ser mais estáveis em pHs neutros do que em $\mathrm{pH}$ ácidos. Em $\mathrm{pHs}$ baixos a estabilidade da "coiled-coil" parece aumentar conforme se adiciona $\mathrm{NaCl}$ ao meio. Nós devemos notar que, em pHs ácidos, as "coiled-coils" possuem uma alta densidade de cargas positivas e que o aumento da força iônica deve promover uma blindagem destas cargas.

O desenovelamento de grandes "coiled-coils" como a Tm é mais complicado do que o desenovelamento de pequenas "coiled-coils" encontradas em peptídeos modelos, as quais parecem desenovelar e dissociar cooperativamente através de um processo de dois estados (nativo $\leftrightarrow$ desenovelado). Estudos por microcalorimetria (Potekhin e Privalov, 1982) mostravam que a desnaturação térmica da estrutura nativa da $\alpha$-Tm era um processo complexo que consistia de vários estágios. Tais estudos levaram os autores a propor que a molécula de tropomiosina era composta por 7 blocos cooperativos de vários tamanhos com diferentes estabilidades que estariam levando à observação dos vários estágios semi-independentes de desenovelamento. Este modelo também sugeria que a estrutura de blocos cooperativos não inclui as partes terminais da molécula. Um trabalho recente, publicado por Holtzer et al. (2001), discorda da existência dos blocos cooperativos independentes, mostrando que dois sub-fragmentos (190-254 e 253-280) correspondentes a dois blocos cooperativos (3 e 4) propostos por 
Potekhin e Privalov (1982) não apresentam a soma de suas curvas de desnaturação igual a curva experimental do fragmento 190-284.

Estudos de desnaturação por pressão, realizados recentemente com uma Tm esquelética de coelho, marcada com uma sonda fluorescente na cisteína 190 (N-(1-pirenil) iodoacetamida), covalentemente ligada, indicam que existem subdomínios independentes de enovelamento, os quais apresentam diferentes suscetibilidades à pressão ao longo da estrutura "coiled-coil" da Tm (Suarez et al., 2001), como foi anteriormente proposto por Potekhin (1982). Entretanto, não se sabe quantas e quais são as regiões correspondentes a estes subdominios. Consistente com a existência de regiões parcialmente desenoveladas é a observação de que o desenovelamento térmico de uma aTm oxidada (onde as duas cisteínas que ocupam a posição 190 estão formando uma ponte dissulfeto) parece ocorrer com uma pré-transição inicial, onde $20 \%$ da estrutura é perdida, seguida pelo completo desenovelamento a altas temperaturas (Lehrer, 1978; Mo et al., 1991).

Um trabalho publicado por Kammerer et al. (1998) propõe um mecanismo de enovelamento autônomo para "coiled-coils" em geral, sugerindo inclusive a existência de uma seqüência consenso mínima ( $x x L E x c-h x c x c c x$ ), no caso da Tm localizada na região C-terminal da molécula entre os resíduos 228 a 238, onde, $\mathbf{x}$ significa um resíduo qualquer, $\mathbf{h}$ significa resíduo hidrofóbico e c significa resíduo carregado. Segundo eles, esta região poderia ser responsável pela formação de unidades de enovelamento helicoidais autônomas, as quais logo em seguida estariam contribuindo para a formação do dímero parcialmente enovelado. Então, somente após a dimerização é que ocorreria o enovelamento completo da proteína. Este modelo, porém, não explica por quê fragmentos derivados de várias regiões diferentes da molécula de Tm (algumas das quais nem possuem a seqüência consenso proposta) adotam uma estrutura "coiled-coil".

Estudos sobre a cinética de enovelamento realizados por Mo et al. (1991) mostram que, de fato, a etapa limitante do processo de enovelamento da Tm não é a sua dimerização. Neste trabalho, eles observam que a 
constante de velocidade de enovelamento é igual para uma Tm reduzida e para uma Tm oxidada (ou seja, onde as duas cadeias de a-hélice estão ligadas através de uma única ponte dissulfeto existente entre as cisteínas que se encontram na posição 190 do monômero de a-Tm).

Apesar dos dados fornecidos por estes trabalhos serem de grande relevância, até agora não se sabe com precisão se o enovelamento da Tm ocorre realmente através da formação de "sítios específicos de nucleação" e muito menos quais seriam estas regiões. Mesmo que a Tm não seja formada de blocos cooperativos como sugerido anteriormente, não podemos nos esquecer do fato de que a molécula ainda assim pode conter regiões que poderiam contribuir mais ou menos para a estabilidade da Tm como um todo, bem como para o processo de dimerização. Estas diferenças em estabilidade podem refletir as diferenças funcionais das variadas regiões da molécula.

\section{7 - Estudos do efeito do TFE sobre a estrutura de proteínas.}

Em 1971, Goodman et al. (1971) mostraram que o TFE era capaz de estabilizar estruturas $\alpha$-hélice em proteínas que possuíam alguma propensão intrínseca à formação desta estrutura. Segundo uma revisão recente publicada por Buck (1998) o TFE (2,2,2-trifluoroetanol) é um co-solvente conhecido por desestabilizar interações hidrofóbicas dentro de uma cadeia polipeptídica (Fan et al.,1993; Wei e Fasman, 1995) e por estabilizar pontes de hidrogênio locais entre resíduos próximos na seqüência de aminoácidos.

A titulação de uma proteína com TFE, acompanhada por dicroísmo circular, pode ser de grande utilidade para se obter informações estruturais acerca da proteína. Altas concentrações de TFE podem ser utilizadas para se caracterizar a propensão à formação de estrutura $\alpha$-hélice em pequenos peptídeos, sendo que uma boa correlação com a elipticidade predita pode ser obtida, baseada no comportamento médio de segmentos de peptídeos em proteínas. 
Luidens et al. (1996) mostraram que o TFE também é conhecido por induzir a formação de estrutura a-hélice em proteínas cuja estrutura original era folha $\beta$. Os resultados indicavam que a estrutura observada na presença de TFE poderia não refletir a estrutura que seria apresentada pela proteína em outro solvente. No mesmo ano, Jayaraman et al. (1996) mostraram que uma proteina cuja estrutura era toda folha $\beta$, CTX II (análogo II da cardiotoxina), que não apresenta nenhum trecho com propensão a assumir estrutura helicoidal segundo métodos de predição de estrutura secundária, foi capaz de apresentar estrutura $\alpha$-hélice quando na presença de $60 \%$ (v/v) TFE ou mais. Ambos os trabalhos indicavam que o TFE pode induzir a conformação em $\alpha$ hélice em peptídeos e proteínas de forma não específica. Entretanto, em 1998, Dong et al. mostraram que as estruturas a-hélice induzidas pelo TFE em proteínas predominantemente folha $\beta$ ( $\beta$-lactoglobulina e $\alpha$-quimotripsina) são instáveis em comparação com proteinas de estrutura predominantemente helicoidal sob condições idênticas, convertendo-se prontamente em agregados de folha $\beta$. Os espectros de infravermelho mostram que imediatamente após a dissolução das proteínas com estrutura folha $\beta$ em $50 \%$ de TFE, aparece uma forte banda em $1654 \mathrm{~cm}^{-1}$ em $\mathrm{H}_{2} \mathrm{O}$ que é tipica para estrutura $\alpha$-hélice. Entretanto, estas bandas vão diminuindo de intensidade com o passar do tempo (análises feitas entre 5 e 95 minutos) e vão aparecendo bandas próximas a $1620 \mathrm{~cm}^{-1}$ e $1684 \mathrm{~cm}^{-1}$ em $\mathrm{H}_{2} \mathrm{O}$ que são típicas do padrão espectral no infravermelho para agregados intermoleculares de folha $\beta$.

Wei e Fasman (1995) propuseram que o TFE deve desestabilizar as estruturas em folha $\beta$. Isto ocorreria porque a estrutura em folha $\beta$ envolve um alinhamento de regiões não contíguas da cadeia polipetídica, que é estabilizada pelo empacotamento de resíduos não polares no interior da folha, e como o TFE tem sido proposto como um desnaturante que desestabiliza regiões hidrofóbicas de algumas proteínas (Fan et al., 1993; Wei e Fasman, 1995), supõe-se que o TFE estaria desestabilizando as interações que mantêm a estrutura da folha $\beta$. 
Existem muitas controvérsias a respeito de como o TFE estaria atuando para a estabilização da estrutura $\alpha$-hélice. Storrs et al. (1992) sugeriram que o efeito estabilizante das $\alpha$-hélices produzido pelo TFE seria devido a um efeito geral de solvatação e não ao resultado da interação direta entre o TFE com o estado helicoidal da cadeia polipeptídica. Este efeito de solvatação seria manifestado pelo favorecimento das pontes de hidrogênio dentro da cadeia polipeptídica em detrimento das pontes de hidrogênio entre a proteína e o solvente. Além disso, a constante dielétrica do TFE aproxima-se a constante dielétrica do interior da proteína, correspondendo aproximadamente a 1/3 da constante dielétrica da água (Llinas e Klein 1975), o que poderia fortalecer as interações entre grupos carregados. Por outro lado, Nelson e Kallenbach (1986) mostraram que o TFE não altera a estabilidade $\mathrm{pH}$ dependente do peptídeo $\mathrm{S}$ da ribonuclease $\mathrm{A}$ evidenciando que a indução de hélice por TFE não é devida as suas propriedades dielétricas.

Em 1994, Jasanoff e Fersht estudaram as curvas de titulação com TFE de 5 peptídeos em função da temperatura e do tamanho do peptídeo. As análises foram feitas usando-se uma equação que assume que ocorre uma interação TFE-peptídeo. As equações utilizadas para o ajuste dos dados assumem: 1- um modelo de dois estados para a transição hélice-"coil”; 2- A energia livre de formação de hélice é linearmente proporcional com a concentração de TFE; 3- o valor de m (cooperatividade da curva) é proporcional ao número de sítios de ligação do TFE no estado helicoidal e "coil". Os ajustes dos dados com estas equações estão em perfeita concordância com os dados experimentais. Além disso, observou-se uma dependência linear do valor da cooperatividade da curva $(m)$ em função do tamanho dos peptídeos (respectivamente 10, 12 e 14 resíduos). Desta maneira eles propõem que a estabilização das hélices se dá através da ligação direta do TFE em sítios específicos do polipeptídeo, em vez de se dar através de um efeito de solvatação como proposto por Storrs et al. (1992).

Mais recentemente, estudos do efeito do TFE, como um co-solvente, sobre a estabilidade de três peptídeos diferentes (para entender melhor as 
bases moleculares da indução de estrutura secundária pelo TFE foram realizados por Roccatano et al. (2002). Baseado em simulações de dinâmica molecular, os autores propuseram que em uma mistura água-TFE o cosolvente orgânico agrega em torno do peptídeo, formando uma matriz que exclui parcialmente as moléculas de água. Desta maneira, o TFE remove pontes de hidrogênio entre a água e o peptídeo e também provê um ambiente de menor constante dielétrica. Juntos, estes fatores promovem a formação de pontes de hidrogênio intrapeptídicas. O TFE, em contraste com a maioria de outros solventes orgânicos, interage muito fracamente com os resíduos apolares (Chitra, 2001), pois embora seja formada uma camada de TFE em torno do peptídeo, as interações peptídeo-TFE não competem com as interações hidrofóbicas dentro destes peptídeos, pelo menos nas condições estudadas. Como uma conseqüência, o TFE estaria promovendo a estabilidade em vez da desnaturação destes peptídeos.

\section{8 - Objetivos e estratégia de estudo.}

Experimentos realizados por Wahl et al. (1978) mostram que a Tm é uma molécula flexivel e que esta flexibilidade diminui quando ela interage com a $\mathrm{Tn}$, sendo parcialmente restaurada após a adição de $\mathrm{Ca}^{2+}$. A flexibilidade da molécula de Tm também foi evidenciada através de estudos feitos com a estrutura cristalina da Tm (Phillips et al., 1986), em que uma variação da temperatura entre $0^{\circ} \mathrm{C}$ e $30^{\circ} \mathrm{C}$ revela que a flexibilidade da metade $\mathrm{C}$-terminal da molécula de Tm é fortemente dependente da temperatura, em contraste ao comportamento da região $\mathrm{N}$-terminal. Mais recentemente, um trabalho publicado por Greenfield e colaboradores (2002) mostra que a substituição do resíduo $\mathrm{Q}_{263}$ por uma Leu torna o fragmento C-terminal estudado ( $T M 9 a_{251-284}$ ) mais estável, reduzindo desta maneira a sua habilidade de interação com um fragmento N-terminal e também com a TnT70-170. Este trabalho mostra que a estabilidade conformacional da Tm é crucial para as funções de ligação do C- 
terminal. Além disso, faz sentido imaginar que a flexibilidade da Tm é importante para a sua função, desde que uma parte integral do mecanismo de controle da contração muscular é o deslocamento da molécula de Tm sobre a superfície de Ac (ver Figuras 6,7 e 8).

Considerando a importância da flexibilidade estrutural da Tm para a sua função e sabendo que a região C-terminal é bem menos estável que a região $\mathrm{N}$-terminal, além de ser responsável pelas interações com o complexo Tn (vide Figura 5), bem como para as interações cabeça-cauda, nós decidimos estudar a estabilidade estrutural de vários fragmentos localizados na região $\mathrm{C}$-terminal da molécula de Tm. Além disso, a Tm pode ser usada como um modelo simples de ocorrência natural para entendermos as interações inter- e intramoleculares que governam a estabilidade de "coiled-coils" em geral.

Desta maneira, nós produzimos oito fragmentos recombinantes de Tm (Tm 143-284(5OHW), Tm 189-284(5OHW), Tm189-284, Tm $220-284(50 H W), \mathrm{Tm}_{220-284}, \mathrm{Tm}_{143-235}$, $\mathrm{Tm}_{167-260}$ e $\left.T \mathrm{~m}_{143-260}\right)$ e um peptídeo sintético $\left(\mathrm{Ac}-\mathrm{Tm}_{215-235}\right)$. Estes fragmentos, esquematizados na Figura 15, foram caracterizados quanto ao seu estado de oligomerização através de ensaios de ultracentrifugação analítica e quanto à sua estabilidade conformacional através de ensaios de desnaturação acompanhados por CD.

Os fragmentos $\mathrm{Tm}_{143-284(50 H W),} \mathrm{Tm}_{189-284(50 H W)}$ e $\mathrm{Tm}_{220-284(50 H W)}$ contêm uma mutação pontual na posição 278 , tendo sido substituída uma leucina por

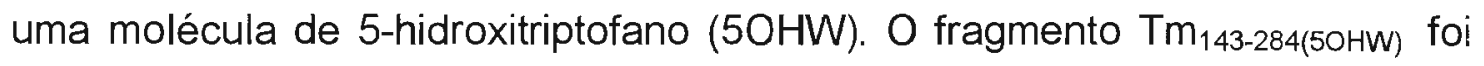
utilizado como um controle, já que representa toda a região C-terminal da molécula de $\mathrm{Tm}$. Os fragmentos $\mathrm{Tm}_{189-284(50 H W)}, \mathrm{Tm}_{189-284}, \mathrm{Tm}_{143-235}, \mathrm{Tm}_{167-260}$ foram escolhidos por representarem as regiões terminal e central, respectivamente, da metade C-terminal da molécula de $\mathrm{Tm}$, contendo mais de 90 aminoácidos cada. $\mathrm{O}$ fragmento $\mathrm{Tm}_{220-284}$ foi escolhido por conter a região codificada pelo exon 9a (258-284), o qual é específico para as Tms de músculo estriado. Além disso, este fragmento foi planejado para conter aproximadamente o mesmo tamanho do maior fragmento C-terminal, relatado 
na literatura até a época do início do projeto, que não apresentava estrutura secundária (183-244). Ver tabela 1.

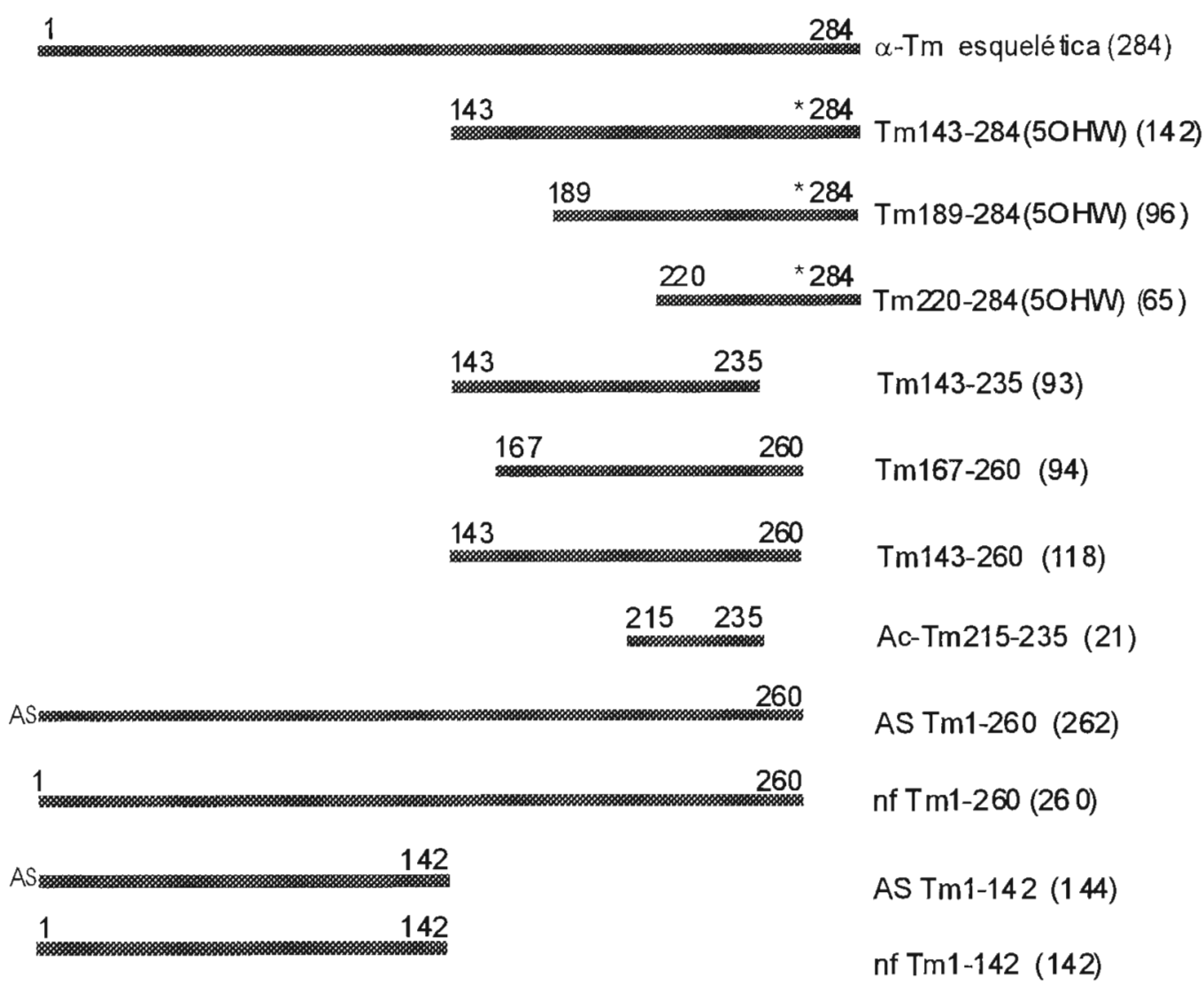

Figura 15 - Esquema dos fragmentos de Tm utilizados neste estudo. O número de aminoácidos em cada molécula é indicado entre parênteses. O asterisco indica uma mutação pontual, onde uma leucina foi substituida por um análogo do triptofano, 5-hidroxitriptofano na

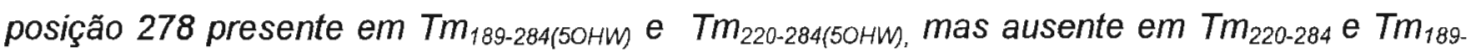
284.

O peptídeo Ac- $\mathrm{Tm}_{215-235}$ foi planejado posteriormente, com a finalidade de investigarmos a existência de uma região consenso mínima dentro da molécula de Tm, a qual poderia ser responsável pelo suposto enovelamento autônomo da molécula (Kammerer et al., 1998).

Os dois grupos amino-terminais da $\alpha$-tropomiosina nativa encontram-se em posições a, dentro do centro hidrofóbico. As nossas proteínas 
recombinantes, por serem expressas em E.coli, não sofrem modificações póstraducionais e, portanto, apresentam a metionina inicial não acetilada. Desta forma uma carga líquida positiva estaria presente nesta posição e a repulsão eletrostática entre os grupos amino-terminais poderia reduzir a estabilidade da "coiled-coil". Por tal motivo, todos os fragmentos foram planejados para que os resíduos $\mathrm{N}$-terminais caíssem em posições externas da repetição heptapeptídica (c, g ou f) (tabela 2) que estão expostas ao solvente, para evitar que houvesse repulsões eletrostáticas entre os grupos a-amino protonados, os quais devem desestabilizar a estruturas da "coiled-coil" (ver as estruturas N-terminais não acetiladas na Figura 13 e Monteiro et al., 1994). Por outro lado todos os residuos C-terminais foram planejados para caírem em posições internas da repetição heptapeptídica (a ou d) de forma a mimetizar o C-terminal da Tm nativa, onde o resíduo ${ }^{284}$ ocupa uma posição d (veja tabela 2). O peptídeo Ac- $\mathrm{Tm}_{215-235}$ foi sintetizado com o $\mathrm{N}$-terminal acetilado e com o C-terminal livre.

Tabela 2- Apresenta a localização dos resíduos $\mathrm{N}$-terminais e $\mathrm{C}$-terminais para cada mutante, segundo o arranjo heptapeptídico (MacLachlan e Stewart,1975).

\begin{tabular}{|l|l|l|}
\hline $\begin{array}{l}\text { Fragmentos C- } \\
\text { terminais de Tm } \\
\text { Recombinantes }\end{array}$ & $\begin{array}{l}\text { Posição do } \\
\text { aminoácido } \\
\text { N-terminal }\end{array}$ & $\begin{array}{c}\text { Posição do } \\
\text { aminoácido } \\
\text { C-terminal }\end{array}$ \\
\hline $\mathrm{Tm}_{143-284(5 \mathrm{OHW})}$ & C & d \\
\hline $\begin{array}{l}\mathrm{Tm}_{189-284} \\
\mathrm{Tm}_{189-284(5 \mathrm{OHW})}\end{array}$ & g & d \\
\hline $\mathrm{Tm}_{220-284}$ & c & d \\
$\mathrm{Tm}_{220-284(5 \mathrm{OHW})}$ & c & d \\
\hline $\mathrm{Tm}_{143-235}$ & f & a \\
\hline $\mathrm{Tm}_{167-260}$ & c & a \\
\hline $\mathrm{Tm}_{143-260}$ & & \\
\hline
\end{tabular}

Estudos prévios realizados em nosso laboratório pela Dra. Áurea Denise de Sousa e pela a aluna de iniciação científica Ângela Mika Katsuyama revelaram que uma $\mathrm{Tm}$ recombinante, onde os últimos 24 aminoácidos Cterminais da molécula estão ausentes e que contêm a fusão dipeptídica AS na 
ponta $\mathrm{N}$-terminal (ASTm ${ }_{1-260}$ ), possuía uma viscosidade muito maior que a $\mathrm{Tm}$ contendo o tamanho integral (ASTm). Tais estudos também mostraram que esta proteína recombinante tem a sua polimerização sensível à força iônica e que uma Tm truncada na mesma posição, porém sem a fusão Ala-Ser (NFTm), possui uma viscosidade altamente reduzida, indicando que o novo Cterminal deste mutante é capaz de polimerizar e de fazer interações cabeçacauda com maior afinidade do que a Tm nativa, embora não se ligue ao filamento de actina.

Neste trabalho, nós procuramos investigar quais seriam as características mais importantes para a interação cabeça-cauda responsável pela polimerização da molécula de Tm. Desta forma, foram construídos dois fragmentos que compreendem a região $\mathrm{N}$-terminal da molécula de $\mathrm{Tm}$, sendo um deles não acetilado e o outro contendo a fusão dipeptídica AS (nfTm1-142 e ASTm $_{1-142}$ respectivamente, ambos construídos pela aluna de iniciação científica Ângela Mika Katsuyama sob a minha co-orientação). Os fragmentos $\mathrm{N}$-terminais foram avaliados quanto à sua capacidade de interação cabeçacauda com a Tm recombinante nfTm26950HW. A nfTm26950HW representa a molécula de Tm de tamanho integral, porém com uma mutação pontual, na posição 269, para uma sonda fluorescente (5-hidroxitriptofano), sensível à interação cabeça-cauda (Sousa e Farah, 2002). Os fragmentos ASTm1-142 e $\mathrm{nfTm}_{1-142}$ também foram misturados com os três fragmentos $\mathrm{C}$-terminais de $\operatorname{Tm}\left(\mathrm{Tm}_{167-260}\right.$ e $\mathrm{Tm}_{143-260}$ e $\left.\mathrm{Tm}_{220-284}\right)$ e então, avaliados quanto à formação de interação cabeça-cauda através de medidas conformacionais e por ensaios de desnaturação térmica acompanhados por dicroísmo circular. 


\section{2- Materiais e Métodos}

\section{1- Construção dos plasmídeos para expressão dos fragmentos de Tm.}

Os oligonucleotídeos utilizados para a construção dos fragmentos de Tm foram desenhados a partir da seqüência do c-DNA de $\alpha-T m$ de músculo esquelético de galinha (Gooding et al., 1987). A seqüência de aminoácidos da $\alpha$ Tm de músculo esquelético de galinha, juntamente com a posição heptapeptídica que cada resíduo ocupa na estrutura "coiled-coil", está mostrada na figura 16.

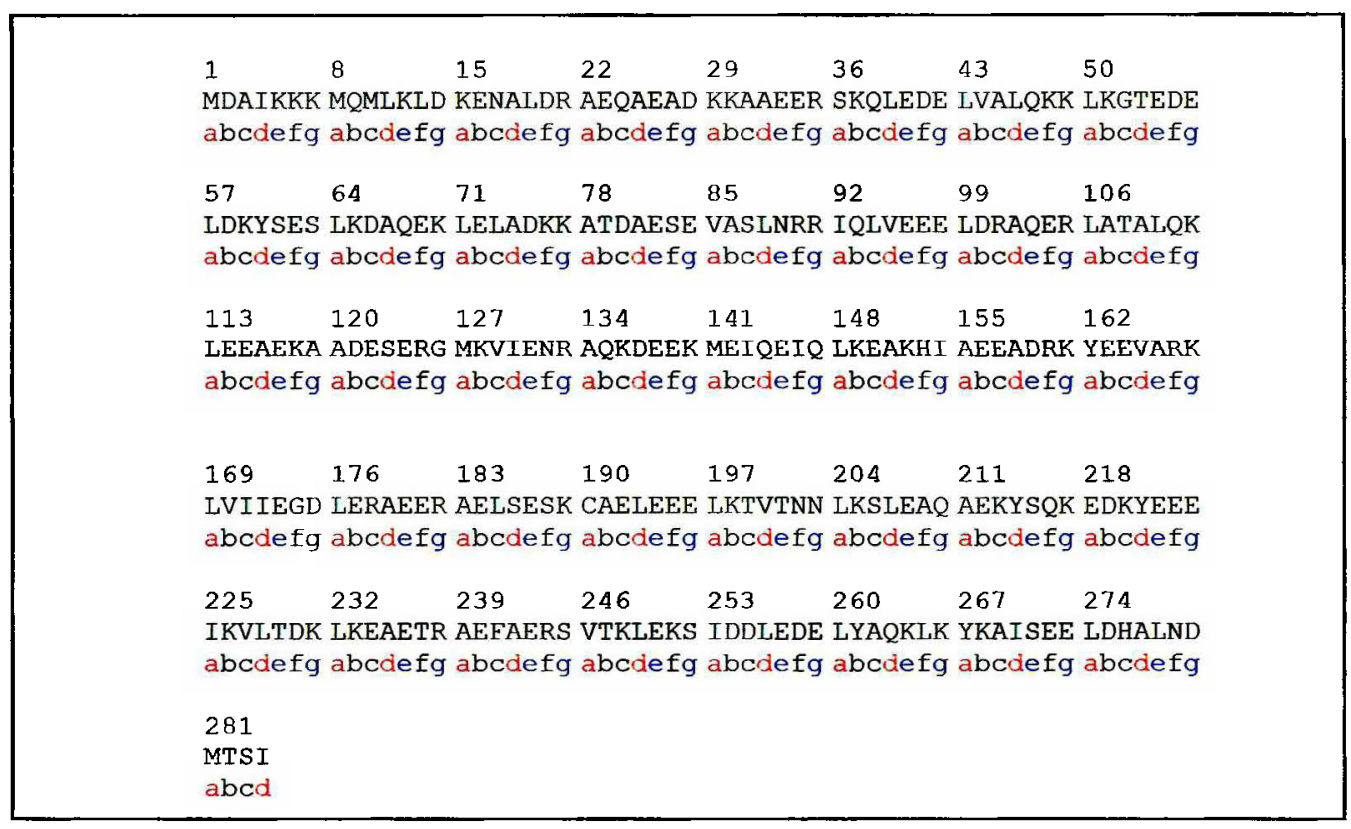

Figura 16 - Seqüência de aminoácidos da $\alpha$-tropomiosina de músculo esquelético de galinha (Gooding et al., 1987). Abaixo da sequeência da proteína encontram-se as letras referentes a posiçăo heptapeptídica ocupada por cada aminoácido dentro da estrutura "coiled-coil".

Para os mutantes contendo a sonda fluorescente $50 \mathrm{HW}$ na posição 278 , utilizou-se como molde nas reaçōes de PCR um plasmídeo, pETMASTmy278W, construido por Farah e colaboradores (não publicado), onde um códon para leucina na posição 278 foi substituído por um códon para triptofano por mutagênese sítio-dirigida. Para a construção dos mutantes de deleção contendo a seqüência nativa da molécula utilizou-se o pET-MASTmy (Monteiro 
et al. 1994) (Figura 17). A Tabela 3 mostra os oligonucleotídeos que foram utilizados nas reações de $P C R$ para produzir as seqüências que codificam para cada fragmento de Tm. Os oligos $A, B, C$ e $D$ contêm a seqüência (CATATG), que por sua vez contém um sítio de restrição para Ndel e um códon para a metionina inicial na região $\mathrm{N}$-terminal da molécula. Os oligos $\mathrm{E}, \mathrm{F}$ e I contêm um sítio AAG CTT para Hindlll e um códon de terminação TTA.

Tabela 3- Oligonucleotídeos utilizados para a construção dos fragmentos recombinantes de Tm. A seqüência CATATG é um sítio para a enzima de restrição Ndel e possui um códon de iniciação para metionina. A seqüência AAGCTTTTA apresenta um sítio de restrição para Hind III (AAGCTT) e um códon de terminação TTA.

\begin{tabular}{|l|l|l|}
\hline & Oligonucleotídeo & Seqüência \\
\hline A & NdeM142 & 5'GAA GAG AAG CATATG ATC CAA GAG ATC3' \\
B & NdeM188 & 5'GAA CTA TCA CATATG AAA TGT GCT GAG 3' \\
C & NdeM219 & 5'TCG CAG AAA CATATG AAA TAT GAA GAG3' \\
D & NdeM166 & 5'AAG TAT GAA GAG CATATG CGT AAG CTC GTG3' \\
E & $* 236 H i n d$ & 5'AGC AAA TTC AGC AAGCTTTTA AGC CTC CTT CAG3' \\
F & $* 261$ Aind & 5'CTT CAG TTT AAGCTTTTA AAG CTC ATC TTC 3' \\
G & EcoR1(-) & 5'CAT TAA CCT ATA AAA ATA GGC G3' \\
H & T7 & 5'CAC TAT AGG GAG ACC ACA ACG GTT TCC 3' \\
I & $* 143 H i n d$ & 5'CTG GAT AAGCTTTTA TTC CAT CTT CTC TTC ATC C3'
\end{tabular}

Os pares de nucleotídeos utilizados para produzir as sequências que codificam cada fragmento de Tm foram: NdeM142 e EcoRI(-) para Tm $143-$ 284(5OHW), NdeM188 e EcoRI(-) para $\mathrm{Tm}_{189-284(50 H W)}$ e $\mathrm{Tm}_{189-284}$, NdeM219 e EcoRI(-) para $\mathrm{Tm}_{220-284(5 \mathrm{OHW})}$ e $\mathrm{Tm}_{220-284}$, NdeM142 e ${ }^{*} 236 \mathrm{Hind}$ para $\mathrm{Tm}_{143-235}$, NdeM166 e *261Hind para $\operatorname{Tm}_{167-260}$, NdeM142 e *261Hind para $\operatorname{Tm}_{143-260}$, e finalmente $T 7 e^{*} 143$ Hind para $A S T m_{1-142}$. Os plasmídeos utilizados para expressar ASTm $_{1-142}$ e $\mathrm{nfTm}_{1-142}$ foram construídos pela aluna de iniciação científica Ângela Mika Katsuyama e o plasmídeo utilizado para expressar $\mathrm{Tm}_{143-}$ 
${ }_{260}$ foi construído pelo aluno de iniciação científica Eduardo Dutra Pastor, ambos sob a minha co-orientação.
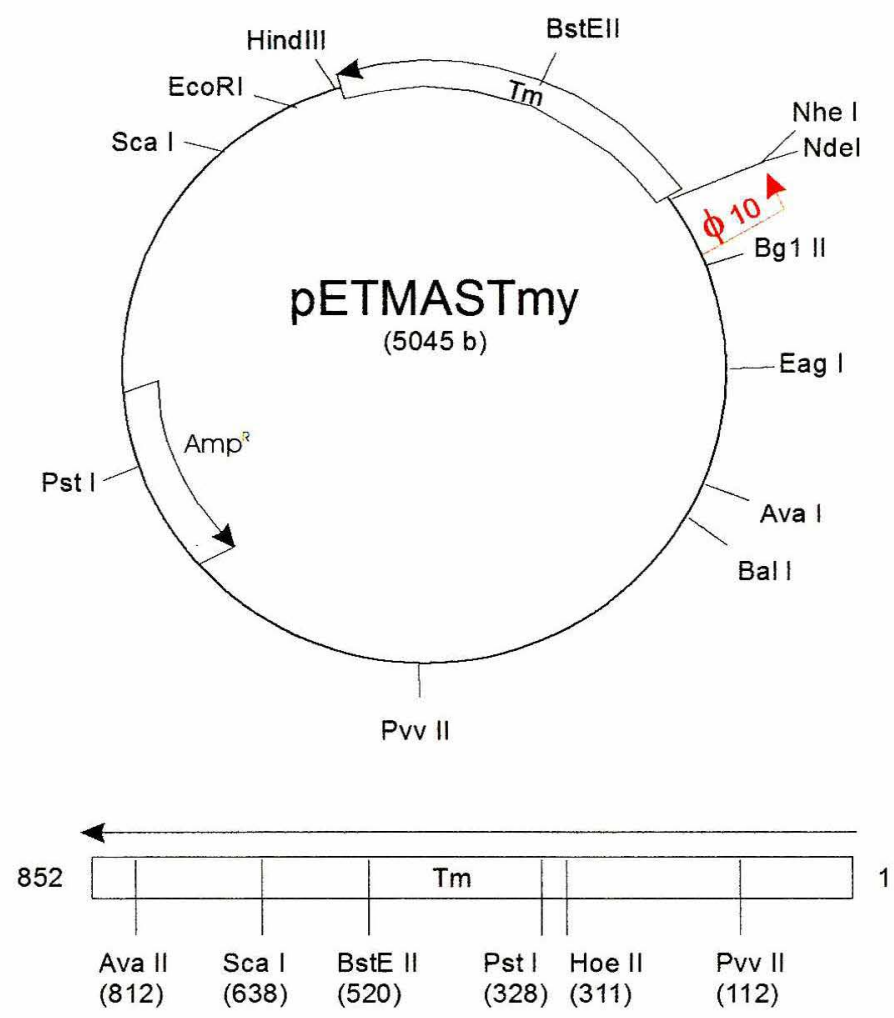

Figura 17 - A figura mostra o pETMASTmy e todos os sítios de restrição dentro e fora do inserto. $\$ 10$ é o promotor do fago $T 7$.

Para cada oligo calculou-se a temperatura de "melting" $\left(T_{m}\right)$ e a temperatura de formação de grampos intramoleculares, com a finalidade de encontrar a temperatura adequada para a reação de PCR. As temperaturas utilizadas foram estabelecidas levando-se em conta as $T_{\mathrm{ms}}$ do par de oligos em questão, utilizando-se para tanto o programa OLIGO 4.0.

As reações de PCR foram feitas nas seguintes condições: $100 \mathrm{mM}$ de $\mathrm{KCl} ; 200 \mathrm{mM}$ de Tris- $\mathrm{HCl}, \mathrm{pH} 8,8 ; 100 \mathrm{mM}$ de $\left(\mathrm{NH}_{4}\right)_{2} \mathrm{SO}_{4} ; 20 \mathrm{mM}$ de $\mathrm{MgSO}_{4} ; 10 \%$ de Triton X-100; 0,2 $\mu \mathrm{M}$ de cada oligo; $200 \mu \mathrm{M}$ de cada dNTP; 2 mM de $\mathrm{MgSO}_{4}$; 
$1 U$ de enzima Deep Vent DNA polimerase e 4,0 nM de pET ASTmy. A Tabela 4 sumariza as melhores condições de temperatura encontradas para a amplificação por PCR para cada inserto produzido.

Tabela 4 - Condições de temperatura e número de ciclos utilizados para a amplificação por PCR dos fragmentos recombinantes de Tm.

\begin{tabular}{|l|l|l|l|l|l|l|l|}
\hline $\mathbf{T m}_{143-284}, \mathbf{T m}_{189-284} \mathbf{e} \mathbf{T m}_{220-284}$ \\
\hline 1 ciclo & 4 ciclos & \multicolumn{2}{l|}{28 ciclos } & 1 ciclo \\
\hline 5 min & $30 \mathrm{seg}$ & $30 \mathrm{seg}$ & $60 \mathrm{seg}$ & $30 \mathrm{seg}$ & $30 \mathrm{seg}$ & $60 \mathrm{seg}$ & $10 \mathrm{~min}$ \\
\hline $94^{\circ} \mathrm{C}$ & $94^{\circ} \mathrm{C}$ & $50^{\circ} \mathrm{C}$ & $72^{\circ} \mathrm{C}$ & $94^{\circ} \mathrm{C}$ & $54^{\circ} \mathrm{C}$ & $72^{\circ} \mathrm{C}$ & $72^{\circ} \mathrm{C}$ \\
\hline
\end{tabular}

\begin{tabular}{|c|c|c|c|c|c|c|c|}
\hline \multicolumn{8}{|c|}{$T m_{143-260}, T m_{167-260}$ e $T m_{143-235}$} \\
\hline \multirow{2}{*}{$\begin{array}{l}\text { ciclo } \\
5 \mathrm{~min}\end{array}$} & \multicolumn{3}{|c|}{4 ciclos } & \multicolumn{3}{|c|}{24 ciclos } & \multirow{2}{*}{$\begin{array}{l}1 \text { ciclo } \\
10 \mathrm{~min}\end{array}$} \\
\hline & 30 seg & $30 \mathrm{seg}$ & $60 \mathrm{seg}$ & $30 \mathrm{seg}$ & $30 \mathrm{seg}$ & $60 \mathrm{seg}$ & \\
\hline $94^{\circ} \mathrm{C}$ & $94^{\circ} \mathrm{C}$ & $56^{\circ} \mathrm{C}$ & $72^{\circ} \mathrm{C}$ & $94^{\circ} \mathrm{C}$ & $58^{\circ} \mathrm{C}$ & $72^{\circ} \mathrm{C}$ & $72^{\circ} \mathrm{C}$ \\
\hline
\end{tabular}

\begin{tabular}{|c|c|c|c|c|c|c|c|}
\hline \multicolumn{8}{|c|}{$\operatorname{ASTm}_{1-142}$} \\
\hline \multirow{2}{*}{$\begin{array}{l}1 \text { ciclo } \\
2 \mathrm{~min}\end{array}$} & \multicolumn{3}{|c|}{5 ciclos } & \multicolumn{3}{|c|}{30 ciclos } & \multirow{2}{*}{$\begin{array}{l}1 \text { ciclo } \\
10 \mathrm{~min}\end{array}$} \\
\hline & 20 seg & $20 \mathrm{seg}$ & $20 \mathrm{seg}$ & $20 \mathrm{seg}$ & $20 \mathrm{seg}$ & $20 \mathrm{seg}$ & \\
\hline $96^{\circ} \mathrm{C}$ & $95^{\circ} \mathrm{C}$ & $54^{\circ} \mathrm{C}$ & $72^{\circ} \mathrm{C}$ & $95^{\circ} \mathrm{C}$ & $58^{\circ} \mathrm{C}$ & $72^{\circ} \mathrm{C}$ & $72^{\circ} \mathrm{C}$ \\
\hline
\end{tabular}

\subsection{2 - Digestão e clonagem dos insertos}

Os produtos de PCR foram digeridos com Hindll e Ndel e em seguida subclonados no vetor de expressão pET-3a (Studier et al., 1990) previamente digerido com as mesmas enzimas de restrição. $\mathrm{O}$ vetor contendo 0 inserto de interesse foi transformado em células DH5a (Método de transformação por $\mathrm{CaCl}_{2}$, Sambrook et al.,1989). Em seguida, procedeu-se a mini-preparação dos plasmídeos (Sambrook et al., 1989). 


\subsection{3 - Seqüenciamento}

$O$ seqüenciamento foi feito utilizando-se um seqüenciador automático $A B I$ 377 Perkin-Elmer Applied Biosystems. A reação de seqüenciamento foi feita utilizando-se um kit "Ready reaction" da ABI. O protocolo de reação foi: $4 \mu \mathrm{L}$ do Big Dye terminator, $250 \mathrm{ng}$ do DNA dupla fita (plasmídeo), 1,6 pmol do primer (EcoR1), e $\mathrm{H}_{2} \mathrm{O}$ Milli-Q para um volume total de $10 \mu \mathrm{L}$ (Manual $\mathrm{ABI}$ Prism, protocol), conforme as condições de reação apresentadas na Tabela 5.

Tabela 5 - Condições de temperatura e números de ciclos utilizados para a amplificação por PCR para seqüenciamento dos fragmentos recombinantes de Tm.

\begin{tabular}{|l|l|l|}
\hline \multicolumn{2}{|c|}{25 ciclos } \\
\hline 10 segundos & 5 segundos & 4 minutos \\
\hline $96^{\circ} \mathrm{C}$ & $50^{\circ} \mathrm{C}$ & $60^{\circ} \mathrm{C}$ \\
\hline
\end{tabular}

\subsection{4 - Purificação dos plasmídeos}

A cepa de bactéria utilizada para a preparação de plasmídeo em larga escala foi HMS 174 (Studier et al.,1990). Utilizou-se um kit de colunas da Life Technologies (Concert ${ }^{\mathrm{TM}}$ high Purity Plasmid Midiprep System) e seguiu-se 0 protocolo indicado com algumas modificações: utilizou-se $200 \mathrm{~mL}$ de meio de cultura em vez de 25 a $100 \mathrm{~mL}$ como é indicado no protocolo e, após a neutralização que segue a lise alcalina das células, centrifugou-se por 30 minutos em vez de $10 \mathrm{~min}$.

\section{2- Expressão e purificação das proteínas recombinantes}

A expressão dos fragmentos de Tm contendo a sonda 5-hidroxitriptofano na posição 278 ( $\operatorname{Tm}_{143-284(50 H W)}, \operatorname{Tm}_{189-284(50 H W)}$ e $\left.\operatorname{Tm}_{220-284(50 H W)}\right)$ foi feita como descrito em Farah et al. (1999). Os fragmentos $\operatorname{Tm}_{189-284}, \mathrm{Tm}_{220-284}, \mathrm{Tm}_{143-235}$, 
$\operatorname{Tm}_{167-260}$ e $T m_{143-260}$ foram expressos como descrito em Monteiro et al. (1994). O protocolo de purificação utilizado para todos os fragmentos está descrito em Monteiro et al. (1994) e contém a seguinte modificação: Após a precipitação ácida da proteína em $\mathrm{pH}$ 4,6 seguida de centrifugação, as proteínas foram diretamente ressuspensas em $50 \mathrm{~mL}$ de tampão Tris $(50 \mathrm{mM}$ de Tris- $\mathrm{HCl}, \mathrm{pH}$ 8,0; 0,5 mM de EDTA e 14 mM de $\beta$-Mercaptoetanol), e então dialisadas por 12 horas contra $2 \mathrm{~L}$ do mesmo tampão. No dia seguinte, adicionou-se $8 \mathrm{M}$ de uréia a esta solução e a mesma foi passada por uma coluna de troca iônica Hiload $^{\mathrm{TM}}$ 26/10 Q-Sepharose ${ }^{\mathrm{TM}}$ FF da Armeshan Pharmacia Biotech, previamente equilibrada com tampão Tris- $\mathrm{HCl}$ pH $8,0 \mathrm{com} 8 \mathrm{M}$ de uréia. Utilizou-se um gradiente de eluição entre 0 e $250 \mathrm{mM}$ de $\mathrm{NaCl}$, cujo volume total era de 12 volumes de coluna, e um fluxo de eluição de $2 \mathrm{~mL} / \mathrm{min}$. As proteínas foram então precipitadas com sulfato de amônio como descrito em Monteiro et al. (1994). Em seguida, as proteínas foram ressuspensas em $10 \mathrm{~mL}$ de tampão fosfato ( $50 \mathrm{mM}$ de fosfato de sódio, $\mathrm{pH} \mathrm{7,0;100} \mathrm{mM} \mathrm{de} \mathrm{KCl} ; 0,5 \mathrm{mM}$ de EDTA e $1 \mathrm{mM}$ de DTT). A solução foi passada por uma coluna de gel filtração Hiload ${ }^{\mathrm{TM}}$ 26/60 Superdex ${ }^{\top m} 75$ pg previamente equilibrada com o mesmo tampão. A proteína foi eluída com 1,5 volume de coluna a um fluxo de $1,5 \mathrm{~mL} / \mathrm{min}$. As proteínas puras foram então dialisadas uma vez contra $2 L$ de tampão Tris, e duas vezes contra $2 \mathrm{~L}$ de $\mathrm{H}_{2} \mathrm{O}$ e, então, liofilizadas e estocadas para a utilização. As concentrações das soluções protéicas utilizadas nos experimentos foram determinadas pelo método modificado de Lowry (Hartree, 1972).

\subsection{Experimentos de Dicroísmo Circular (CD).}

A técnica de dicroísmo circular $(C D)$ é muito utilizada para a análise da estrutura secundária e terciária de uma proteína. $O$ espectro de $C D$ é o resultado das diferenças vetoriais dos campos elétricos de um feixe de luz polarizada à esquerda e um feixe de luz polarizada à direita $\left(E_{L}-E_{R}\right)$. Esta diferença entre as amplitudes dos vetores do campo elétrico $E_{L}$ e $E_{R}$ é gerada após a incidência de 
um feixe de luz circularmente polarizada (onde $E_{L}$ e $E_{R}$ possuem a mesma amplitude) sobre uma amostra opticamente ativa. Um parâmetro chamado de elipticidade ( $\theta$, dado em graus) é freqüentemente usado para representar o feixe elipticamente polarizado oriundo da diferença entre os vetores $E_{L} \in E_{R}$ (Fasman, 1996).

Alguns cromóforos específicos são responsáveis pelo espectro de CD em proteínas: 1- As ligações peptídicas, onde dois tipos de transições $\left(n \rightarrow \pi^{*}\right.$ e $\left.\pi \rightarrow \pi^{*}\right)$ podem ser vistas na região do UV distante (190 a 260 nm). Estas duas transições dão origem a três bandas espectrais separadas, devido a transição $\pi \rightarrow \pi^{*}$ ser desdobrada em $\pi \rightarrow \pi_{\|}{ }^{*}$ (paralela, polarizada paralelamente ao eixo da hélice) e $\pi \rightarrow \pi^{*} \perp$ (perpendicular, polarizada perpendicularmente ao eixo de hélice) em hélices infinitas (Holzwarth e Doty, 1965; Gratzer et al., 1961). 2- Cadeias laterais aromáticas (triptofano, fenilalanina e tirosina), cujas transições podem ser vistas no ultravioleta próximo (entre 250 e $300 \mathrm{~nm}$ ) e distante, 3- pontes dissulfeto. 4- cromóforos que não fazem parte da estrutura peptídica, como por exemplo, o grupo heme (Simons, 1981).

A figura 18 mostra os espectros de CD característicos para estruturas secundárias em $\alpha$-hélice, folha $\beta$ pregueada e estrutura randômica. $\mathrm{O}$ espectro da estrutura randômica é composto por duas bandas compostas pelas transições $n \rightarrow \pi^{*}$ em $217 \mathrm{~nm}$ e $\pi \rightarrow \pi^{*}$ em $195 \mathrm{~nm}$. A estrutura da folha $\beta$ pregueada apresenta uma banda negativa da transição $n \rightarrow \pi^{*}$ em $215 \mathrm{~nm}$ e uma banda positiva da transição $\pi \rightarrow \pi^{*}$ em $198 \mathrm{~nm}$. Já o espectro de a-hélice apresenta duas bandas para a transição $\pi \rightarrow \pi^{*}$, a qual é degenarada, uma positiva em aproximadamente $191 \mathrm{~nm}(\perp$, perpendicular) e outra negativa em $208 \mathrm{~nm}$ (II, paralela). A transição $\mathrm{n} \rightarrow \pi^{*}$ produz uma banda negativa em $222 \mathrm{~nm}$ (Fasman, 1996).

Devido a esta sensibilidade à estrutura secundária, a técnica de CD tem sido muito útil para caracterizar a estabilidade de uma proteína, para acompanhar o processo de enovelamento/desenovelamento, e para detectar a presença de intermediários entre o estado nativo enovelado e desenovelado de uma proteína. Conhecendo-se o espectro de CD de uma determinada proteína é 
possível acompanhar a sua desnaturação térmica ou desnaturação por cosolventes (uréia ou cloreto de guanidinio) utilizando-se a banda de intensidade máxima do espectro. No caso de uma proteína com alto conteúdo de a-hélice, utiliza-se a banda em 222nm (Fasman, 1996; Simons, 1981).

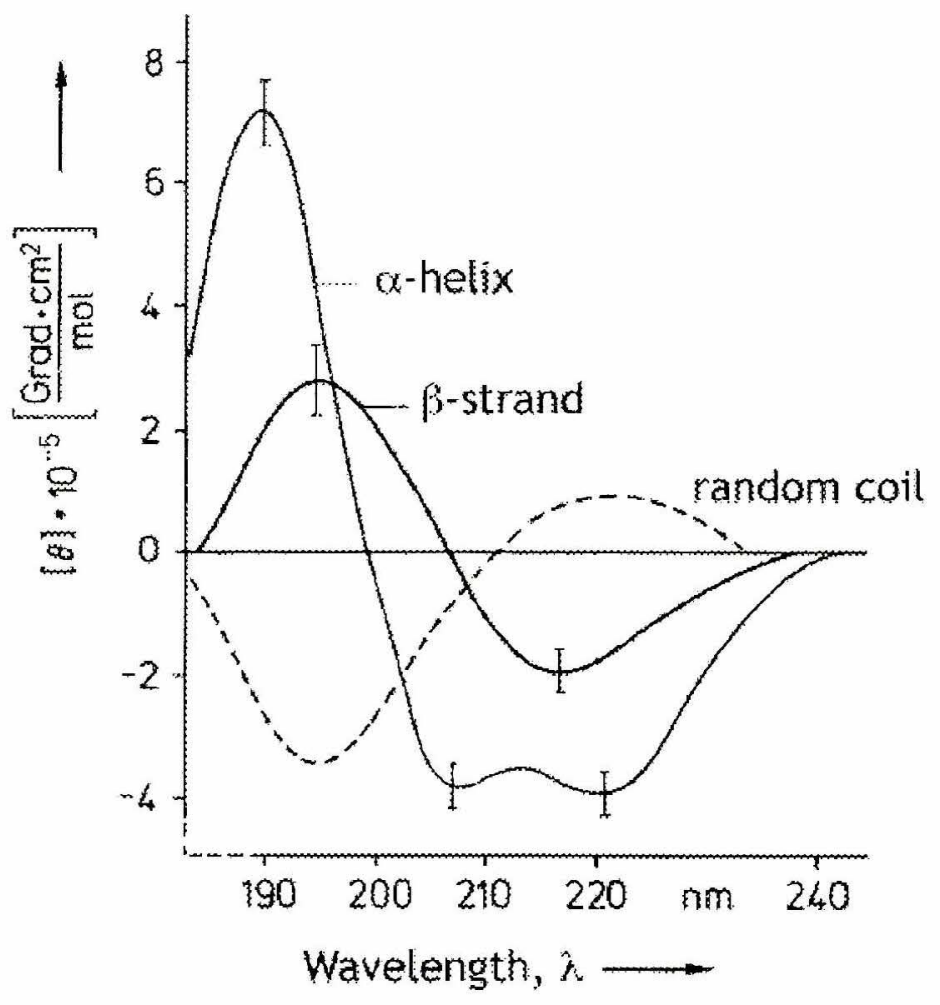

Figura 18 - Espectros de $C D$ característicos das estruturas $\alpha$-hélice, folha $\beta$ e randômica. Note que o espectro da estrutura $\alpha$-hélice possui três bandas características, uma positiva em $190 \mathrm{~nm}$ e duas negativas, uma em $208 \mathrm{~nm}$ e outra em $222 \mathrm{~nm}$.

A técnica de CD também pode ser utilizada para medir a interação entre duas proteínas através das diferenças entre espectros. Nesta metodologia, assume-se que o sinal de elipticidade produzido por um complexo será igual a soma dos sinais de elipticidade produzidos por seus componentes, caso a formação do complexo não tenha alterado a conformação ou o ambiente dos cromóforos opticamente ativos presentes na solução. Se o espectro de CD observado para a mistura entre os componentes não for igual à soma de seus 
componentes, então uma interação que resulta em mudanças conformacionais em um ou ambos os componentes, ocorreu (Simons, 1981).

\subsubsection{Varreduras no UV distante. Espectros para curvas de} desnaturação com uréia e curva de desnaturação térmica do fragmento Tm 143-235.

Os espectros de CD para os ensaios de desnaturação por uréia dos fragmentos C-terminais e para o ensaio de desnaturação térmica do fragmento $\mathrm{Tm}_{143-235}$ foram coletados em um espectropolarímetro Jasco 720 pertencente ao departamento de Bioquímica do Instituto de Química da Universidade de São Paulo. Os espectros de CD na região do UV distante (190 to $260 \mathrm{~nm}$ ) foram coletados em intervalos de 0,5 nm usando um tempo de resposta de 0,25 s e uma velocidade de $100 \mathrm{~nm} / \mathrm{min}$. Um total de 4 varreduras foi coletado para cada ponto das curvas de desnaturação por uréia $\left(a^{\circ} 10^{\circ} \mathrm{C}\right)$ e desnaturação térmica do fragmento $\mathrm{Tm}_{143-235}$, e um total de 8 varreduras foi coletado para os espectros de todos os fragmentos aqui estudados na região do UV distante a $25^{\circ} \mathrm{C}$. As condições do tampão para os experimentos de desnaturação por uréia estão descritas no item 2.3.4. Os experimentos de desnaturação térmica da $\operatorname{Tm}_{143-235}$ foram feitos incubando-se $10 \mu \mathrm{M}$ de cada proteína em tampão $50 \mathrm{mM}$ de fosfato

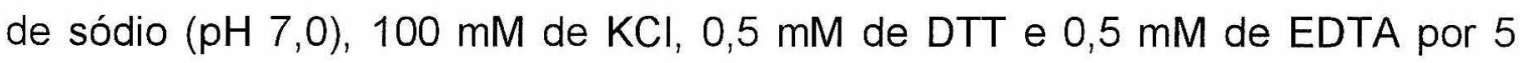
minutos em cada temperatura antes de coletar o espectro de CD como descrito acima.

2.3.2 Desnaturação térmica das misturas contendo fragmentos C- e $\mathrm{N}$-terminais de Tm monitorada pelo espectro de CD.

Os espectros foram coletados em um espectropolarímetro JASCO-810 pertencente ao Laboratório Nacional de Luz Sincrotron (Campinas, Brasil).

As proteínas (10 $\mu \mathrm{M}$ do dímero) foram ressupendidas em tampão $10 \mathrm{mM}$ de fosfato de sódio ( $\mathrm{pH} \mathrm{7,0);0,5} \mathrm{mM} \mathrm{de} \mathrm{EDTA;} \mathrm{1,0} \mathrm{mM} \mathrm{de} \mathrm{DTT.} \mathrm{As} \mathrm{medidas}$ 
foram feitas em $222 \mathrm{~nm}$ e coletadas em intervalos de $0,5^{\circ} \mathrm{C}$ entre $4^{\circ} \mathrm{C}$ e $80^{\circ} \mathrm{C}$ a uma velocidade de $1^{\circ} \mathrm{C} / \mathrm{min}$ (usando $1 \mathrm{~nm}$ de abertura de fenda e $4 \mathrm{~s}$ de tempo de resposta). As desnaturações térmicas foram feitas para ASTm ${ }_{1-142}, \mathrm{nfTm}_{1-142}$, $\mathrm{Tm}_{167-260}, \operatorname{Tm}_{143-260}$ e $\operatorname{Tm}_{220-284}$ individualmente (utilizando-se $10 \mu \mathrm{M}$ de concentração de proteína), bem como para as seguintes combinações: Tm 167-260 + ASTm 1-142, Tm ${ }_{167-260}+$ nfTm 1-142, $\operatorname{Tm}_{143-260}+$ ASTm $_{1-142,} \operatorname{Tm}_{143-260}+$ nfTm 1 142, Tm 220-284 + ASTm 1-142 e Tm 220-284 + nfTm 1-142, mantendo-se a estequiometria de 1:1 e utilizando-se $10 \mu \mathrm{M}$ de cada proteína. Os espectros das misturas entre dois componentes foram comparados com o espectro obtido para a soma dos espectros individuais.

\subsection{3- Cálculo da fração de $\alpha$-hélice}

O conteúdo de $\alpha$-hélice foi calculado através do algoritmo desenvolvido por Holtzer et al. (1983) para proteínas "coiled-coil" como descrito abaixo:

$$
\Phi_{\mathrm{h}}=\left\{[\theta]-\left[\theta_{\mathrm{c}}\right]+\left(2.55 \mathrm{I}\left[\theta_{\mathrm{h}}{ }^{\infty}\right] / \mathrm{n}\right)\right\} /\left\{\left[\theta_{\mathrm{h}}{ }^{\infty}\right]-\left[\theta_{\mathrm{c}}\right]\right\} \text { onde, }
$$

$\Phi_{\mathrm{h}}=$ fração de hélice, $\theta_{\mathrm{h}}{ }^{\infty}=$ elipticidade residual média a $222 \mathrm{~nm}$ para uma hélice infinita $\left.\left(-386 \text { graus. } \mathrm{cm}^{2} \text {.(mmol de ligações peptícas }\right)^{-1}\right), \theta_{\mathrm{c}}=$ elipticidade residual média para uma cadeia randômica a $222 \mathrm{~nm}\left(-10\right.$ graus $\left.\mathrm{cm}^{2} \cdot(\mathrm{mmol} \text { de ligações peptídicas })^{-1}\right), \mathbf{I}=$ número médio de hélices por cadeia (neste caso é igual a 1), $\mathbf{n}=$ número de ligações peptídicas e $\theta=$ elipticidade medida em $222 \mathrm{~nm}$.

\subsection{4- Desnaturação por uréia dos fragmentos $C$-terminais monitorada} por $C D$

Os estudos de desnaturação por uréia foram feitos em tampão $50 \mathrm{mM}$ de fosfato de sódio ( $\mathrm{pH} 7,0), 100 \mathrm{mM}$ de $\mathrm{KCl}, 0,5 \mathrm{mM}$ de DTT e 0,5 mM de EDTA. Uma solução estoque de aproximadamente $9 \mathrm{M}$ de uréia (Sigma ultra pure grade) foi preparada no mesmo tampão acima e misturada com as proteínas $(10 \mu \mathrm{M}$, 
considerando os fragmentos de Tm como dímeros de duas a-hélices) nas proporções corretas para a concentração final de uréia desejada. A concentração de uréia foi previamente confirmada através do índice de refração da amostra, conforme calculado em Pace e Scholtz (1997). As amostras foram incubadas a $10^{\circ} \mathrm{C}$ por $3 \mathrm{~h}$ para alcançar o tempo de equilíbrio antes da coleta dos espectros de CD. As curvas de desnaturação por uréia foram analisadas como descrito anteriormente e mostrado abaixo (Pace e Scholtz, 1997):

$\Delta G^{0}=-R T \operatorname{lnK}=-R T \ln [(Y f-Y) /(Y-Y u)]=\mathbf{m}\left([\text { uréia }]_{1 / 2}-[\right.$ uréia] $)$ (1). Portanto:

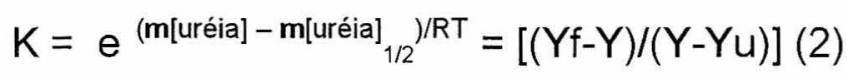

Onde: $\Delta G^{0}=$ energia livre de desenovelamento para cada ponto na curva de desnaturação, $Y=$ elipticidade residual média em $222 \mathrm{~nm}$, [uréia] $]_{1 / 2}=$ concentração de uréia na qual $50 \%$ das moléculas encontram-se desenoveladas (assumindo uma transição de dois-estados), $\mathbf{m}=$ medida da inclinação da transição, Yf e $Y u=$ equações lineares que definem as linhas bases de pré e pós-transição (as sensibilidades à uréia no espectro de $C D$ para os estados enovelados $\mathrm{e}$ desenovelados, respectivamente).

Temos que:

$Y f=Y_{f l}+m_{f}[$ uréia] (3) e

$Y_{u}=Y_{u l}+m_{u}[u r e ́ i a](4)$

$Y_{f l}$ e $m_{f}$ são respectivamente os coeficientes lineares e angulares da linha base de pré-transição, e $Y_{u l}$ e $m_{u}$ são respectivamente os coeficientes lineares e angulares da linha base de pós-transição. É importante notar que Yf e Yu variam para cada concentração de uréia.

Substituindo-se (3) e (4) em (2) e isolando o valor de $Y$, pode-se obter uma equação para o ajuste da curva de desnaturação em função da concentração de uréia ([uréia]), onde os parâmetros $Y_{\mathrm{fl}}, \mathrm{m}_{\mathrm{f}}, \mathrm{Y}_{\mathrm{ul}}, \mathrm{m}_{\mathrm{u}}$, [uréia] $]_{1 / 2}$ e $\mathbf{m}$ podem ser encontrados:

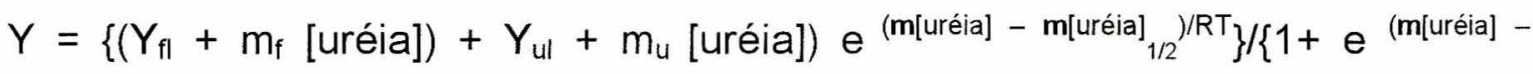
$\mathrm{m}\left[\right.$ uréia] $\left.{ }_{1 / 2} \mathrm{~V} / \mathrm{RT}\right\}(5)$

Para todos os fragmentos, Yu foi obtido diretamente das curvas de

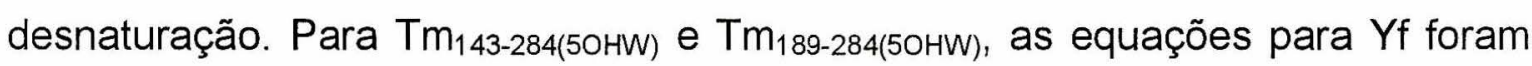
também estimadas diretamente a partir das curvas de desnaturação. Para os fragmentos que se apresentavam relativamente instáveis, o Yf não pôde ser 
estimado com precisão a partir dos dados da desnaturação, e portanto, nós decidimos utilizar valores de acordo com a similaridade da forma da curva de desnaturação com a de outros fragmentos. Desta maneira, o Yf utilizado para

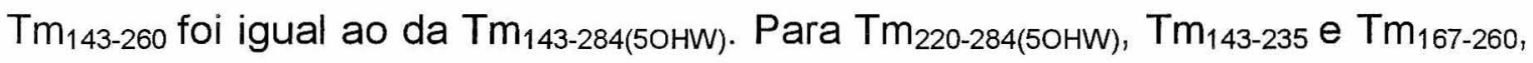
nós utilizamos a mesma equação de $\mathrm{Yf}$ utilizada para $\mathrm{Tm}_{189-284(50 H W) \text {. As }}$ simulações de ajuste das curvas mostraram que os valores de $\mathbf{m}$ e [uréia] $]_{1 / 2}$ foram insensíveis à equação específica empregada para Yf.

\subsection{Fluorescência}

A espectroscopia por fluorescência tem sido grandemente utilizada para estudar a estrutura, a dinâmica e a interação de proteínas em soluções. Quando uma molécula, no seu estado eletrônico fundamental $S_{0}$ absorve luz, ela é promovida instantaneamente $\left(\sim 10^{-15} \mathrm{~s}\right)$ para os estados eletrônicos $S_{1}$ ou $S_{2}$. Este processo é seguido por conversões internas entre os estados $S_{2}$ e $S_{1}$ e por relaxações vibracionais para o nível $S_{1}$. A partir do nível $S_{1}$ vários processos podem ocorrer para dissipar a energia remanescente como, por exemplo, o decaimento radiativo com uma constante de velocidade $\mathrm{k}_{\mathrm{r}}$ para produzir fluorescência, dentre outros (Eftink, 1991).

A utilização de sondas intrínsecas de fluorescência como o triptofano, tem permitido a observação do sistema sem que ocorra uma perturbação química. $\mathrm{O}$ espectro de absorção do triptofano se estende para comprimentos de onda de menor energia quando comparados com os da fenilalanina e tirosina, permitindo assim que 0 triptofano possa ser excitado seletivamente em comprimentos de onda (293 nm) onde a fenilalanina e a tirosina não o são.

Apesar de o triptofano possuir vantagens como sonda intrínseca, é difícil utilizá-lo no estudo de interação entre proteínas, já que muitas proteínas contêm triptofano na sua seqüência natural e a diferenciação entre os sinais produzidos pelos diversos triptofanos presentes no sistema torna-se difícil (Ross et al., 1997). A utilização de análogos do triptofano tem resolvido este problema, já que estas 
sondas podem ser excitadas em comprimentos de onda específicos, permitindo assim uma maior seletividade.

O análogo 5-hidroxitriptofano tem sido utilizado extensivamente em nosso laboratório como uma sonda seletiva para o estudo da interação entre as proteínas envolvidas na regulação da contração muscular (Paulucci et al., 2002; Sousa e Farah, 2002; Farah et al. 1999; Das et al. 1999). A Figura 19 mostra o espectro de excitação de fluorescência do triptofano em comparação com o do 5hidroxitriptofano. Como podemos observar, ambos possuem um máximo de excitação em $280 \mathrm{~nm}$, entretanto o $50 \mathrm{HW}$ possui também um "ombro" de excitação em $312 \mathrm{~nm}$. Ambos emitem em $338 \mathrm{~nm}$. Desta maneira, a excitação seletiva do $50 \mathrm{HW}$ pode ser feita em $312 \mathrm{~nm}$. A Figura 20 mostra os espectros de emissão e de excitação de um fragmento recombinante contendo a sonda $5 \mathrm{OHW}$ incorporada.

\section{triptofano}<smiles>N[C@@H](Cc1c[nH]c2ccccc12)C(=O)O</smiles>

\section{5-hidroxitriptofano}
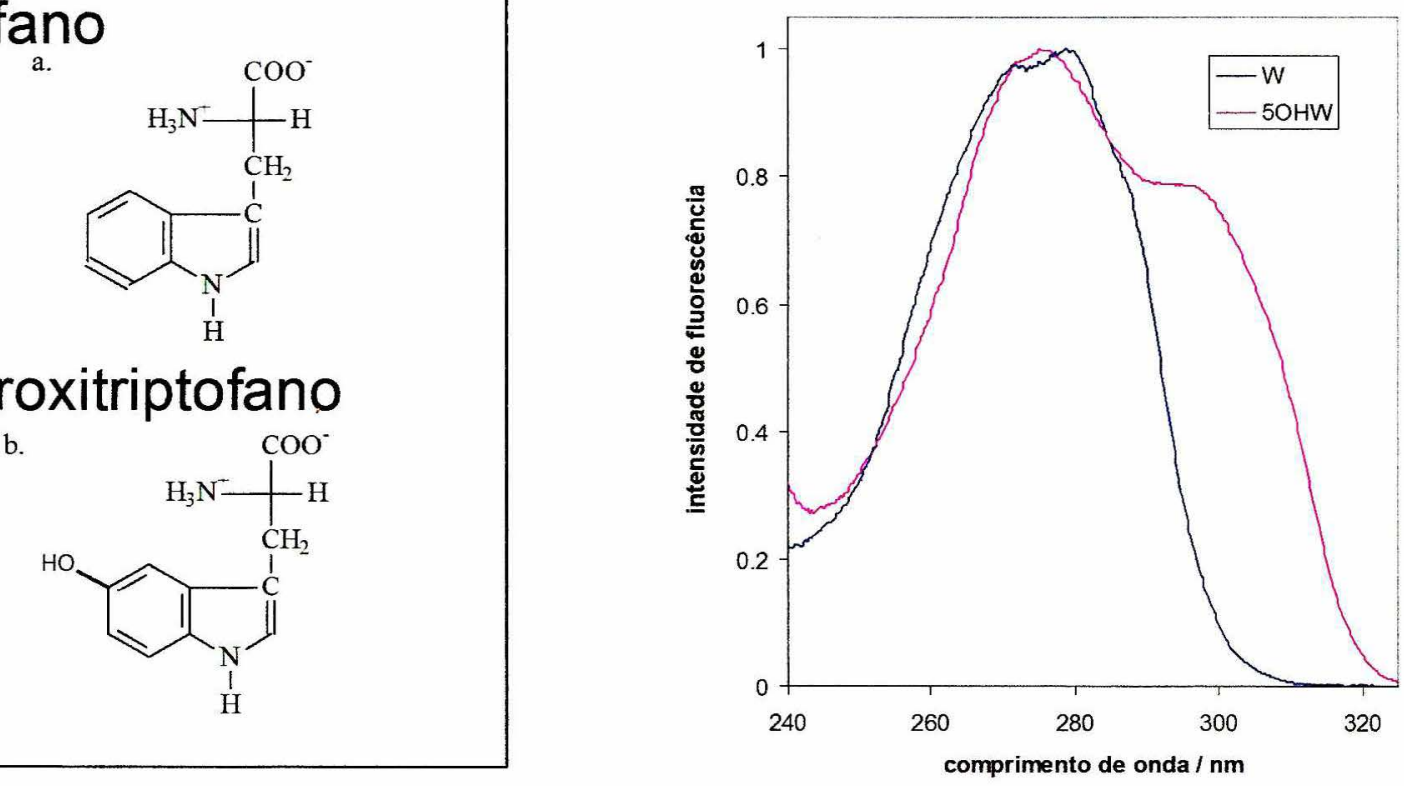

Figura 19 - Espectros de excitação de fluorescência do triptofano e do 50HW (cujas estruturas estão mostradas no quadro da esquerda). Note que ambos possuem uma intensidade máxima do sinal por volta de $280 \mathrm{~nm}$. Entretanto o $50 \mathrm{HW}$ também pode ser excitado em 312nm. 


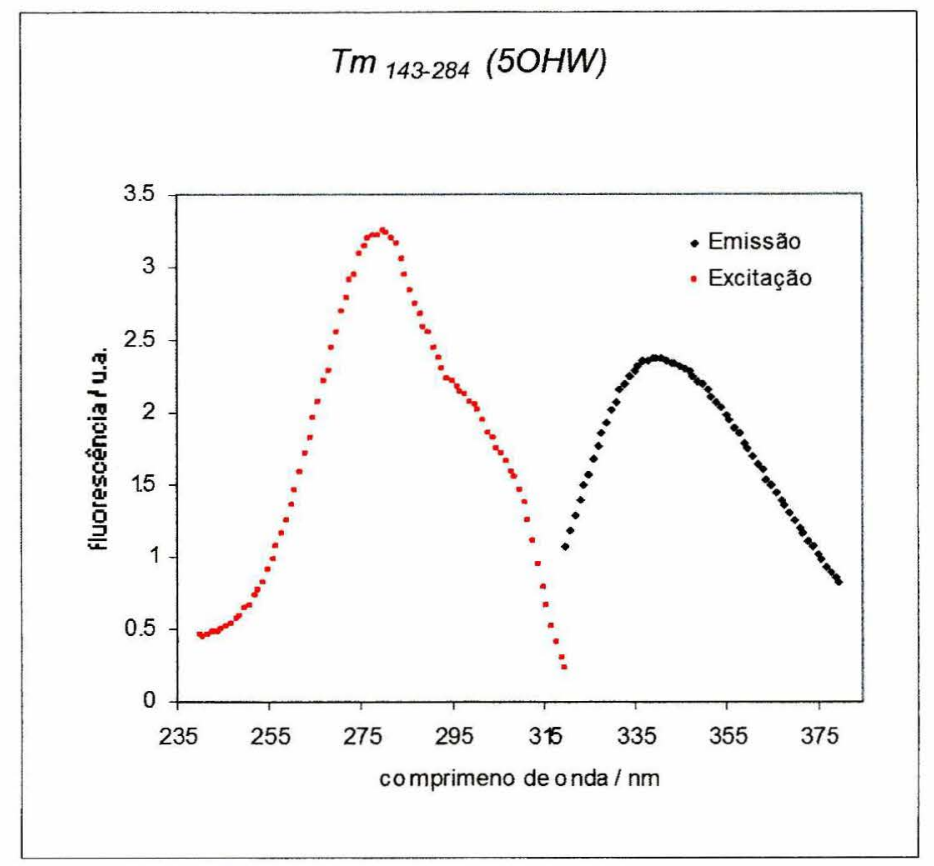

Figura 20 - Espectro de excitação e de emissão de fluorescência do

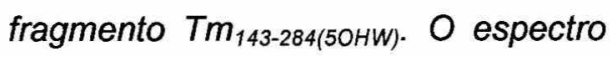
de excitação mostra um "ombro" em $312 \mathrm{~nm}$ e o espectro de emissão possui um máximo de intensidade em aproximadamente $338 \mathrm{~nm}$.

2.4.1. - Desnaturação por uréia monitorada por fluorescência do 5hidroxitriptofano

Os experimentos de fluorescência foram realizados em um espectrofluorímetro (AVIV Automated Titrating Differential/Ratio ATF105) a $10^{\circ} \mathrm{C}$. Os espectros de emissão de fluorescência foram coletados a $337 \mathrm{~nm}$ (usando-se $5 \mathrm{~nm}$ de abertura de fenda) utilizando-se um comprimento de onda para excitação de $305 \mathrm{~nm}$ (usando-se $1 \mathrm{~nm}$ de abertura de fenda). As condições do tampão foram as mesmas descritas para os experimentos de desnaturação por uréia acompanhada por dicroísmo circular. Alíquotas de uma solução estoque de $9 \mathrm{M}$ de uréia foram adicionadas de forma automatizada nas cubetas da amostra e da referência e as soluções foram equilibradas por 5 minutos antes de cada medição. No final de cada titulação, a reversibilidade das curvas foi confirmada medindo-se a fluorescência da amostra após a diluição com 20 volumes de tampão sem uréia. Os dados foram analisados de maneira similar àquela descrita para os experimentos de CD. Os valores de $\mathrm{Yu}$ foram obtidos diretamente das

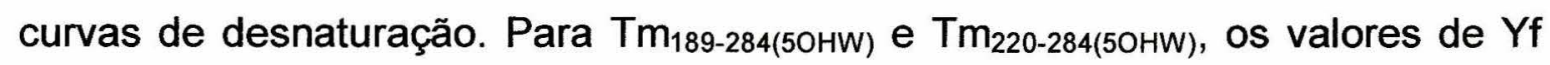


foram iguais aos de Yf estimados para a curva de desnaturação de $\mathrm{Tm}_{143}$ $284(5 \mathrm{OHW})$.

\subsection{2 - Experimentos de interação cabeça-cauda entre nfTm269(5OHW) e nfTm1-142 e entre nfTm269(5OHW) e ASTm1-142 acompanhados por fluorescência}

A fluorescência da sonda 5-hidroxitriptofano localizada na posição 269 de uma molécula de Tm sem fusão dipeptídica Ala-Ser amino-terminal, nfTm269(50HW) a $2 \mu \mathrm{M}$ (Sousa e Farah, 2002), foi monitorada durante a

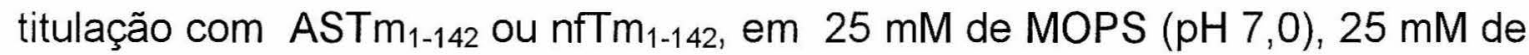
$\mathrm{NaCl}, 5 \mathrm{mM}$ de $\mathrm{MgCl}_{2}, 1 \mathrm{mM}$ de DTT. Os espectros foram obtidos a $25^{\circ} \mathrm{C}$ usando-se um comprimento de onda de excitação de $302 \mathrm{~nm}$ e um comprimento de onda de emissão de $337 \mathrm{~nm}$, com aberturas de fendas de 1 e 5 nm respectivamente. Depois de cada adição de ASTm $_{1-142}$ ou nfTm 1-142, a mistura foi equilibrada por 5 minutos. A intensidade de emissão representa a emissão total coletada entre 320 e $420 \mathrm{~nm}$.

\section{5 - Ultracentrifugação Analítica (AUC)}

A ultracentrifugação analítica (AUC) foi desenvolvida na década de 1920 e é uma técnica muito apropriada para a caracterização de interações macromoleculares. Em 1926, Svedberg conquistou o prêmio Nobel pelo desenvolvimento e aplicação da ultracentrífuga, que se tornou de uso comum por volta dos anos 40 quando se tornou comercial. Atualmente existem instrumentos modernos que usam interferência óptica e absorção e que permitem uma análise mais acurada das interações moleculares em solução (Hensley, 1996). 
Existem dois tipos de experimentos gerais utilizados para estudos de ultracentrifugação analítica: a velocidade de sedimentação (SV), em que a taxa de transporte da macromolécula é medida, e o equilíbrio de sedimentação (SE).

No experimento de equilíbrio de sedimentação, um pequeno volume de uma solução inicialmente uniforme é centrifugado em uma velocidade angular menor do que nos experimentos de velocidade de sedimentação. Conforme o soluto começa a sedimentar em direção ao fundo da cela e a concentração vai aumentando nesta direção, ocorre um processo de difusão que se opõe a este processo de sedimentação. Depois de um período de tempo apropriado, os dois processos se aproximam do equilíbrio, e a concentração do soluto aumenta exponencialmente em direção ao fundo da cela. No equilíbrio, a distribuição do soluto é invariável com o tempo e, medindo-se a concentração em diferentes pontos é possível determinar a massa molecular do soluto (Ralston, 1993). O tempo necessário para encontrar o equilíbrio depende do comprimento da cela na direção radial. Para um comprimento de $3 \mathrm{~mm}$ são necessárias 18 horas de equilíbrio, enquanto que para uma cela de $1 \mathrm{~mm}$ de comprimento são necessárias 2 horas de equilíbrio.

Para compreender as equações envolvidas na análise de dados obtidos através da AUC, é necessário conhecer alguns princípios básicos de hidrodinâmica:

\section{a- Sedimentação de partículas num campo gravitacional}

Quando a partícula de um soluto de massa $m$ é ressuspendida em um solvente e submetida a um campo gravitacional, três forças agem sobre esta partícula.

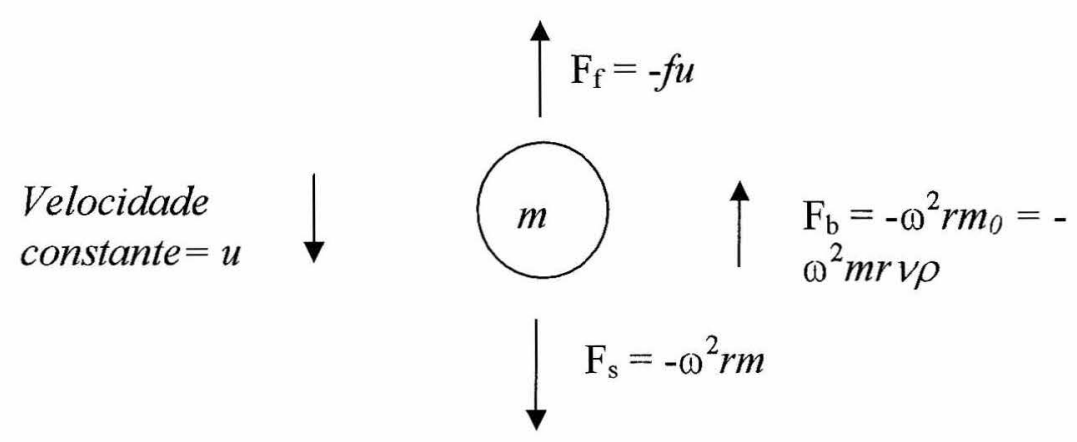


Inicialmente nós temos a força gravitacional ou força de sedimentação (Fs), que é proporcional à massa da partícula:

Fs $=\omega^{2} r m=M / N\left(\omega^{2} r\right)(1)$, onde: $N=$ número de Avogrado, $M=$ massa molecular em g/mol, $\omega=$ velocidade angular em radianos por segundo, $r$ = distância da partícula ao eixo de rotação em $\mathrm{cm}$.

Em segundo lugar, temos a força de empuxo $(\mathrm{Fb})$ que, segundo o princípio de Arquimedes, é igual ao peso do fluido deslocado:

$\mathrm{Fb}=-\omega^{2} r m_{0}=-m v \rho \omega^{2} r=-\mathrm{M} / \mathrm{N}(v \rho) \omega^{2} r(2)$, onde: $m_{0}=$ massa de fluido deslocado pela partícula, $v=$ volume parcial específico em $\mathrm{mL}$ que cada grama de soluto ocupa em solução $(\mathrm{mL} / \mathrm{g}), \rho=$ densidade do solvente $\mathrm{em} \mathrm{g} / \mathrm{mL}$.

Conforme a partícula começa a se mover ao longo do caminho radial em direção ao fundo da cela, a sua velocidade $(u)$ irá aumentar devido ao aumento da distância radial. Então, a partícula irá sofrer a força de atrito (Ff) que é dada por:

$\mathrm{F}_{\mathrm{f}}=-\mathbf{f u}(\mathbf{3})$, onde: $f=$ constante de atrito, $u=$ velocidade da partícula

Em um tempo muito curto $\left(10^{-6} \mathrm{~s}\right)$, as três forças entram em equilíbrio, de forma que:

$$
\mathrm{Fs}+\mathrm{Fb}+\mathrm{F}_{\mathrm{f}}=0
$$

Entao, M/N $\left(\omega^{2} r\right)-M / N(v \rho) \omega^{2} r-f u=0$

Rearranjando os termos, temos:

$M / N(1-v \rho) \omega^{2} r-f u=0$

$M(1-v \rho) / N f=u / \omega^{2} r \equiv s(4)$

O termo $u / \omega^{2} r$, é a velocidade da partícula por unidade de aceleração gravitacional, sendo também denominado coeficiente de sedimentação (s), e pode ser visto como sendo dependente das propriedades da partícula. $O$ coeficiente de sedimentação é dado em segundos e, para muitas substâncias, o valor de s está entre (1 e 100) $\times 10^{-13} \mathrm{~s}$. A unidade de Svedberg (abreviada como $\mathrm{S})$ é definida como $10^{-13}$ segundos. Portanto, $4,5 \times 10^{-13}=4,5 \mathrm{~S}$, por exemplo.

Como já foi dito anteriormente, no equilíbrio de sedimentação os processos de sedimentação e de difusão estão balanceados. A distribuição da 
concentração do topo da célula para o fundo não muda com o tempo e é uma função do peso molecular.

\section{b- Lei de Fick}

Para a difusão, a primeira Lei de Fick para um componente simples ideal pode ser escrita da seguinte forma (Laue et al., 1991):

$J_{D}=-D d c / d r=-(R T / N f) d c / d r(5)$,

onde: $J_{D}=$ fluxo devido à difusão $\left(\mathrm{g} / \mathrm{cm}^{2}-\mathrm{seg}\right), \mathrm{D}=$ coeficiente de difusão $\left(\mathrm{cm}^{2} / \mathrm{seg}\right), \mathrm{R}=$ constante dos gases, $\mathrm{T}=$ temperatura absoluta em Kelvin, $\mathrm{dc} / \mathrm{dr}=$ gradiente da concentração em função da posição radial.

O fluxo de sedimentação $\left(J_{S}\right)$ num sistema de dois componentes é o produto da concentração da massa do soluto pela sua velocidade:

$\mathrm{J}_{\mathrm{S}}=\mathrm{c} d \mathrm{~d} / \mathrm{dt}=\operatorname{cs} \omega^{2} \mathrm{r}(6)$

No equilíbrio:

$\mathrm{J}_{S}+\mathrm{J}_{\mathrm{D}}=0$. Portanto:

$\operatorname{cs} \omega^{2} r=D d c / d r$

Rearranjando, temos que:

$s \omega^{2} / D=(1 / \mathrm{rc})(\mathrm{dc} / \mathrm{dr})=\mathrm{d}(\ln \mathrm{c}) / \mathrm{d}\left(\mathrm{r}^{2} / 2\right)=\sigma(7)$,

onde: $\sigma=$ peso molecular aparente reduzido

Como visto anteriormente em (5) e em (4):

$D=(R T / N f)$ e $s=M(1-v \rho) / N f$. Portanto:

$\mathrm{d}(\ln \mathrm{c}) / \mathrm{d}\left(\mathrm{r}^{2} / 2\right)=\mathbf{s} \omega^{2} / \mathrm{D}=\omega^{2}[\mathrm{M}(1-v \rho)] /(\mathrm{RT})=\sigma(8)$

Portanto, a massa molecular $\mathbf{M}$ do monômero pode ser calculada, já que o coeficiente angular do gráfico de Inc versus $r^{2} / 2$ é proporcional a $\mathbf{M}$, onde:

$(\operatorname{lnc}) /\left(r^{2} / 2\right)=M \omega^{2}(1-v \rho) / R T$ (9) (equação de Lam)

A equação acima descreve o movimento de moléculas em um campo centrífugo. Embora esta equação descreva basicamente o processo de sedimentação, os dados de sedimentação de equilíbrio são em geral melhor analisados por procedimentos que envolvem o método não linear dos mínimos quadrados e que permitem acomodar casos mais complicados envolvendo associação e não-idealidade. 
Para uma análise dos mínimos quadrados, a diferença entre as funções ajustadas e os dados experimentais é elevada ao quadrado e, então, somados. Os parâmetros são variados até minimizar esta soma.

Quando o método de análise dos mínimos quadrados é usado, uma equação matemática ou modelo que descreve a distribuição do macro-soluto na cela se faz necessária para o procedimento de ajuste da curva.

Então, fazendo a diferencial da equação de Lam em função do raio $\mathbf{r}$, temos que:

$\mathrm{d}($ Inc $) / \mathrm{dr}=\mathrm{d}\left(\mathbf{M} \omega^{2}(1-v \rho) \mathrm{r}^{2} / 2 \mathrm{RT}\right) / \mathrm{dr}$

$\mathrm{d}(\mathrm{Inc}) / \mathrm{dr}=\mathbf{M} \omega^{2}(1-v \rho) / 2 \mathrm{RT}\left(\mathrm{r}^{2}-\mathrm{r}_{0}{ }^{2}\right)$

$C_{r}=C_{0} e^{[(M \omega 2(1-v p) / 2 R T)(r 2-r 02)]}(10)$, onde $C_{r}=$ concentração no raio $r, C_{0}=$ concentração no raio referência $r_{0}$.

A equação 10 descreve a distribuição das espécies simples ideais no equilíbrio. Para um equilíbrio monômero-dímero a absorbância total medida representa a soma das duas espécies, logo:

$\mathrm{C}_{\text {total }}=\mathrm{C}_{\mathrm{r}}=\mathrm{C}_{0 \text { monômero }} \mathrm{e}^{[(\mathrm{M \omega} 2(1-\mathrm{v} \mathrm{p}) / 2 \mathrm{RT})(\mathrm{r} 2-\mathrm{r} 02)]}+\mathrm{C}_{0 \text { dimero }} \mathrm{e}^{\left[\left(\mathrm{M \omega} 2\left(1-\mathrm{v}_{\mathrm{\rho}}\right) / 2 \mathrm{RT}\right)(\mathrm{r} 2-\mathrm{r} 02)\right]}$

Desta forma, pode-se estender esta equação para n espécies de forma a se obter o melhor ajuste para os dados experimentais (MaRorie e Voelker, 1993).

\subsection{1 - Experimentos de Equilíbrio de Sedimentação}

Este trabalho foi realizado em colaboração com Leslie Hicks e Dr. Cyril M. Kay na Universidade de Alberta (Edmonton, Canadá), durante um estágio realizado entre 25 de junho de 2001 e 19 de julho de 2001 .

As soluções de proteínas foram dialisadas contra $50 \mathrm{mM}$ de fosfato de

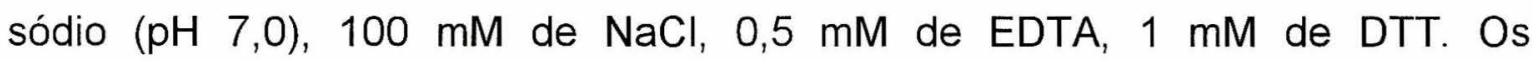
experimentos de equilíbrio de sedimentação foram feitos em uma ultracentrífuga analítica Beckman XL-I, usando-se absorbância ótica e seguindo-se os procedimentos descritos em Laue e Stafford (1999). Os fragmentos C-terminais foram usados em duas concentrações diferentes a $10^{\circ} \mathrm{C}$, na ausência e na 
presença de 30\% TFE, e na ausência e na presença de 5 M uréia. Alíquotas de $110 \mu \mathrm{L}$ de amostra foram colocadas em celas especiais de "Charcoal Filled Epon" (CFE) contendo 6 compartimentos. Os experimentos foram feitos em pelo menos duas velocidades diferentes e cada velocidade foi mantida até que não houvesse nenhuma diferença significante nos valores dos espectros de absorbância versus $r^{2} / 2$, coletados duas horas depois para garantir que o equilíbrio fosse alcançado. Os resultados de equilíbrio de sedimentação foram tratados usando-se o programa NONLIM, o qual incorpora um algoritmo para ajuste de curvas pelo método não-linear dos mínimos quadrados, como descrito em Johnson et al. (1981). Os dados foram ajustados tanto para um modelo de espécies ideais quanto para um modelo de duas espécies associadas. Os volumes específicos parciais das proteínas e a densidade dos solventes foram estimados usando-se o programa SEDNTERP, o qual incorpora os cálculos detalhados por Laue et al. (1991).

\section{6 - Experimentos de ligação cruzada com glutaraldeído.}

As proteínas, previamente dissolvidas em tampão fosfato $(50 \mathrm{mM}$ de fosfato de sódio, $\mathrm{pH}$ 7,0; $100 \mathrm{mM}$ de $\mathrm{KCl} ; 0,5 \mathrm{mM}$ de EDTA e $1 \mathrm{mM}$ de DTT), foram equilibradas por 30 minutos sob as condições indicadas na legenda da figura 27. O glutaraldeído foi adicionado para uma concentração final de $0.02 \%$ e depois de 15 minutos a reação foi bloqueada através da adição de tampão de amostra para SDS-PAGE contendo 52 mM de tampão Tris- $\mathrm{HCl}, \mathrm{pH} 6,8 ; 2 \%$ de SDS, $0,1 \%$ de azul de bromofenol, $10 \%$ de glicerol e $10 \mathrm{mM}$ de $\beta$ mercaptoetanol. Os produtos de ligação cruzada foram analisados em géis de $15 \%$ SDS-PAGE.

\section{7 - Sintese, purificação e caracterização do peptídeo Ac-Tm $215-235$}

O peptídeo $\boldsymbol{A c}^{-T m_{215-235}}$ (Ac-SQKEDKYEEEIKVLTDKKLEA) foi sintetizado pela Dr. Alessandra Machado sob orientação da Prof. Dr. Maria 
Terêsa M. de Miranda no laboratório de síntese de peptídeos do Instituto de Química da USP.

O peptídeo foi preparado manualmente pelo método de fase-sólida usando-se química Boc (tert-butyloxycarbonyl) como descrito em Stewart e Young (1984) e em Varanda e Miranda (1997). A análise e purificação foram feitas por cromatografia líquida de alta performance de fase reversa usando-se colunas $\mathrm{C}_{18}$. $A$ identidade química dos peptídeos purificados foi confirmada por espectrometria de massa, "electrospray ionization mass spectrometry", e análise dos aminoácidos.

\section{8- Análise teórica da tendência de formação de estrutura a-hélice em função da região C-terminal.}

As análises teóricas para estimar a tendência de formação de estrutura $\alpha$ hélice em função da região $\mathrm{C}$-terminal foram feitas pelo programa AGADIR (Muñoz e Serrano 1995 a,b; Lacroix et al., 1998) disponível na internet no endereço abaixo:

http://www.emblheidelberg.de/Services/serrano/agadir/agadir-start.html

O AGADIR é um programa baseado na teoria de transição hélice-"coil" que possui um banco de dados contendo as contribuições energéticas de várias interações que participam da estrutura $\alpha$-hélice como: propriedades intrínsecas de formação de hélice, interações entre cadeias laterais, interações entre pontes de hidrogênio da cadeia principal, efeitos de "capping", interações entre grupos carregados e macro-dipolos da hélice. Em princípio, este algoritmo foi desenvolvido para calcular o conteúdo de a-hélice de peptídeos homopoliméricos em solução sem nenhuma interação terciária. Entretanto, é possível usá-lo no desenho de proteínas para aumentar a estabilidade de $\alpha$ hélices isoladas escolhendo-se as mutações corretas (Muñoz e Serrano 1995 a,b; Lacroix et al., 1998).

Foram feitas análises, usando o AGADIR, para todos os fragmentos recombinantes C-terminais em duas condições, onde os parâmetros de força 
iônica ou temperatura foram variados: $1-25^{\circ} \mathrm{C}, \mathrm{pH} 7,0$, variando-se a força iônica de 0 até $1 \mathrm{M}$. 2- força iônica constante em $0,1 \mathrm{M}, \mathrm{pH} 7,0$, variando-se temperatura de $0^{\circ} \mathrm{C}$ até $100^{\circ} \mathrm{C}$.

\section{9- Análise teórica da tendência de formação de estrutura "coiled-coil" para os fragmentos da região C-terminal da Tm.}

Esta análise foi feita para todos os fragmentos C-terminais de Tm utilizando o programa STABLECOIL que pode ser encontrado no seguinte endereço na internet:

http://www.pence.ualberta.ca/software/stablecoil/latest/stablecoil.html

O programa prediz a localização e a estabilidade de conformações $\alpha$ hélice "coiled-coil" dentro de seqüências de proteínas. O programa soma as pontuações dos resíduos em "janelas" com comprimento de 21, 28, 35 e 42 aminoácidos e compara a pontuação total com proteínas globulares conhecidas e seqüências contendo "coiled-coil" citoesqueléticas. O programa mostra a região e a sua probabilidade de formação de estrutura "coiled-coil" (em kcal/mol) para uma seqüência em particular. As propensões de a-hélice e os coeficientes de estabilidade usados no programa são oriundos de dados experimentais mostrados em Zhou et al. (1994c); Wagschal et al. (1999) e Tripet et al. (2000).

\subsection{0 - Medidas de Viscosidade}

Os experimentos de viscosidade foram realizados em um semimicroviscosímetro (C30) "Cannon-Manning" com um tempo de lavagem com tampão de $242,32 \mathrm{seg}$, a $21 \pm 1{ }^{\circ} \mathrm{C}$. Ressuspendeu-se $8 \mu \mathrm{M}$ de cada proteína em tampão $10 \mathrm{mM}$ de imidazol- $\mathrm{HCl}(\mathrm{pH} \mathrm{7,0)}$ contendo $2 \mathrm{mM}$ de DTT e as amostras forma equilibradas por 7 horas antes das medidas. 


\section{3- Resultados}

\section{1- Caracterização conformacional dos fragmentos recombinantes C-terminais da molécula de $\mathrm{Tm}$}

Nós inicialmente caracterizamos os fragmentos recombinantes Cterminais de Tm quanto à sua propensão de adquirirem estrutura helicoidal através da técnica de dicroísmo circular. Inicialmente, as proteínas foram analisadas em $50 \mathrm{mM}$ de tampão fosfato, $\mathrm{pH}$ 7,0; 0,5 mM de DTT e 0,5 mM de EDTA e a $25^{\circ} \mathrm{C}$ em cinco condições: A) na ausência de $100 \mathrm{mM} \mathrm{KCl}$, B) na ausência de $100 \mathrm{mM}$ de $\mathrm{KCl}+50 \%$ TFE, C) na presença de $100 \mathrm{mM} \mathrm{KCl}$, D) na presença de $100 \mathrm{mM}$ de $\mathrm{KCl}+30 \%$ TFE e E) na presença de $100 \mathrm{mM} \mathrm{KCl}$ $+50 \%$ TFE.

A Figura 21 mostra os espectros de CD na região do UV distante para os fragmentos de Tm na ausência de $\mathrm{KCl}$, com e sem $50 \%$ (v/v) de TFE. A Figura 22 mostra os espectros de CD na presença de $\mathrm{KCl}$, sem e com $30 \%$ (v/v) e $50 \%$ (v/v) de TFE.

A fração do conteúdo de a-hélice calculada para todos os fragmentos em tampão fosfato aumenta com a força iônica. O conteúdo de a-hélice estimado para cada fragmento, com base na elipticidade residual em $222 \mathrm{~nm}$ nas duas condições (com e sem $\mathrm{KCl}$ ), pode ser visualizado na Tabela 6 . A estabilidade da Tm nativa é conhecida por aumentar em função da força iônica (Mo et al. 1990; Lehrer e Yuan, 1998) e, portanto estes dados mostram-se de acordo com dados apresentados na literatura.

Nós observamos que, na ausência de TFE, o conteúdo de $\alpha$-hélice dos fragmentos derivados da metade C-terminal da Tm não é só dependente dos seus respectivos tamanhos, como também da região específica compreendida por eles. Tanto na presença quanto na ausência de $\mathrm{KCl}$, os fragmentos $\mathrm{Tm}_{220}$ 284(50HW) e $\mathrm{Tm}_{220-284}$, apesar dos seus tamanhos relativamente pequenos (65 resíduos), apresentam um espectro de CD típico de uma estrutura $\alpha$-helicoidal 
com duas bandas negativas de maior intensidade em 208 e 222nm (ver figuras 21 e 22). A elipticidade residual para cada um dos fragmentos pode ser observada na Tabela 6 . Por outro lado, a Tm143-235, a qual é composta por 93 aminoácidos, apresenta somente $20 \%$ de estrutura helicoidal quando na presença de $100 \mathrm{mM} \mathrm{KCl}$ a $25^{\circ} \mathrm{C}$ (ver Tabela 6). Seu espectro de CD é característico de uma estrutura randômica em ambas as forças iônicas $(0 \mathrm{mM}$ de $\mathrm{KCl}$ e $100 \mathrm{mM}$ de $\mathrm{KCl}$ ) (ver figuras 21 e 22). O fragmento $\mathrm{Tm}_{167-260}$ (94 resíduos), por sua vez, também apresenta um baixo conteúdo de estrutura em $\alpha$-hélice (28\%) na presença de $100 \mathrm{mM}$ de $\mathrm{KCl}$ a $25^{\circ} \mathrm{C}$. Como pode ser visto na Figura 22, todos os outros fragmentos recombinantes de Tm apresentam um espectro típico de proteínas com estrutura em $\alpha$-hélice quando em tampão fosfato na presença de $100 \mathrm{mM}$ de $\mathrm{KCl}$. Portanto, para aqueles fragmentos contendo 96 resíduos de aminoácidos ou menos, a presença dos resíduos 261-284 parece ser essencial para que possamos observar um conteúdo substancial de estrutura helicoidal, pelo menos nestas condições. Quando a temperatura é abaixada para $10^{\circ} \mathrm{C}$, ocorre um aumento no conteúdo de estrutura $\alpha$-helicoidal para todos os fragmentos exceto para $\operatorname{Tm}_{143-284(50 H W)}$ (OS espectros de $\mathrm{CD}$ a $10{ }^{\circ} \mathrm{C}$ não são mostrados). Nesta temperatura, todos os fragmentos recombinantes têm um conteúdo de a-hélice de pelo menos $60 \%$ (ver o conteúdo de $\alpha$-hélice na Tabela 6 ).

A presença de $30 \%(\mathrm{v} / \mathrm{v})$ ou de $50 \%(\mathrm{v} / \mathrm{v})$ de TFE promove um aumento no conteúdo de $\alpha$-hélice para $\operatorname{Tm}_{220-284(50 H W),} \operatorname{Tm}_{220-284}, \operatorname{Tm}_{143-235}, \operatorname{Tm}_{167-260} \mathrm{e}$ $\operatorname{Tm}_{143-260}$ (ver Figura 21 e 22 e Tabela 6). O aumento do conteúdo de $\alpha$-hélice parece ser gradual quando se vai de $30 \%$ para $50 \%$ de TFE para os fragmentos $\operatorname{Tm}_{220-284}$ e $\operatorname{Tm}_{143-260}$. Entretanto, para o fragmento $\operatorname{Tm}_{143-235}$, o conteúdo de $\alpha$-hélice é maior em $30 \%$ de TFE do que em $50 \%$ de TFE (ver as diferenças nas elipticidades residuais em $222 \mathrm{~nm}$ na tabela 6). Este mesmo padrão parece ser observado para $\mathrm{Tm}_{167-260}$, porém, como a diferença é pequena, não podemos concluir que ele ocorre de fato (ver Tabela 6). Uma comparação dos espectros na presença e na ausência de $30 \%$ e $50 \%$ de TFE mostra que todos os fragmentos apresentam uma inversão nas magnitudes 
relativas dos seus mínimos de elipticidade em 208 nm e 222 nm (Figuras 21 e 22 e Tabela 6).
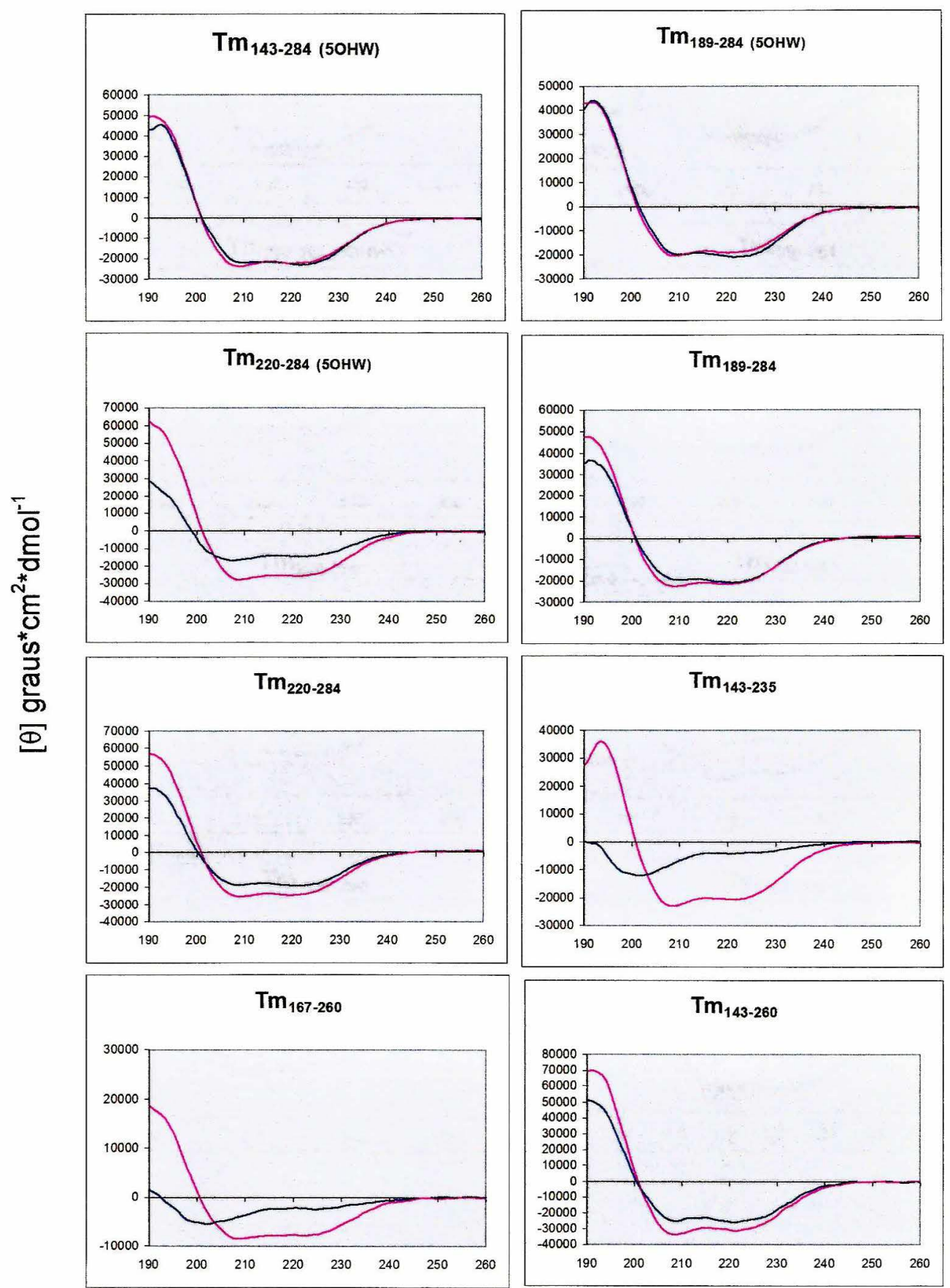

$\mathrm{nm}$

Figura 21 - Espectros de Dicroísmo Circular na região do UV distante para fragmentos Cterminais de $\operatorname{Tm}\left(10 \mu \mathrm{M}\right.$ do dímero) a $25{ }^{\circ} \mathrm{C}$. Tampão: $50 \mathrm{mM}$ de fosfato de sódio ( $\left.\mathrm{pH} 7,0\right), 0,5$ mM de EDTA e 0,5 mM de DTT. Linha azul: na ausência de TFE. Linha rosa: na presença de $50 \%(V / V)$ de TFE. 

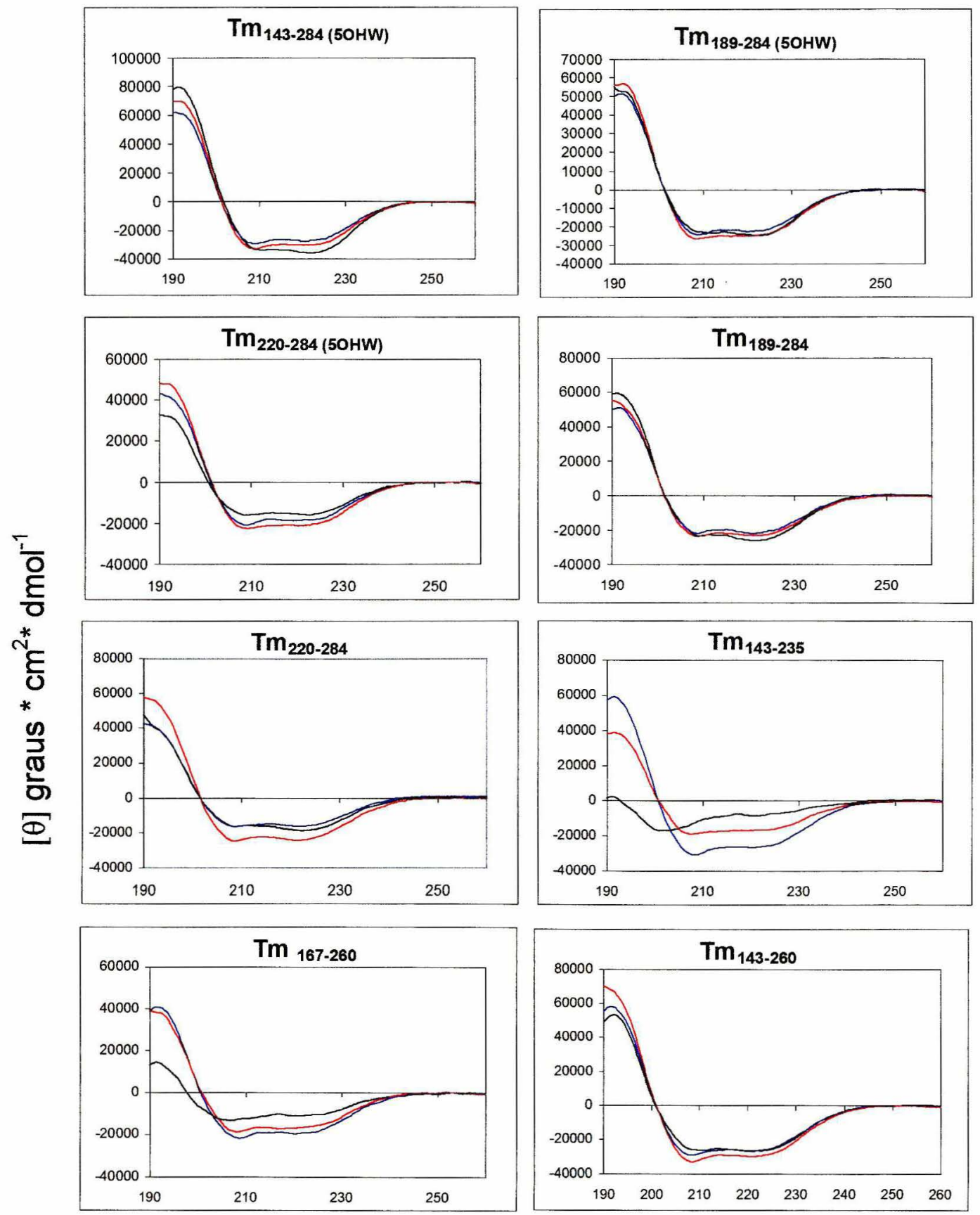

$\mathrm{nm}$

Figura 22- Espectro de Dicroísmo Circular na região do UV distante para fragmentos Cterminais de $\mathrm{Tm}$ a $25^{\circ} \mathrm{C}$. Tampão: $50 \mathrm{mM}$ de fosfato de sódio $(\mathrm{pH7}, 0), 100 \mathrm{mM}$ de $\mathrm{KCl}, 0,5 \mathrm{mM}$ de EDTA e 0,5 mM de DTT. Linha preta: na ausência de TFE. Linha azul: na presença de $30 \%$ TFE. Linha vermelha: na presença de $50 \%$ TFE. 


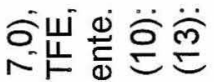

드응

옹항 ᅯ

음 0

of

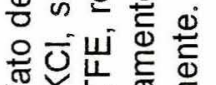

娄证

응 퉁응 를

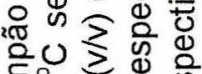

的喝

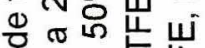

틀

हा

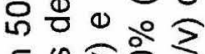

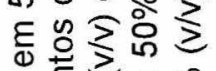

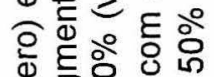

ब.

Eं

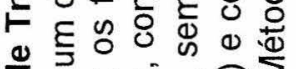

음

政

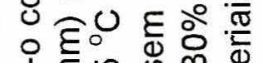

은 선 0

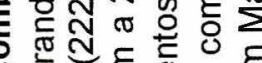

政

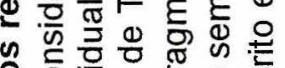

罂

政

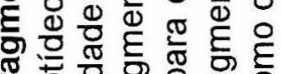

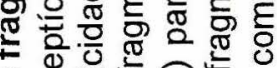

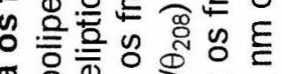

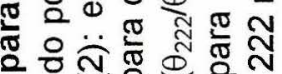

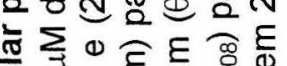

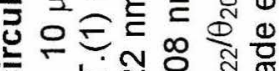

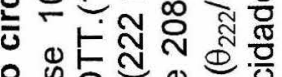

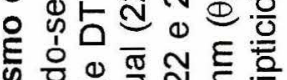

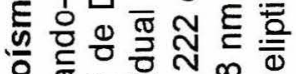
는

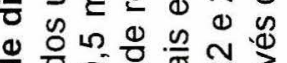

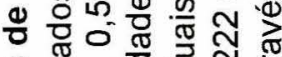

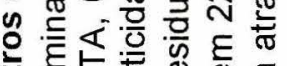

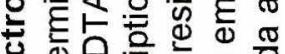

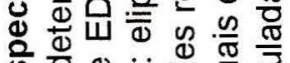

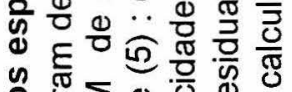

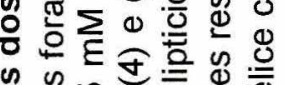

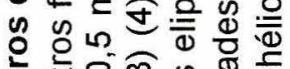

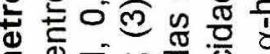

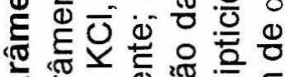
ธ。

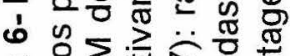
Ti

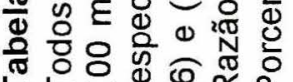

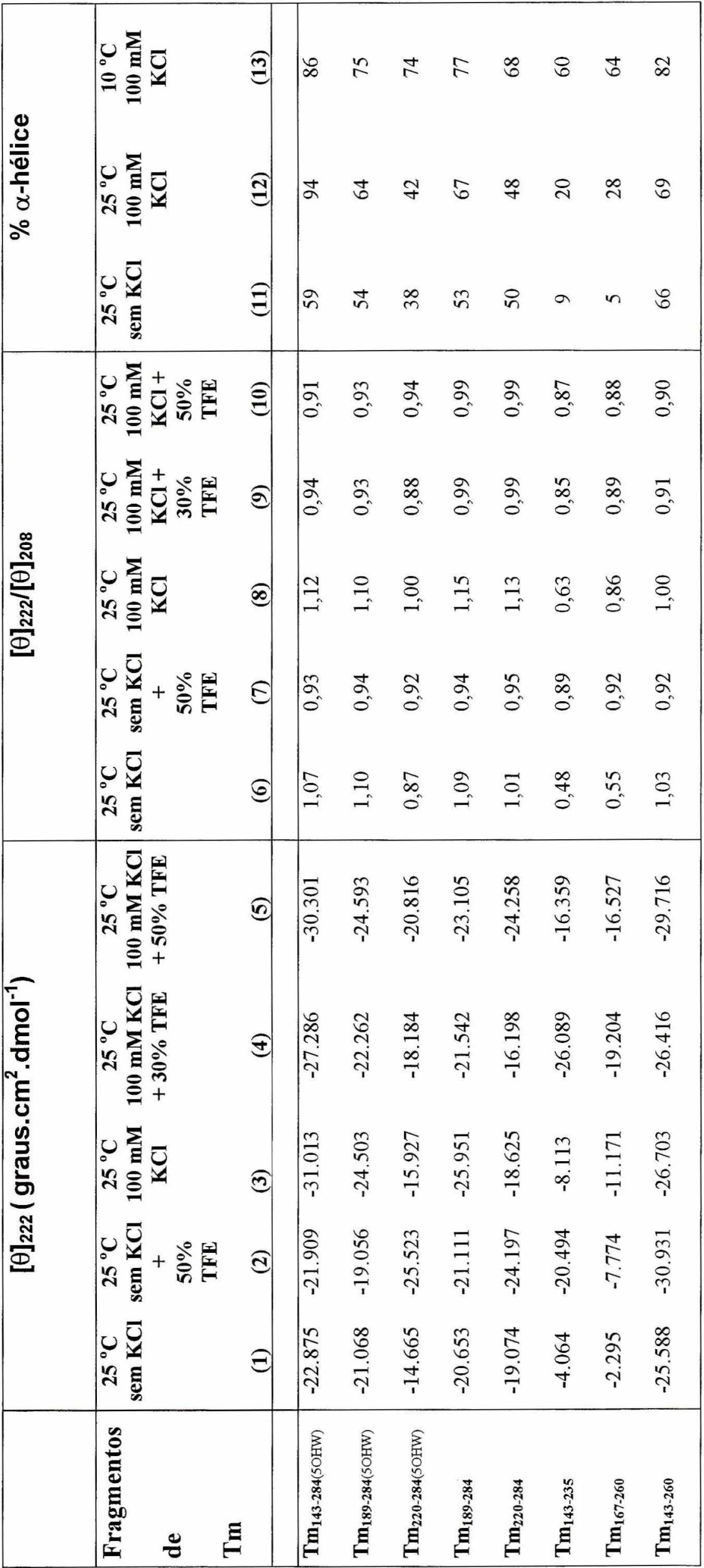




\section{2- Estado de oligomerização dos fragmentos de Tm}

A razão entre os mínimos de elipticidade em 222nm e em 208nm $\left(\theta_{222} / \theta_{208}\right)$ tem sido proposta como uma função do estado de oligomerização de proteínas "coiled-coil", sendo maior que 1 quando a proteína se encontra dimerizada e menor que 1 quando a proteína "coiled-coil" se encontra dissociada (Lau et al., 1984; Zhou et al., 1992a; Monera et al., 1993; Zhou et al., 1994a) . A razão $\theta_{222} / \theta_{208}$ para todos os fragmentos, exceto para $\operatorname{Tm}_{143-235} \mathrm{e}$ $\mathrm{Tm}_{167-260}$, os quais não apresentam muita estrutura secundária sob estas condições, é maior ou igual a 1,0 (ver Tabela 6) na ausência de TFE. Já na presença de $50 \%$ (v/v) TFE, o valor de $\theta_{222} / \theta_{208}$ é reduzido para valores abaixo da unidade.

Para uma melhor caracterização conformacional dos fragmentos recombinantes tanto na presença quanto na ausência de TFE, nós decidimos investigar o estado de oligomerização dos fragmentos recombinantes da região $\mathrm{C}$-terminal da $\mathrm{Tm}$ através da técnica de ultracentrifugação analítica (AUC) sob uma variedade de condições. Experimentos de equilíbrio de sedimentação nos permitiram calcular a massa molecular aparente para cada uma das proteínas recombinantes nas condições desejadas. A Figura 23 mostra as curvas para o experimento de equilíbrio de sedimentação da $\operatorname{Tm}_{220}$ $284(50 \mathrm{HW}$ ) em tampão fosfato (acrescidos de $\mathrm{NaCl}$ para $100 \mathrm{mM}$ finais) com e sem TFE ou na presença de $5 \mathrm{M}$ de uréia. Para este fragmento, os dados em cada caso podem ser ajustados para um modelo de espécies simples, onde aparecem dímeros em tampão fosfato, monômeros na presença de $5 \mathrm{M}$ de uréia e trímeros na presença de TFE.

Nós havíamos determinado previamente que todos os fragmentos de Tm se encontravam desenovelados em $5 \mathrm{M}$ de uréia, como será mostrado adiante. Analisando a Tabela 7, podemos ver que todas as proteínas apresentam uma massa molecular aparente (coluna 3) próxima daquela estimada teoricamente para apenas uma das cadeias polipeptídicas de cada 
fragmento (coluna 5) quando em $5 \mathrm{M}$ de uréia. Estes resultados indicam que os fragmentos se encontram na sua forma monomérica nestas condições.

Uma análise da coluna 1 da Tabela 7 mostra que todos os fragmentos contendo os últimos 24 resíduos C-terminais (261-284) da molécula de Tm

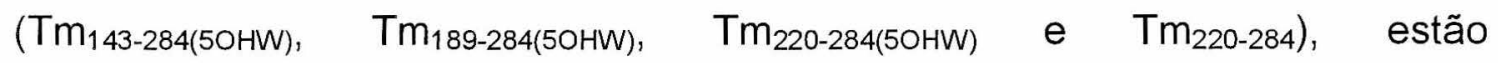
completamente dimerizados a $10 \mu \mathrm{M}$ (concentração determinada considerando-se a proteína como um dímero) em tampão fosfato contendo $100 \mathrm{mM}$ de $\mathrm{NaCl}$. Já os fragmentos que não possuem esta região ( $\mathrm{Tm}_{143-235}$, $\mathrm{Tm}_{143-260}$ e $\mathrm{Tm}_{167-260}$ ) apresentam-se em um equilíbrio entre monômero-dímero nas mesmas condições (Tabela 7). Estes últimos fragmentos apresentaram-se dimerizados (ou quase completamente dimerizados no caso da $\operatorname{Tm}_{143-260}$ ) em concentrações maiores (variando de $100 \mu \mathrm{M}$ até $140 \mu \mathrm{M}$ de acordo com o fragmento; ver coluna 2 da Ver Tabela 7). Esta dependência da concentração é consistente com a dimerização.

Experimentos de AUC realizados na presença de 30\% (v/v) TFE com a proteína numa concentração de $10 \mu \mathrm{M}$ (considerando-a como um dímero) mostraram que os fragmentos que possuem os resíduos 261-284 formam trímeros estáveis (ver Tabela 7, coluna 4). Nesta mesma condição, os fragmentos que não possuem esta região apresentam uma massa molecular aparente significantemente menor do que a esperada para um trímero (ver tabela 7). Os dados obtidos para $\operatorname{Tm}_{143-235}$ são mais bem ajustados para um modelo de dímero, enquanto que os dados obtidos para $\operatorname{Tm}_{143-260}$ e $T m_{167-260}$ são mais bem ajustados assumindo-se uma mistura de monômeros e dímeros ou uma mistura de monômero e trímeros. Para estes dois fragmentos, os dados de AUC ajustam-se igualmente bem para um equilíbrio monômerodímero ou monômero-trímero e, portanto, a formação de trímeros não pode ser descartada. Desta maneira, nós observamos que a tendência para formar trímeros na presença do TFE não é só uma função da estabilidade da "coiledcoil", já que o segundo maior fragmento e que apresenta um alto conteúdo de estrutura em $\alpha$-hélice, $\operatorname{Tm}_{143-260}$, não se encontra completamente na forma de trímeros nestas condições. (ver Tabela 7). A formação de trímeros também 
não deve ser atribuída à presença da sonda $5 \mathrm{OHW}$ na posição 278 em vez de uma leucina, já que o fragmento controle $\mathrm{Tm}_{220-284}$ também forma trímeros na presença de $30 \%(\mathrm{v} / \mathrm{v})$ de TFE (Tabela 7). A maneira pela qual o TFE está induzindo a formação de trímeros nestes fragmentos não é clara, mas estes resultados serão discutidos em detalhe na parte de discussão deste trabalho.

Em conjunto, os resultados de AUC e de CD indicam que, pelo menos no caso dos polipeptídeos derivados da região $\mathrm{C}$-terminal da $\mathrm{Tm}$, a inversão da razão $\theta_{222} / \theta_{208}$ induzida por TFE não está associada a uma transição de "coiled-coil" para o monômero de $\alpha$-hélice, mas deve de fato estar associada a mudanças conformacionais sutis na estrutura $\alpha$-hélice (Holtzer e Holtzer, 1995). 

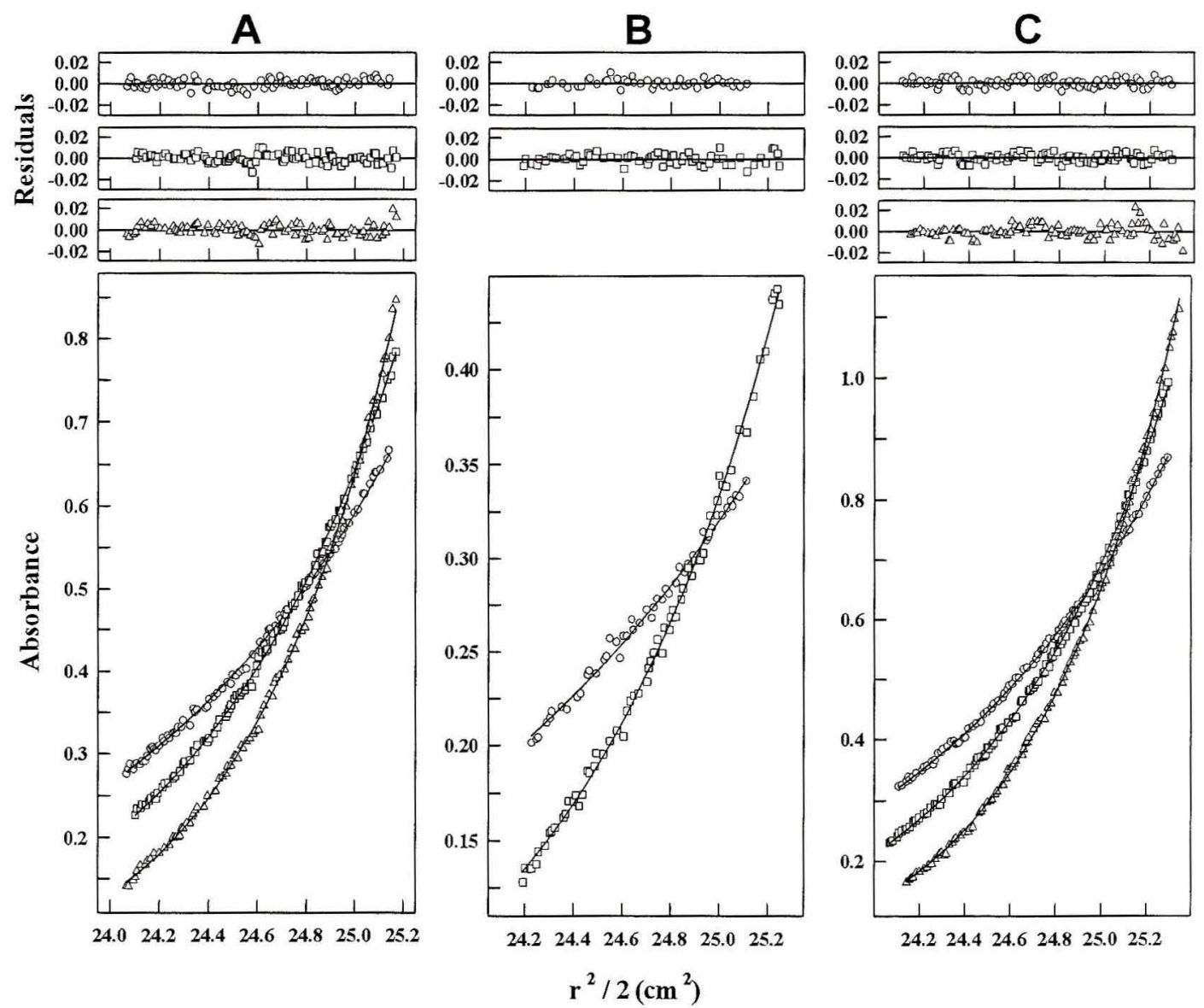

Figura 23 - Dados de equilíbrio de sedimentação para $T_{220-284(50 H m)}$ coletados em diferentes condições a $10^{\circ} \mathrm{C}$. Os gráficos inferiores ilustram os valores de absorbância versus $r^{2} / 2-o s$ símbolos representam os pontos dos dados medidos experimentalmente e as linhas representam os ajustes das curvas com base no modelo de espécies simples (dímeros em $\boldsymbol{A}$, trimeros em $\boldsymbol{B}$ e monômeros em $\boldsymbol{C}$ ). Os gráficos superiores ilustram os residuais obtidos a partir dos ajustes dos pontos experimentais com base no modelo de espécies simples. Uma distribuição randômica, não sistemática, dos residuais indica um bom ajuste dos dados aos modelos. Condições: A) $50 \mathrm{mM}$ fosfato de sódio, $\mathrm{pH}$ 7,0, $100 \mathrm{mM}$ de $\mathrm{NaCl}, 0,5 \mathrm{mM}$ de EDTA e $1 \mathrm{mM}$ de DTT, concentração protéica usada: $10 \mu \mathrm{M}$; círculos - $20.000 \mathrm{rpm}$; quadrados $24.000 \mathrm{rpm}$; triângulos - $28.000 \mathrm{rpm}$. B) Mesmo tampão usado em A, acrescido de TFE para $30 \%$ (V/V) finais; concentração protéica: $10 \mu \mathrm{M}$; círculos - $20.000 \mathrm{rpm}$; quadrados - 28,000 $\mathrm{rpm}$. C) Mesmo tampão usado em $A$, acrescido de uréia para $5 \mathrm{M}$ finais; concentração protéica: $44 \mu \mathrm{M}$; círculos - $32.000 \mathrm{rpm}$; quadrados - $38.000 \mathrm{rpm}$; triângulos $-44.000 \mathrm{rpm}$. 
Tabela 7- Ultracentrifugação analítica para os fragmentos recombinantes de Tm.

Valores da massa molecular aparente $\left(\mathrm{MW}_{\text {app }}\right)$ calculados a partir de experimentos de equilíbrio de sedimentação a $10^{\circ} \mathrm{C}$ em $50 \mathrm{mM}$ fosfato de sódio $(\mathrm{pH} 7,0), 100 \mathrm{mM}$ de $\mathrm{NaCl}, 0,5 \mathrm{mM}$ de DTT e $0,5 \mathrm{mM}$ de EDTA. O melhor ajuste para as espécies dominantes ou equilíbrio entre misturas presentes em cada condição está indicado entre parênteses: $M$ (monômero), D (dímero), T (trímero). (1) $M W_{\text {app }}$ para todas as proteínas a $10 \mu \mathrm{M}$ (concentração do dímero). (2) $\mathrm{MW}_{\mathrm{app}}$ em concentrações maiores: $\mathrm{Tm}_{143-284(50 H \mathrm{H})}$ $(73 \mu \mathrm{M}), \mathrm{Tm}_{189-284(5 \mathrm{OHW})}(82 \mu \mathrm{M}), \mathrm{Tm}_{220-284(50 \mathrm{OH})}(100 \mu \mathrm{M}), \mathrm{Tm}_{143-235}(100 \mu \mathrm{M}), \mathrm{Tm}_{167-260}(140 \mu \mathrm{M}), \mathrm{Tm}_{143-260}$ $(100 \mu \mathrm{M})$. (3) $\mathrm{MW}_{\text {app }}$ em $5 \mathrm{M}$ de uréia nas seguintes concentrações (considerando a proteína como um dímero): $\operatorname{Tm}_{143-284(5 \mathrm{OH})}(22 \mu \mathrm{M}), \mathrm{Tm}_{189-284(5 \mathrm{OHW})}(23 \mu \mathrm{M}), \mathrm{Tm}_{220-284(5 \mathrm{OHW})}(44 \mu \mathrm{M}), \mathrm{Tm}_{143-235}(64 \mu \mathrm{M}), \mathrm{Tm}_{167-260}$ $(100 \mu \mathrm{M}), \mathrm{Tm}_{143-260}(79 \mu \mathrm{M})$. (4) $\mathrm{MW}_{\text {app }}$ para todas as proteínas $(10 \mu \mathrm{M}$ do dímero) na presença de $30 \%$ $(\mathrm{v} / \mathrm{v})$ de TFE. (5) Massa molecular aparente teórica calculada ( $\left.\mathrm{MW}_{\text {calc }}\right)$.

\begin{tabular}{|c|c|c|c|c|c|}
\hline & \multicolumn{4}{|c|}{$\mathrm{MW}_{\mathrm{app}}(\mathrm{kDa})^{*}$} & $\begin{array}{l}\mathrm{MW}_{\text {calc }} \\
(\mathrm{kDa})\end{array}$ \\
\hline $\begin{array}{l}\text { Fragmento de } \\
\text { Tm }\end{array}$ & $\begin{array}{c}10 \mu M \\
(1)\end{array}$ & $\begin{array}{c}\text { Maiores } \\
\text { concentrações } \\
\text { (2) }\end{array}$ & $\begin{array}{c}+5 M \text { de urea } \\
\text { (3) }\end{array}$ & $\begin{array}{c}+30 \% \text { de } T F E \\
\text { (4) }\end{array}$ & (5) \\
\hline $\operatorname{Tm}_{143-284(50 н W)}$ & $\begin{array}{l}35,71 \text { (D) } \\
(+/-1,67)\end{array}$ & $\begin{array}{l}33,45 \text { (D) } \\
(+/-1,38)\end{array}$ & $\begin{array}{l}16,96(\mathrm{M}) \\
(+/-0,50)\end{array}$ & $\begin{array}{l}49,12(\mathrm{~T}) \\
(+/-2,80)\end{array}$ & 16,68 \\
\hline $\mathrm{Tm}_{189-284(\text { (5ОНW) }}$ & $\begin{array}{l}25,36 \text { (D) } \\
(+/-2,24)\end{array}$ & $\begin{array}{l}25,04 \text { (D) } \\
(+/-1,27)\end{array}$ & $\begin{array}{c}13,08 \text { (M-D) } \\
(+/-0,27)\end{array}$ & $\begin{array}{l}33,53(\mathrm{~T}) \\
(+/-0,74)\end{array}$ & 11,36 \\
\hline $\operatorname{Tm}_{220-284(50 H W)}$ & $\begin{array}{l}16,60 \text { (D) } \\
(+/-0,23)\end{array}$ & $\begin{array}{l}17,35 \text { (D) } \\
(+/-0,82)\end{array}$ & $\begin{array}{l}8,32(\mathrm{M}) \\
(+/-0,43)\end{array}$ & $\begin{array}{l}19,00(\mathrm{~T}) \\
(+/-0,69)\end{array}$ & 7,81 \\
\hline $\operatorname{Tm}_{220-284}$ & $\begin{array}{l}16,48 \text { (D) } \\
(+/-0,24)\end{array}$ & ----- & ---- & $\begin{array}{l}22,45(\mathrm{~T}) \\
(+/-0,33)\end{array}$ & 7,60 \\
\hline $\mathbf{T m}_{143-235}$ & $\begin{array}{c}17,44(M-D) \\
(+/-0,48)\end{array}$ & $\begin{array}{l}22,96 \text { (D) } \\
(+/-1,36)\end{array}$ & $\begin{array}{l}11,50(\mathrm{M}) \\
(+/-0,90)\end{array}$ & $\begin{array}{l}22,82(\mathrm{D}) \\
(+/-0,42)\end{array}$ & 10,93 \\
\hline $\mathbf{T m}_{167-260}$ & $\begin{array}{c}17,74(\mathrm{M}-\mathrm{D}) \\
(+/-0,62)\end{array}$ & $\begin{array}{l}21,90 \text { (D) } \\
(+/-1,11)\end{array}$ & $\begin{array}{l}10,87(\mathrm{M}) \\
(+/-0,35)\end{array}$ & $\begin{array}{c}21,66 \\
(\mathrm{M}-\mathrm{D} \text { or } \mathrm{M}-\mathrm{T}) \\
(+/-0,72)\end{array}$ & 11,05 \\
\hline $\mathbf{T m}_{143-260}$ & $\begin{array}{c}17,62(\mathrm{M}-\mathrm{D}) \\
(+/-0,71)\end{array}$ & $\begin{array}{c}22,37 \text { (M-D) } \\
(+/-1,26)\end{array}$ & $\begin{array}{l}13,46(\mathrm{M}) \\
(+/-0,88)\end{array}$ & $\begin{array}{c}17,79 \\
(\mathrm{M}-\mathrm{D} \text { or } \mathrm{M}-\mathrm{T}) \\
(+/-0,95)\end{array}$ & 13,84 \\
\hline
\end{tabular}




\section{3- Estudos da estabilidade conformacional dos fragmentos de Tm}

A análise da estabilidade conformacional dos fragmentos recombinantes de Tm foi realizada em mais detalhe através do desenovelamento induzido por uréia acompanhado por dicroísmo circular em $222 \mathrm{~nm}$. Estes experimentos foram realizados em tampão fosfato contendo $100 \mathrm{mM}$ de $\mathrm{KCl}$ e a $10^{\circ} \mathrm{C}$. Nós decidimos realizar estes experimentos nestas condições já que os fragmentos menos estáveis apresentaram maior conteúdo de a-hélice a $10^{\circ} \mathrm{C}$ e na presença de $100 \mathrm{mM}$ de $\mathrm{KCl}$ (Tabela 6). As curvas de desnaturação induzidas por uréia estão apresentadas na Figura 24. O enovelamento da $\mathrm{Tm}$ e seus fragmentos é conhecido por ser completamente reversível (Mo et al., 1991). Os dados de desnaturação por uréia foram analisados quantitativamente para que pudéssemos calcular o valor de [uréia] $]_{1 / 2}$, ou seja a concentração de uréia em que $50 \%$ das moléculas se encontram desenoveladas, e o valor de $\mathrm{m}$, uma constante associada com a cooperatividade da transição da curva de desnaturação (ver Tabela 8 e Materiais e Métodos). Quando nós comparamos as curvas de desnaturação de $\operatorname{Tm}_{143-284(50 H W)}$ (142 resíduos), Tm189-284(5OHW) ou Tm 189-284, (96 resíduos) e $\mathrm{Tm}_{220-284(50 H W)}$ ou $\mathrm{Tm}_{220-284}$, (65 resíduos), nós observamos que suas estabilidades relativas, refletidas no valor de [uréia] $]_{1 / 2}$, são dependentes do tamanho. Ou seja, em termos do valor de [uréia] $]_{1 / 2}$ :

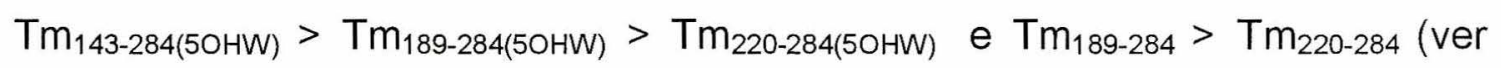
tabela 8 e Figura 24). Todos estes fragmentos possuem os resíduos 261-284, os quais nós identificamos previamente como importantes para dimerização e estabilidade. A substituição da leucina 278 por 5-hidroxitriptofano parece ocasionar um efeito significativo, porém pequeno, na estabilidade dos fragmentos $\mathrm{Tm}_{189-284}$ e $\mathrm{Tm}_{220-284}$. Fazendo-se uma comparação de $\mathrm{Tm}_{189-284}$

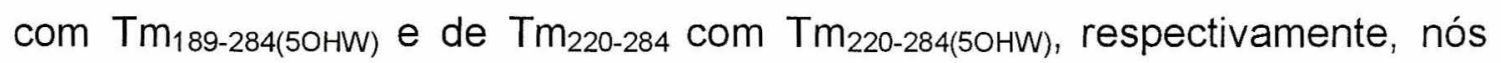
observamos que ambos os fragmentos no estado nativo ( $\operatorname{Tm}_{189-284}$ e $\left.\mathrm{Tm}_{220-284}\right)$ desnaturam com um valor de [uréia $]_{1 / 2}$ 0,4-0,5 M maior que o observado para os fragmentos correspondentes contendo a sonda 5-hidroxitriptofano ( $\operatorname{Tm}_{189-}$ $284(50 H W)$ e $\mathrm{Tm}_{220-284(50 H W)}$ ) (ver Figura 25; Tabela 8). Ainda não possuímos 
suficientes evidências na literatura para dizer se o 5-hidroxitriptofano estabiliza ou desestabiliza $\alpha$-hélices com respeito a leucina. $\mathrm{Na}$ Tm, o resíduo 278 ocupa uma posição e dentro da repetição heptapeptídica. A posição e em "coiledcoils" canônicas, como já foi mencionado anteriormente, é freqüentemente ocupada por resíduos carregados, que formam contatos com os resíduos das posições g' (i-5) da fita vizinha na estrutura "coiled-coil" de dupla fita, neste caso um ácido glutâmico $\left(\mathrm{Glu}^{273}\right)$. Já que tanto a leucina quanto o 5hidroxitriptofano são resíduos não carregados e desde que a região $\mathrm{C}$-terminal da Tm pode não ser uma "coiled-coil" canônica (ver Introdução e Discussão, Li et al., 2002; Greenfield et al., 2003) para nós não fica evidente a base molecular precisa das diferenças em estabilidade observadas entre os fragmentos nativos e aqueles contendo a sonda $5 \mathrm{OHW}$ na posição 278 .

A comparação das curvas de desnaturação de fragmentos contendo o mesmo tamanho, porém compreendendo porções diferentes da metade Cterminal da molécula de $T \mathrm{~m}, \mathrm{Tm}_{143-235}$ (93 resíduos), $\operatorname{Tm}_{167-260}$ (94 resíduos) e

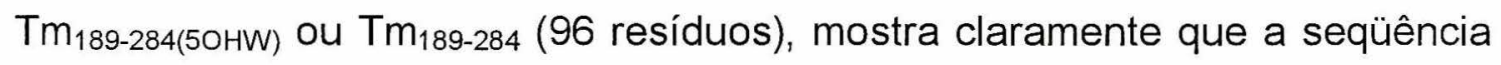
específica de aminoácidos é muito importante para a estabilidade conformacional dos fragmentos C-terminais de Tm. Além disto, esta estabilidade aumenta conforme as seqüências analisadas "movem-se" em direção as regiões C-terminal da molécula. Ou seja, em termos do valor de [uréia] $]_{1 / 2}: T m_{189-284}>\operatorname{Tm}_{167-260}>\operatorname{Tm}_{143-235}$ (ver tabela 8 e Figura 24). Esses resultados estão consistentes com os conteúdos de a-hélice observados para as proteínas na presença de $100 \mathrm{mM}$ de $\mathrm{KCl}$ a $25^{\circ} \mathrm{C}$. Esses experimentos de desnaturação novamente mostram que $\operatorname{Tm}_{143-235}$ é o fragmento de $\mathrm{Tm}$ menos estável e, embora os fragmentos $\mathrm{Tm}_{220-284(50 \mathrm{HW})}$ e $\mathrm{Tm}_{220-284}$ possuam um pequeno tamanho eles apresentam um valor de [uréia] $]_{1 / 2}(1,17 \mathrm{M}$ e $1,57 \mathrm{M}$, respectivamente) maior que 0 da $\operatorname{Tm}_{143-235}(0,23 \mathrm{M})$ ou o da $\operatorname{Tm}_{167-260}(0,68 \mathrm{M})$ (Tabela 8). 


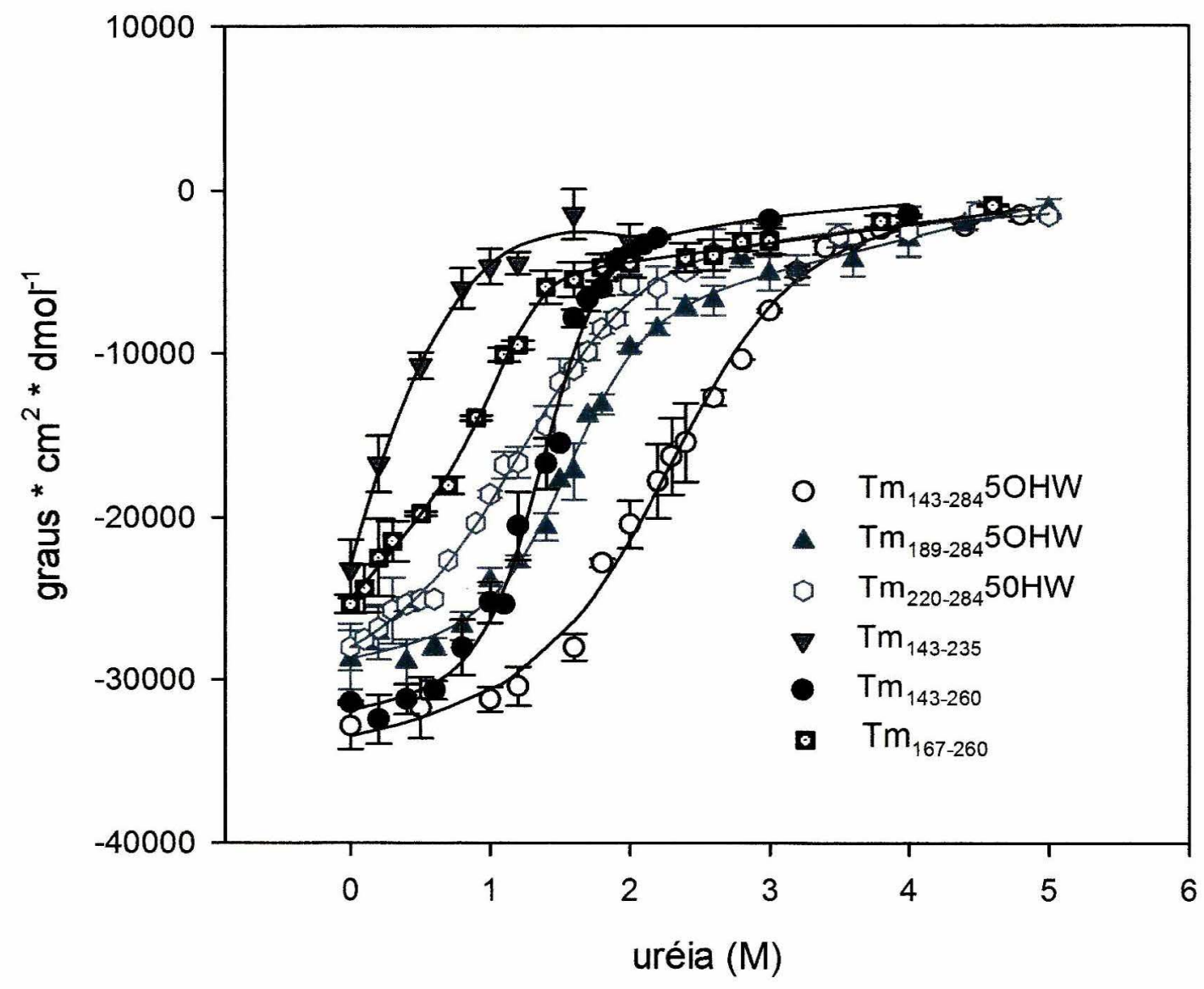

Figura 24 - Desnaturação por uréia dos fragmentos de Tm. Aqui são apresentadas

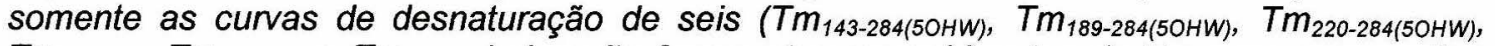
$T m_{143-235}, T m_{167-260}$ e $T m_{143-260}$ ) dos oito fragmentos recombinantes de $T m$ para uma melhor visualização dos gráficos. Os fragmentos controles Tm189-284 e Tm220-284 serão apresentados nas próximas figuras (figuras 25 e 26). Condições: $50 \mathrm{mM}$ de fosfato de sódio (pH 7,0), $100 \mathrm{mM}$ de $\mathrm{NaCl}, 0,5 \mathrm{mM}$ de DTT e 0,5 mM de EDTA, $10{ }^{\circ} \mathrm{C}$. 
Tabela 8 - Parâmetros determinados a partir da curva de desnaturação por uréia para fragmentos C-terminais recombinantes de $\mathrm{Tm}$.

Os valores de $\mathbf{m}$ e [uréia] $]_{1 / 2}$ foram estimados com descrito em Materiais e Métodos. Aqui estão mostrados os valores de $\mathbf{m}$ e [uréia] $]_{1 / 2}$ obtidos a partir das curvas de desnaturação apresentadas na figura 24 . Em parênteses, encontram-se os valores de $\mathbf{m}$ e [uréia] $]_{1 / 2}$ obtidos para experimentos de desnaturação por uréia, acompanhado por fluorescência, para os

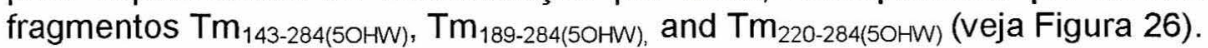

\begin{tabular}{|c|c|c|}
\hline $\begin{array}{l}\text { Fragmentos } \\
\text { de } \\
\text { Tm }\end{array}$ & $\begin{array}{c}\mathbf{m} \\
\left(\mathrm{kcal}^{\mathrm{mol}}{ }^{-1} \cdot \mathrm{M}^{-1}\right)\end{array}$ & $\begin{array}{c}\text { [uréia] }_{1 / 2} \\
\text { (M) }\end{array}$ \\
\hline $\mathbf{T m}_{143-284(5 \mathrm{OHW})}$ & $1,5(1,9)$ & $2,29(2,16)$ \\
\hline $\mathbf{T m}_{189-284(5 \mathrm{OHW})}$ & $2,0(1,9)$ & $1,55(1,37)$ \\
\hline $\mathbf{T m}_{220-284(5 \mathrm{OHW})}$ & $1,4(1,9)$ & $1,17(1,36)$ \\
\hline $\mathrm{Tm}_{189-284}$ & 1,7 & 2,06 \\
\hline $\mathbf{T m}_{220-284}$ & 1,3 & 1,57 \\
\hline $\mathbf{T m}_{143-235}$ & 2,4 & 0,23 \\
\hline$T m_{167-260}$ & 1,3 & 0,68 \\
\hline $\operatorname{Tm}_{143-260}$ & 3,0 & 1,35 \\
\hline
\end{tabular}

Uma inspeção das curvas de desnaturação na Figura 24 mostra que os valores para as cooperatividades (refletidas no valor de $\mathbf{m}$, Tabela 8 ) das transições de desnaturação variam de fragmento para fragmento. Uma comparação entre os valores de $\mathrm{m}$ obtidos para fragmentos similares contendo leucina ou 5-hidroxitriptofano na posição 278 mostra valores próximos. Entretanto, quando nós comparamos os dados para $\operatorname{Tm}_{143-284(5 \mathrm{OHW})}$ e $\operatorname{Tm}_{143-260}$, o qual não contém apenas os últimos 24 aminoácidos da molécula de Tm, nós percebemos que a ausência dos resíduos 261-284 promove um aumento significatico no valor de $\mathbf{m}$ (de 1,5 para $3,0 \mathrm{kcal}^{\mathrm{mol}}{ }^{-1} \mathrm{M}^{-1}$ ), indicando um aumento na cooperatividade da curva de desnaturação, que é bem evidente na Figura 24 (ver também Tabela 8). O fragmento Tm $143-235$ também desnatura com alta cooperatividade $\left(m=2,4 \mathrm{kcal} \cdot \mathrm{mol}^{-1} \cdot \mathrm{M}^{-1}\right)$ enquanto que $\mathrm{Tm}_{167-260}$ apresenta um baixo valor para $\mathbf{m}\left(1,3 \mathrm{kcal}^{\mathrm{mol}} \mathrm{l}^{-1} \mathrm{M}^{-1}\right)$. 
Nós devemos notar que os valores calculados de $\mathrm{m}$ para estes dois últimos fragmentos menos estáveis $\left(\operatorname{Tm}_{143-235}\right.$ e $\left.\operatorname{Tm}_{167-260}\right)$ não devem ser muito precisos, já que os fragmentos se encontram parcialmente desenovelados (Figura 24) e não completamente dimerizados (Tabela 7) na ausência de uréia. Desta maneira, os dados necessários para estimarmos precisamente os valores de $\mathbf{m}$ neste caso não são suficientes. Portanto aqui neste trabalho nós nos ativemos a comparar o valor da cooperatividade entre fragmentos com as linhas-base de pré- e de pós-transição relativamente bem definidas como é o caso dos dois fragmentos maiores, $\operatorname{Tm}_{143-284(50 H W)}$ e $\mathrm{Tm}_{143-260}$. Neste caso, fica claro que o fragmento que contém os resíduos 261-284 desnatura menos cooperativamente que o fragmento que não contém esta região. Este comportamento pode indicar a presença de intermediários de enovelamento como será discutido adiante. 
A

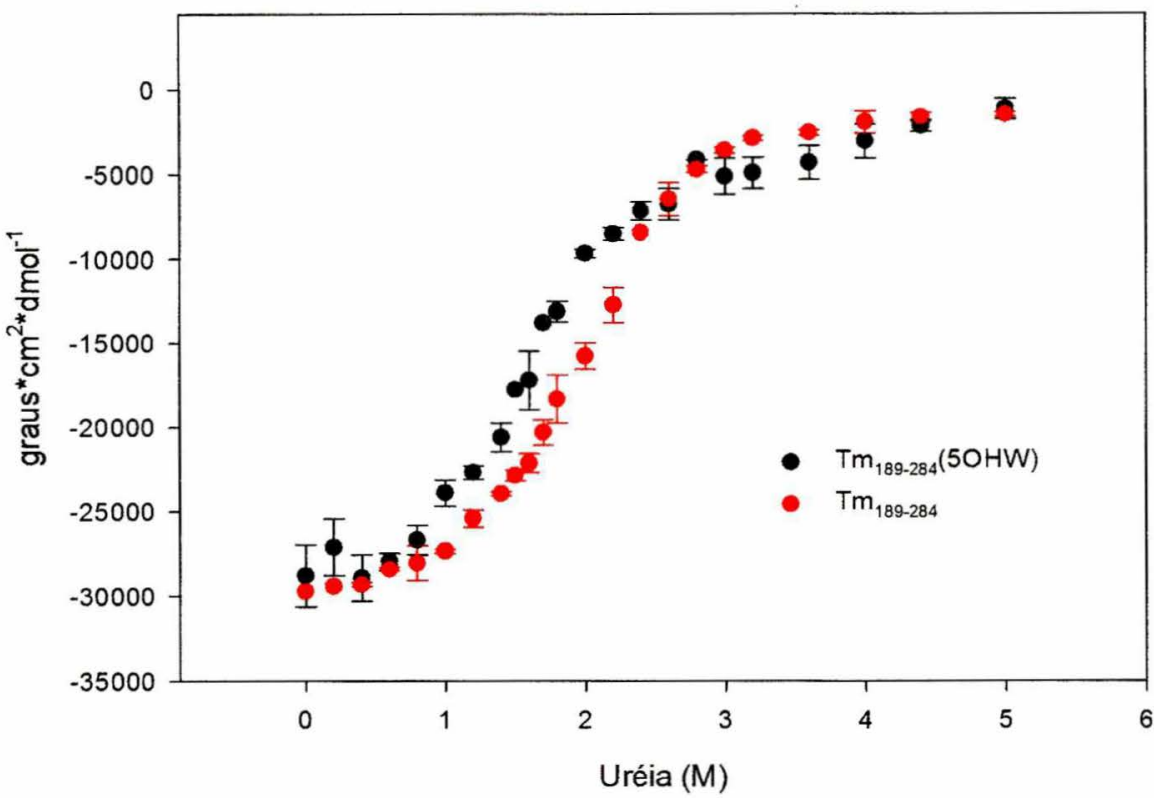

B

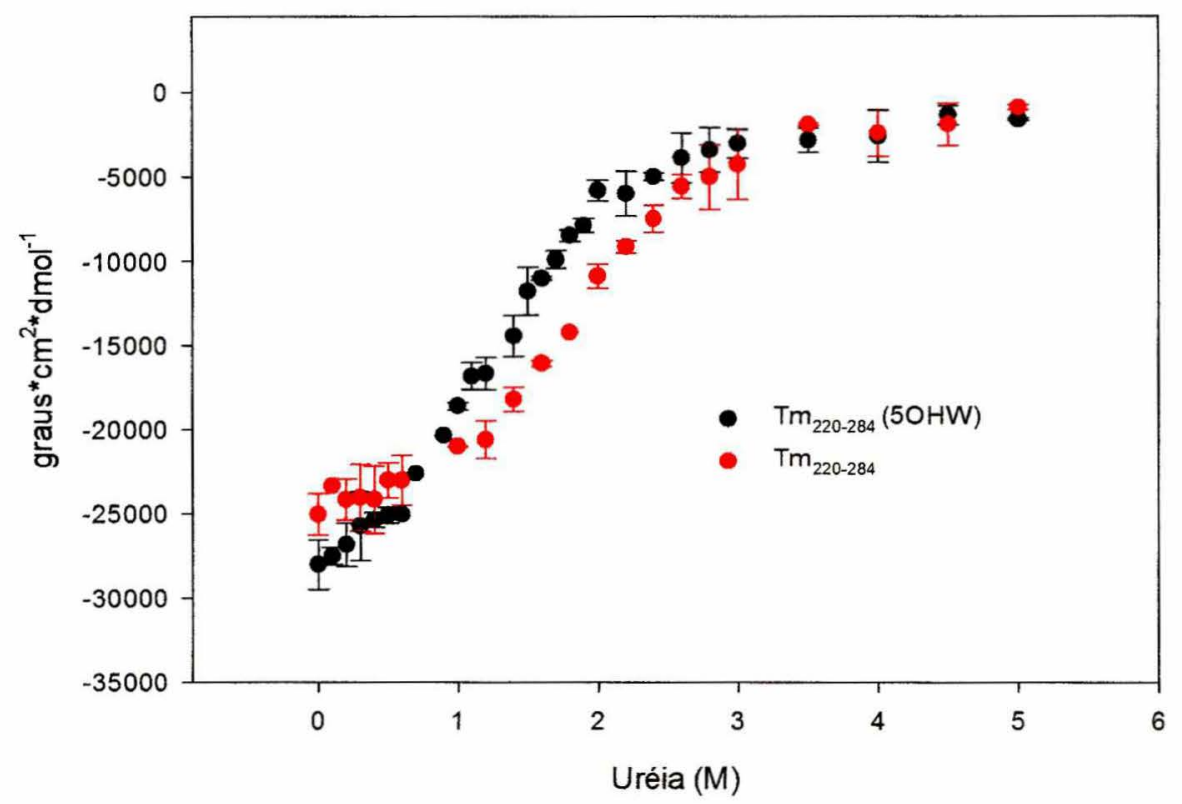

Figura 25 - Curvas de desnaturação por uréia dos fragmentos controles (sem a sonda fluorescente $50 H W$ na posição 278) comparadas com as curvas dos respectivos fragmentos contendo a sonda. A) $T m_{189-284}$ e B) $T m_{220-284}$. As condições do experimento são as mesmas que as da Figura 24. 
A desnaturação por uréia dos fragmentos $\left.\operatorname{Tm}_{143-284(50 H W)}, \operatorname{Tm}_{189-284(50 H W}\right)$ e $\mathrm{Tm}_{220-284(50 \mathrm{HW})}$ foi monitorada também através de mudanças na intensidade de fluorescência da sonda 5OHW na posição 278 (ver Figura 26). A figura mostra o progresso da transição em cada concentração de uréia. A fração de proteína enovelada, $F_{f}$ (do inglês "fraction folded", ver Materiais e Métodos) foi calculada e comparada com aquelas obtidas através dos experimentos de CD (Figura 26). Da mesma maneira que os experimentos de CD refletem a média dos estados conformacionais da cadeia polipeptídica, os dados de fluorescência são sensíveis ao micro-ambiente da sonda em condições específicas. Os resultados de desnaturação acompanhados por fluorescência mostram que $\mathrm{o}$ fragmento $\mathrm{Tm}_{143-284(5 \mathrm{OHW})}$ é mais estável que $\mathrm{Tm}_{189-284(5 \mathrm{OHW})}$ e $\mathrm{Tm}_{220-284(5 \mathrm{OHW})}$ da mesma forma que os resultados obtidos por CD. Os dados de fluorescência, entretanto, não refletem as diferenças nas estabilidades que foram observadas para $\mathrm{Tm}_{189-284(5 \mathrm{OHW})}$ e $\mathrm{Tm}_{220-284(5 \mathrm{OHW})}$ nos experimentos de desnaturação por uréia acompanhados por CD (Figura 24, Tabela 8). As curvas de desnaturação acompanhadas por fluorescência para $\operatorname{Tm}_{189-284(50 H W)}$ e $\operatorname{Tm}_{220-284(50 H W)}$ (valores de [uréia] $1 / 2$ iguais a 1,37 e 1,36, respectivamente) são praticamente sobreponíveis, ao passo que as curvas de desnaturação dos mesmos fragmentos acompanhadas por CD são distintas e apresentam valores de [uréia] $]_{1 / 2}$ de 1,55 e 1,17 M, respectivamente (Tabela 8). Além disso, como já mencionado anteriormente, os valores de $\mathbf{m}$ para os experimentos de fluorescência foram similares mas não iguais àqueles obtidos pelos experimentos de desnaturação por $\mathrm{CD}$, principalmente para o fragmento $\mathrm{Tm}_{143}$ $284(5 \mathrm{OHW})$ que apresenta linhas base de pos- e pré- transição bem definidas (ver Tabela 8). No caso de uma transição de dois estados, nós deveríamos esperar que os espectros de $C D$ e fluorescência fossem sobreponíveis. A não sobreposição das curvas monitoradas por diferentes métodos pode ser interpretada como uma evidência de que existam de intermediários estáveis ou meta-estáveis. Desta forma, a presença de intermediários poderia explicar as diferenças na cooperatividade de transição observada para os experimentos 
de desnaturação acompanhados por CD. Este fenômeno será discutido em maior detalhe na Discussão.

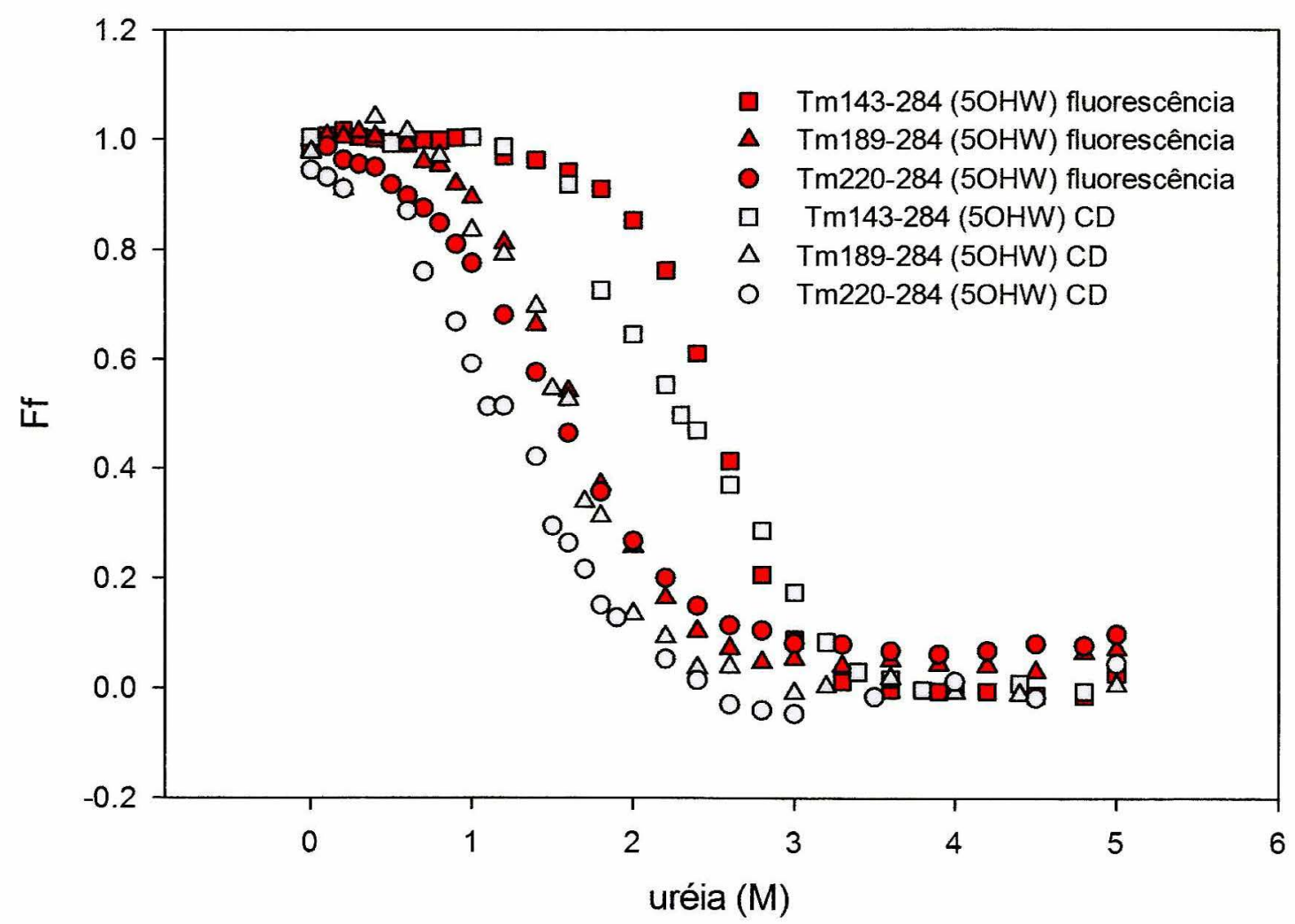

Figura 26 - Comparação das curvas de desnaturação por uréia para $T m_{143-284(50 H W),} T m_{189-}$ ${ }_{284(50 \mathrm{HW})}$ e $\mathrm{Tm}_{220-284(5 \mathrm{OHW})}$ determinadas por fluorescência (curvas vermelhas) e por $C D$ (curvas cinza). Para comparação nós mostramos a fração de proteína enovelada (Ff, do inglês "fraction folded") onde $F f=\left(Y-Y_{u}\right) /\left(Y_{f}-Y_{u}\right)$. Veja Meteriais e Métodos. 


\section{4- Caracterização da Tm143-235}

Como foi mencionado anteriormente, o fragmento $\operatorname{Tm}_{143-235}$ é particularmente instável quando comparado com outros fragmentos derivados da metade C-terminal da molécula de Tm. Além disso, o conteúdo de $\alpha$-hélice para $\operatorname{Tm}_{143-235}$ é muito sensível a presença de TFE (ver Tabela 6 e Figura 21 e 22). $\mathrm{Em} 100 \mathrm{mM}$ de $\mathrm{KCl}$, a elipticidade residual deste fragmento a $222 \mathrm{~nm}$ varia de -8.113 graus. $\mathrm{cm}^{2}$. dmol ${ }^{-1}$ na ausência de TFE para -16.527 graus. $\mathrm{cm}^{2}$. $\mathrm{dmol}^{-1}$ na presença de $50 \%(\mathrm{v} / \mathrm{v})$ de TFE a $25{ }^{\circ} \mathrm{C}$. Para caracterizar melhor a instabilidade conformacional do fragmento $\operatorname{Tm}_{143-235}$, nós realizamos experimentos de desnaturação térmica monitorados por $C D$, os quais mostram que este fragmento possui uma baixa temperatura de desnaturação $\left(17,4{ }^{\circ} \mathrm{C}\right.$; ver Figura 27), estando extensamente enovelado ( $78 \%$ de estrutura a-hélice) a $5{ }^{\circ} \mathrm{C}$ e desenovelado a $30{ }^{\circ} \mathrm{C}$. Além disto, a elipticidade residual deste fragmento mostrou ser altamente dependente da concentração do peptídeo (Figura $27 \mathrm{~B}$ ), sendo que, a $10^{\circ} \mathrm{C}$, um aumento de 50 vezes na concentração do peptídeo resulta em um significante aumento no conteúdo de $\alpha$-hélice, indicando que o fragmento está se oligomerizando como previamente mostrado pelos experimentos de AUC.

Nós realizamos experimentos de ligação cruzada com glutaraldeído para este mesmo fragmento $\left(\mathrm{Tm}_{143-235}\right)$ em intervalos de $5{ }^{\circ} \mathrm{C}$ entre 10 e $30{ }^{\circ} \mathrm{C}$ como mostrado na Figura $27 \mathrm{C}$. Os dímeros covalentes induzidos pela adição do glutaraldeído podem ser detectados até $25{ }^{\circ} \mathrm{C}$, temperatura em que o fragmento se encontra praticamente desenovelado (Comparar Figura 27A e 27C). 
A

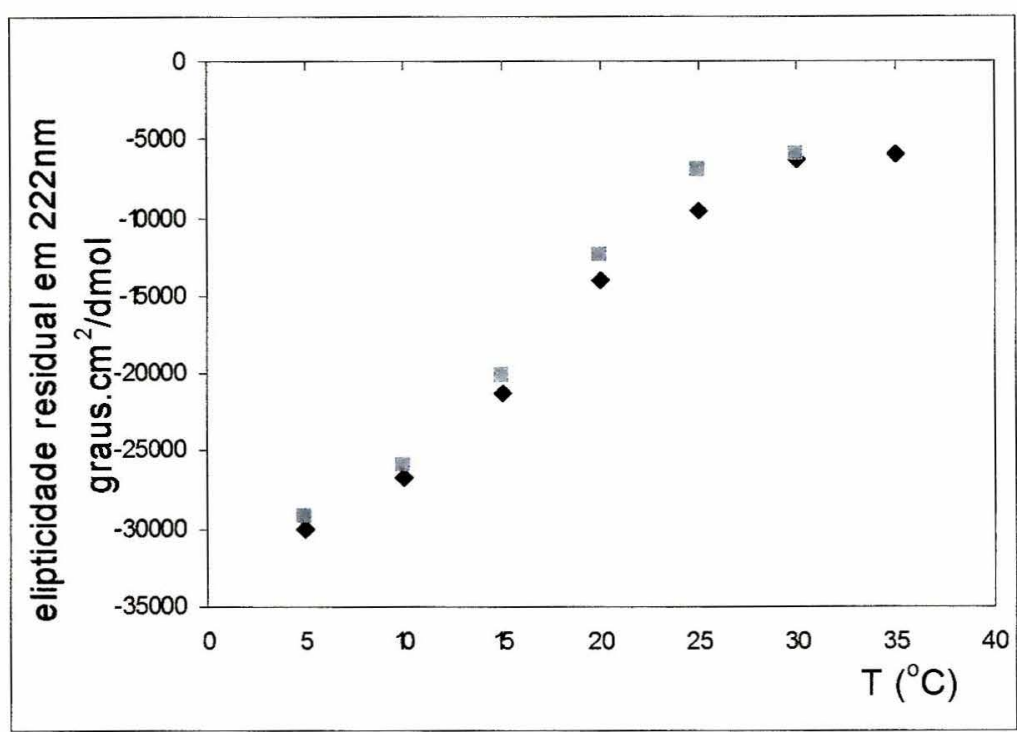

B

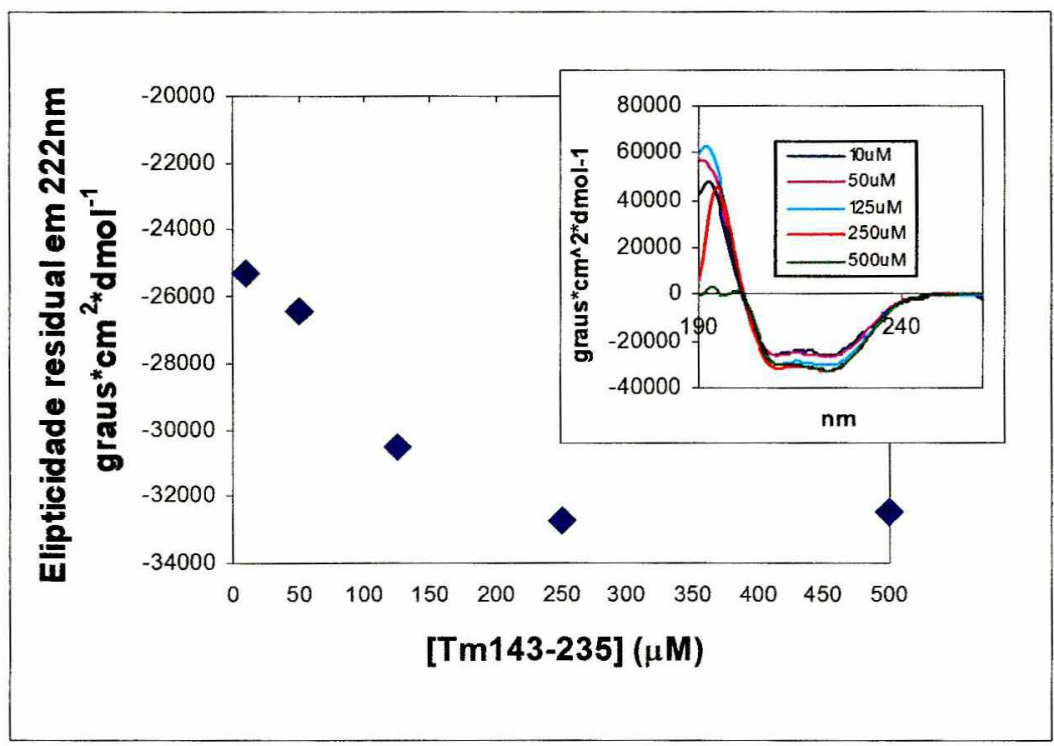

C

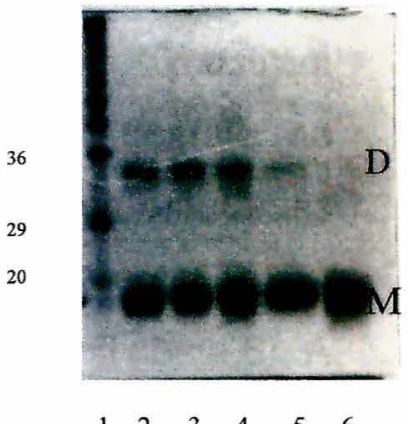

$\begin{array}{llllll}1 & 2 & 3 & 4 & 5 & 6\end{array}$

Figura 27 - A) Elipticidade residual em $222 \mathrm{~nm}$ da $\operatorname{Tm}_{143-235}(10 \mu \mathrm{M}$ do dímero) em função da temperatura. Preto- curva de desnaturação, Cinza- Curva de renaturação. B) Elipticidade residual em $222 \mathrm{~nm}$ em função da concentração da $T_{143-235}$ a $10^{\circ} \mathrm{C}$. C) Experimento de ligação cruzada para $T m_{143-235} \mathrm{com}$ glutaraldeído em função da temperatura. A proteína foi equilibrada por 30 minutos na temperatura desejada, e em seguida, foi tratada com $0,02 \%(\mathrm{~V} / \mathrm{V})$ de glutaraldeído por $15 \mathrm{~min}$. 1: marcador de peso molecular; 2: $\operatorname{Tm}_{143-235}$ a $10^{\circ} \mathrm{C}$; 3: $\operatorname{Tm}_{143-235}$ a $15^{\circ} \mathrm{C}$; 4: $\mathrm{Tm}_{143-235}$ a $20^{\circ} \mathrm{C} ; 5: \mathrm{Tm}_{143-235}$ a $25^{\circ} \mathrm{C}$; $6: \mathrm{Tm}_{143-235}$ a $30^{\circ} \mathrm{C}$. $\boldsymbol{D}=$ dímero, $\boldsymbol{M}=$ monômero. Condições: $50 \mathrm{mM}$ fosfato de sódio $(\mathrm{pH} 7,0), 100 \mathrm{mM}$ de $\mathrm{NaCl}, 0,5 \mathrm{mM}$ de DTT e 0,5 mM de EDTA. 


\section{5- Caracterização do peptídeo Ac-Tm $215-235$}

A relativa instabilidade da $\operatorname{Tm}_{143-235}$ pareceu-nos interessante, já que esta região continha 10 dos 13 primeiros resíduos de uma região consenso mínima que havia sido proposta na literatura como sendo responsável pelo enovelamento autônomo de proteínas "coiled-coil" (Kammerer et al., 1998). Esta seqüência consenso alvo (xxLExc-hxcxccx), onde $\mathbf{x}$ representa qualquer resíduo, h representa resíduos hidrofóficos e c representa um resíduo carregado, corresponde aos aminoácidos 226-238 da Tm (Tabela 9) e é encontrada em todos os nossos fragmentos recombinantes. Desta maneira, nós decidimos sintetizar o peptídeo Ac-Tm $215-235$ com o intuito de testar se a dependência do conteúdo de $\alpha$-hélice apresentado pelo fragmento $\operatorname{Tm}_{143-235}$, em função da sua própria concentração e da concentração de TFE, se devia a uma pequena estrutura bem enovelada que poderia estar se associando para nuclear e estabilizar a formação da estrutura "coiled-coil".

O peptídeo Ac-Tm $215-235$ foi analisado por CD e os resultados mostram que ele assume muito pouca estrutura helicoidal em tampão fosfato na presença de $100 \mathrm{mM}$ de $\mathrm{KCl}$, a $10^{\circ} \mathrm{C}$, em todas as concentrações estudadas (entre 0,1 e 2 mM; Figura 28 A). Nestas condições, o peptídeo parental Tm143235 possui um significante conteúdo de $\alpha$-hélice (60\%; Figura 22 e Tabela 6). A adição de TFE aumenta o conteúdo helicoidal do Ac-Tm215-235 de 0,4\% para 33\% (Figura 28 A e 28 B). Portanto, apesar de os resíduos 215-235 possuírem um potencial intrínseco de formação de estrutura a-hélice, nós não conseguimos levantar nenhuma evidência para o enovelamento autônomo desta região na ausência de TFE. 
A

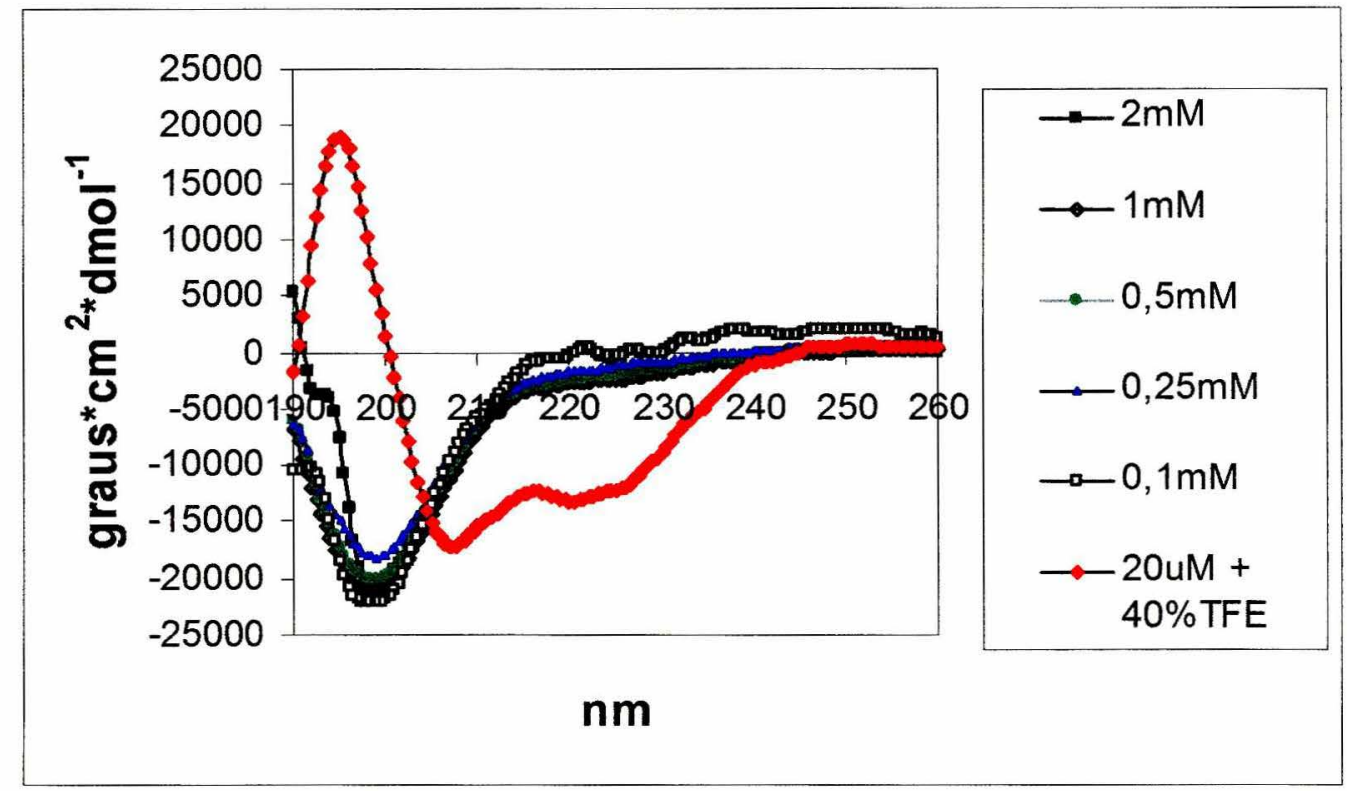

B

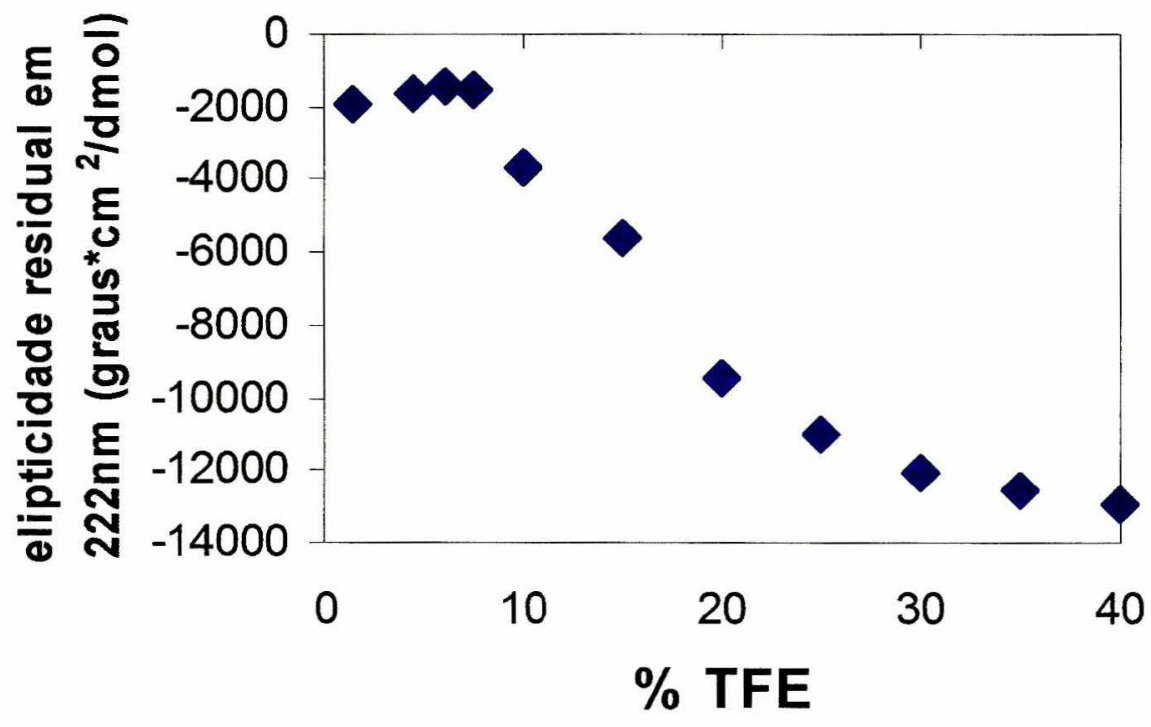

Figura 28 - A) Espectros de CD da Ac-Tm $m_{215-235}$ em diferentes concentrações de proteína (0,1; 0,$25 ; 0,5 ; 1$ e $2 \mathrm{mM}$, como indicado na legenda) e proteína a $20 \mu \mathrm{M}$ em $40 \%$ TFE. B) Elipticidade Residual em $222 \mathrm{~nm}$ para Ac-Tm $215-235(20 \mu \mathrm{M})$ em função da concentração de TFE. Condições: $50 \mathrm{mM}$ fosfato de sódio (pH 7,0), $100 \mathrm{mM}$ de $\mathrm{NaCl}, 0,5 \mathrm{mM}$ de DTT e 0,5 mM de EDTA. 
Tabela 9- Alinhamento da seqüência-consenso alvo proposta por Kammerer et al. (1998) com as seqüências de proteínas "coiled-coil" (dentre elas duas isoformas de Tm e a seqüência do peptídeo sintético Tm215-235 derivado da $\alpha$-Tm de músculo esquelético de galinha). $\mathrm{Na}$ seqüência consenso, $\mathbf{h}$ representa resíduos hidrofóbicos, $\mathbf{c}$ representa residuos carregados $\mathbf{e}$ $\mathbf{x}$ representa qualquer resíduo.

\begin{tabular}{|l|c|}
\hline Posição heptapeptídica & bcdefg abcdefg \\
\hline $\begin{array}{l}\text { Seqüência-consenso (Kammerer } \text { et al., } \\
\text { 1998) }\end{array}$ & xXLExc hxcxccx \\
\hline Cortexilina I & MELEAR LAKTEKD \\
\hline GCN4 & YHLENE VARLKKL \\
\hline Kinesina & QWLENE LNRWRNG \\
\hline Miosina & SELEVR LKKEEKS \\
\hline $\boldsymbol{\beta}$-Tm (Músculo Esquelético Humano) & KLLEEK LKEAETR \\
\hline$\alpha$-Tm (Músculo Esquelético de Galinha) & KVLTDK LKEAETR \\
\hline $\boldsymbol{T m} 215-235$ & SQKEDKYEEEIKVLTDK LKEA \\
\hline
\end{tabular}




\section{6- Estudo da interação cabeça-cauda}

Estudos preliminares haviam mostrado que pequenas modificações nas regiões $\mathrm{N}$ - e C-terminais da $\mathrm{Tm}$, bem como a não acetilação do $\mathrm{N}$ terminal e a deleção de alguns resíduos no $\mathrm{C}$-terminal (mais que três, como descrito na Introdução) aboliam a polimerização e reduziam a afinidade da Tm pela molécula de Ac quando na ausência do complexo Th (Ueno et al., 1976; Mak et al., 1983; Cho et al., 1990; Johnson e Smilie, 1977; Heald et al., 1988; Hitchcock e Heald, 1987). Portanto, quando o nosso grupo de pesquisa decidiu construir duas Tms truncadas no seu C-terminal, nfTm 1-260 e ASTm $_{1-260}$, a primeira sem a acetilação $\mathrm{N}$-terminal e a última com uma fusão dipeptídica Ala-Ser no $\mathrm{N}$-terminal, nós acreditávamos que estas moléculas seriam deficientes no processo de polimerização. Entretanto, para a nossa surpresa, experimentos de viscosidade mostraram que ASTm1-260 era capaz de se polimerizar mais intensamente que a tropomiosina nativa contendo a fusão dipeptídica AS no $\mathrm{N}$-terminal (ASTm). Estes resultados foram apresentados na tese de doutoramento da Dra. Áurea Denise de Sousa.

Os resultados inesperados obtidos para ASTm $_{1-260}$ nos levaram a testar se pequenos fragmentos $\mathrm{N}$-terminais de $\mathrm{Tm}$, com e sem a fusão dipeptídica, seriam capazes de interagir com pequenos fragmentos $\mathrm{C}$ terminais de Tm que terminavam nas posições 284 e 260. Em vez de formarem polímeros, estes complexos, caso fossem formados deveriam produzir dímeros 1:1. Os fragmentos $\mathrm{N}$-terminais escolhidos foram ASTm $_{1-142}$ e nfTm 1 142.

A Figura 29 mostra a viscosidade cinemática de vários fragmentos de $\mathrm{Tm}$ em função da concentração de $\mathrm{NaCl}$. Estes experimentos foram realizados pela aluna de iniciação científica Ângela Mika Katsuyama. Como se pode observar, a viscosidade de $\mathrm{ASTm}_{1-260}$ é muito maior que a viscosidade de ASTm em todas as forças iônicas testadas. Além disso, 
$n f T m_{1-260}$ possui uma viscosidade bem menor que ASTm1-260. A sensibilidade da polimerização de $\mathrm{ASTm}_{1-260}$ à presença ou à ausência da fusão dipeptídica Ala-Ser no amino-terminal mimetiza o efeito observado na Tm recombinante de tamanho integral (nfTm e ASTm; Fig. 29; Monteiro et al., 1994; Sousa e Farah, 2002). Estas observações indicam fortemente que ASTm $_{1-260}$ também polimeriza linearmente através de interações cabeçacauda. Devemos notar ainda que $\mathrm{nfTm}_{1-260}$ mostra um significante grau de polimerização, produzindo soluções menos viscosas que ASTm, porém mais viscosas que $\mathrm{nfTm}$ em baixas concentrações de $\mathrm{NaCl}$ (Figura 29B). Os fragmentos $\operatorname{Tm}_{167-260}$ e $T m_{143-260}$, que terminam na posição 260 e não contêm a região $\mathrm{N}$-terminal da $\mathrm{Tm}$ também não polimerizam, como já havia sido mostrado previamente através dos resultados de ultracentrifugação analítica (ver Tabela 7, Paulucci et al., 2002). A figura 29 também mostra que os fragmentos $\mathrm{N}$-terminais que terminam na posição 142 (ASTm $\left.{ }_{1-142}, \mathrm{nfTm}_{1-142}\right)$ tampouco polimerizam, como esperado. Estas observações acerca do estado de polimerização de cada uma das Tm recombinantes são resumidas na Figura 30. 

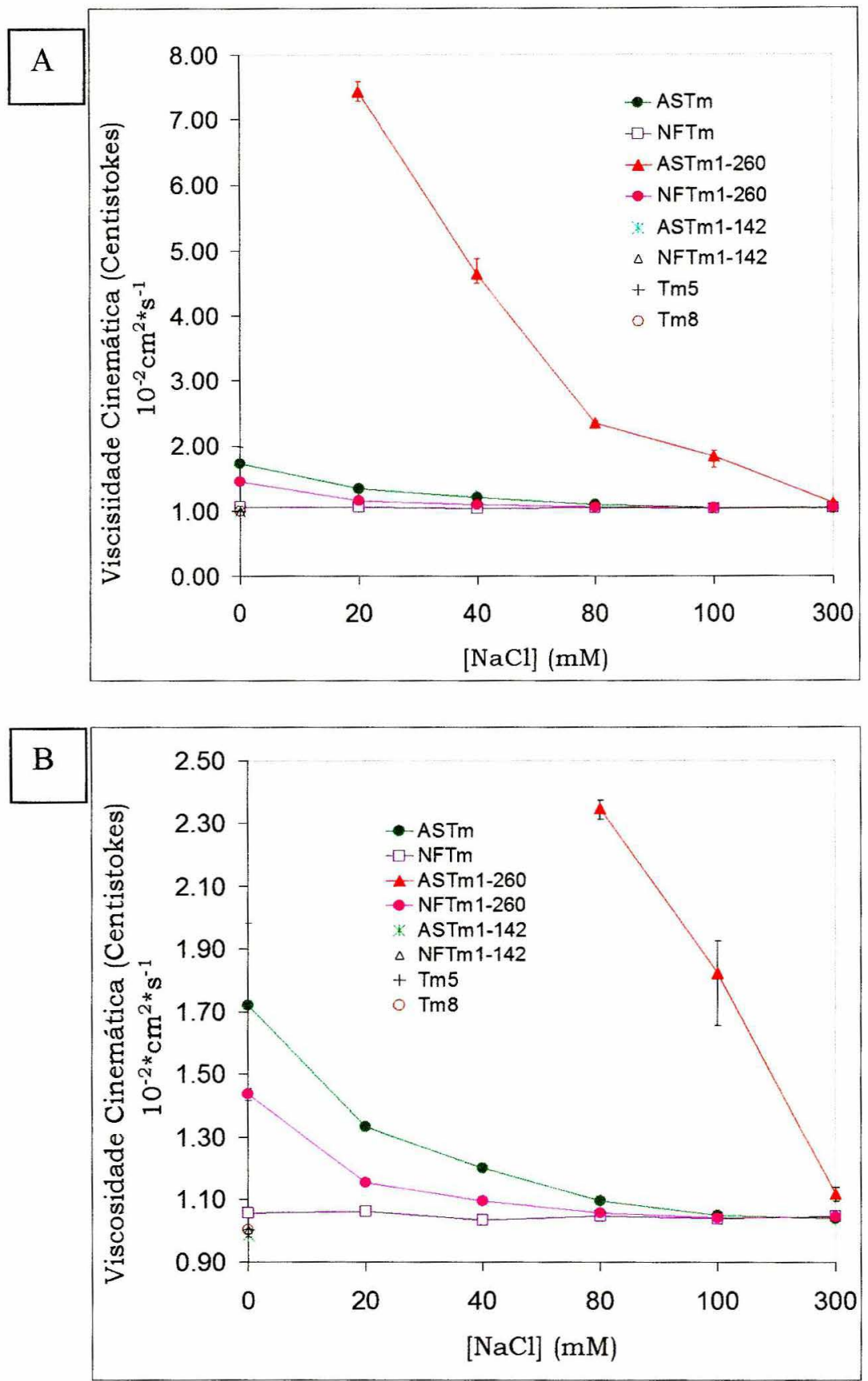

Figura 29- Experimento de Viscosidade (Realizados pela aluna de iniciação científica Ângela $M$. Katsuyama). A) O gráfico mostra as viscosidades cinemáticas para ASTm, NFTm, ASTm1-260 e NFTm1260 em função da força iônica. Para ASTm1-142, NFTm1-142, Tm167-260 e Tm143-260 as vicosidades cinemáticas são mostradas apenas em $0 \mathrm{M}$ de NaCl, que é o ponto onde deveria haver maior polimerização (note que nenhum destes fragmentos polimerizam nesta condição). As proteinas ASTm e NFTm foram utilizadas como controle. B) Corresponde ao mesmo gráfico indicado na parte $A$, mas com uma escala reajustada para permitir uma melhor visualização das variações nas viscosidades. As medidas de viscosidade foram feitas usando-se um semiviscosimetro Cannon-Manning (C30) com um tempo de efluxo de tampão de $242,32 \mathrm{~s}$, a $21 \pm 1^{\circ} \mathrm{C}$. As proteínas $(8 \mu \mathrm{M})$ foram ressupensas em $2 \mathrm{mM}$ de DTT, $10 \mathrm{mM}$ de tampão imidazol-HCl $(\mathrm{pH} \mathrm{7,0)}$ e foram previamente equilibradas por $7 \mathrm{~h}$ antes de cada experimento. 
Tropomiosinas Esquema das recombinantes Tms

ASTm

nfTm
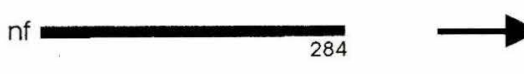

$\operatorname{ASTm}_{1.142}$

AS

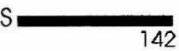

$\mathrm{nfTm}_{1-142}$

nf

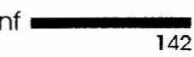

$\mathrm{Tm}_{220-284}$

$\mathrm{Tm}_{143-260}$

$\mathrm{Tm}_{167-260}$

ASTM $_{1-260}$

$\mathrm{nfTm}_{1-260}$
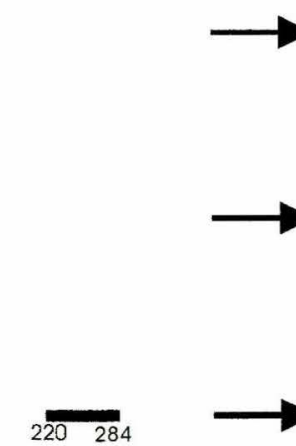

42

142

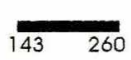

$\overline{167 \quad 260}$
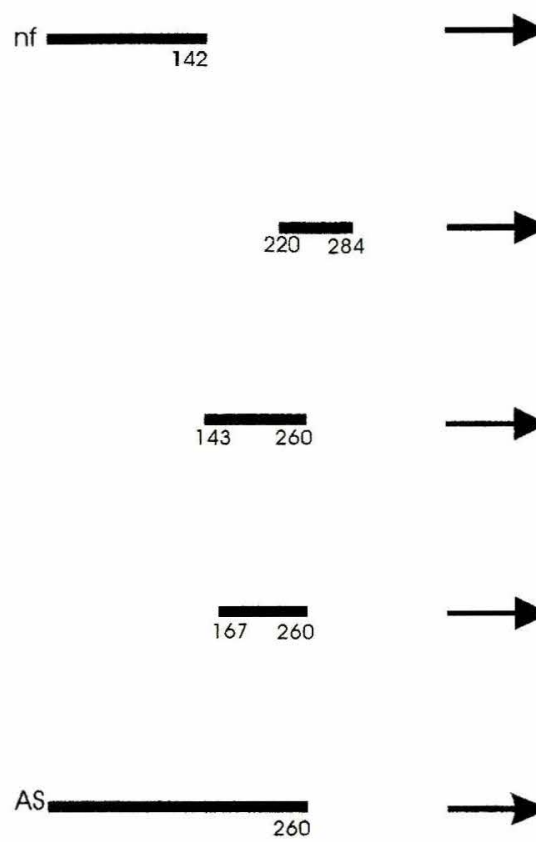
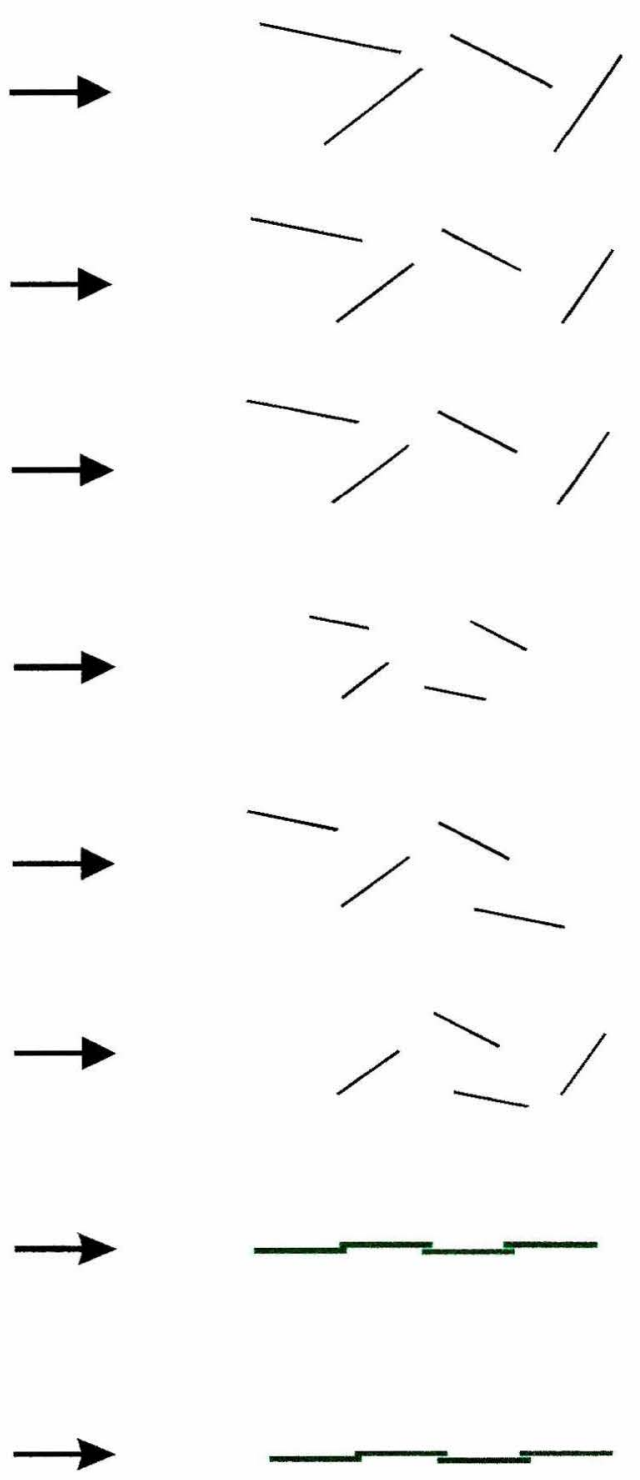

Ocorre Polimerizacão? 
Nós primeiramente procuramos demonstrar que ASTm $_{1-142}$ é capaz de interagir com o C-terminal da Tm de maneira similar àquela observada em experimentos de interação cabeça-cauda para a Tm inteira. Para isto nós utilizamos uma Tm recombinante contendo uma sonda $50 \mathrm{HW}$ na posição 269 , cuja intensidade de fluorescência é sensível à polimerização cabeça-cauda como mostrado previamente por Sousa e Farah (2002).

Sousa e Farah (2002) mostraram que, ao passo que a fluorescência de ASTm269(50HW) é sensível à força iônica do meio, a de nfTM269(50HW) não é. Isto é consistente com o fato de a que ausência da fusão dipeptídica Ala-Ser resulta em uma drástica diminuição da polimerização (Monteiro et al., 1994). Desta forma, nós esperávamos que o C-terminal de nfTm269(50HW) fosse capaz de se ligar ao N-terminal de ASTm $_{1-142}$, o que resultaria em um aumento da intensidade de fluorescência da sonda $50 \mathrm{HW}$ na posição 269. A Figura 31 mostra as curvas de titulação de nfTm269(50HW) com ASTm 1-142, acompanhada pelo sinal de fluorescência da sonda $50 \mathrm{HW}$. Os resultados claramente revelam que existe uma interação entre estas duas proteínas. Portanto, como mostrado recentemente por Palm et al. (2001), um fragmento de Tm sem a região C-terminal da molécula não impede que ele participe de interações cabeça-cauda com um outro fragmento contendo a região Cterminal. Além disso, a titulação de nfTm269(50HW) com nfTm $1-142$ não resultou em nenhum aumento significante na intensidade de fluorescência da sonda (figuras 31A e 31B), consistente com a esperada ausência de interação no caso da utilização de uma proteína não fusionada no seu $\mathrm{N}$-terminal (nfTm 142).

Estes resultados permitiram-nos concluir que as interações entre

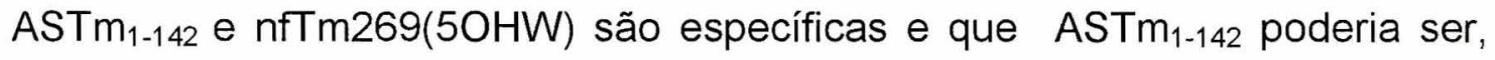
portanto, utilizada para testar as interações cabeça-cauda. A Figura 31 mostra também que a adição de $300 \mathrm{mM}$ de $\mathrm{NaCl}$ após a titulação da nfTm269(50HW) com ASTm1-142 diminui o sinal de fluorescência de aproximadamente $8 \%$ abaixo do valor inicial. Isto indica que a interação cabeça-cauda formada entre nfTm269(50HW) e ASTm1-142 foi abolida, como 
esperado, em altas forças iônicas. O fato de o sinal de fluorescência da nfTm269(50HW) com ASTm1-142, após a adição de 300 mM de $\mathrm{NaCl}$, ser menor que o sinal de fluorescência da nfTm269(50HW) sozinha em baixas concentrações salinas, pode ser explicado da seguinte maneira: embora nfTm269(50HW) não seja acetilada ela deve possuir um nível basal de polimerização em baixas forças iônicas, assim como a Tm nativa não acetilada (nfTm) como pode ser visto na Figura 29 através da viscosidade cinemática. A presença de altas concentrações de $\mathrm{NaCl}$ está promovendo uma pequena queda na viscosidade de nfTm (ver figura 29). Esta pequena queda na viscosidade após adição de $\mathrm{NaCl}$ deve ocorrer também para a nfTm recombinante com a sonda na posição 269 (nfTm269(50HW)) e pode ser observada através desta diferença no sinal de fluorescência após a adição de $300 \mathrm{mM}$ de $\mathrm{NaCl}$. 
A
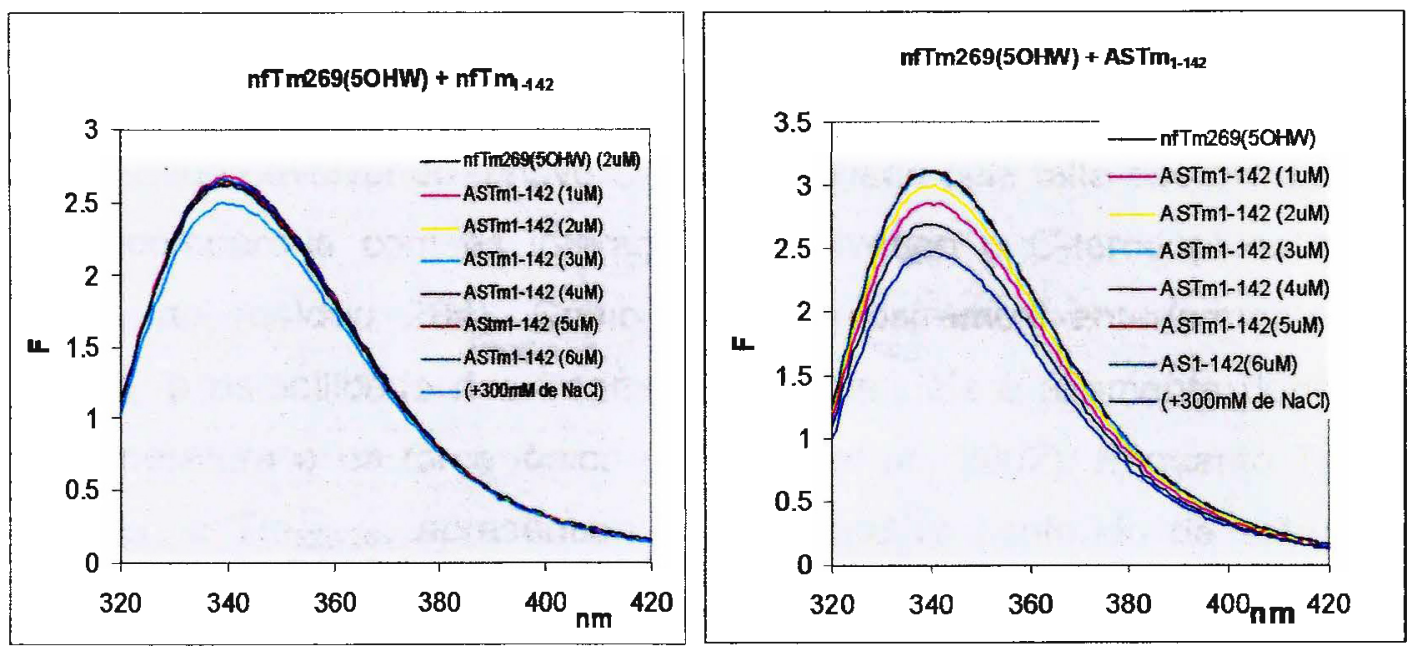

B

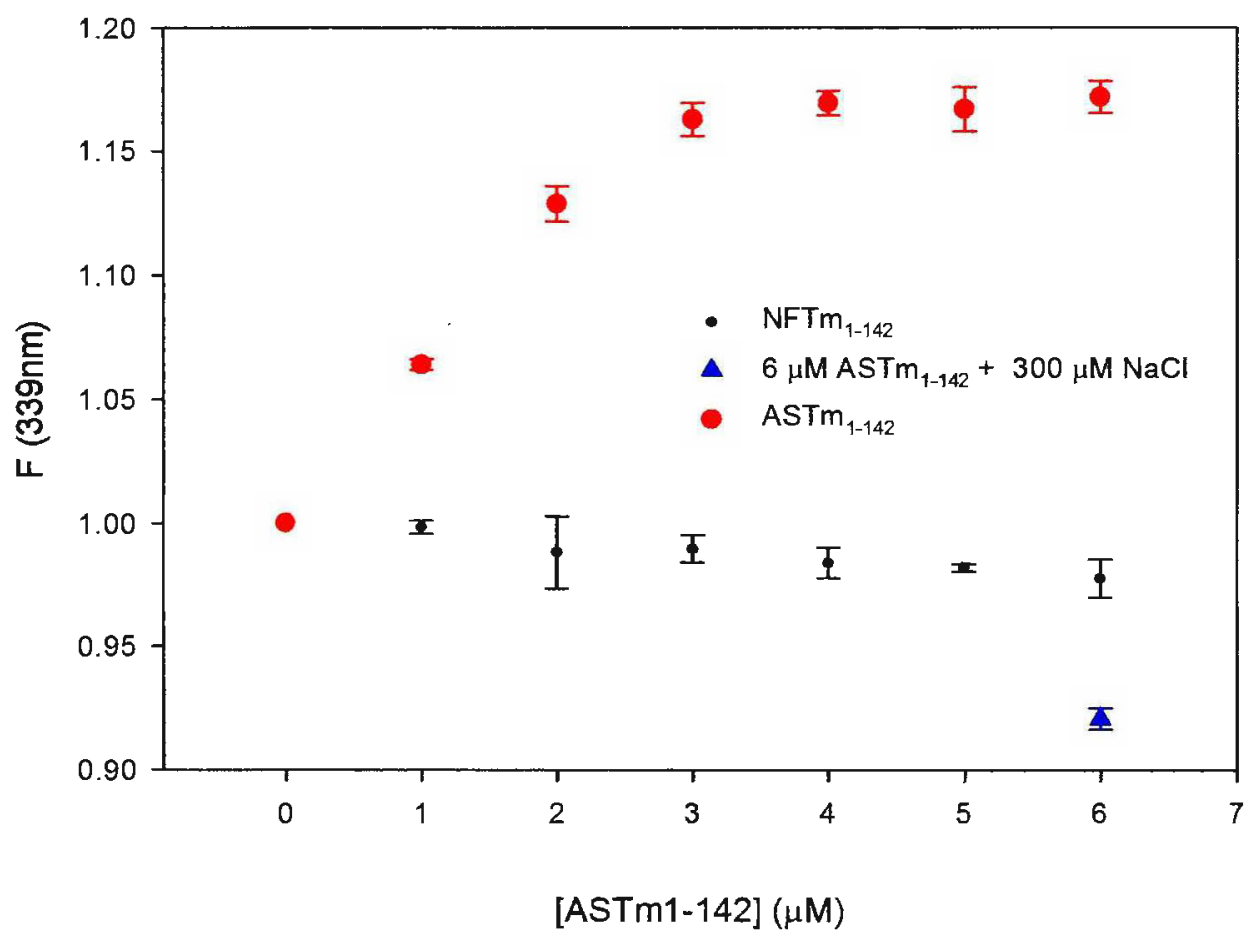

Figura 31 -Titulação da nfTm269 (5OHW) com os fragmentos $\mathrm{N}$-terminais de $\operatorname{Tm}_{\text {(ASTm }}$ 1-142 $e$ NFTm $\left.{ }_{1-142}\right)$. A) Espectros de fluorescência de nfTm269 (5OHW) $(2 \mu \mathrm{M})+\mathrm{NFTm}_{1-142}$ e ASTm . $_{\text {- }}$

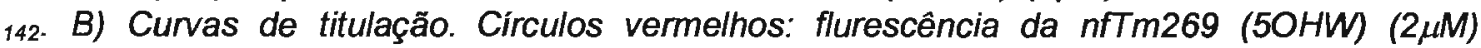
titulada com ASTm ${ }_{1-142 .}$. Circulos pretos: flurescência da nfTm269 (5OHW) $(2 \mu \mathrm{M})$ titulada com $N F T m_{1-142 .}$. Triângulo azul: nfTm269 (5OHW) $(2 \mu M)+$ ASTm $_{1-142}(6 \mu M)$ após a adição de 300 $\mathrm{mM} \mathrm{NaCl}$. Condições: $25 \mathrm{mM}$ de tampão MOPS, $\mathrm{pH} 7,0 ; 0,5 \mathrm{mM}$ de $\mathrm{MgCl}_{2} ; 1 \mathrm{mM}$ de $\mathrm{DTT} ; 25$ ${ }^{\circ} \mathrm{C}$. Comprimento de onda de excitação de $302 \mathrm{~nm}$ e comprimento de onda de emissão de $337 \mathrm{~nm}$. 
Nós decidimos realizar experimentos que combinassem os fragmentos C-terminais $\operatorname{Tm}_{167-260}, \mathrm{Tm}_{143-260}$ e $\mathrm{Tm}_{220-284}$ com os fragmentos $\mathrm{N}$-terminais ASTm $_{1-142}$ e nfTm 1-142 com a intenção de investigar a natureza da interação cabeça-cauda evolvendo o novo C-terminal criado pela falta dos resíduos 261 284 e compará-la com as interações envolvendo o C-terminal nativo (que termina no resíduo 284). Como nós já mostramos anteriormente neste trabalho, a estabilidade dos fragmentos C-terminais é altamente dependente da temperatura e da força iônica (Paulucci et al., 2002). Enquanto $\operatorname{Tm}_{167-260,}$ $\mathrm{Tm}_{143-260}$ e $\mathrm{Tm}_{220-284}$ apresentam um significativo conteúdo de estrutura $\alpha$ hélice (> 60\%) em tampão $50 \mathrm{mM}$ fosfato contendo $100 \mathrm{mM}$ de $\mathrm{KCl}$ a $10^{\circ} \mathrm{C}$ (Paulucci et al., 2002), esta estrutura secundária é perdida em grande parte na ausência de $\mathrm{KCl}$, a $25^{\circ} \mathrm{C}$ e em menor força iônica (10 mM de fosfato de sódio) (ver tabela $10 \mathrm{~A}$ ). Por outro lado, os dois fragmentos $\mathrm{N}$-terminais permanecem relativamente estáveis sob estas condições e também não sofrem grandes variações em função da temperatura (entre 10 e $25^{\circ} \mathrm{C}$ ) e da força iônica. ASTm $_{1-142}$ apresenta aproximadamente $90 \%$ de a-hélice a $25^{\circ} \mathrm{C}$ na ausência de $\mathrm{KCl}$ e $97 \%$ a $10^{\circ} \mathrm{C}$ na presença de $100 \mathrm{mM}$ de $\mathrm{KCl}$, enquanto que $\mathrm{nfTm}$ 1-142 apresenta $81 \%$ de estrutura a-hélice a $25^{\circ} \mathrm{C}$ na ausência de $\mathrm{KCl}$ e aproximadamente $99 \%$ a $10^{\circ} \mathrm{C}$ na presença de $100 \mathrm{mM}$ de $\mathrm{KCl}$ (ver tabela 10 A). Esta diferença entre a estabilidade das metades $\mathrm{N}$ - e C-terminal da molécula de $\mathrm{Tm}$ é refletida nas diferenças entre as estabilidades térmicas (Tabela 10 B) e é consistente com observações prévias de outros grupos (Pato et al., 1981b; Holtzer e Holtzer, 1990).

Desta maneira, nós decidimos realizar experimentos de dicroísmo circular usando misturas equimolares dos fragmentos $\mathrm{N}$ - e C-terminais em condições em que o $\mathrm{C}$-terminal se encontra pouco enovelado ao passo que o $\mathrm{N}$-terminal se encontra mais enovelado (10 mM tampão fosfato, $\mathrm{pH} 7,0 ; 0,5$ $\mathrm{mM}$ de EDTA e $1 \mathrm{mM}$ de DTT, $10 \mu \mathrm{M}$ de concentração de proteína e $25^{\circ} \mathrm{C}$ ). Também devemos notar que, em baixas forças iônicas, a interação cabeçacauda é favorecida (Figura 29 e 31). Nós esperávamos que uma interação cabeça-cauda fosse acompanhada por um aumento no conteúdo de a-hélice 
devido a um enovelamento dos fragmentos C-terminais e, desta forma, nós poderíamos detectar a interação através da técnica de dicroísmo circular.

A Figura 32 mostra os espectros de CD na região do UV distante para todos os fragmentos individuais e para a mistura equimolar entre os dois fragmentos $\mathrm{N}$ - e C-terminais (aqui chamada de curva experimental) a $25^{\circ} \mathrm{C}$. A soma dos espectros dos fragmentos $\mathrm{N}$ - e $\mathrm{C}$-terminais individuais (aqui chamada de curva teórica) é também mostrada para uma comparação. Os resultados mostram que as curvas experimentais para as misturas dos três fragmentos C-terminais com ASTm 1-142 $_{1}$ apresentam um aumento na intensidade dos valores de elipticidade quando comparados com as respectivas curvas teóricas. Estas diferenças não foram observadas quando usamos a nfTm ${ }_{1-142}$ em vez de ASTm 1-142 (Ver figura 32). 

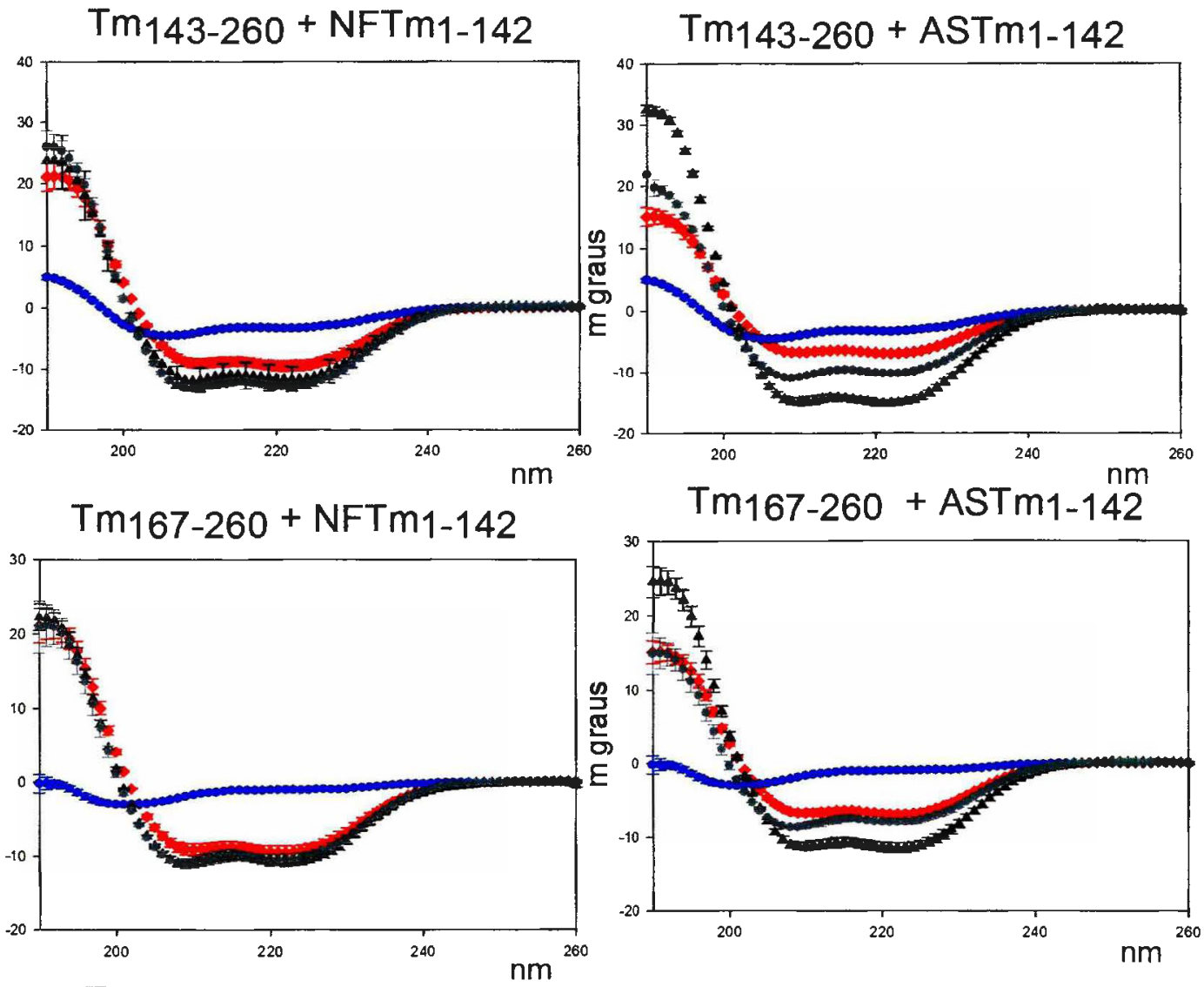

Tm220-284 + NFTm1-142

Tm220-284 + ASTm1-142
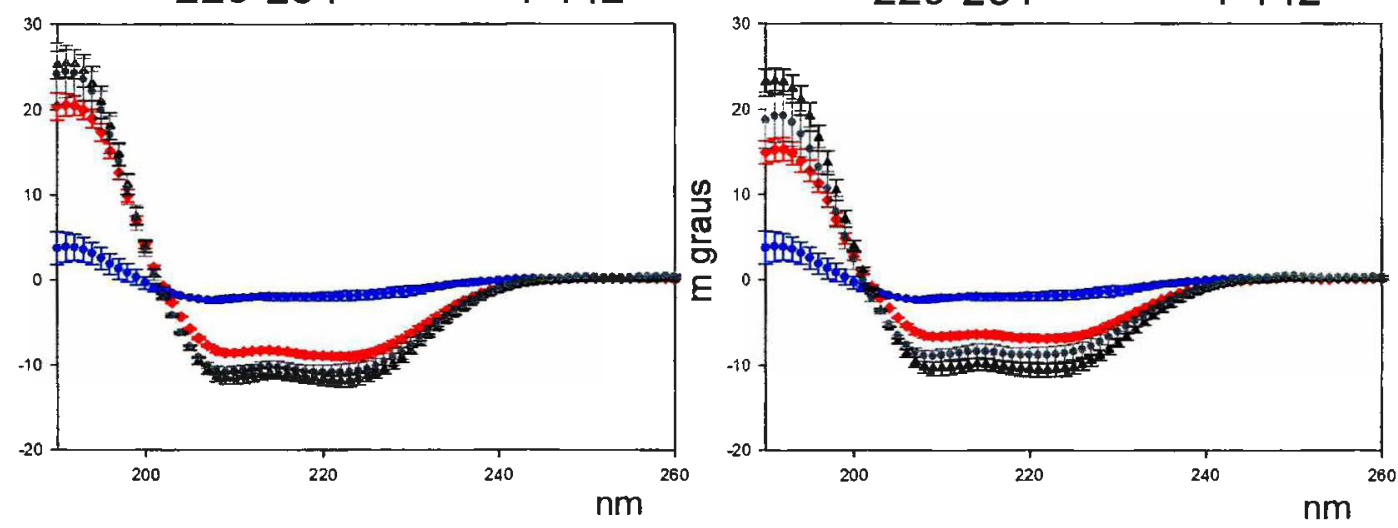

Figura 32 - Experimentos de interação cabeça-cauda através da combinação entre fragmentos compreendendo as regiōes $\mathrm{N}$-e C-terminais da $\mathrm{Tm}$. Os espectros de CD na região do UV distante mostram que os fragmentos que terminam na posição 260 são mais sensiveis a interação com $\mathrm{ASTm}_{1-142}$ que aqueles que terminam na posição 284. Condições: $10 \mathrm{mM}$ fosfato de sódio ( $\mathrm{pH}$ 7,0), 1,0 mM de DTT e 0,5 mM de EDTA. Concentração das proteínas = $10 \mu \mathrm{M}$. Circulos azuis - fragmentos C-terminais de $\mathrm{Tm}$, como indicado no título de cada figura. Losangos vermelhos- ASTm $_{1-142}$ ou $\mathrm{nTT}_{1-142}$, como indicado na figura. Círculos cinza - Curva teórica, representa a soma dos espectros individuais dos fragmentos $\mathrm{C}$ e $\mathrm{N}$-terminais. Triângulos pretos- Curva experimental obtida da mistura entre os fragmentos $\mathrm{N}$ - e C-teminais. 
Para caracterizar melhor este fenômeno, nós realizamos experimentos de desnaturação por temperatura monitorada por CD para cada um dos cinco fragmentos individuais e para todas a seis combinações entre fragmentos $\mathrm{N}$-e C-terminais. A Figura 33 mostra que quase não houve variação na estabilidade dos fragmentos C-terminais quando em combinação com nfTm ${ }_{1-142}$. As curvas teóricas coincidem com as curvas experimentais. Entretanto nós observamos um aumento considerável nas estabilidades indicadas pelas curvas de

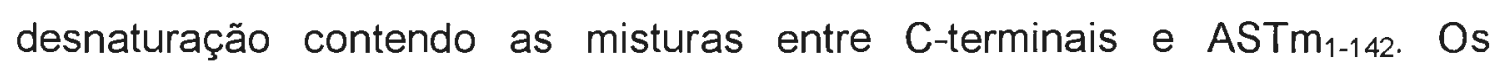
resultados apresentados nas figuras 32 e 33 indicam que todos os fragmentos

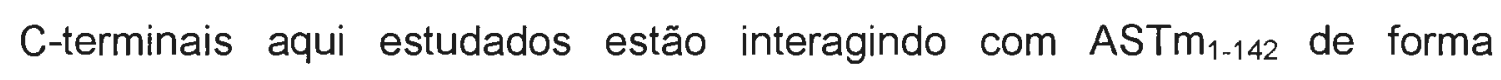
específica e que esta interação é acompanhada por um aumento significante na estabilidade de uma ou de ambas as cadeias polipeptídicas diméricas $\mathrm{N}$ e/ou C-terminais. Como já foi mencionado anteriormente, os fragmentos $\mathrm{N}$ terminais são mais estáveis que os fragmentos $\mathrm{C}$-terminais, apresentando temperaturas de desnaturação $\left(T_{m}\right)$ maiores para fragmentos de mesmo tamanho (Pato e Smilie, 1981b; Holtzer e Holtzer, 1990) (ver Tabela 10). Portanto, parece que grande parte das mudanças conformacionais que estão ocorrendo acontecem nos fragmentos C-terminais. Nós observamos, através do espectros de $C D$ a $25^{\circ} \mathrm{C}$, que $\operatorname{Tm}_{167-260}$ e $\operatorname{Tm}_{143-260}$ são mais sensíveis a interação com ASTm 1-142 que $\operatorname{Tm}_{220-284}$ (Figura 32 e 33). Os espectros experimentais para os complexos formados entre ASTm ${ }_{1-142}$ e $\operatorname{Tm}_{167-260}$, e entre

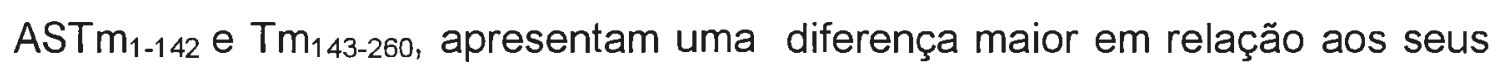
respectivos espectros teóricos, em $222 \mathrm{~nm}$, do que aquela observada entre o espectro experimental e o espectro teórico da mistura de ASTm $_{1-142}$ com $\mathrm{Tm}_{220-284}$ (Figura 33).

Os insertos da Figura 33 mostram as diferenças porcentuais entre as curvas experimentais e teóricas em função da temperatura. Os gráficos confirmam que existe uma maior variação entre as curvas experimentais e teóricas para $\operatorname{Tm}_{167-260}$ e $\operatorname{Tm}_{143-260}$ (um máximo de aproximadamente 100\%) do que para $\mathrm{Tm}_{220-284}$ (aproximadamente 60\%) quando da interação com ASTm 142. Além disso, a aproximadamente $30^{\circ} \mathrm{C}$, as diferenças entre as curvas 
experimentais e teóricas são mais pronunciadas. Isto indica que esta é a melhor temperatura para acompanhar mudanças conformacionais como uma função da interação cabeça-cauda, já que, nesta temperatura, as proteinas não são muito estáveis sozinhas e, ao mesmo tempo, se encontram parcialmente enoveladas quando juntas. O fato das conformações da $\operatorname{Tm}_{167-260}$ e da $\operatorname{Tm}_{143-260}$ estarem sendo mais afetadas pela interação com ASTm $1-142$ do que a conformação da $\mathrm{Tm}_{220-284}$ não significa que esteja ocorrendo uma interação mais forte entre os fragmentos $\mathrm{Tm}_{167-260}$ e $\mathrm{Tm}_{143-260}$ com o fragmento

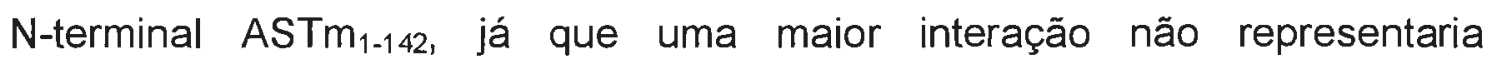
necessariamente um aumento na estrutura secundária da proteína. Estes resultados serão discutidos detalhadamente na parte da discussão.

A Figura 34 resume os dados obtidos com uma representação esquemática das interações que ocorrem entre os fragmentos $\mathrm{N}$ - e C-terminais da $\alpha-T m$ de músculo esquelético de galinha. 

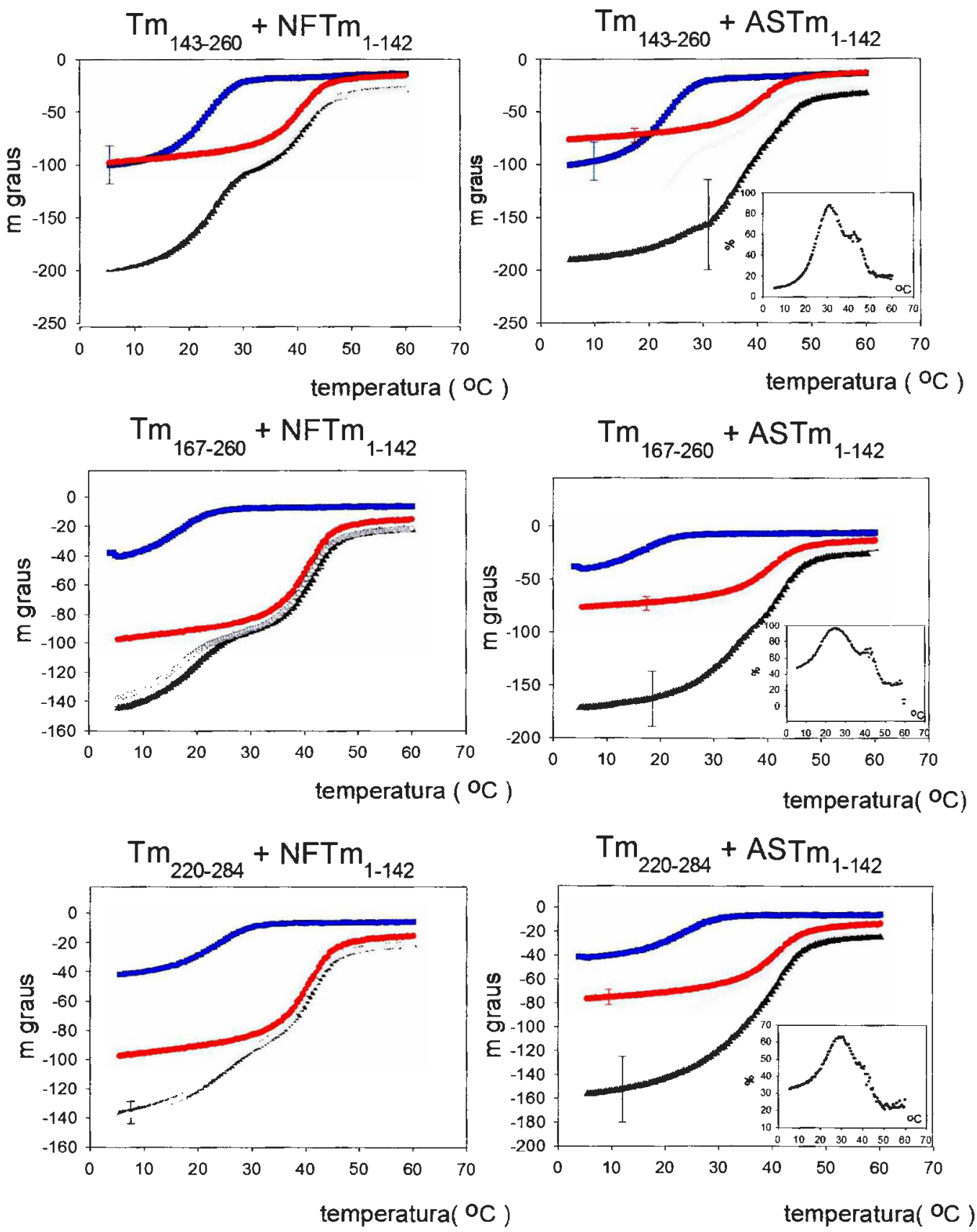

Figura 33 - Curvas de desnaturação térmica para fragmentos individuais e para a combinação entre fragmentos compreendendo as regiốes $\mathrm{N}$ - e C-terminais da Tm. Os valores de elipticidade foram obtidos em $222 \mathrm{~nm}$ Condições: $10 \mathrm{mM}$ fosfato de sódio $(\mathrm{pH} 7,0), 1.0 \mathrm{mM}$ de $D T T$ e $0,5 \mathrm{mM}$ de EDTA. Concentração das proteínas $=10 \mu \mathrm{M}$. Círculos azuis - fragmentos $C$ terminais de Tm, como indicado no título de cada figura. Losangos vermelhos- $A S T m_{1-142}$ ou $n f T m_{1-142}$, como indicado na figura. Círculos cinza - curva teórica, representa a soma dos espectros individuais dos fragmentos $\mathrm{C}$ e $\mathrm{N}$-terminais. Triângulos pretos- curva experimental obtida a partir da mistura entre os fragmentos $\mathrm{N}$ - e C-terminais. Aqui, mostramos somente as barras de erro para os pontos que apresentaram maior desvio padrão para um conjunto de dois experimentos. Os gráficos intemos representam as diferenças porcentuais entre as curvas teóricas e experimentais, ou seja, ((curva experimental - curva teórica)/(curva teórica))*(100). 
Tabela 10 - A) Conteúdo de $\alpha$-hélice para os fragmentos de Tm usados no estudo de interação cabeça-cauda em função da temperatura e da força iônica. (1) e (2) $50 \mathrm{~m} \mathrm{M}$ de fosfato de sódio, pH 7,0; $1 \mathrm{mM}$ de DTT e 0,5 mM de EDTA. (3) $10 \mathrm{mM}$ de fosfato de sódio, $\mathrm{pH}$ 7,0; $1 \mathrm{mM}$ de DTT e 0,5 mM de EDTA. O conteúdo de $a$-hélice foi calculado com descrito em Materiais e Métodos. B) Valores para temperatura de "melting" ( $\left.T_{\mathrm{ms}}\right)$ dos fragmentos de Tm e dos complexos formados entre ASTm $_{1-142}$ e os fragmentos C-terminais.

A)

\begin{tabular}{|c|c|c|c|}
\hline $\begin{array}{l}\text { Fragmentos } \\
\text { C-terminais de Tm }\end{array}$ & $\begin{array}{l}\% \text { de } \alpha \text {-helice a } \\
10^{\circ} \mathrm{C}, 100 \mathrm{mM} \text { de } \\
\mathrm{KCl} \\
\text { (1) }\end{array}$ & $\begin{array}{l}\% \text { de } \alpha \text {-hélice a } \\
25^{\circ} \mathrm{C}, 100 \mathrm{mM} \\
\mathrm{KCl} \\
\text { (2) }\end{array}$ & $\begin{array}{l}\% \text { de a-hélice a } \\
25^{\circ} \mathrm{C}, 0 \mathrm{mM} \mathrm{KCl} \\
\text { (3) }\end{array}$ \\
\hline $\mathrm{Tm}_{220-284}$ & 68 & 48 & 32 \\
\hline $\mathrm{Tm}_{167-260}$ & 64 & 28 & 7.7 \\
\hline $\mathrm{Tm}_{143-260}$ & 82 & 69 & 54 \\
\hline ASTm $_{1-142}$ & 97 & 91 & 90 \\
\hline$n f m_{1-142}$ & 99 & 92 & 81 \\
\hline
\end{tabular}

B)

\begin{tabular}{|c|c|}
\hline Proteina & $\operatorname{Tm}\left({ }^{\circ} \mathrm{C}\right)$ \\
\hline$n f T m_{1-142}$ & 40 \\
\hline $\mathrm{AS}_{\mathrm{Tm} 1-142}$ & 40 \\
\hline $\mathrm{Tm}_{220-284}$ & 22 \\
\hline $\mathrm{Tm}_{143-260}$ & 23 \\
\hline $\mathrm{Tm}_{167-260}$ & 16 \\
\hline $\operatorname{ASTm}_{1-142}+\operatorname{Tm}_{220-284}$ & 37 \\
\hline $\mathrm{AS}_{\text {Tm 1-142 }} \mathrm{Tm}_{143-260}$ & 38 \\
\hline ASTm $_{1-142}+\operatorname{Tm}_{167-260}$ & 38 \\
\hline
\end{tabular}

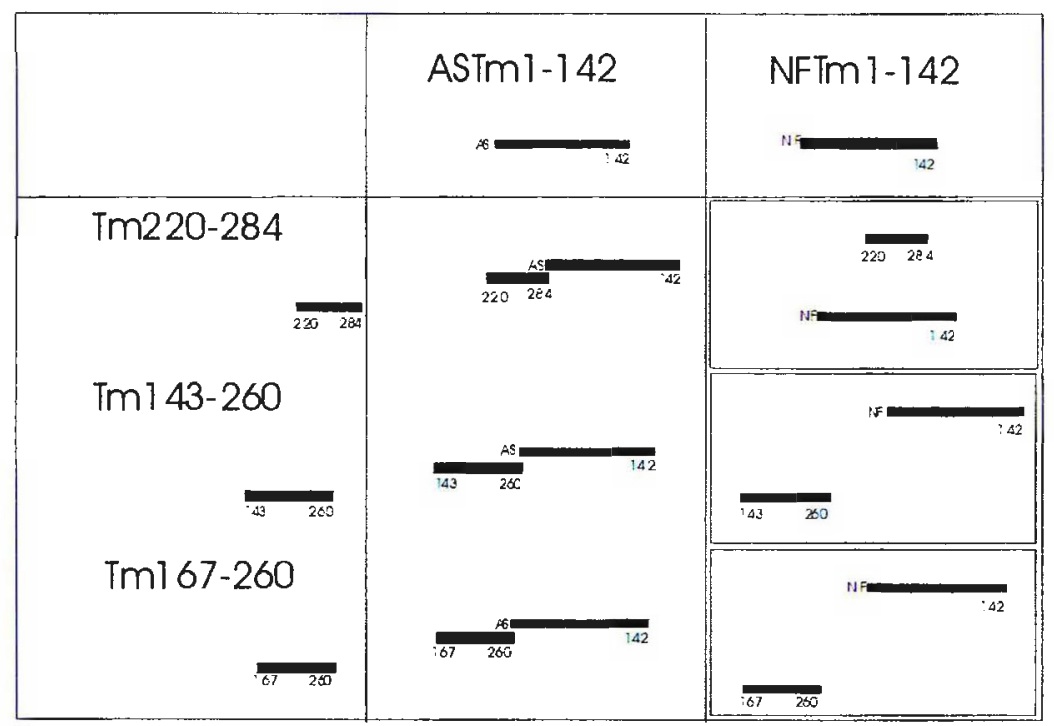

Figura 34 - Representação esquemática das interações que ocorrem entre os fragmentos $C$ - $e$ $N$-terminais da $T m$. 


\section{4- Discussão}

\section{Parte A - Seqüências Específicas Determinam a Estabilidade e Cooperatividade de Enovelamento da Metade C-terminal da Tropomiosina.}

Os experimentos de ultracentrifugação analítica nos permitiram observar que os fragmentos que não contêm os resíduos de aminoácidos 261-284 (quando presentes a $10 \mu \mathrm{M}$ ) estão em equilíbrio monômero-dímero, enquanto que os fragmentos que possuem esta região ( $\mathrm{Tm}_{143-284(50 H W),} \mathrm{Tm}_{189-284(50 H W)}$, $\mathrm{Tm}_{220-284(50 H W)}$ e $\mathrm{Tm}_{220-284}$ ) formam dímeros estáveis nas mesmas condições. Os conteúdos de $\alpha$-hélice a $25^{\circ} \mathrm{C}$ e os valores de [uréia] $]_{1 / 2}$ a $10^{\circ} \mathrm{C}$, obtidos através da técnica de dicroismo circular, mostram que $\operatorname{Tm}_{220-284(50 H W)}$ e $\operatorname{Tm}_{220}$ 284 (65 resíduos) são mais estáveis que outros fragmentos de até 94 aminoácidos que não contêm os residuos 261-284. Em estudos anteriores, fragmentos de Tm que continham 95 aminoácidos ou mais foram capazes de formar "coiled-coil" estáveis (Whitby e Phillips, 2000; Pato et al.; 1981b). Por outro lado, os únicos dois fragmentos estudados até agora na literatura, com tamanhos comparáveis ao de $\mathrm{Tm}_{220-284(50 \mathrm{HW})}$ e $\mathrm{Tm}_{220-284}$ mostraram-se particularmente instáveis (Pato et al., 1981b; Holtzer et al., 2001). Um fragmento correspondendo aos 183-244 da Tm apresentou um espectro de CD característico de uma estrutura randômica a $27{ }^{\circ} \mathrm{C}$ e somente $17 \%$ de estrutura a-hélice a $10{ }^{\circ} \mathrm{C}$ (Pato et al., 1981b). Recentemente, Holtzer et al. (2001) mostraram que um fragmento de 65 aminoácidos (resíduos 190-254) apresentou um significante conteúdo de estrutura em $\alpha$-hélice $(\sim 43 \%)$, quando presente em altas concentrações $(115 \mu \mathrm{M})$ em $50 \mathrm{mM}$ de tampão fosfato, pH $7,4,100 \mathrm{mM}$ de $\mathrm{NaCl}$ e $10 \mathrm{mM}$ de DTT a $10^{\circ} \mathrm{C}$. Entretanto, este mesmo fragmento apresentou-se completamente desenovelado a $25^{\circ} \mathrm{C}$, embora estivesse em altas concentrações. Estes resultados são consistentes com nossas observações para $\operatorname{Tm}_{143-235}$ e $\operatorname{Tm}_{167-260}$, cujas baixas estabilidades não podem ser explicadas pelos seus tamanhos, mas devido a uma instabilidade 
intrínseca apresentada pela região central da cadeia polipeptídica da $\mathrm{Tm}$ (resíduos 143-235). Além disso, outros estudos apresentaram evidências de que a região em torno da Cys190 é particularmente instável (Potekhin e Pivalov, 1982; Lehrer, 1978).

Os experimentos de equilibrio de sedimentação indicam que o TFE não promoveu, neste caso, uma dissociação das hélices envolvidas na formação da estrutura "coiled-coil" dos fragmentos, mas que induziu a formação de trímeros em alguns fragmentos e um concomitante decréscimo na razão $\theta_{222} / \theta_{208}$. Portanto, nós podemos concluir que a inversão na razão $\theta_{222} / \theta_{208}$ não é o resultado da dissociação das a-hélices que compõem a estrutura "coiledcoil". Quadrifoglio e Urry (1968) observaram um efeito similar para um peptídeo sintético copoly-L-Glu-Ala-Lys, o qual não adota estrutura "coiled-coil". Estudos mais recentes mostraram que alguns peptídeos são induzidos à associação, formando dímeros, trímeros e até mesmo tetrâmeros, quando na presença de TFE (MacPhee et al., 1997; Maroun et al., 1999). Portanto, a inversão na elipticidade aqui observada possivelmente deve-se a mudanças conformacionais na estrutura helicoidal ou a efeitos causados pelo solvente em vez de uma transição "coiled-coil" para o monômero de a-hélice (Holtzer e Holtzer, 1995).

A análise do padrão de polaridade/natureza química dos resíduos encontrados entre os aminoácidos 258 e 275 de várias isoformas de Tms de músculo estriado mostra que esta região apresenta vários resíduos com características hidrofóbicas nas posições b, c e f (superfície externa da molécula), e com características hidrofílicas no interior da hélice (posição d) (Áurea D. Sousa, 2002, tese de doutoramento; Sousa e Farah, 2002). Este padrão não é típico para os residuos que ocupam as referidas posições dentro de uma estrutura "coiled-coil" e não se reproduz nas seqüências de Tm não musculares e de músculo liso que compreendem esta região (ver tese de doutoramento, Áurea D. Sousa, 2002). Este trabalho mostra que existe em particular a conservação de quatro resíduos apolares (Ala, Leu ou Tyr) na superfície externa da Tm de músculo esquelético, sendo eles: Tyr261, Ala262, 
Leu265 e Ala269 na Tm de músculo esquelético de galinha (ver figura 16 em Materiais e Métodos).

Embora o TFE seja conhecido por romper interações hidrofóbicas, uma vez que ele altera a estrutura do solvente, devido à caracteristica hidrofóbica do grupo $\mathrm{CF}_{3}$, existem muitos trabalhos que mostram que pode ocorrer a formação de "clusters hidrofóbicos" formados a partir das cadeias laterais de aminoácidos que se encontram próximos na seqüência polipeptídica quando na presença de concentrações consideráveis de TFE (para revisão ver Buck, 1998). Desta maneira, nós podemos supor que a formação de trímeros pelos fragmentos que contêm os resíduos $261-284$, quando na presença de $30 \%$ TFE, deve-se à formação de "clusters" hidrofóbicos entre estas cadeias laterais hidrofóbicas expostas que estão localizadas entre os resíduos 261 e 269. Possivelmente, estes "clusters" podem estar sendo reforçados pela conformação em $\alpha$-hélice da cadeia principal, a qual é estabilizada pelo TFE.

Nós hipotetizamos que este alto grau de associação para os fragmentos que contêm os últimos 24 aminoácidos da molécula de Tm deve estar de alguma forma mimetizando as interações terciárias com as outras proteínas do filamento fino (actina e troponina). Por exemplo, a subunidade Troponina T do complexo Tn é conhecida por possuir uma seqüência com um alto conteúdo de estrutura em $\alpha$-hélice ( $80 \%$ ) entre os resíduos $71-151$ os quais devem estar interagindo com a região C-terminal da molécula de Tm de forma antiparalela, como foi mostrado na figura 5 (Pearlstone et al., 1977).

Nossos resultados mostram que os resíduos 261-284 apresentam claramente um papel importante no mecanismo de desenovelamento da metade C-terminal da molécula de Tm, já que a sua presença ou ausência afeta claramente a estabilidade conformacional, a formação de trímeros induzidos por TFE e a cooperativade da transição de desenovelamento (m) dos fragmentos de Tm. A desnaturação do fragmento $\operatorname{Tm}_{143-260}$ foi mais cooperativa do que a do $\operatorname{Tm}_{143-284}(5 \mathrm{OHW})$. A cooperatividade de desenovelamento deste fragmento de 116 aminoácidos ( $\left.\operatorname{Tm}_{143-260}\right)$ não está relacionada a uma instabilidade particular deste fragmento em condições 
benignas, já que ele se apresenta altamente enovelado na ausência do desnaturante com e sem a adição de 100 mM KCl (por exemplo, possui 82\% de $\alpha$-hélice a $10^{\circ} \mathrm{C}$, ver tabela 6 ) e começa a desnaturar em concentrações de uréia maiores que 0,5 M (Figura 24). Por que, então, a presença dos últimos resíduos C-terminais (261-284) reduziria a cooperatividade da curva de transição de desenovelamento? Se a região C-terminal da Tm forma uma estrutura particularmente estável, a qual permanece enovelada mesmo quando as seqüências vizinhas começam a desenovelar, então a transição de desenovelamento dos fragmentos contendo esta estrutura deveria ser um processo de múltiplos passos e deveria ocorrer numa faixa larga de concentração de uréia, embora as espécies intermediárias não sejam claramente detectadas. Nós não temos condições de definir precisamente os limites desta possível região mais estável, já que deleções parciais deveriam desestabilizá-la. Mas as evidências que nós apresentamos acima parecem indicar que ela deve estar entre os resíduos 220 e 284 , incluindo pelo menos os últimos 24 aminoácidos. Um fragmento de 31 aminoácidos, o qual inclui os resíduos 253-280 da molécula de Tm apresentou-se completamente desenovelado a $2^{\circ} \mathrm{C}$ e em altas concentrações (1,1 mM) (Holtzer et al., 1995), indicando que a estabilidade conferida pelos resíduos 261-284 é dependente das seqüências vizinhas.

Peptídeos-modelo com estruturas primárias de complexidade relativamente baixa são úteis para testar a hipótese sobre a contribuição de contatos específicos entre cadeias laterais para a estabilidade de "coiled-coils" (Zhou et al., 1994a,b; Oakley e Kim, 1998). Entretanto, a aplicação das conclusões obtidas a partir destes resultados em "coiled-coils" de ocorrência natural como a Tm não é tão óbvia. Isso ocorre porque as seqüências de proteínas naturais são altamente complexas e acabam, por tal motivo, criando um micro-ambiente único para cada um dos pares de resíduos que podem interagir potencialmente. Espera-se que detalhes eletrostáticos e topológicos deste micro-ambiente sejam de grande importância para se determinar se e com que grau de afinidade duas ou mais cadeias laterais irão interagir e a 


\section{BIB LIOTECA \\ INSTITUTO DE QUIMICA \\ Universidade de São Paulo}

contribuição destas interações para a estabilidade geral da molécula. Vários grupos vêm desenvolvendo um grande número de algoritmos, baseados em dados estruturais e termodinâmicos, com a finalidade de predizer a estabilidade de estruturas a-hélice e "coiled-coil" (Lupas et al., 1991; Berger et al., 1995; Muñoz e Serrano, 1995 a,b; Lacroix et al., 1998; Zhou et al., 1994 a,b; Wagschal et al., 1999; Tripet et al., 2000).

É razoável partir do pressuposto de que a estabilidade de uma estrutura "coiled-coil" é, pelo menos em parte, uma função da estabilidade das hélices individuais. Nós fizemos uma análise da seqüência de aminoácidos na região C-terminal da molécula de Tm (resíduos 143-284), numa tentativa de identificar possiveis padrões que pudessem explicar as estabilidades diferenciais entre os fragmentos de Tm estudados. Primeiramente, nós analisamos fatores que pudessem estabilizar ou desestabilizar as conformações helicoidais dos fragmentos de Tm. As a-hélices podem ser estabilizadas ou desestabilizadas por interações atrativas ou repulsivas entre cadeias laterais de resíduos carregados nas posições i e i+3 ou i+4 (Muñoz e Serrano, 1995a). Embora nossa análise tenha mostrado um grande número de pares iônicos desestabilizantes, nós não detectamos nenhuma diferença no número (normalizado em relação ao tamanho do fragmento) de possíveis repulsões intra-hélice entre as cadeias laterais carregadas nos fragmentos. Nós observamos que estes pares repulsivos encontram-se distribuídos aleatoriamente ao longo da região estudada.

Nós utilizamos o programa AGADIR (Muñoz e Serrano, 1995 a,b; Lacroix et al., 1998) para predizer a propensão de formação de estrutura $\alpha$ hélice das cadeias polipeptídicas usadas neste estudo. Este algoritmo, baseado na teoria de transição hélice-"coil" leva em conta vários tipos de interações, incluindo as pontes de hidrogênio da cadeia principal, interações entre cadeias laterais, propensões intrínsecas à formação de estrutura helicoidal, interações de "capping" e interações eletrostáticas em distâncias intermediárias. As análises feitas pelo programa AGADIR mostraram que não existe nenhuma diferença significante na propensão para a formação de 
estrutura a-hélice entre os fragmentos recombinantes de Tm. Todos os fragmentos, quando analisados como cadeias simples, apresentaram baixa propensão em adotar estrutura $\alpha$-hélice (3 a $7 \%$ em pH 7, força iônica = 0,1) (ver Figura 35). Estes resultados são consistentes com as análises feitas por Holtzer et al. (1989), que usou a teoria de transição hélice-"coil" de ZimmBragg para demonstrar que mesmo a Tm inteira, nativa, não deveria ser muito helicoidal quando consideramos apenas o seu estado monomérico. Portanto, o fato de que a Tm nativa apresenta uma estrutura completamente helicoidal deve ser explicado em grande parte pela estabilização devido às interações quaternárias de natureza eletrostática e hidrofóbica. Isto é um exemplo claro do quanto as interações terciárias (não-locais) podem influir na estrutura secundária, dominada por interações locais, como no caso das a-hélices. 
A

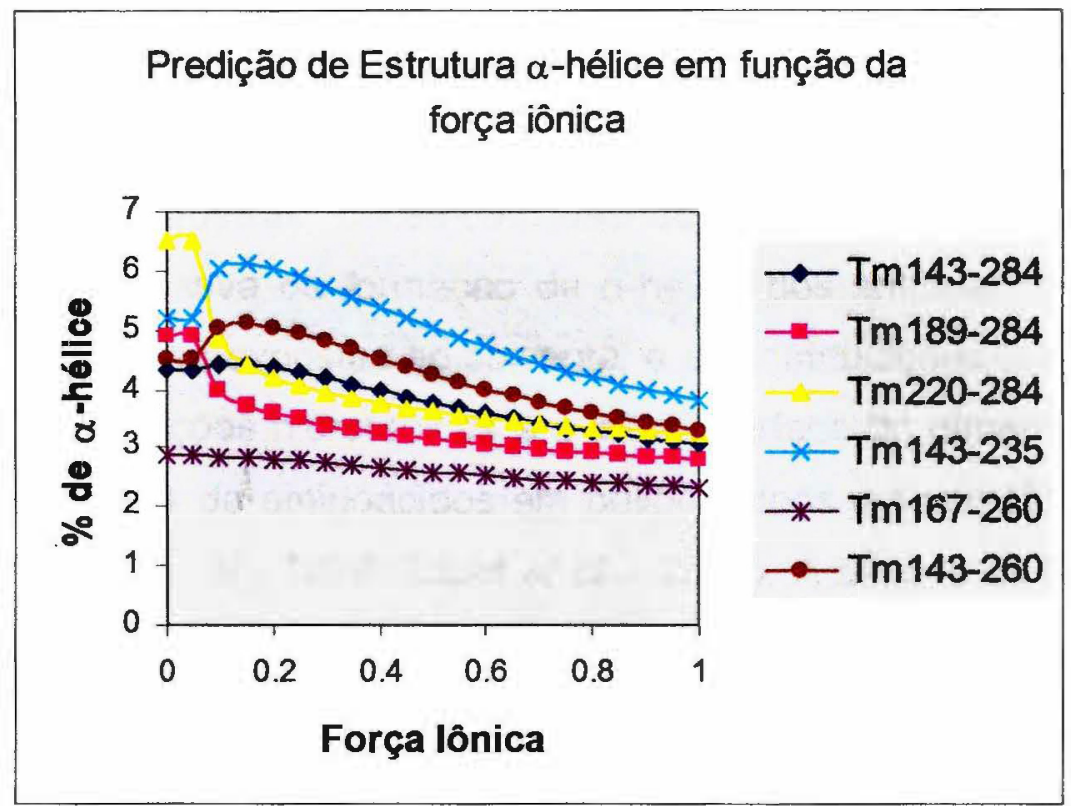

B

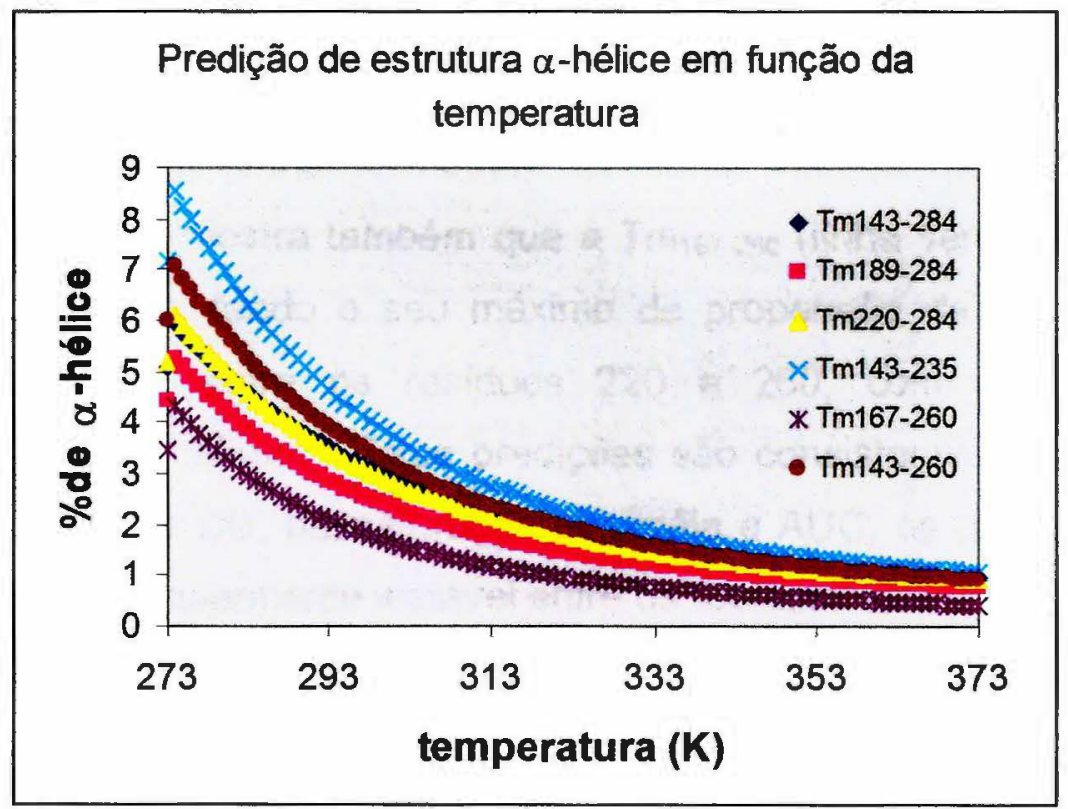

Figura 35- Predição da porcentagem de estrutura a-hélice para as cadeias polipeptídicas monoméricas dos fragmentos C-terminais de Tm, calculada pelo programa AGADIR. APorcentagem de a-hélice para cada fragmento em função da força iônica em temperatura constante de $10^{\circ} \mathrm{C} \mathrm{e} \mathrm{pH} \mathrm{7,0.} \mathrm{B-Porcentagem} \mathrm{de} \mathrm{a-hélice} \mathrm{para} \mathrm{cada} \mathrm{fragmento} \mathrm{em} \mathrm{função} \mathrm{da}$ temperatura em força iônica constante de $0,1 \mathrm{M} \mathrm{e} \mathrm{pH} \mathrm{7,0.}$ 
Muitos programas têm sido desenhados para predizer a tendência de uma seqüência polipeptídica em adotar uma conformação "coiled-coil" (Lupas et al. 1991; Berger et al., 1995; Zhou et al., 1994 a,b; Wagschal et al., 1999; Tripet et al., 2000). O algoritmo STABLECOIL (ver Materiais e Métodos) estima a estabilidade de estruturas "coiled-coil" usando os valores de energia livre para a propensão relativa de formação de a-hélice dos aminoácidos que se encontram em posições expostas ao solvente, e as contribuições dos resíduos encontrados nas posições hidrofóbicas a e $\mathbf{d}$ da interface do dímero, obtida a partir de substituições de aminoácidos em polipeptídeos modelo (Zhou et al., 1994 a,b; Wagschal et al., 1999; Tripet et al., 2000). A análise da seqüência de Tm usando o programa STABLECOIL indica um forte potencial para formação de estrutura "coiled-coil" entre os resíduos 220-284 (Ver Figura 36). Devemos notar que os valores (em $\mathrm{kcal} / \mathrm{mol}$ ) de propensão de formação de estrutura "coiled-coil" aumentam em direção ao C-terminal da molécula. Note que o fragmento $\mathrm{Tm}_{220-284}$ (símbolos amarelos na Figura 36) apresenta valores de probabilidade de formação de estrutura "coiled-coil" entre 3 e $6 \mathrm{kcal} / \mathrm{mol}$, ao passo que a $\operatorname{Tm}_{143-235}$ (linha vermelha) apresenta valores menores que 2 $\mathrm{kcal} / \mathrm{mol}$. A Figura 36 mostra também que a $\mathrm{Tm}_{167-260}$ (linha verde) apresenta valores intermediários, tendo o seu máximo de propensão de formação de estrutura "coiled-coil" entre os resíduos 220 e 260, com um valor de aproximadamente $3 \mathrm{kcal} / \mathrm{mol}$. Estas predições são consistentes com nossos resultados obtidos por $C D$, desnaturação por uréia e AUC, os quais apontam para uma região particularmente instável entre os resíduos 143 e 235. 


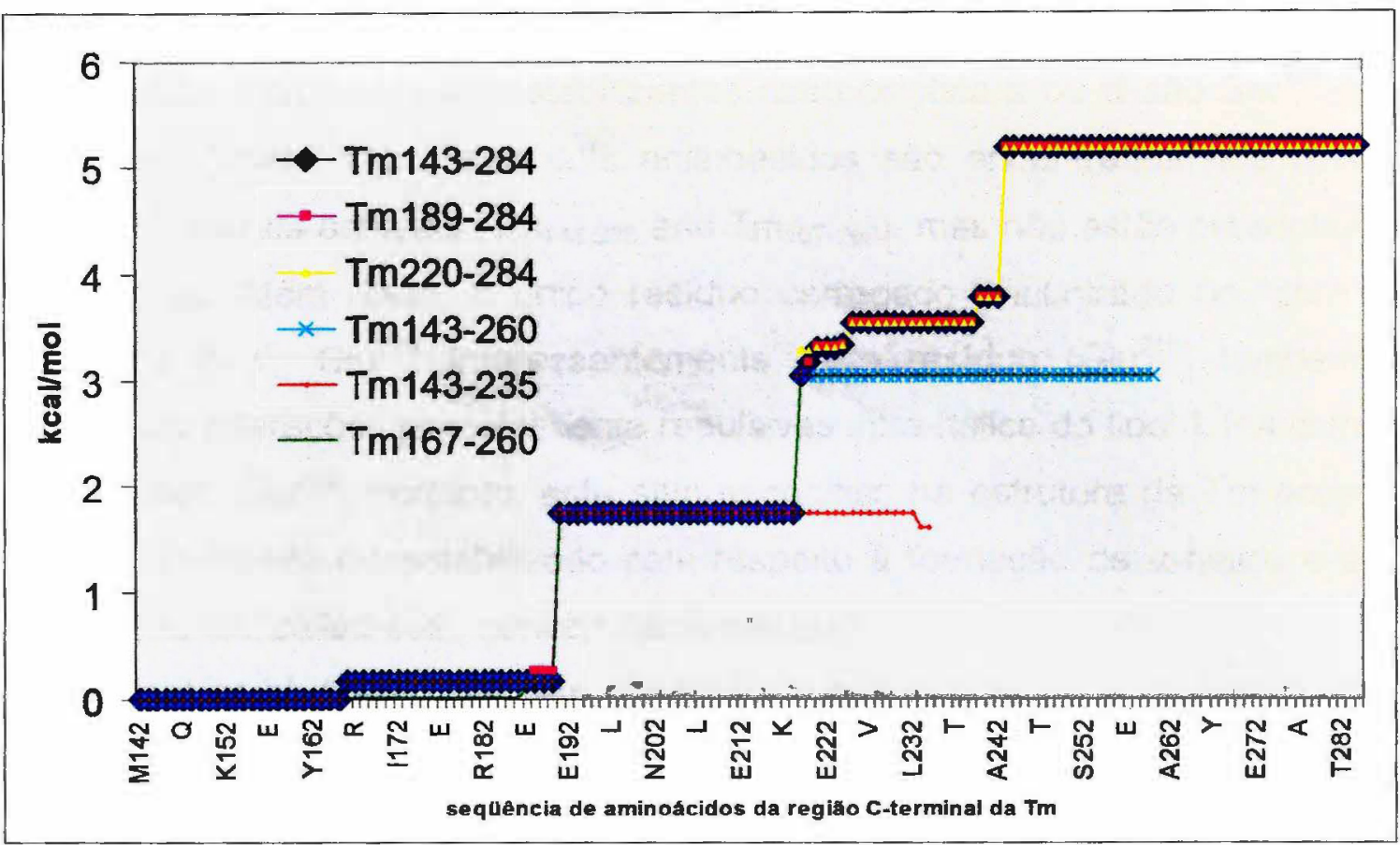

Figura 36 - Propensão para a formação de estrutura "coiled-coil" calculada pelo programa STABLECOIL. O programa mostra a região e a probabilidade em $\mathrm{kcal} / \mathrm{mol}$ que uma sequeência em particular irá adotar na forma de estrutura "coiled-coil". As regiōes que apresentam um valor de estabilidade predita para "coiled-coil" maior que $1 \mathrm{kcal} / \mathrm{mol}$ acima do valor limite estabelecido pelo programa têm uma probabilidade maior que 95\% de ser "coiled-coil". Note que a propensão para a formaçăo de estrutura "coiled-coil" de todos os fragmentos é maior quando se caminha para o C-terminal da molécula.

Um fator importante para a estabilidade da estrutura "coiled-coil" é a natureza das interaçōes hidrofóbicas que ocorrem entre os resíduos nas posições a e d da repetição heptapeptídica, as quais resultam na associação das hélices (Hodges et al., 1972; Zhou et al., 1992a,b). Tripet et al. (2000) compararam as contribuições relativas de cada aminoácido nas posições a e d da repetição heptapeptídica. Desta maneira, eles foram capazes de classificar os aminoácidos em cada posição como termodinamicamente estabilizantes ou desestabilizantes em relação a alanina, a qual devemos considerar neutra. Por exemplo, a ordem decrescente de estabilidade termodinâmica apresentada para a posição d foi: Leu, Met, lle, Tyr, Phe, Val, Gin, Ala, Trp, Asn, His, Thr, Lys, Ser, Asp, Glu, Arg, e Gly . A Tabela 11 mostra os resíduos encontrados nas posiçōes a e d da metade C-terminal da Tm. Estas posições são normalmente ocupadas por aminoácidos estabilizantes ( 26 posiçōes ocupadas 
por Leu, Ile, Val, Tyr, Met) ou aminoácidos neutros (10 Ala e 2 Gln). Os únicos dois resíduos claramente desestabilizantes nas posições a ou d são $\operatorname{Ser}^{186}$ e $\mathrm{Glu}^{218}$ (ver Tabela 11). Estes dois aminoácidos são encontrados nos dois fragmentos menos estáveis ( $\mathrm{Tm}_{143-235}$ and $T \mathrm{~m}_{167-260}$ ), mas não estão presentes em Tm220-284. Além disso, o único resíduo carregado encontrado no "core" hidrofóbico é o $\mathrm{Glu}^{218}$. Interessantemente, este resíduo ( $\mathrm{Glu}^{218}$ ) também participa em interações possivelmente repulsivas intra-hélice do tipo i, i+4 com o aminoácido $\mathrm{Glu}^{222}$. Portanto, este sítio específico na estrutura da Tm pode ser particularmente desestabilizado com respeito à formação de a-hélice e a dimerização da "coiled-coil", concomitantemente.

Tripet et al. (2000) também observaram que a posição a da repetição heptapeptídica é relativamente insensivel ao fato da cadeia lateral ser ou não $\beta$-ramificada, isto é, existe uma diferença pequena entre as estabilidades observadas para Leu, lle e Val. Por outro lado, a posição d possui uma preferência clara para Leu $\left(\Delta \Delta \mathrm{G}_{\mathrm{u}}(\mathrm{Ala})^{*}=3,8 \mathrm{kcal} / \mathrm{mol}\right)$ em vez de lle $\left(\left(\Delta \Delta \mathrm{G}_{\mathrm{u}}(\right.\right.$ Ala $\left.)=3,0 \mathrm{kcal} / \mathrm{mol}\right)$ e Val $\left(\Delta \Delta \mathrm{G}_{\mathrm{u}}(\right.$ Ala $\left.)=1,1 \mathrm{kcal} / \mathrm{mol}\right)$. Desconsiderando-se o resíduo C-terminal lle $\left(l l e^{284}\right)$, nós observamos que quarto posições d são ocupadas por Val ou lle na metade C-terminal da molécula de Tm. Três destes resíduos $\left(\mathrm{Val}^{165}, \| \mathrm{e}^{172}, \mathrm{Val}^{200}\right.$ ) são encontrados no fragmento menos estável $\left(\mathrm{Tm}_{143-235}\right)$. Por outro lado, os fragmentos relativamente mais estáveis $\left(\mathrm{Tm}_{220-284}\right.$ e $\left.\mathrm{Tm}_{189-284}\right)$ possuem, respectivamente, apenas uma ou duas posições $\mathbf{d}$ ocupadas por Val ou lle (Tabela 11).

As interações hélice-hélice das estruturas "coiled-coils" podem também ser estabilizadas ou desestabilizadas por interações inter-hélices entre resíduos carregados (i) na posição $\mathbf{g}$ de umas das hélices e um outro resíduo carregado (i+5) na posição e' da hélice vizinha (McLachlan e Stewart, 1976). $\mathrm{Na}$ Tabela 11 nós podemos ver os aminoácidos presentes nas posições e e $\mathbf{g}$ da metade C-terminal da $\mathrm{Tm}$. Interessantemente, uma repulsão única

\footnotetext{
* Uma caracterização biofísica completa foi realizada em um coiled-coil modelo, onde 20 diferentes resíduos de aminoácidos foram substituídos em uma posição d para determinar seu efeito sobre a estabilidade da proteína. $\Delta \Delta \mathrm{G}_{\mathrm{u}}$ (Ala) é a diferença da energia livre de desenovelamento $\left(\Delta \mathrm{G}_{\mathrm{u}}\right)$ relativa a uma Ala substituída na mesma posição de um peptídeo "coiled-coil" sintético.
} 
envolvendo dois resíduos carregados negativamente foi encontrada entre Asp $^{175}$ e Glu $^{180}$ nas posições $\mathbf{g}$ e e' respectivamente. Esta repulsão também deve estar contribuindo para as instabilidades relativas dos fragmentos $\mathrm{Tm}_{143-}$ 235 e $T m_{167-260}$, quando comparados aos fragmentos de mesmo tamanho, ou menores, que não contém estes resíduos ( $\operatorname{Tm}_{189-284}$ e $\left.T m_{220-284}\right)$ (Tabela 11).

Analisando-se a Tabela 11, podemos ver que a maioria dos resíduos coloridos, os quais implicam em algum efeito desestabilizante, estão localizados na região $\mathrm{N}$-terminal da metade $\mathrm{C}$-terminal da molécula de $\mathrm{Tm}$. Portanto, apesar da dificuldade em identificar as interações responsáveis pela baixa estabilidade da região central da molécula de Tm, nós acreditamos que conseguimos encontrar uma combinação de fatores que, juntos, podem explicar as nossas observações. Estas hipóteses podem ser testadas no futuro por mutagênese sítio-dirigida. 
Tabela 11. Resíduos encontrados nas posições heptapeptídicas a, d, e, e g da metade Cterminal da $\alpha$-Tm de músculo esquelético de galinha. Os resíduos coloridos são mencionados especificamente no texto. $L 5 \mathrm{OHW}_{278}$ : leucina ou $5 \mathrm{OHW}$ na posição 278

\begin{tabular}{|l|l|l|l|}
\hline $\mathbf{a}$ & $\mathbf{d}$ & $\mathbf{e}$ & $\mathbf{g}$ \\
\hline & $\mathrm{Q}_{144}$ & $\mathrm{E}_{145}$ & $\mathrm{Q}_{147}$ \\
$\mathrm{~L}_{148}$ & $\mathrm{~A}_{151}$ & $\mathrm{~K}_{152}$ & $\mathrm{I}_{154}$ \\
$\mathrm{~A}_{155}$ & $\mathrm{~A}_{158}$ & $\mathrm{D}_{159}$ & $\mathrm{~K}_{161}$ \\
$\mathrm{Y}_{162}$ & $\mathbf{V}_{165}$ & $\mathrm{~A}_{166}$ & $\mathrm{~K}_{168}$ \\
$\mathrm{~L}_{169}$ & $\mathbf{I}_{172}$ & $\mathrm{E}_{173}$ & $\mathrm{D}_{175}$ \\
$\mathrm{~L}_{176}$ & $\mathrm{~A}_{179}$ & $\mathrm{E}_{180}$ & $\mathrm{R}_{182}$ \\
$\mathrm{~A}_{183}$ & $\mathrm{~S}_{186}$ & $\mathrm{E}_{187}$ & $\mathrm{~K}_{189}$ \\
$\mathrm{C}_{190}$ & $\mathrm{~L}_{193}$ & $\mathrm{E}_{194}$ & $\mathrm{E}_{196}$ \\
$\mathrm{~L}_{197}$ & $\mathbf{V}_{200}$ & $\mathrm{~T}_{201}$ & $\mathrm{~N}_{203}$ \\
$\mathrm{~L}_{204}$ & $\mathrm{~L}_{207}$ & $\mathrm{E}_{208}$ & $\mathrm{Q}_{210}$ \\
$\mathrm{~A}_{211}$ & $\mathrm{Y}_{214}$ & $\mathrm{~S}_{215}$ & $\mathrm{~K}_{217}$ \\
$\mathrm{E}_{218}$ & $\mathrm{Y}_{221}$ & $\mathrm{E}_{222}$ & $\mathrm{E}_{224}$ \\
$\mathrm{I}_{225}$ & $\mathrm{~L}_{228}$ & $\mathrm{~T}_{229}$ & $\mathrm{~K}_{231}$ \\
$\mathrm{~L}_{232}$ & $\mathrm{~A}_{235}$ & $\mathrm{E}_{236}$ & $\mathrm{R}_{238}$ \\
$\mathrm{~A}_{239}$ & $\mathrm{~A}_{242}$ & $\mathrm{E}_{243}$ & $\mathrm{~S}_{245}$ \\
$\mathrm{~V}_{246}$ & $\mathrm{~L}_{249}$ & $\mathrm{E}_{250}$ & $\mathrm{~S}_{252}$ \\
$\mathrm{I}_{253}$ & $\mathrm{~L}_{256}$ & $\mathrm{E}_{257}$ & $\mathrm{E}_{259}$ \\
$\mathrm{~L}_{260}$ & $\mathrm{Q}_{263}$ & $\mathrm{~K}_{264}$ & $\mathrm{~K}_{266}$ \\
$\mathrm{Y}_{267}$ & $\mathbf{I}_{270}$ & $\mathrm{~S}_{271}$ & $\mathrm{E}_{273}$ \\
$\mathrm{~L}_{274}$ & $\mathrm{~A}_{277}$ & ${\mathrm{~L} / 50 H W_{278}}$ & $\mathrm{D}_{280}$ \\
$\mathbf{M}_{281}$ & $\mathrm{I}_{284}$ & & \\
\hline
\end{tabular}

O complexo Tn é constituído de três subunidades ( $T n C, T n l$ e $T n T$ ), cada uma das quais está dividida em dois domínios funcionais. Um deles é responsável pelas propriedades regulatórias e, o outro, responsável pelos contatos que mantêm as subunidades associadas e ligadas ao filamento de actina (Farah e Reinach, 1995, Gordon et al., 2000). A TnT media a ligação do complexo Tn com a Tm: o $\mathrm{N}$-terminal da TnT é estendido ao longo da região Cterminal da Tm, incluindo a região de interação cabeça-cauda entre duas Tms adjacentes, enquanto que o C-terminal da TnT interage com a $\mathrm{Tnl}$ e a $\mathrm{TnC}$, as quais, juntas, interagem com a actina (ver figura 4) e com a região central da Tm, dependendo da concentração de $\mathrm{Ca}^{2+}$ (Farah e Reinach, 1995; Gordon et al., 2000; White et al., 1987; Malnic et al., 1998) . 
A Tm é uma molécula flexivel (Phillips et al., 1986) e esta flexibilidade é diminuída quando ela interage com o complexo $\mathrm{Tn}$, sendo completamente restaurada após a ligação de $\mathrm{Ca}^{2+}$ à Tn (Wahl et al., 1978). O movimento da Tm sobre a molécula de Ac induzido através da ligação de $\mathrm{Ca}^{2+}$ tem sido observado por microscopia eletrônica (Lehman et al., 1994). Farah e Reinach (1999) mostraram que, quando o $\mathrm{Ca}^{2+}$ liga no complexo $\mathrm{Tn}$, ocorre uma mudança no micro-ambiente da sonda 50HW na posição 122 da Tm, um resíduo o qual esperava-se não estar em contato direto com a Tn. Portanto, a correlação entre a estabilidade conformacional e a função deve existir: transições estruturais locais devem ter um papel na ligação da Tm ao domínio de Tn sensivel ao $\mathrm{Ca}^{2+}$, bem como mudanças de posição sobre o filamento de actina em resposta ao $\mathrm{Ca}^{2+}$ e a ligação com miosina (Phillips et al., 1986).

Considerando-se que o movimento da Tm sobre a superfície de actina em resposta ao $\mathrm{Ca}^{2+}$ é, de fato, parte do mecanismo regulatório da contração muscular, nós devemos esperar que os últimos resíduos da região C-terminal da molécula de Tm necessitam ser mais estáveis para poderem se associar com o complexo TnT de forma independente de $\mathrm{Ca}^{2+}$, e também para poderem manter as interações cabeça-cauda entre moléculas de Tms. Por outro lado, a labilidade estrutural da parte central da molécula de Tm, a qual liga Tn dependentemente de $\mathrm{Ca}^{2+}$, deve promover mudanças conformacionais na estrutura da "coiled-coil", facilitando o seu reposicionamento sobre o filamento fino (Phillips et al., 1986). Recentemente, um trabalho publicado por Narita et al. (2001) apresentou um modelo no qual a Tm adota uma conformação curvada ao longo do filamento fino na ausência de $\mathrm{Ca}^{2+}$. Neste modelo, uma maior curvatura, estabilizada pela ligação de Tn à Ac, foi localizada na metade da quarta e em toda a quinta repetição $\alpha \beta$ (ver figura 12) da molécula de Tm, isto é, entre os resíduos 145 e 204. Esta é precisamente a região que nós demonstramos ser particularmente instável nos nossos estudos. Os resultados apresentados neste trabalho sugerem que os últimos cinqüenta resíduos da Tm conferem estabilidade para a metade C-terminal da molécula de Tm, enquanto que a região compreendida pelos resíduos 143-235 é 
particularmente instável. Além disso, a presença ou ausência dos resíduos 261-284, que são codificados pelo exon 9a (258-284), o qual é específico para músculo estriado (Lees-Miller et al., 1991), influencia fortemente o mecanismo de desenovelamento da estrutura "coiled-coil". Os estados conformacionais da Tm devem ser de grande importância para o seu papel fisiológico no controle da contração muscular. Como já foi mencionado anteriormente, Li et al. (2002) observaram através de estudos por cristalografia de raios-X que a região 254262 da molécula de Tm, bem como a região N-terminal da proteína GCN4 a ela fusionada, adota uma estrutura "coiled-coil" canônica, enquanto que as hélices formadas pelos resíduos 263-284 estão separadas e, a partir do resíduo 267 fazem um contato do tipo cauda-cauda com uma molécula simétrica. Mais recentemente, Greenfield et al. (2003) mostraram através de estudos de RMN que os resíduos 270-279 da molécula de Tm estão formando uma estrutura $\alpha$-helicoidal, mas não "coiled-coil" como ao longo da molécula de $\mathrm{Tm}$, sendo que os dímeros estão arranjados de uma maneira paralela nesta região. Além do mais, os resíduos 280-284 encontram-se em estrutura randômica (não helicoidal).

Desta maneira, é interessante interpretar nossos resultados com base nestas estruturas, desde que a região em que as hélices parecem estar separadas (estruturas de RMN e cristalografia publicadas por Greenfield et al., 2003 e Li et al., 2002) corresponde exatamente aos resíduos que nós observamos como sendo importantes para a estabilidade e cooperatividade de enovelamento da região C-terminal da molécula de Tm. Estas propriedades não podem ser atribuídas à formação de tetrâmeros como observado por Li et al. (2002), pois os nossos resultados de AUC mostraram que todos os fragmentos contendo os resíduos 261-284 formavam dimeros estáveis sob condições benignas. A seqüência de Tm entre os resíduos 261 e 269 mostra um significante desvio do padrão de polaridade normalmente observado em uma estrutura "coiled-coil", como já foi mencionado anteriormente (Li et al., 2002; Sousa e Farah, 2002) e isso deve ocasionar a separação das duas hélices observada por cristalografia, bem como a formação da estrutura 
tetramérica (Li et al., 2002). Para que os residuos 261-284 fiquem separados em solução de uma maneira similar àquela observada na estrutura cristalina, é necessário que a conformação a-hélice destes resíduos seja particularmente estável, como mostrado por Greenfield et al. (2003) e, portanto, de acordo com as nossas observações.

\section{Parte B - Investigando a interação cabeça-cauda de tropomiosinas} recombinantes truncadas no C-terminal

Hitchcock-DeGregori e colaboradores mostraram que são necessárias repetições $\alpha \beta$ (ver figura 12 na Introdução) integrais e uma estrutura "coiledcoil" contínua para a ligação da Tm de músculo estriado ao filamento de Ac (Hitchcock e An, 1996). Este mesmo grupo mostrou que quatro ou mais períodos $\alpha \beta$ são necessários para a Tm ligar à Ac com uma afinidade razoável (Moraczewska e Hitchcock-DeGregori, 2000).

Embora nós soubéssemos que nossos fragmentos não contêm um número de aminoácidos que envolvam um número integral de repetições $\alpha \beta$, e muito menos um total de quatro repetições, nós decidimos realizar experimentos de co-sedimentação (nos quais qualquer proteína que ligue à actina apresenta-se no precipitado após uma ultracentrifugação) para investigar se a ligação entre os fragmentos de $\operatorname{Tm}_{167-260}$ ou $\operatorname{Tm}_{143-260}$ e ASTm 1 . 142 iria promover alguma interação com a Ac. Nossos resultados na presença de 10, 25 e $50 \mathrm{mM}$ de $\mathrm{NaCl}$ (10 mM de MOPS, pH7,0; $5 \mathrm{mM}$ de $\mathrm{MgCl}_{2} ; 0,5 \mathrm{mM}$ de EGTA e $1 \mathrm{mM}$ de DTT a $25^{\circ} \mathrm{C}$ ) não mostraram nenhuma afinidade entre as combinações de $\left(\mathrm{Tm}_{167-260}, \mathrm{Tm}_{220-284}\right.$ ou $\left.\mathrm{Tm}_{143-260}\right)+\mathrm{ASTm}_{1-142}$ para actina (dados não mostrados).

Os resultados de viscosidade sugerem que o novo $\mathrm{C}$-terminal, que termina na posição 260, possui uma maior afinidade de interação cabeçacauda quando comparado com a ASTm. Apesar das aparentes diferenças em afinidades, a interação parece ser similar em natureza àquela observada para o C-terminal da proteína nativa, já que: a) a polimerização é fortemente 
dependente da força iônica, confirmando a natureza eletrostática da interação e b) a interação diminui muito em intensidade para a Tm recombinante contendo o $\mathrm{N}$-terminal não acetilado, $\mathrm{nfTm}_{1-260}$, demonstrando que a interação que nós estamos observando é especifica e dependente da estrutura do amino-terminal da $\mathrm{ASTm}_{1-260}$, ou seja, a interação é de fato do tipo cabeçacauda.

Trabalhos apresentados na literatura mostram que a fosforilação da serina 283, da $\alpha$-Tm, fortalece a interação cabeça-cauda da molécula de Tm (Heeley et al., 1989 e Heeley, 1994). Além disso, uma carga negativa extra (onde a serina 283 é substituída por um glutâmico, em STm283E) nesta posição, mimetizando a fosforilação, fortalece a interação cabeça-cauda, enquanto uma carga positiva extra (como em STm283K) enfraquece a interação cabeça-cauda (Sano et al., 2000a). Uma possivel hipótese para explicar o aumento da afinidade de ligação para os fragmentos que terminam na posição 260 é que os últimos onze aminoácidos da região Cterminal (lekksiddledel) apresentam uma concentração muito maior de resíduos carregados negativamente (ao todo 14 por dímero incluindo o carboxilato $\mathrm{C}$-terminal) em comparação com o $\mathrm{C}$-terminal da proteína nativa (eldhalndmsti), o qual apresenta 8 resíduos carregados por dímero. Desta maneira, o C-terminal que termina em 260 deve interagir mais fortemente com a região $\mathbf{N}$-terminal que está carregada positivamente (mdaikkkmqmlk (Veja Tabela 12). 
Tabela 12- Comparação entre as seqüências $\mathrm{N}$ - e C-terminais da $\mathbf{\alpha}$-Tm de tamanho

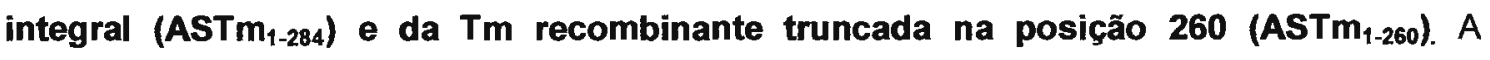
seqüencia $\mathrm{N}$-terminal é similar àquela codificada pelo exon $1 \mathrm{a}$, porém com uma fusão dipetídica (AS) na ponta $\mathrm{N}$-terminal. A seqüência $\mathrm{C}$-terminal nativa é codificada pelo exon $9 a$.

\begin{tabular}{|c|c|c|c|}
\hline Proteína & Viscosidade & Seqüência N-terminal & Seqüência C-terminal \\
\hline$a-T m_{1-284}$ & Normal & $\begin{array}{r}\text { fgabcde fgabcde } \\
\text { +ASmdaikkkmqmik }\end{array}$ & $\begin{array}{l}\text { gabcdefgabcd } \\
\text { eldhalndmsti- }\end{array}$ \\
\hline$a-\operatorname{Tm}_{1-260}$ & Alta & $\begin{array}{r}\text { fgabcdefgabcde } \\
\text { +ASmdaikkkmqmlk }\end{array}$ & $\begin{array}{l}\text { defgabcdefga } \\
\text { leksiddledel- }\end{array}$ \\
\hline
\end{tabular}

O excesso de cargas presentes no C-terminal da proteina que termina em 260 poderia desestabilizar esta região quando na ausência do fragmento $\mathrm{N}$-terminal, principalmente em baixas forças iônicas (onde existe uma enorme repulsão entre as cadeias laterais dos resíduos negativamente carregados na estrutura em a-hélice), contribuindo assim para a instabilidade dos fragmentos que terminam nesta região.

Os experimentos de dicroísmo circular apresentados neste trabalho, mostram que a interação cabeça-cauda entre os fragmentos $\operatorname{Tm}_{167-260}, \mathrm{Tm}_{143-}$ ${ }_{260}$ e $\operatorname{Tm}_{220-284}$ com ASTm ${ }_{1-142}$ é acompanhada por um significativo aumento no grau de enovelamento dos fragmentos $\mathrm{C}$-terminais. Como todos os fragmentos C-terminais envolvidos neste estudo não são muito estáveis nas condições dos ensaios (10 mM de fosfato de sódio pH7,0; 0,5 mM de EDTA; $1 \mathrm{mM}$ de DTT) (ver figura 32 e tabela 10), nós podemos supor que a interação com o Nterminal, o qual é carregado positivamente (ASTm ${ }_{1-142}$ ), esteja neutralizando as cargas negativas no $\mathrm{C}$-terminal e, desta maneira, fazendo com que as conformações helicoidais dos fragmentos $\mathrm{C}$-terminais fiquem mais estáveis que antes.

As seqüências $\mathrm{N}$ - e C-terminais da molécula de $\mathrm{Tm}$ são um fator determinante na força de comunicação entre duas moléculas de Tm adjacentes sobre o filamento de actina, bem como para a interação com a Tn (Lehrer et al. 1997, Palm et al. 2003). Recentemente, Palm et al. (2003) estudaram a formação de complexos entre peptídeos contendo as seqüências C-terminais e $\mathrm{N}$-terminais da $\mathrm{Tm}$. As seqüências utilizadas para os estudos 
envolviam regiões codificadas pelos exons 1a e 1b (que codificam respectivamente as regiões $\mathrm{N}$-terminais das isoformas de alto peso molecular contendo 284aa, expressas em células musculares e não musculares, e as de baixo peso molecular contendo 247 aa, expressas somente em células não musculares) e o exon 9 a (que codifica as regiões $\mathrm{C}$-terminais das isoformas específicas de músculo estriado) e exon $9 d$ (expresso em músculos lisos e isoformas não musculares). Neste trabalho, observou-se que existe a formação de uma interação cabeça-cauda entre as quatro possíveis combinações de fragmentos $\mathrm{N}$-terminais (região codificada pelos exons 1a ou 1b) e os fragmentos C-terminais (região codificada pelos exons 9a e 9d). Este trabalho mostrou ainda que ambos os peptídeos C-terminais (9a ou 9d) formaram complexos binários mais estáveis com o $\mathrm{N}$-terminal codificado pelo exon $1 \mathrm{~b}$ (seqüência: AGSSSLEAVRRKIRSL) do que o N-terminal codificado pelo exon 1a (seqüência: MDAIKKKMQMLK). Estes resultados estão de acordo com resultados anteriores apresentados por Lehrer et al.(1997), os quais mostram que uma Tm recombinante de fibroblasto (5aTm, não muscular), cujas seqüências $\mathrm{N}$ - e $\mathrm{C}$-terminais são iguais, respectivamente, àquelas codificadas pelos exons $1 b$ e $9 d$, apresentavam uma interação cabeça-cauda mais forte que a Tm de músculo esquelético, RSTm, onde as seqüências $\mathrm{N}$ - e Cterminais são codificadas pelos exons 1 a e 9 a.

Sander e Smillie (1984) e Graceffa (1989) mostraram que uma Tm de músculo liso, GTm (moela de galinha, onde o $\mathrm{N}$-terminal é codificado pelo exon 1a e o C-terminal é codificado pelo exon 9d), apresentava uma interação cabeça-cauda mais forte do que a de uma tropomiosina de músculo esquelético, RSTm (músculo esquelético de coelho), observada através de medidas de viscosidade em baixas concentrações salinas. Uma análise das seqüências do $\mathrm{C}$-terminal mostra que a diferença principal entre as isoformas $\alpha$ e $\beta$ da Tm de músculo esquelético e as correspondentes Tms de músculo liso é a seqüência dos nove últimos resíduos $\mathrm{C}$-terminais, onde as Tms de músculo liso apresentam duas asparaginas (N282 e N283) que parecem ser 
conservadas entre elas, mas que não existem na seqüência das isoformas de músculo esquelético (ver Tabela 13 em azul claro).

Nós decidimos, dessa maneira, fazer um alinhamento entre as seqüências $C$-terminais das isoformas $\alpha$ e $\beta$ de músculo estriado e de músculo liso da Tm que são conhecidas por ligar actina e por fazer interações cabeçacauda (Sanders e Smillie 1984, Graceffa 1989, Lehrer et al. 1997, Palm et al. 2003) com a região C-terminal (últimos 30 aminoácidos) do fragmento que termina na posição 260 (Tabela 13). Comparando-se todas as seqüências, podemos observar a existência de uma alta similaridade entre o C-terminal de $\mathrm{Tm}_{1-260}$ com as isoformas $\alpha$ e $\beta$ de músculo estriado e $\alpha$ e $\beta$ de músculo liso. Além dos resíduos que são similares entre todas as seqüências analisadas, existe na seqüência da ASTm $_{1-260}$ um ácido aspártico (D254) que apresenta similaridade com a asparagina (N279) das isoformas musculares a e $\beta$, e que não aparece nas isoformas de músculo liso. No entanto, os residuos E257 e D258 da Tm 1-260 apresentam similaridade com as asparaginas (N282 e N283) que aparecem somente nas isoformas de músculo liso. Devemos notar ainda que todas as isoformas listadas na Tabela 13 têm seqüências $\mathrm{N}$-terminais idênticas ou quase idênticas (substituição conservativa, D por $E$, do segundo aminoácido). Logo, as diferenças em afinidade cabeça-cauda podem ser atribuidas às diferenças nas seqüências/estruturas dos seus C-terminais.

O fato de a ASTm 1-260 apresentar resíduos similares aos que aparecem somente nas isoformas de músculo liso (N282 e N283), além de todos os outros resíduos conservados, unido ao fato dela apresentar um maior número de resíduos carregados nesta região, pode explicar o porquê destas Tms truncadas na posição 260 estarem sendo capazes de interagir de forma cabeça-cauda.

Recentemente, Greenfield et al. (2002) mostraram que os deslocamentos químicos do ${ }^{1} \mathrm{H}$ e do ${ }^{15} \mathrm{~N}$ dos resíduos 274 a $284 \mathrm{da} \mathrm{Tm}$ são altamente perturbados após a interação entre dois peptídeos $\mathrm{N}$ - e C-terminais. Os picos dos resíduos 1 a 8 e 11 a 12 da região $\mathrm{N}$-terminal parecem apresentar deslocamentos também após esta interação (resultados não 
publicados, ver Palm et al., 2003). Estes resultados sugerem o envolvimento dos 11 resíduos $\mathrm{C}$ - e $\mathrm{N}$-terminais nas interações cabeça-cauda.

O modelo de interação cabeça-cauda originalmente proposto por McLachlan e Stewart (1975) propõe a existência de três pontes salinas intermoleculares específicas entre aminoácidos em uma das fitas da região $\mathrm{C}$ terminal e a outra fita da região $\mathrm{N}$-terminal da molécula de $\mathrm{Tm}$. Neste modelo a His276 de uma a-hélice C-terminal estaria interagindo com o Asp2 de uma das hélices $\mathrm{N}$-terminais. Da mesma forma, estariam interagindo Asp280 com Lys6 e lle284 ( $\mathrm{COO}^{-}$) com Lys7 (ver Figura 37). Recentemente, Sousa e Farah (2002) propuseram a existência de outras interações salinas, em adição àquelas propostas por McLachlan e Stewart, onde a cadeia lateral positivamente carregada da Lys12 e o segundo carboxilato da 1284 , que se encontra na outra hélice da molécula de Tm, estariam interagindo. 
Tabela 13- Alinhamento dos últimos quatorze resíduos C-terminais de várias isoformas de $\mathrm{Tm}$ com os últimos 30 resíduos C-terminais da $\mathrm{Tm}$ recombinante $\mathrm{Tm}_{1-260}$. A comparação está sendo feita entre a $\mathrm{Tm}_{1-260}$ recombinante e as isoformas musculares lisas e esqueléticas conhecidas na literatura por fazerem interações cabeça-cauda. Em azul, vermelho e marrom estão mostradas respectivamente todas as leucinas, ácidos glutåmicos e treoninas idênticas, conservadas ou semi-conservadas em todos os $\mathrm{C}$-terminais apresentados. Em verde estāo mostradas as $\mathbf{N}_{279}$ nas isoformas a- e $\boldsymbol{\beta}$ - musculares que possuem similaridade com $\circ \mathrm{D}_{254}$ da $\mathrm{Tm}_{1-260}$. Em azul claro estão mostrados os aminoácidos que apresentam similaridade entre a $\mathbf{T m}_{1-260} \mathrm{e}$ as isoformas não musculares. Em letra sublinhada estão todos os resíduos, dentre os onze últimos, que apresentam cargas negativas. $O$ alinhamento foi feito através do programa ClustalW que se encontra no seguinte endereço da Internet: http://www.ebi.ac.uk/clustalw/\#. A seqüência de pontos abaixo da seqüência da $\mathrm{Tm}_{1-260}$ mostra a pontuação do alinhamento da $\mathrm{Tm}_{1-260} \mathrm{com}$ as isoformas $\boldsymbol{\alpha}$ - e $\boldsymbol{\beta}$ - de músculo liso. A seqüência de pontos acima da seqüência da $\mathbf{T m}_{1-260}$ mostra a pontuação do alinhamento entre $T m_{1-260}$ e isoformas $\alpha$ - e $\beta$ - de músculo estriado. Onde * significa que existe identidade entre os aminoácidos e : significa que os aminoácidos såo conservados. *1(Kluwe et al. 1995), "2(Mische et al. 1987), "3(Gooding et al. 1987), "4 (Ohara et al. 1989), *5(Hardy et al. 1991), ${ }^{*} 6$ (Widada et al.1988) ${ }^{*} 7$ (Mak et al.1980) ${ }^{*} 8$ (Hardy et al.1992), ${ }^{*} 9$ (Helfman et al. 1983, Sanders e Smillie, 1985), ${ }^{*}$ 10(Ruiz-Opazo et al. 1985).

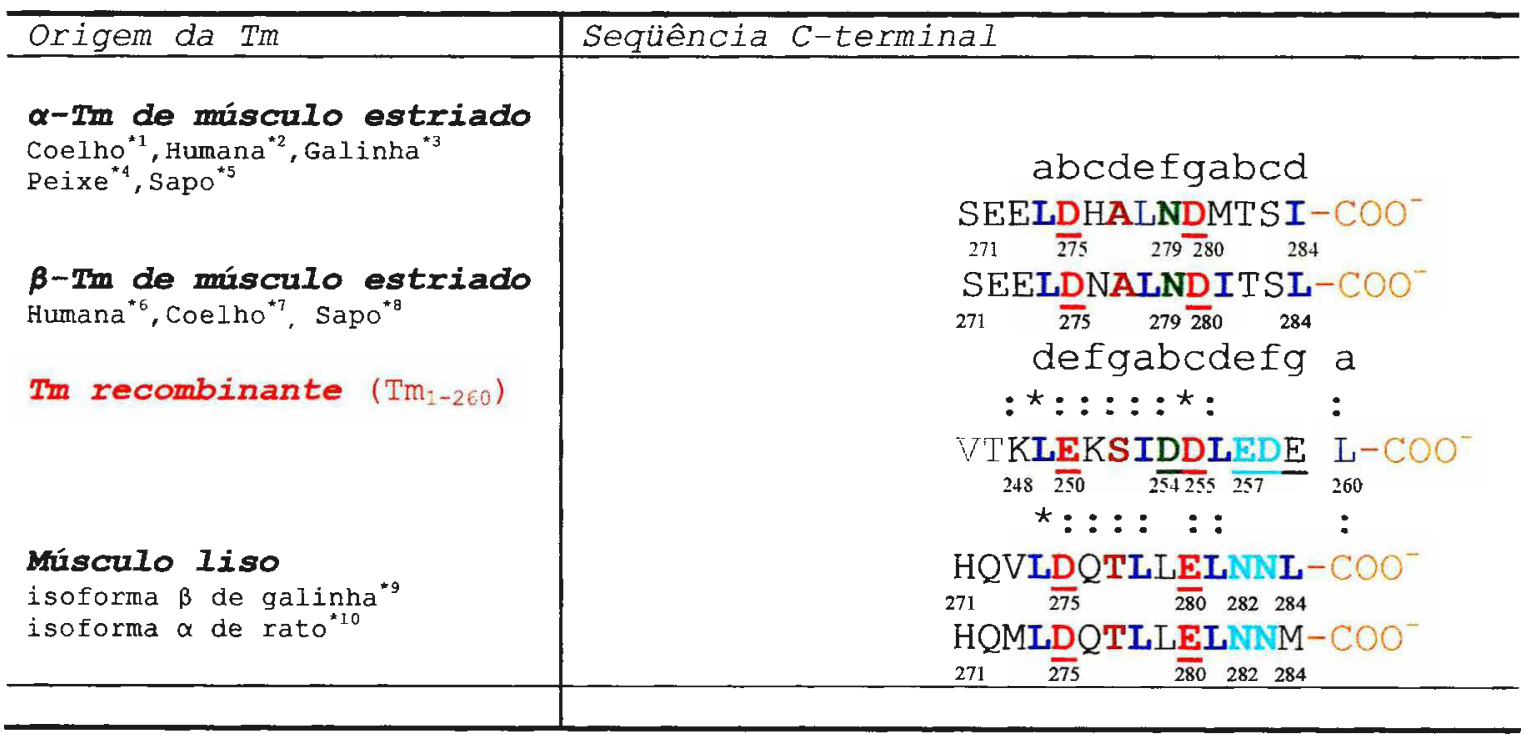




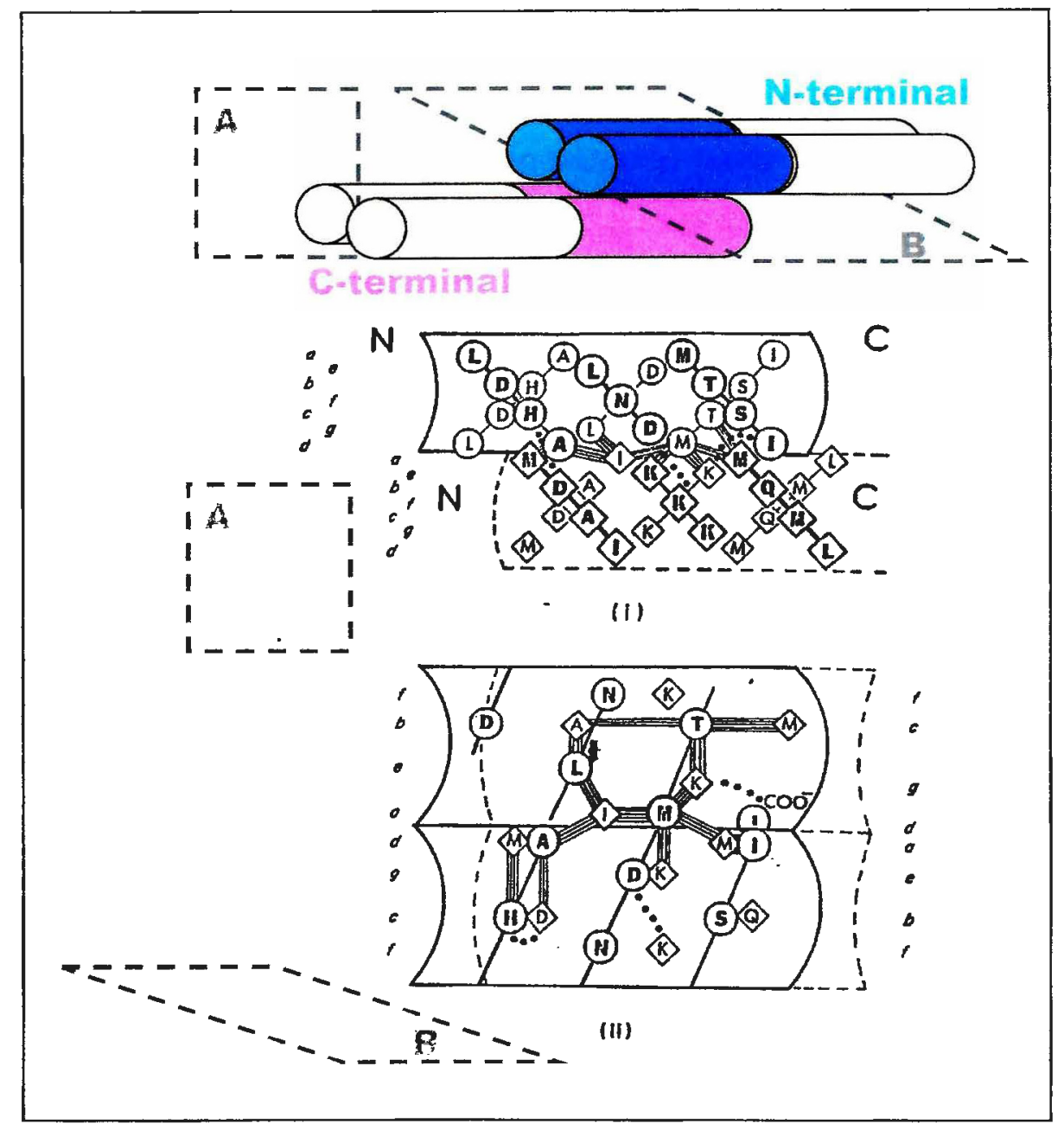

Figura 37- O Esquema mostra o modelo de McLachlan e Stewart (1975) para as interações cabeça-cauda. No modelo, McLachlan e Stewart propõem a sobreposição de 9 aminoácidos localizados no $\mathrm{N}$ - e no C-terminal da molécula de $\mathrm{Tm}$. As interações cabeça-cauda estão esquematizadas na figura colorida. Esta figura foi divida em dois planos, $A$ e $B$, para que possamos entender o modelo de McLachlan e Stewart. No plano A observa-se um corte vertical que permite-nos visualizar a interface entre as cadeias $\mathrm{N}$-e $\mathrm{C}$-terminais. A parte superior da figura (i) representa os aminoácidos C-terminais, representados por círculos, e a parte inferior representa os aminoácidos $\mathrm{N}$-terminais, representados por losangos. As pontes salinas propostas entre His276-Asp2, Asp280-Lys6 e lle284(COO)-Lys7 estão representadas em linha pontilhadas. As linhas contíguas representam as interações de van der Waal's. No plano $B$ observa-se um corte horizontal, onde se podem observar estas mesmas interações (figura (ii)). 
Nós não conhecemos a estrutura da região $\mathrm{C}$-terminal da Tm truncada (ASTm ${ }_{1-260}$ ) e, desta maneira, fica difícil propor um modelo das interações específicas que poderiam estar ocorrendo entre as cargas negativas adicionais apresentadas por este polipeptídeo na região $\mathrm{C}$-terminal e a região $\mathrm{N}$-terminal da molécula. De qualquer forma, uma comparação desta seqüência com o Cterminal da Tm nativa nos permite observar que o C-terminal da ASTm1-260 apresenta uma lisina na posição 251 (K251), correspondente a His276 na molécula nativa, e um aspártico na posição 255 (D255), correspondente ao Asp280 na molécula nativa (comparar as seqüências da $\mathrm{ASTm}_{1-260}$ e da $\alpha-\mathrm{Tm}$ de músculo estriado na tabela 13). Desta forma, as interações propostas por McLachlan e Stewart para os resíduos Asp280 e His 276 da molécula nativa podem estar sendo conservadas no caso da Tm recombinante truncada

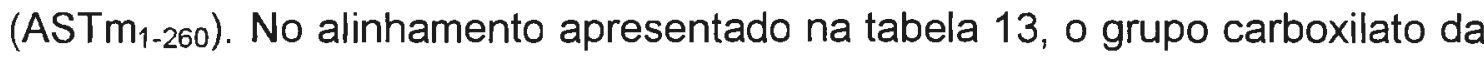
$\mathrm{Tm}_{\text {1-260 }}$ está deslocado por um aminoácido do grupo carboxilato da Tm nativa. Entretanto é possível que a existência de um ácido glutâmico na posição 259 da $T m_{1-260}$ pode estar mimetizando, através da sua cadeia lateral, o carboxilato terminal da forma nativa. Além disso, existe uma outra lisina na posição 15 do $\mathrm{N}$-terminal (K15) e nós não devemos desconsiderar a possibilidade de a interação cabeça-cauda entre ASTm $_{1-260}$ estar se estendendo além dos 12 aminoácidos iniciais.

Assumindo que as interações cabeça-cauda que ocorrem em ASTm1-260 sejam conservadas em relação às interações cabeça-cauda que ocorrem na molécula nativa, propostas por McLachlan e Stewart (1975), algumas observações interessantes podem nos ajudar a propor um modelo para as interações cabeça-cauda:

1- No alinhamento da Tabela 13, os resíduos C-terminais da ASTm 1-260 não se encontram na mesma posição heptapeptídica que os resíduos similares a eles na molécula de Tm nativa. Por exemplo, o resíduo D280 da molécula nativa ocupa uma posição heptapeptídica $\mathbf{g}$, enquanto que o resíduo com o qual ele alinha na $\operatorname{Tm}_{1-260}$ (D255) ocupa uma posição c (ver Tabela 13). Desta 
forma, se as interações eletrostáticas $\mathrm{N}$ - e C-terminais entre os resíduos conservados estiverem sendo mantidas como proposto por McLachlan e Stewart (1975) e por Sousa e Farah (2002), elas não estão ocorrendo entre aminoácidos presentes na mesma posição tridimensional (da repetição heptapeptídica) que os da Tm nativa. Entretanto, se os últimos resíduos Cterminais não adotarem uma estrutura "coiled-coil" canônica, o alinhamento da estrutura baseado na repetição heptapeptídica perde o sentido. Neste caso, é possivel que os C-terminais das proteínas terminando em 260 e em 284 adotem estruturas similares quando complexadas com o $\mathrm{N}$-terminal da Tm. Para distinguir entre estas duas hipóteses é necessário conhecer a estrutura desta região da molécula.

2- Como já foi visto anteriormente, a simples não acetilação do $\mathbf{N}$ teminal afeta a magnitude das interações cabeça-cauda. Isto se deve ao fato de que o N-terminal da Tm não acetilado apresenta uma estrutura não tão estável quando comparada com a estrutura do N-terminal acetilado (ver figura 13, Palm et al., 2003, Greenfield et al. 1998 e Brown et al. 2001). Entretanto,

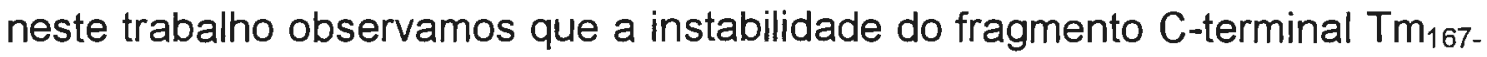
260 não o impede de fazer interações cabeça-cauda. Esta instabilidade deve estar relacionada à alta incidência das cargas negativas no C-terminal, já que ela é afetada pela força iônica do meio e pela interação com o N-terminal positivamente carregado. Logo concluímos que a instabilidade da região Cterminal não afeta a magnitude das interações cabeça-cauda.

Estas observações, unidas aos dados de estrutura das regiões $\mathrm{N}$ - e Cterminais independentes, publicadas recentemente por Greenfield et al.(1998, 2003) e por Li et al.(2002), os quais mostram que o $\mathrm{N}$-terminal assume uma estrutura "coiled-coil", ao passo que no C-terminal as duas a-hélices encontram-se separadas, nos levam a propor que na interação cabeça-cauda - N-terminal permanece com a sua estrutura "coiled-coil" inserida entre as duas fitas C-terminais, as quais devem estar separadas (como mostrado na Figura 38A). Isto explicaria também o porquê do aumento da quantidade de cargas no C-terminal criado pela mutação estaria promovendo um aumento na 
intensidade de polimerização, já que haveria desta maneira um maior número de possibilidades para a ocorrência de interações eletrostáticas entre as cargas localizadas no $\mathrm{N}$ - e no $\mathrm{C}$-terminal, devido a um aumento na superfície de contato entre as cadeias polipeptídicas.

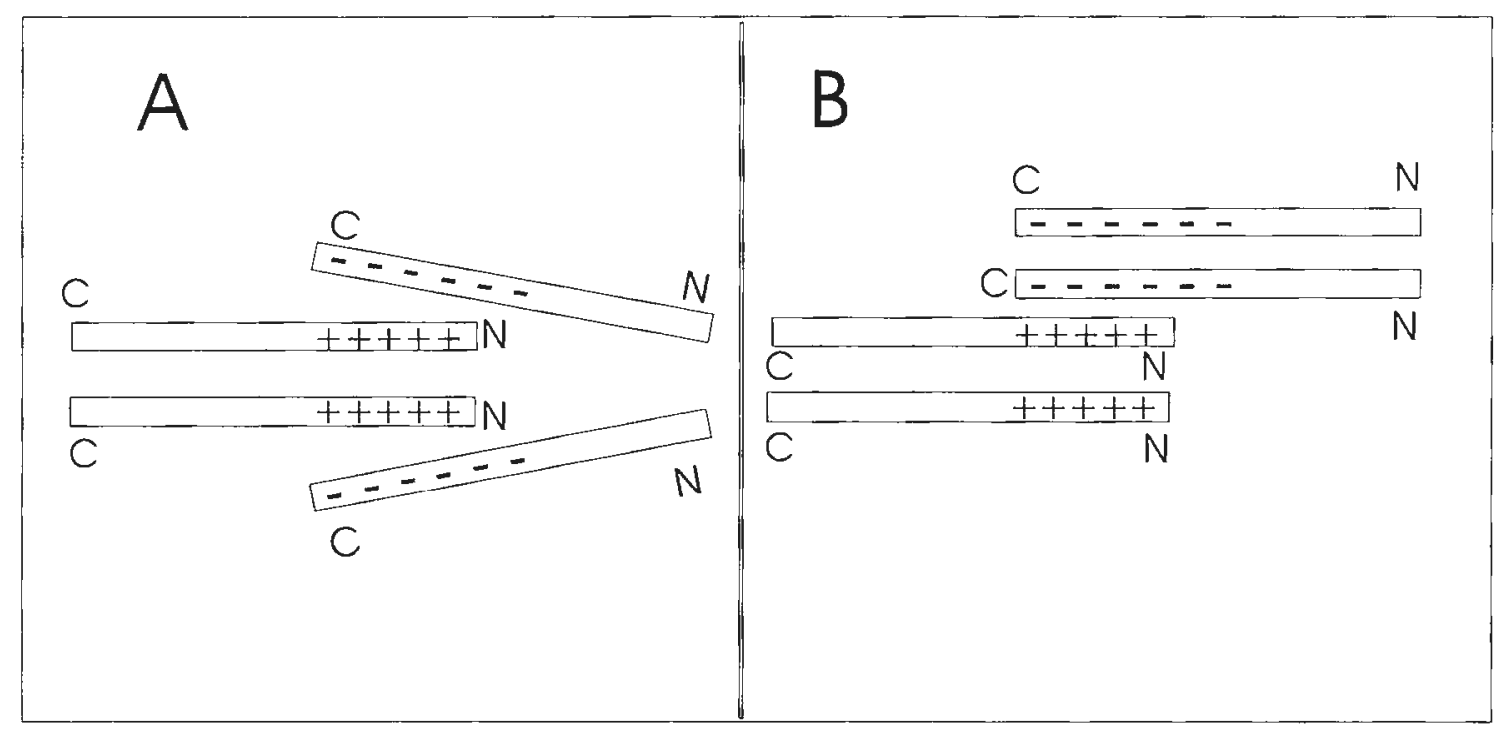

Figura 38 - A) O esquema mostra que existe um maior número de possibilidades para interações eletrostáticas entre o $\mathrm{N}$ - terminal "coiled-coil" e o C-terminal apresentando os últimos resíduos das fitas $\alpha$-hélices separados, como proposto por Li et al.(2002) e Greenfield et al. (2003). B) O esquema mostra que as possibilidades de interação eletrostática diminuem se ocorre uma interação do N-terminal em estrutura "coiled-coil" com o C-terminal também em estrutura "coiled-coill", como proposto por McLachlan e Stewart (1975).

Obviamente, esta hipótese teria que ser testada através da cristalização dos complexos $\operatorname{Tm}_{167-260}$-ASTm ${ }_{1-142}$ e $\mathrm{Tm}_{220-284}$-ASTm ${ }_{1-142}$. Neste sentido, nós estabelecemos uma colaboração com o grupo do Dr. F.Javier Medrano no Laboratório Nacional de Luz Sincrotron (LNLS), e o complexo Tm 220-284-ASTm1. 142 já vem sendo empregado em testes para obtenção das melhores condições de cristalização. Devido à alta sensibilidade da interação cabeça-cauda à força iônica, o complexo envolvendo o C-terminal nativo pode ser desestabilizado pelas condições de cristalização. $O$ fato da ASTm $_{1-260}$ encontrar-se significantemente polimerizada em forças iônicas elevadas (veja figura 29) sugere que a utilização de fragmentos $\mathrm{C}$-terminais que terminam na posição 
260 podem ser valiosa para que consigamos cristalizar um complexo que faz interações do tipo cabeça-cauda.

A Tm é uma molécula que possui muitas regiões similares dentro da sua seqüência polipeptídica devido à repetição da seqüência heptapeptídica, que caracteriza a estrutura "coiled-coil" e as repetições $\alpha \beta$, que supostamente caracterizam os sítios de ligação à actina (ver figura 12 da introdução, McLachlan e Stewart, 1976). Desta maneira, fazendo-se um alinhamento da região C-terminal da Tm com a molécula inteira, é possível encontrar outras regiões, além da região 260, que são similares à região C-terminal. Desta forma, este trabalho abre oportunidades para outras investigações, em que a produção de novos mutantes de deleção poderá responder perguntas acerca da especificidade da interação cabeça-cauda. 


\section{5- Conclusões}

Nossos experimentos de equilíbrio de sedimentação e de desnaturação por uréia acompanhada por CD revelam que a região 261284 é de grande importância para a estabilidade da metade C-terminal da Tm. Como o fragmento 253-284 estudado por Holtzer et al. (1995) mostrouse completamente instável mesmo a baixas temperaturas e altas concentrações, nós concluímos que a estabilidade conferida pela região 261-284 é dependente de seqüências vizinhas.

Os fragmentos que estão localizados mais para a região central da molécula são mais instáveis. Dois fragmentos com aproximadamente 60 aminoácidos que haviam sido previamente apresentados na literatura (183244, de 62aa e 190-254, de 65aa) mostraram-se pouco estáveis em baixas concentrações e a $25^{\circ} \mathrm{C}$. Logo, as instabilidades observadas para os fragmentos $\operatorname{Tm}_{167-260}$ (94aa) e $\operatorname{Tm}_{143-235}$ (93aa) são uma conseqüência da instabilidade intrínseca da região central da molécula.

O TFE não induz a dissociação dos fragmentos de Tm, mas induz a formação de trímeros estáveis naqueles fragmentos que contém a região 261-284 e um concomitante decréscimo na razão $\theta_{222} / \theta_{208}$.

A ausência da região 261-284 na molécula de Tm cria, de fato, um "novo C-terminal" capaz de fazer interações cabeça-cauda na molécula de Tm. A nfTm269(50HW), não polimerizável, a qual possui uma sonda fluorescente sensível à polimerização cabeça-cauda, interage de forma específica com um fragmento de Tm contendo somente a metade $\mathrm{N}$ -

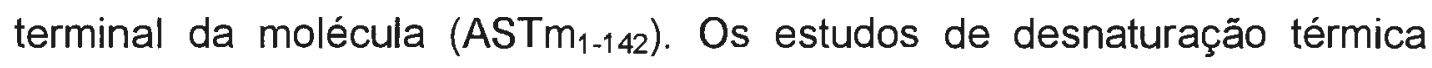
acompanhada por CD mostram que os fragmentos de $\mathrm{Tm}$ não polimerizáveis que terminam na posição 260 ( $\left.\mathrm{Tm}_{167-260}, \mathrm{Tm}_{143-260}\right)$, bem como $\mathrm{Tm}_{220-284}$ São capazes de interagir com o fragmento não polimerizável N-terminal (ASTm ${ }_{1-142}$ ).

A instabilidade relativa apresentada pelos fragmentos $\mathrm{Tm}_{167-260}$, $\mathrm{Tm}_{143-260}$ e $\mathrm{Tm}_{220-284} \mathrm{em}$ baixa força iônica e a $25^{\circ} \mathrm{C}$ não os impede de fazer 
interações do tipo cabeça-cauda. Os resultados mostram que a interação cabeça-cauda é acompanhada por um aumento significante no grau enovelamento dos fragmentos da região $\mathrm{C}$-terminal da $\mathrm{Tm}$ em baixas forças iônicas.

Uma possível hipótese para explicar o aumento da ligação para os fragmentos que terminam em 260 é:

a) os últimos onze resíduos $\mathrm{C}$-terminais apresentam uma grande quantidade de resíduos carregados negativemente quando comparados com o C-terminal nativo.

b) A seqüência C-terminal da $\operatorname{Tm}_{1-260}$ possui um grande grau de similaridade com C-terminais de várias isoformas de Tm nativas. 


\section{6- Referências}

Adelstein, R. S. \& Eisenberg, E. (1980). Regulation and Kinetics of the Actin-Myosin-Atp Interaction. Annu. Rev. Biochem. 49, 921-956.

Araya, E., Berthier, C., Kim, E., Yeung, T., Wang, X., \& Helfman, D. M. (2002). Regulation of coiled-coil assembly in tropomyosins. J. Struct. Biol. 137, 176-183.

Berger, B., Wilson, D. B., Wolf, E., Tonchev, T., Milla, M., \& Kim, P. S. (1995). Predicting Coiled Coils by Use Sf Pairwise Residue Correlations. Proc. Natl. Acad. Sci. USA. 92, 8259-8263.

Bodwell, C. E., Kominz, D. R., \& Duntley, B. J. (1965). Thermostability of Tropomyosin. Biochem. Biophys. Res. Commun. 21, 210-214.

Brown, J. H., Kim, K. H., Jun, G., Greenfield, N. J., Dominguez, R., Volkmann, N., Hitchcock-DeGregori, S. E., \& Cohen, C. (2001). Deciphering the design of the tropomyosin molecule. Proc. Natl. Acad. Sci. USA 98, 8496-8501.

Buck, M. (1998). Trifluoroethanol and colleagues: cosolvents come of age. Recent studies with peptides and proteins. Q. Rev. Biophys. 31, 297-355.

Chitra, R. \& Smith, P. E. (2001). Preferential interactions of cosolvents with hydrophobic solutes. J. Phys. Chem. B 105, 11513-11522.

Cho, Y. J., Liu, J., \& Hitchcock-DeGregori, S. E. (1990). The amino terminus of muscle tropomyosin is a major determinant for function. J. Biol. Chem. 265, 538-545.

Cohen, C. (1975). The protein switch of muscle contraction. Sci. Am. 233, 36-45.

Cohen, C. \& Parry, D. A. D. (1990). Alpha-Helical Coiled Coils and Bundles - How to Design An Alpha-Helical Protein. Proteins 7, 1-15.

Das, K., Ashby, K. D., Smirnov, A. V., Reinach, F. C., Petrich, J. W., \& Farah, C. S. (1999). Fluorescence properties of recombinant tropomyosin containing tryptophan, 5-hydroxytryptophan and 7-azatryptophan. Photochem Photobiol. 70, 719-730.

Dong, A., Matsuura, J., Manning, M. C., \& Carpenter, J. F. (1998). Intermolecular betasheet results from trifluoroethanol-induced nonnative alpha-helical structure in beta-sheet predominant proteins: infrared and circular dichroism spectroscopic study. Arch. Biochem. Biophys. 355, 275-281.

Ebashi, S. (1976). Excitation-contraction coupling. Annu. Rev. Physiol. 38, 293-313.

Eftink, M. R. (1991). Fluorescence Techniques for Studying Protein-Structure. Methods. Biochem. Anal. 35, 127-205.

Fan, P., Bracken, C., \& Baum, J. (1993). Structural characterization of monellin in the alcohol-denatured state by NMR: evidence for beta-sheet to alpha-helix conversion. Biochemistry 32, 1573-1582.

Farah, C. S. \& Reinach, F. C. (1995). The troponin complex and regulation of muscle contraction. FASEB J. 9, 755-767. 
Farah, C. S. \& Reinach, F. C. (1999). Regulatory properties of recombinant tropomyosins containing 5-hydroxytryptophan: Ca2+-binding to troponin results in a conformational change in a region of tropomyosin outside the troponin binding site. Biochemistry 38, 10543-10551.

Fasman GD (1996). Circular Dichroism and the Conformational Analysis of Biomolecules Plenum Press - New York and London.

Gooding, C., Reinach, F. C., \& Macleod, A. R. (1987). Complete nucleotide sequence of the fast-twitch isoform of chicken skeletal muscle alpha-tropomyosin. Nucleic Acids Res. 15, 8105.

Goodman, M., Naider, F., \& Toniolo, C. (1971). Circular Dichroism Studies of Isoleucine Oligopeptides in Solution. Biopolymers 10, 1719-1730.

Gordon, A. M., Homsher, E., \& Regnier, M. (2000). Regulation of contraction in striated muscle. Physiol. Rev. 80, 853-924.

Graceffa, P. \& Lehrer, S. S. (1980). The excimer fluorescence of pyrene-labeled tropomyosin. A probe of conformational dynamics. J. Biol. Chem. 255, 1129611300.

Graceffa, P. (1989). In-register homodimers of smooth muscle tropomyosin. Biochemistry $28,1282-1287$.

Gratzer, W. B., Doty, P., \& Holzwarth, G. M. (1961). Polarization of Ultraviolet Absorption Bands in Alpha-Helical Polypeptides. Proceedings of the National Academy of Sciences of the United States of America 47, 1785.

Greaser, M. L. \& Gergely, J. (1971). Reconstitution of troponin activity from three protein components. J. Biol. Chem. 246, 4226-4233.

Greaser, M. L. \& Gergely, J. (1973). Punification and properties of the components from troponin. J. Biol. Chem. 248, 2125-2133.

Greenfield, N. J., Montelione, G. T., Farid, R. S., \& Hitchcock-DeGregori, S. E. (1998). The structure of the N-terminus of striated muscle alpha-tropomyosin in a chimeric peptide: nuclear magnetic resonance structure and circular dichroism studies. Biochemistry 37, 7834-7843.

Greenfield, N. J., Palm, T., \& Hitchcock-DeGregori, S. E. (2002). Structure and interactions of the carboxyl terminus of striated muscle alpha-tropomyosin: it is important to be flexible. Biophys. J. 83, 2754-2766.

Greenfield, N. J., Swapna, G. V., Huang, Y., Palm, T., Graboski, S., Montelione, G. T., \& Hitchcock-DeGregori, S. E. (2003). The structure of the carboxyl terminus of striated alpha-tropomyosin in solution reveals an unusual parallel arrangement of interacting alpha-helices. Biochemistry 42, 614-619.

Hanson, J. \& Lowy, J. (1963). The structure of F-actin and of actin filaments isolated from muscle. J. Mol. Biol. 6, 46-60.

Harbury, P. B., Zhang, T., Kim, P. S., \& Alber, T. (1993). A switch between two-, three-, and four-stranded coiled coils in GCN4 leucine zipper mutants. Science 262, 1401-1407. 
Harbury, P. B., Kim, P. S., \& Alber, T. (1994). Crystal-Structure of An Isoleucine-Zipper Trimer. Nature 371, 80-83.

Hardy, S., Fiszman, M. Y., Osborne, H. B., \& Thiebaud, P. (1991). Characterization of Muscle and Nonmuscle Xenopus-Laevis Tropomyosin Messenger-Rnas Transcribed from the Same Gene - Developmental and Tissue-Specific Expression. Eur. J. Biochem. 202, 431-440.

Hardy, S. \& Thiebaud, P. (1992). Isolation and Characterization of Cdna Clones Encoding the Skeletal and Smooth-Muscle Xenopus-Laevis Beta Tropomyosin Isoforms. Biochim. Biophys. Acta. 1131, 239-242.

Hartree, E. F. (1972). Determination of protein: a modification of the Lowry method that gives a linear photometric response. Anal. Biochem. 48, 422-427.

Haselgrove, J. C. (1972). X-ray evidence for a conformational change in the actincontaining filaments of vertebrate striated muscle. Cold Spring Harbour Symp. Quant. Biol. 37, 341-352.

Heald, R. W. \& Hitchcock-DeGregori, S. E. (1988). The structure of the amino terminus of tropomyosin is critical for binding to actin in the absence and presence of troponin. J. Biol. Chem. 263, 5254-5259.

Heeley, D. H., Golosinska, K., \& Smillie, L. B. (1987). The effects of troponin T fragments $\mathrm{T} 1$ and $\mathrm{T} 2$ on the binding of nonpolymerizable tropomyosin to F-actin in the presence and absence of troponin I and troponin C. J. Biol. Chem 262, 9971 9978.

Heeley, D. H., Watson, M. H., Mak, A. S., Dubord, P., \& Smillie, L. B. (1989). Effect of phosphorylation on the interaction and functional properties of rabbit striated muscle alpha alpha-tropomyosin. J. Biol. Chem. 264, 2424-2430.

Heeley, D. H. (1994). Investigation of the effects of phosphorylation of rabbit striated muscle alpha alpha-tropomyosin and rabbit skeletal muscle troponin-T. Eur. J. Biochem. 221, 129-137.

Helfman, D. M., Feramisco, J. R., Fiddes, J. C., Thomas, G. P., \& Hughes, S. H. (1983). Identification of Clones That Encode Chicken Tropomyosin by Direct Immunological Screening of A Cdna Expression Library. Proceedings of the National Academy of Sciences of the United States of America-Biological Sciences 80, 31-35.

Hensley, P. (1996). Defining the structure and stability of macromolecular assemblies in solution: The re-emergence of analytical ultracentrifugation as a practical tool. Structure 4, 367-373.

Herzberg, O. \& James, M. N. G. (1985). Common structural framework of the two $\mathrm{Ca} 2+/ \mathrm{Mg} 2+$ binding loops of the troponin $\mathrm{C}$ and other $\mathrm{Ca} 2+$ binding proteins. Biochemistry 24, 5298-5302.

Hill, T. L., Eisenberg, E., \& Greene, L. (1980). Theoretical model for the cooperative equilibrium binding of myosin subfragment 1 to the actin-troponin-tropomyosin complex. Proc. Natl. Acad. Sci. USA 77, 3186-3190. 
Hitchcock-DeGregori, S. E. \& Heald, R. W. (1987). Altered actin and troponin binding of amino-terminal vaniants of chicken striated muscle alpha-tropomyosin expressed in Escherichia coli. J. Biol. Chem. 262, 9730-9735.

Hitchcock-DeGregori, S. E. \& An, Y. (1996). Integral repeats and a continuous coiled coil are required for binding of striated muscle tropomyosin to the regulated actin filament. J. Biol. Chem. 271, 3600-3603.

Hitchcock, S. E., Huxley, H. E., \& Szent-Gyorgyi, A. G. (1973). Calcium sensitive binding of troponin to actin-tropomyosin: a two-site model for troponin action. J. Mol. Biol. $80,825-836$.

Hodges, R. S., Sodek J, Smillie, L. B., \& Jurasek L (1972). Tropomyosin: amino acid sequence and coiled-coil structure. Cold Spring Harbor Symp. Quant. Biol. 37, 299-310.

Hodges, R. S., Saund, A. K., Chong, P. C. S., Stpierre, S. A., \& Reid, R. E. (1981). Synthetic Model for 2-Stranded Alpha-Helical Coiled-Coils - Design, Synthesis, and Characterization of An 86-Residue Analog of Tropomyosin. J. Biol. Chem. 256, 1214-1224.

Holmes, K. C. (1995). The actomyosin interaction and its control by tropomyosin. Biophys. J. 68, 2S-5S.

Holtzer A, Holtzer, M. E., \& Scolnick J (1989). Does the Unfolding Transition of TwoChain, Coiled-Coil Proteins Involve a Continuum of Intermediates? In Protein Folding, Deciphering the Second Half of the Genetic Code (Gierash L.M \& King J., eds), pp. 177-190, American Association for the Advancement Science, Washington.

Holtzer, M. E., Holtzer, A., \& Scolnick J (1983). $\alpha$-Helix-to-random-coil transition of twochain, coiled coils. Theory and experiments for thermal denaturation of $\alpha$-tropomyosin. Macromolecules 16, 173-180.

Holtzer, M. E. \& Holtzer, A. (1990). Alpha-helix to random coil transitions of two-chain coiled coils: experiments on the thermal denaturation of isolated segments of alpha alpha-tropomyosin. Biopolymers 30, 985-993.

Holtzer, M. E. \& Holtzer, A. (1991). Uncooperative Block in the Tropomyosin Coiled Coil. J. Am. Chem. Soc. 113, 7444-7445.

Holtzer, M. E. \& Holtzer, A. (1995). The use of spectral decomposition via the convex constraint algorithm in interpreting the CD-observed unfolding transitions of coiled coils. Biopolymers 36, 365-379.

Holtzer, M. E., Crimmins, D. L., \& Holtzer, A. (1995). Structural stability of short subsequences of the tropomyosin chain. Biopolymers 35, 125-136.

Holtzer, M. E., Mints, L., Hogue, A. R., d'Avignon, D. A., \& Holtzer, A. (2001). CD and (13)C(alpha)-NMR studies of folding equilibria in a two-stranded coiled coil formed by residues 190-254 of alpha-tropomyosin. Biopolymers 59, 257-265. 
Holzwarth.G \& Doty, P. (1965). Ultraviolet Circular Dichroism of Polypeptides. J. Am. Chem. Soc. 87, 218-\&.

Huxley, H. E. (1965). The mechanism of muscular contraction. Sci. Am. 213, 18-27.

Huxley, H. E. (1969). The mechanism of muscular contraction. Science 164, 1356-1365.

Huxley, H. E. (1972). Structural changes in the actin- and myosin-containing filaments during contraction. Cold Spring Harbour Symp. Quant. Biol. 37, 361-376.

Jasanoff, A. \& Fersht, A. R. (1994). Quantitative determination of helical propensities from trifluoroethanol titration curves. Biochemistry 33, 2129-2135.

Jayaraman, G., Kumar, T. K., Arunkumar, A. I., \& Yu, C. (1996). 2,2,2-Trifluoroethanol induces helical conformation in an all beta-sheet protein. Biochem. Biophys. Res. Commun. 222, 33-37.

Johnson, M. L., Correia, J. J., Yphantis, D. A., \& Halvorson, H. R. (1981). Analysis of data from the analytical ultracentrifuge by nonlinear least-squares techniques. Biophys. J. 36, 575-588.

Johnson, P. \& Smillie, L. B. (1977). Polymerizability of Rabbit Skeletal Tropomyosin Effects of Enzymic and Chemical Modifications. Biochemistry 16, 2264-2269.

Kabsch, W., Mannherz, H. G., Suck, D., Pai, E. F., \& Holmes, K. C. (1990). Atomic structure of the actin:DNase I complex. Nature 347, 37-44.

Kammerer RA, Schulthess T, Landwehr R, Lustig A, Engel J, Aebi U, \& Steinmetz MO (1998). An autonomous folding unit mediates the assembly of two-stranded coiled coils. Proc. Natl. Acad. Sci. USA 95, 13419-13424.

Kay, C. M. \& Bailey, K. (1960). Light Scattering in Solutions of Native and Guanidinated Rabbit Tropomyosin. Biochim. Biophys. Acta. 40, 149-156.

Kluwe, L., Maeda, K., Miegel, A., Fujitabecker, S., Maeda, Y., Talbo, G., Houthaeve, T., \& Kellner, R. (1995). Rabbit Skeletal-Muscle Alpha-Alpha-Tropomyosin Expressed in Baculovirus-Infected Insect Cells Possesses the Authentic N-Terminus Structure and Functions. J. Muscle. Res. Cell. Motil. 16, 103-110.

Lacroix, E., Viguera, A. R., \& Serrano, L. (1998). Elucidating the folding problem of alphahelices: local motifs, long-range electrostatics, ionic-strength dependence and prediction of NMR parameters. J. Mol. Biol. 284, 173-191.

Lau, S. Y., Taneja, A. K., \& Hodges, R. S. (1984). Synthesis of a model protein of defined secondary and quaternary structure. Effect of chain length on the stabilization and formation of two-stranded alpha-helical coiled-coils. J. Biol. Chem. 259, 13253-13261.

Laue, T. M., Sarah BD, Ridgeway TM, \& Pelletier SL (1991). Computer-aided interpretation of analytical sedimentation data for proteins. In Analytical Ultracentrifugation in Biochemistry and Polymer Science, ed. S. E. Harding, A. J. Rowe, J. C. Horton. Cambridge, UK: R. Soc. Chem 125.

Laue, T. M. \& Stafford, W. F., III (1999). Modern applications of analytical ultracentrifugation. Annu. Rev. Biophys. Biomol. Struct. 28, 75-100. 
Lees-Miller, J. P. \& Helfman, D. M. (1991). The molecular basis for tropomyosin isoform diversity. Bioessays 13, 429-437.

Lehman, W., Craig, R., \& Vibert, P. (1994). Ca(2+)-induced tropomyosin movement in Limulus thin filaments revealed by three-dimensional reconstruction. Nature 368 , 65-67.

Lehrer, S. S. (1978). Effects of an interchain disulfide bond on tropomyosin structure: intrinsic fluorescence and circular dichroism studies. J. Mol. Biol. 118, 209-226.

Lehrer, S. S., Golitsina, N. L., \& Geeves, M. A. (1997). Actin-tropomyosin activation of myosin subfragment 1 ATPase and thin filament cooperativity. The role of tropomyosin flexibility and end-to-end interactions. Biochemistry 36, 1344913454.

Lehrer, S. S. \& Yuan, A. (1998). The stability of tropomyosin at acid $\mathrm{pH}$ : effects of anion binding. J. Struct. Biol. 122, 176-179.

Li, Y., Mui, S., Brown, J. H., Strand, J., Reshetnikova, L., Tobacman, L. S., \& Cohen, C. (2002). The crystal structure of the C-terminal fragment of striated-muscle alphatropomyosin reveals a key troponin T recognition site. Proc. Natl. Acad. Sci. U SA 99, 7378-7383.

Llinás, M. \& Klein, M. P. (1975). Charge Relay at the Peptide Bond. A Proton Magnetic Resonance Study of Solvation Effects on the Amide Electron Density Distribution. J. Am. Chem. Soc. 97, 4731-4737.

Lovejoy, B., Choe, S., Cascio, D., Mcrorie, D. K., Degrado, W. F., \& Eisenberg, D. (1993). Crystal-Structure of A Synthetic Triple-Stranded Alpha-Helical Bundle. Science 259, 1288-1293.

Lowey, S. (1965). Comparative Study of Alpha-Helical Muscle Proteins - Tyrosyl Titration and Effect 3F Ph on Conformation. J. Biol. Chem. 240, 2421-2427.

Lowey, S., Slayter, H. S., Weeds, A. G., \& Baker, H. (1969). Substructure of Myosin Molecule .I. Subfragments of Myosin by Enzymic Degradation. J. Mol. Biol, 42, 129.

Luidens, M. K., Figge, J., Breese, K., \& Vajda, S. (1996). Predicted and trifluoroethanolinduced alpha-helicity of polypeptides. Biopolymers 39, 367-376.

Lupas, A., Van Dyke, M., \& Stock, J. (1991). Predicting coiled coils from protein sequences. Science 252, $1162-1164$.

Lupas, A. (1996). Coiled coils: New structures and new functions. Trends. Biochem. Sci. 21, 375-382.

Lymn, R. W. \& Taylor, E. W. (1971). Mechanism of adenosine triphosphate hydrolysis by actomyosin. Biochemistry 10, 4617-4624.

MacPhee, C. E., Perugini, M. A., Sawyer, W. H., \& Howlett, G. J. (1997). Trifluoroethanol induces the self-association of specific amphipathic peptides. FEBS Lett. 416, 265-268. 
Mak, A. S., Smillie, L. B., \& Stewart, G. R. (1980). A Comparison of the Amino-AcidSequences of Rabbit Skeletal-Muscle Alpha-Tropomyosin and BetaTropomyosin. J. Biol. Chem. 255, 3647-3655.

Mak, A. S. \& Smillie, L. B. (1981). Non-Polymerizable Tropomyosin - Preparation, Some Properties and F-Actin Binding. Biochem. Biophys. Res. Commun. 101, 208-214.

Mak, A. S., Golosinska, K., \& Smillie, L. B. (1983). Induction of Nonpolymenizable Tropomyosin Binding to F-Actin by Troponin and Its Components. J. Biol. Chem. 258, $4330-4334$.

Malnic, B., Farah, C. S., \& Reinach, F. C. (1998). Regulatory properties of the NH2- and $\mathrm{COOH}$-terminal domains of troponin T. ATPase activation and binding to troponin I and troponin C. J. Biol. Chem. 273, 10594-10601.

Maroun, R. G., Krebs, D., El Antri, S., Deroussent, A., Lescot, E., Troalen, F., Porumb, H., Goldberg, M. E., \& Fermandjian, S. (1999). Self-association and domains of interactions of an amphipathic helix peptide inhibitor of HIV-1 integrase assessed by analytical ultracentrifugation and NMR experiments in trifluoroethanol/ $\mathrm{H}(2) \mathrm{O}$ mixtures. J. Biol. Chem. 274, 34174-34185.

Mckillop, D. F. A. \& Geeves, M. A. (1993). Regulation of the Interaction Between Actin and Myosin Subfragment-1 - Evidence for 3 States of the Thin Filament. Biophys. J. $65,693-701$.

McLachlan, A. D. \& Stewart, M. (1975). Tropomyosin coiled-coil interactions: evidence for an unstaggered structure. J. Mol. Biol. 98, 293-304.

McLachlan, A. D. \& Stewart, M. (1976). The 14-fold periodicity in alpha-tropomyosin and the interaction with actin. J. Mol. Biol. 103, 271-298.

McRorie DK \& Voelker PJ (1993). Nonlinear Least-Squares Analysis. In Self-Associating Systems in the Analytical Ultracentrifuge, pp. 13-27, Beckman Instruments, Inc.

Milligan, R. A., Whittaker, M., \& Safer, D. (1990). Molecular structure of F-actin and location of surface binding sites. Nature 348, 217-221.

Mische, S. M., Manjula, B. N., \& Fischetti, V. A. (1987). Relation of Streptococcal-M Protein with Human and Rabbit Tropomyosin - the Complete Amino-AcidSequence of Human Cardiac Alpha-Tropomyosin, A Highly Conserved Contractile Protein. Biochem. Biophys. Res. Commun.142, 813-818.

Mo, J. M., Holtzer, M. E., \& Holtzer, A. (1990). The thermal denaturation of nonpolymerizable alpha alpha-tropomyosin and its segments as a function of ionic strength. Biopolymers 30, 921-927.

Mo, J. M., Holtzer, M. E., \& Holtzer, A. (1991). Kinetics of self-assembly of alpha alphatropomyosin coiled coils from unfolded chains. Proc. Natt. Acad. Sci. U. S. A 88, 916-920.

Monera, O. D., Zhou, N. E., Kay, C. M., \& Hodges, R. S. (1993). Comparison of antiparallel and parallel two-stranded alpha-helical coiled-coils. Design, synthesis, and characterization. J. Biol. Chem. 268, 19218-19227. 
Monera, O. D., Zhou, N. E., Lavigne, P., Kay, C. M., \& Hodges, R. S. (1996). Formation of parallel and antiparallel coiled-coils controlled by the relative positions of alanine residues in the hydrophobic core. J. Biol. Chem. 271, 3995-4001.

Monteiro, P. B., Lataro, R. C., Ferro, J. A., \& Reinach, F. C. (1994). Functional alphatropomyosin produced in Escherichia coli. A dipeptide extension can substitute the amino-terminal acetyl group. J. Biol. Chem. 269, 10461-10466.

Moraczewska, J. \& Hitchcock-DeGregori, S. E. (2000). Independent functions for the Nand C-termini in the overlap region of tropomyosin. Biochemistry 39, 6891-6897.

Mornet, D., Pantel, P., Audemard, E., \& Kassab, R. (1979). Limited Tryptic Cleavage of Chymotryptic S-1 - Approach to the Characterization of the Actin Site in Myosin Heads. Biochem. Biophys. Res. Commun. 89, 925-932.

Muñoz, V. \& Serrano, L. (1995a). Elucidating the folding problem of helical peptides using empirical parameters. III. Temperature and $\mathrm{pH}$ dependence. J. Mol. Biol. 245, 297-308.

Muñoz, V. \& Serrano, L. (1995b). Elucidating the folding problem of helical peptides using empirical parameters. II. Helix macrodipole effects and rational modification of the helical content of natural peptides. J. Mol. Biol. 245, 275-296.

Narita, A., Yasunaga, T., Ishikawa, T., Mayanagi, K., \& Wakabayashi, T. (2001). Ca(2+)induced switching of troponin and tropomyosin on actin filaments as revealed by electron cryo-microscopy. J. Mol. Biol. 308, 241-261.

Nelson, J. W. \& Kallenbach, N. R. (1986). Stabilization of the ribonuclease S-peptide alpha-helix by trifluoroethanol. Proteins 1, 211-217.

Oakley, M. G. \& Kim, P. S. (1998). A buried polar interaction can direct the relative orientation of helices in a coiled coil. Biochemistry 37, 12603-12610.

Ohara, O., Dorit, R. L., \& Gilbert, W. (1989). One-Sided Polymerase Chain-Reaction - the Amplification of Cdna. Proc. Natl. Acad. Sci. USA. 86, 5673-5677.

Ohtsuki, I., Maruyama, K., \& Ebashi, S. (1986). Regulatory and Cytoskeletal Proteins of Vertebrate Skeletal Muscle. Adv. Protein Chem. 38, 1-67.

Ooi, T., Mihashi, K., \& Kobayashi, H. (1962). On Polymerization of Tropomyosin. Archives of Biochemistry and Biophysics 98, 1-11.

Pace C.N. \& Scholtz, J. M. (1997). Measuring the conformational stability of a protein. In Protein Structure, A Practical Approach (Creighton T.E., ed), pp. 299-320, Oxford University Press, New York.

Palm, T., Graboski, S., Hitchcock-DeGregori, S. E., \& Greenfield, N. J. (2001). Diseasecausing mutations in cardiac troponin $\mathrm{T}$ : identification of a critical tropomyosinbinding region. Biophys. J. 81, 2827-2837.

Palm, T., Greenfield, N. J., \& Hitchcock-DeGregori, S. E. (2003). Tropomyosin ends determine the stability and functionality of overlap and troponin $T$ complexes. Biophys. J. 84, 3181-3189. 
Parry, D. A. \& Squire, J. M. (1973). Structural role of tropomyosin in muscle regulation: analysis of the $x$-ray diffraction patterns from relaxed and contracting muscles. $J$. Mol. Biol. 75, 33-55.

Pato, M. D. \& Smillie, L. B. (1978). Stability and Troponin-T Binding Properties of Rabbit Skeletal Alpha-Tropomyosin Fragments. FEBS Lett. 87, 95-98.

Pato, M. D., Mak, A. S., \& Smillie, L. B. (1981a). Fragments of rabbit striated muscle alpha-tropomyosin. II. Binding to troponin-T. J. Biol. Chem. 256, 602-607.

Pato, M. D., Mak, A. S., \& Smillie, L. B. (1981b). Fragments of rabbit striated muscle alpha-tropomyosin. I. Preparation and characterization. J. Biol. Chem. 256, 593601.

Paulucci, A. A., Hicks, L., Machado, A., Miranda, M. T., Kay, C. M., \& Farah, C. S. (2002). Specific sequences determine the stability and cooperativity of folding of the C-terminal half of tropomyosin. J. Biol. Chem. 277, 39574-39584.

Pearlstone, J. R. \& Smillie, L. B. (1977). The binding site of skeletal alpha-tropomyosin on troponin-T. Can. J. Biochem. 55, 1032-1038.

Pearlstone, J. R. \& Smillie, L. B. (1978). Troponin T fragments: physical properties and binding to troponin C. Can. J. Biochem. 56, 521-527.

Phillips, G. N., Jr., Fillers, J. P., \& Cohen, C. (1986). Tropomyosin crystal structure and muscle regulation. J. Mol. Biol. 192, 111-131.

Potekhin, S. A. \& Privalov, P. L. (1982). Co-operative blocks in tropomyosin. J. Mol. Biol. 159, 519-535.

Quadrifoglio, F. \& Urry, D. W. (1968). Ultraviolet rotatory properties of polypeptides in solution. I. Helical poly-L-alanine. J. Am. Chem. Soc. 90, 2755-2760.

Ralston G (1993). Sedimentation of Particles in a Gravitational Field. In Introduction to Analytical Uultracentrifugation, pp. 8-10, Beckman Instruments, Inc.

Rayment, I., Rypniewski, W. R., Schmidtbase, K., Smith, R., Tomchick, D. R., Benning, M. M., Winkelmann, D. A., Wesenberg, G., \& Holden, H. M. (1993a). 3Dimensional Structure of Myosin Subfragment-1 - A Molecular Motor. Science $261,50-58$.

Rayment, I., Holden, H. M., Whittaker, M., Yohn, C. B., Lorenz, M., Holmes, K. C., \& Milligan, R. A. (1993b). Structure of the Actin-Myosin Complex and Its Implications for Muscle-Contraction. Science 261, 58-65.

Roccatano, D., Colombo, G., Fioroni, M., \& Mark, A. E. (2002). Mechanism by which 2,2,2-trifluoroethanol/water mixtures stabilize secondary-structure formation in peptides: a molecular dynamics study. Proc. Natl. Acad. Sci. USA 99, 1217912184.

Ross, J. B. A., Szabo, A. G., \& Hogue, C. W. V. (1997). Enhancement of protein spectra with tryptophan analogs: Fluorescence spectroscopy of protein-protein and protein-nucleic acid interactions. Fluorescence Spectroscopy 278, 151-190. 
Ruizopazo, N., Weinberger, J., \& Nadalginard, B. (1985). Comparison of AlphaTropomyosin Sequences from Smooth and Striated-Muscle. Nature 315, 67-70.

Sambrook, J., Fritsch, E. F., \& Maniatis, T. (1989). Molecular Cloning, a Laboratory Manual. Cold Spring Harbor Laboratory Press, Cold Spring Harbor, NY.

Sanders, C. \& Smillie, L. B. (1984). Chicken gizzard tropomyosin: head-to-tail assembly and interaction with F-actin and troponin. Can. J. Biochem. Cell Biol. 62, 443448.

Sanders, C. \& Smillie, L. B. (1985). Amino-Acid Sequence of Chicken Gizzard BetaTropomyosin - Comparison of the Chicken Gizzard, Rabbit Skeletal, and Equine Platelet Tropomyosins. J. Biol. Chem. 260, 7264-7275.

Sano, K., Maeda, K., Oda, T., \& Maeda, Y. (2000a). The effect of single residue substitutions of serine-283 on the strength of head-to-tail interaction and actin binding properties of rabbit skeletal muscle alpha-tropomyosin. J. Biochem. (Tokyo) $127,1095-1102$.

Sano, K., Maeda, K., Taniguchi, H., \& Maeda, Y. (2000b). Amino-acid replacements in an internal region of tropomyosin alter the properties of the entire molecule. Eur. J. Biochem. 267, 4870-4877.

Simons, E. R. (1981). Optical Rotatory Dispersion and circular Dichroism. In Spectroscopy in Biochemistry (J.Ellis Bell, ed.), pp. 63-153, CRC Press, Inc..

Smillie, L. B. (1979). Structure and Functions of Tropomyosins from Muscle and NonMuscle Sources. Trends. Biochem. Sci. 4, 151-155.

Sousa, A. D. \& Farah, C. S. (2002). Quantitative analysis of tropomyosin linear polymerization equilibrium as a function of ionic strength. J. Biol. Chem. 277, 2081-2088.

Stewart J \& Young JD (1984). The Chemistry of Solid Phase Peptide Synthesis. In Solid phase peptide synthesis (Merrifield RB, ed), pp. 1-49, Pierce Chemical Company, Rockford, Illinois, USA.

Storrs, R. W., Truckses, D., \& Wemmer, D. E. (1992). Helix propagation in trifluoroethanol solutions. Biopolymers 32, 1695-1702.

Studier, F. W., Rosenberg, A. H., Dunn, J. J., \& Dubendorff, J. W. (1990). Use of T7 RNA polymerase to direct expression of cloned genes. Methods Enzymol. 185, 60-89.

Suarez, M. C., Lehrer, S. S., \& Silva, J. L. (2001). Local heterogeneity in the pressure denaturation of the coiled-coil tropomyosin because of subdomain folding units. Biochemistry 40, 1300-1307.

Tobacman, L. S. (1996). Thin filament-mediated regulation of cardiac contraction. Annu. Rev. Physiol. 58, 447-481.

Tripet, B., Wagschal, K., Lavigne, P., Mant, C. T., \& Hodges, R. S. (2000). Effects of side-chain characteristics on stability and oligomerization state of a de novodesigned model coiled-coil: 20 amino acid substitutions in position "d". J. Mol. Biol. 300, 377-402. 
Ueno, H., Tawada, Y., \& Ooi, T. (1976). Properties of non-polymerizable tropomyosin obtained by carboxypeptidase A digestion. J. Biochem. (Tokyo) 80, 283-290.

Varanda, L. M. \& Miranda, M. T. (1997). Solid-phase peptide synthesis at elevated temperatures: a search for and optimized synthesis condition of unsulfated cholecystokinin-12. J. Pept. Res. 50, 102-108.

Vibert, P., Craig, R., \& Lehman, W. (1997). Steric-model for activation of muscle thin filaments. J. Mol. Biol. 266, 8-14.

Voet, D. \& Voet, J. G. (1995). Biochemistry John Wiley \& Sons, Inc.

Wagschal, K., Tripet, B., \& Hodges, R. S. (1999). De novo design of a model peptide sequence to examine the effects of single amino acid substitutions in the hydrophobic core on both stability and oligomenization state of coiled-coils. $J$. Mol. Biol. 285, 785-803.

Wahl, P., Tawada, K., \& Auchet, J. C. (1978). Study of tropomyosin labelled with a fluorescent probe by pulse fluorimetry in polarized light. Interaction of that protein with troponin and actin. Eur. J. Biochem. 88, 421-424.

Wei, J. \& Fasman, G. D. (1995). A poly(ethylene glycol) water-soluble conjugate of porin: refolding to the native state. Biochemistry 34, 6408-6415.

Whitby, F. G. \& Phillips, G. N., Jr. (2000). Crystal structure of tropomyosin at 7 Angstroms resolution. Proteins 38, 49-59.

White, S. P., Cohen, C., \& Phillips, G. N., Jr. (1987). Structure of co-crystals of tropomyosin and troponin. Nature $325,826-828$.

Widada, J. S., Ferraz, C., Capony, J. P., \& Liautard, J. P. (1988). Complete NucleotideSequence of the Adult Skeletal Isoform of Human Skeletal-Muscle BetaTropomyosin. Nucleic Acids Res. 16, 3109.

Williams, D. L. \& Swenson, C. A. (1981). Tropomyosin Stability - Assignment of Thermally Induced Conformational Transitions to Separate Regions of the Molecule. Biochemistry 20, 3856-3864.

Yu, Y., Monera, O. D., Hodges, R. S., \& Privalov, P. L. (1996). Ion pairs significantly stabilize coiled-coils in the absence of electrolyte. J. Mol. Biol. 255, 367-372.

Yu, Y. B. (2002). Coiled-coils: stability, specificity, and drug delivery potential. Adv. Drug Deliv. Rev. 54, 1113-1129.

Zhou, N. E., Kay, C. M., \& Hodges, R. S. (1992a). Synthetic model proteins: the relative contribution of leucine residues at the nonequivalent positions of the 3-4 hydrophobic repeat to the stability of the two-stranded alpha-helical coiled-coil. Biochemistry 31, 5739-5746.

Zhou, N. E., Kay, C. M., \& Hodges, R. S. (1992b). Synthetic model proteins. Positional effects of interchain hydrophobic interactions on stability of two-stranded alphahelical coiled-coils. J. Biol. Chem. 267, 2664-2670. 
Zhou, N. E., Zhu, B. Y., Kay, C. M., \& Hodges, R. S. (1992c). The two-stranded alphahelical coiled-coil is an ideal model for studying protein stability and subunit interactions. Biopolymers 32, 419-426.

Zhou, N. E., Kay, C. M., \& Hodges, R. S. (1994a). The role of interhelical ionic interactions in controlling protein folding and stability. De novo designed synthetic two-stranded alpha-helical coiled-coils. J. Mol. Biol. 237, 500-512.

Zhou, N. E., Kay, C. M., \& Hodges, R. S. (1994b). The net energetic contribution of interhelical electrostatic attractions to coiled-coil stability. Protein Eng. 7, 13651372.

Zhou, N. E., Monera, O. D., \& Hodges, R. S. (1994c). Alpha-helical propensities of amino acids in the hydrofobic face of an amphipathis alpha-helix. Protein Pret. Lett. 1, 114-119.

Zot, A. S. \& Potter, J. D. (1987). Structural aspects of troponin-tropomyosin regulation of skeletal muscle contraction. Annu. Rev. Biophys. Biophys. Chem. 16, 535-559. 


\section{OBSERVAÇÃO}

\section{NÃO FOI AUTORIZADA A INCLUSÃO DO(S) ARTIGO(S) NESTE ARQUIVO}

